MARIANA WYSE ABAURRE

\title{
MODELOS DE CONTRATO COLABORATIVO E PROJETO INTEGRADO PARA MODELAGEM DA INFORMAÇÃO DA CONSTRUÇÃO
}

Dissertação apresentada à Escola Politécnica da Universidade de São Paulo para obtenção do título de Mestre em Engenharia

São Paulo 
MARIANA WYSE ABAURRE

\title{
MODELOS DE CONTRATO COLABORATIVO E PROJETO INTEGRADO PARA MODELAGEM DA INFORMAÇÃO DA CONSTRUÇÃO
}

\author{
Dissertação apresentada à Escola Politécnica \\ da Universidade de São Paulo para obtenção do \\ título de Mestre em Engenharia \\ Área de Concentração: Engenharia de \\ Construção Civil \\ Orientador:
}

Prof. Livre-Docente Silvio Burrattino Melhado

São Paulo 
Autorizo a reprodução e divulgação total ou parcial deste trabalho, por qualquer meio convencional ou eletrônico, para fins de estudo e pesquisa, desde que citada a fonte.

Este exemplar foi revisado e alterado em relação à versão original, sob responsabilidade única do autor e com a anuência de seu orientador.

São Paulo, de março de 2014.

Assinatura do autor:

Assinatura do orientador:

FICHA CATALOGRÁFICA

Abaurre, Mariana Wyse

Modelos de contrato colaborativo e projeto integrado para modelagem da informação da construção / M.W. Abaurre. -- São Paulo, 2014. $186 \mathrm{p}$.

Dissertação (Mestrado) - Escola Politécnica da Universidade de São Paulo. Departamento de Engenharia de Construção Civil.

1.Contratos 2.Gestão da informação (Projeto) 3.Construção civil I.Universidade de São Paulo. Escola Politécnica. Departamento de Engenharia de Construção Civil II.t. 
Dedicatória

Dedico este trabalho aos meus pais, Paulo (em memória) e Nely, pelo amor, carinho e suporte incondicionais dedicados a mim e pelo constante incentivo, desde muito cedo, pela busca por conhecimento que me trouxe até aqui. 


\section{AGRADECIMENTOS}

Agradeço à Universidade de São Paulo, e ao Departamento de Engenharia de Construção Civil da Escola Politécnica, que por meio do Programa de Dupla Formação FAU-POLI me proporcionaram um redirecionamento de interesses e desenvolvimento acadêmico, profissional e pessoal. Agradeço especialmente ao Professor Silvio Melhado, querido orientador e amigo, que teve um papel essencial no meu interesse pela gestão de projetos. Silvio, a sua postura sempre positiva, de incentivo, paciência e ética foram e sempre serão exemplos a serem seguidos.

Agradeço ao meu pai, que mesmo não estando mais entre nós, se fez presente durante todo o desenvolvimento desta dissertação. Obrigada pelas lições de vida, exemplos de dedicação, formação e educação dedicados a mim e ao meu irmão. Obrigada por me dar confiança na persistência e no trabalho, e por me fazer entender que as dificuldades fazem parte da recompensa.

Agradeço também à minha mãe, que desde cedo, me deu exemplos positivos de dedicação aos estudos e fez dessa uma tarefa agradável. Além disso, pelo amor, carinho e prontidão, a qualquer hora, para me oferecer seu apoio, tranquilidade e confiança na minha capacidade de alcançar os diversos objetivos aos quais me propus nesses anos.

À minha família, que à sua própria maneira "colaborativa" sempre ofereceu suporte para as decisões de todos os membros da minha geração. Sou muito feliz por ter em meu irmão e todos os meus tios, tias, primos, avôs e avós grandes exemplos de aprendizado e de amor. Sem essa estrutura de não seria confiante e capaz. Obrigada a cada um de vocês.

Agradeço com carinho aos colegas de pós-graduação e amigos, Flavia Rodrigues de Souza e Leonardo Manzione; obrigada por junto com o Professor Silvio me introduzirem ao universo da pesquisa e da gestão, que me trouxe e ainda traz tantas experiências positivas. Espero um dia poder proporcionar a ajuda e colaboração que recebi de vocês, e que foi essencial para o meu desenvolvimento acadêmico, profissional e também pessoal. 
Agradeço às empresas que me receberam para a realização do estudo de caso e ao Professor Arivaldo Leão de Amorim, pela cessão dos resultados da pesquisa do LABCAD da UFBA sobre a implementação de BIM, e novamente ao Professor Silvio por receber o questionário relacionado aos modelos contratuais no Evento Soluções para Empresas de Projeto.

Agradeço aos meus colegas de estudos da FAU e da Poli e colegas profissionais, que sempre ofereceram ótimas oportunidades de trocas de aprendizado, e em muitos momentos reforçaram a minha crença no resultado de um dos principais temas dessa pesquisa: colaboração.

Por fim, mas com muito amor, agradeço ao meu marido, amigo e parceiro de vida, Daniel, que teve paciência e carinho, e me ofereceu suporte, amor, um novo lar e um novo senso de felicidade. Você traz alegria para cada um dos meus dias. 


\section{RESUMO}

O setor da construção civil atualmente apresenta uma forte demanda por inovações nas tecnologias de informação e comunicação na construção. Nesse contexto, a modelagem da informação da construção vem se destacando como um dos principais temas em desenvolvimento no Brasil e no mundo. $O$ foco das pesquisas e iniciativas relacionadas à implementação da modelagem da informação da construção apresenta uma lacuna quanto ao desenvolvimento de seus processos, além de empecilhos relacionados aos aspectos de colaboração entre os agentes. Diante deste quadro, o American Institute of Architects propôs um modelo contratual para projetos integrados, denominado Integrated Project Delivery, que fomenta a relação colaborativa dos agentes do empreendimento por meio do compartilhamento dos resultados entre os participantes. Esta dissertação tem como objetivo a análise da possibilidade de implantação desta dinâmica contratual no cenário da construção civil brasileira. Para tanto, foram avaliados os resultados de dois questionários estruturados e do estudo de caso de empresa de incorporação que vem investindo na implantação da modelagem da informação da construção em seu processo de projeto. Os questionários tiveram enfoque nos estágios de maturidade da implementação da modelagem da informação da construção como cenário para o uso do projeto integrado, e os resultados apresentaram um panorama geral de baixa maturidade. No estudo de caso, avaliaram-se os modelos contratuais utilizados em relação às práticas já implantadas do uso da modelagem da informação da construção. Como resultado, foram identificados diversos aspectos do processo de projeto com potencial para implementação de um contrato relacional, porém ainda limitados pela falta de adequação dos processos e modelo contratual às características de colaboração e integração típicas da modelagem da informação da construção. Este trabalho propõe diretrizes para a adequação dos processos observados na empresa-caso ao modelo de projeto integrado proposto pelo American Institute of Architects.

Palavras Chave: contrato colaborativo, projeto integrado, modelagem da informação da construção 


\begin{abstract}
The civil construction sector has demanded innovations on its communication and information technologies. In this context, Building Information Modeling has been stressed as one of the most important developing themes in Brazil and worldwide. The focus of BIM researches and implementation initiatives has a shortage regarding the development of BIM processes, and restrictions related to the collaboration among actors. Due to this scenario, the American Institute of Architects (2007) proposed a contractual model for integrated projects, called Integrated Project Delivery that stimulates a collaborative relationship among actors through sharing project results with its participants. This Master Thesis aims to analyze the possibility of implementing this contractual dynamics on the Brazilian construction sector. As methodology, two structured surveys were analyzed and a case study was carried out on a real estate company which has invested on incorporating BIM in its design process. The surveys were addressed focusing on the BIM implementation stages as a scenario for the implementation of the integrated project approach. The results pointed to a very low stage of BIM implementation. The case study focused on the evaluation of the contractual models related to the implemented BIM practices. Several potential aspects appropriate for the implementation of a relational contract were identified, but still restricted by the inadequacy of the design processes and contracts to BIM collaboration and integration typical characteristics. This Master Thesis defines guidelines for the forthcoming of the observed processes to the integrated project delivery model proposed by the American Institute of Architects.
\end{abstract}

Key Words: collaborative contract, integrated project, building information modeling. 


\section{SUMÁRIO}

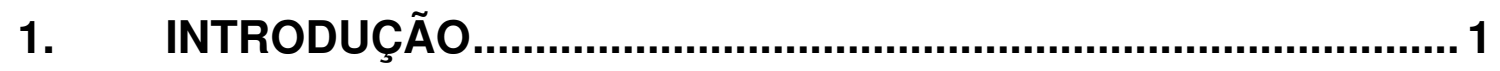

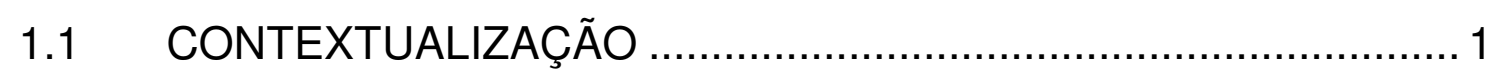

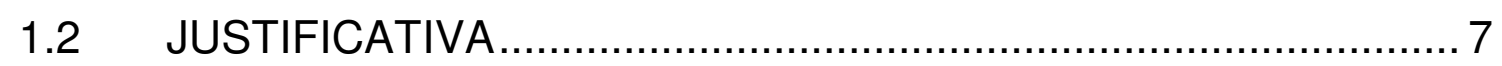

1.2.1 Modelagem da informação da construção e colaboração. Erro! Indicador não definido.

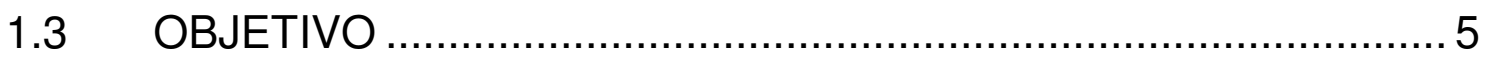

1.4 METODOLOGIA DE PESQUISAERRO! INDICADOR NÃO DEFINIDO.

1.5 ESTRUTURA DO TRABALHO …............................................ 17

2. MODELAGEM DA INFORMAÇÃO DA CONSTRUÇÃO OU BUILDING INFORMATION MODELING (BIM)......................... 20

2.1 CONCEITOS DE MODELAGEM DA INFORMAÇÃO DA

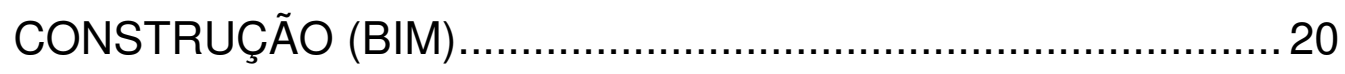

2.2 DIRETRIZES DE IMPLEMENTAÇÃO DA MODELAGEM DA INFORMAÇÃO DA CONSTRUÇÃO ........................................24

2.3 MODELAGEM DA INFORMAÇÃO DA CONSTRUÇÃO NO

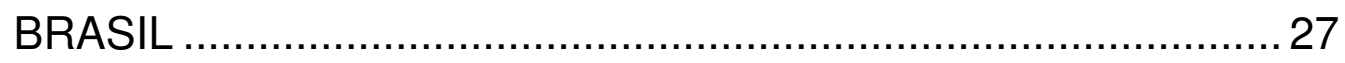

2.4 BARREIRAS PARA A IMPLEMENTAÇÃO DA MODELAGEM DA INFORMAÇÃO DA CONSTRUÇÃO NO BRASIL........................ 30

3. CONTRATOS DA CONSTRUÇÃO CIVIL ...................................33

3.1 CONTEXTUALIZAÇÃO .......ERRO! INDICADOR NÃO DEFINIDO.

3.2 PROCESSOS DE EMPREENDIMENTOS DE CONSTRUÇÃO

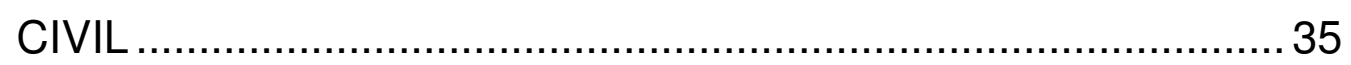

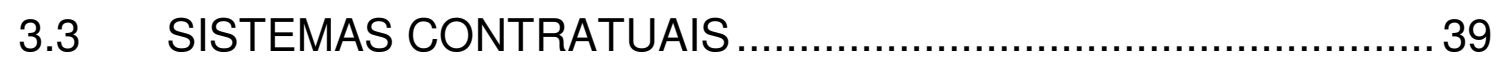

3.4 CONTRATOS TRADICIONAIS .............................................. 41

3.4.1 Contrato sequencial ou design bid build (DBB) .................... 41 
3.4.2 Projeto-construção ou design build (DB).............................43

3.5 CONTRATOS TRANSACIONAIS E CONTRATOS

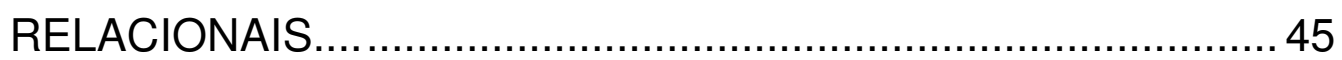

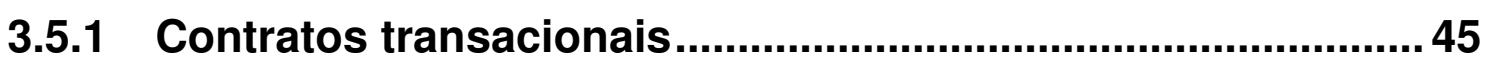

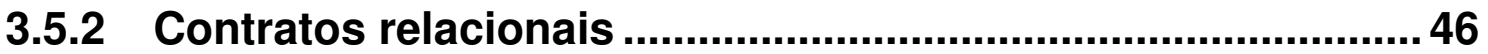

3.6 MODELOS DE DOCUMENTOS CONTRATUAIS ......................57

3.6.1 Modelos contratuais propostos pelo AIA para modelagem da informação da construção e projeto integrado (IPD).............. 63

4. PROJETO INTEGRADO OU INTEGRATED PROJECT DELIVERY (IPD)......................................................................... 71

4.1 O PROJETO INTEGRADO COMO SOLUÇÃO ALTERNATIVA.71

4.2 RELAÇÕES CONTRATUAIS NO PROJETO INTEGRADO (IPD) .75

4.3 FORMAÇÃO DE EQUIPE PARA PROJETOS INTEGRADOS ... 81

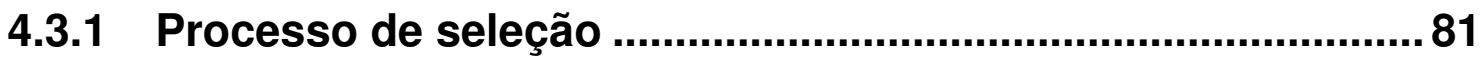

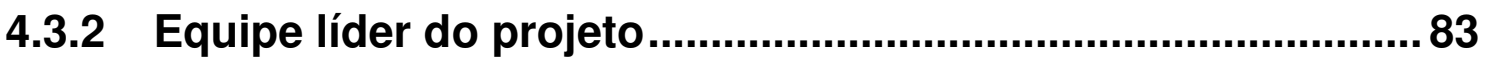

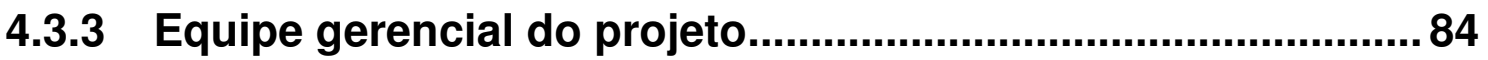

4.4 MODELO DE COMPENSAÇÃO E DISTRIBUIÇÃO DOS

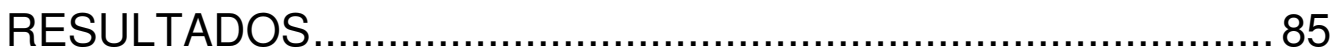

4.5 DETERMINAÇÃO DA ESTRUTURA DE TRABALHO ................86

4.5.1 Mudanças no processo de projeto para projetos integrados 86

4.5.2 Determinação dos produtos do processo de projeto por etapa do empreendimento...................................................................... 89

4.5.3 Nível de desenvolvimento do projeto ..................................... 95

4.6 PROJETO INTEGRADO E MODELAGEM DA INFORMAÇÃO DA

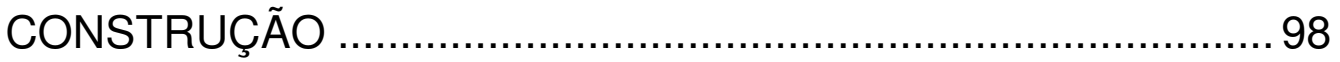


4.6.1 O modelo como documento contratual ..................................99

4.7 PROJETO INTEGRADO E CONSTRUÇÃO ENXUTA............... 100

4.8 ESTUDOS DE CASO DE PROJETO INTEGRADO DOCUMENTADOS PELO AIA .............................................. 101

5. QUESTIONÁRIOS ESTRUTURADOS DE AVALIAÇÃO DO MERCADO BRASILEIRO QUANTO À MODELAGEM DA INFORMAÇÃO DA CONSTRUÇÃO E AO PROJETO

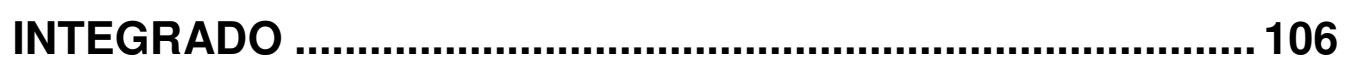

5.1 QUESTIONÁRIO SOBRE O ESTÁGIO DOS MÉTODOS CONTRATUAIS DE SERVIÇOS DE PROJETOS PARA CONSTRUÇÃO CIVIL E SOBRE A IMPLEMENTAÇÃO DE MODELOS DE CONTRATO INTEGRADO ............................. 107

5.2 QUESTIONÁRIO SOBRE A IMPLEMENTAÇÃO DA MODELAGEM DA INFORMAÇÃO DA CONSTRUÇÃO ............ 109

5.3 ANÁLISE DOS QUESTIONÁRIOS ........................................ 114

6. ESTUDO DE CASO..............................................................116

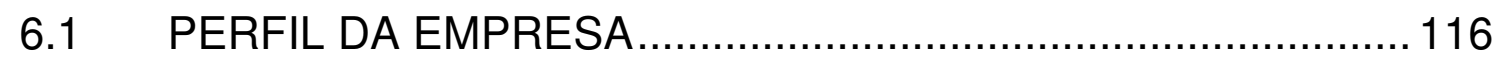

6.2 ADOÇÃO DA MODELAGEM DA INFORMAÇÃO DA

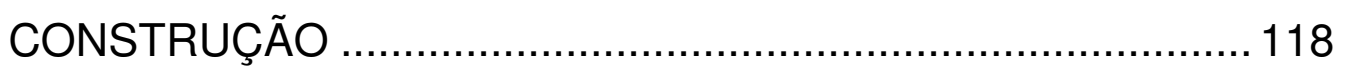

6.3 PROCESSO DE PROJETO DA EMPRESA ESTUDADA ..........123

6.3.1 Estudo de viabilidade com uso da modelagem da informação

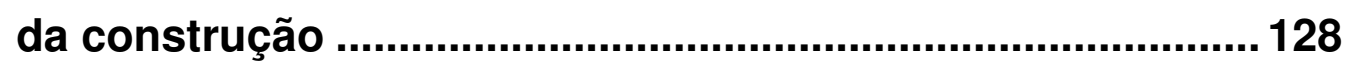

6.3.2 Orçamento preliminar com uso da modelagem da informação da construção 132

6.3.3 Compatibilização de Projetos com uso da modelagem da informação da construção 134

6.3.4 Planejamento de obras e montagem de pré-fabricados com uso da modelagem da informação da construção 141 
6.4 CONTRATOS DE PROJETOS DE MODELAGEM DA INFORMAÇÃO DA CONSTRUÇÃO ....................................... 143

6.5 ANÁLISE DO ESTUDO DE CASO …..................................... 147

6.5.1 Quanto ao modelo de implementação da modelagem da informação da construção na empresa caso.........................147

6.5.2 Quanto ao processo de projeto e às atividades que utilizam a modelagem da informação da construção.............................149

6.5.3 Quanto ao modelo de contrato utilizado ...............................150

6.5.4 Comparação entre a estrutura contratual de projetos integrados e da empresa caso. .............................................. 151

6.5.5 Obstáculos gerais do mercado brasileiro de construção à implementação do projeto integrado...................................... 158

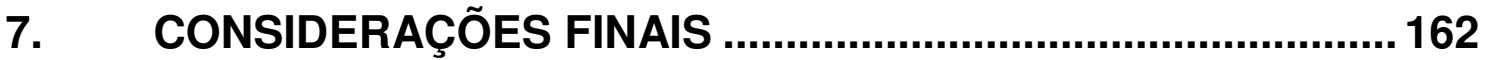

7.1 PROPOSTA DE DIRETRIZES PARA ADEQUAÇÃO DO PROCESSO OBSERVADO DE CONTRATAÇÃO DE PROJETOS DE MODELAGEM DA INFORMAÇÃO DA CONSTRUÇÃO ............165

7.2 DESENVOLVIMENTO DO TEMA DE PESQUISA ..................1093

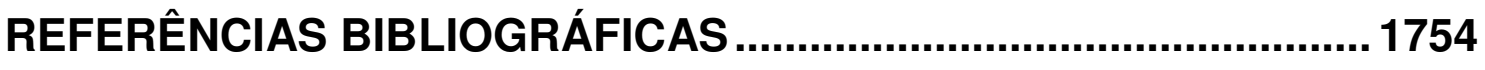

ANEXO I

ARTIGOS PUBLICADOS NO BRASIL COM O TEMA MODELAGEM DA INFORMAÇÃO DA CONSTRUÇÃO ENTRE 2007 E 2011

\section{ANEXO II}

QUESTIONÁRIO SOBRE IMPLEMENTAÇÃO DA MODELAGEM DA INFORMAÇÃO DA CONSTRUÇÃO APLICADO NO EVENTO TIC 2011 


\section{ANEXO III}

QUESTIONÁRIO SOBRE O USO DE CONTRATOS DE PROJETO INTEGRADO APLICADO NO EVENTO SOLUÇÕES PARA EMPRESAS DE PROJETO IV 


\section{LISTA DE FIGURAS}

Figura 1 - Evolução do PIB Nacional e do PIB da Construção Civil 2

Figura 2 - Iniciativas de modelagem da informação da construção no Brasil. 299

Figura 3: Relação entre Tecnologia, Processos, Informações e Colaboração no processo de projeto da modelagem da informação da construção

Figura 4: Evolução de lançamentos na cidade de São Paulo

Figura 5: Proposta para o processo de desenvolvimento do projeto com a ação dos quatro participantes do empreendimento 366

Figura 6: Modelo genérico para Sistemas Contratuais 40

Figura 7: Adaptação de Modelo de Compensação para Aliança de Projetos .. 51

Figura 8: Distribuição de resultados na Aliança de Projetos 52

Figura 9: Adaptação de Diagrama do Processo de Formação da Aliança de Projetos 55

Figura 10: Relações entre agentes em contratos de IPD focadas no processo .76

Figura 11: Relações entre participantes de contratos em IPD focadas no Processo 777

Figura 12: Relações contratuais em modelos de contrato de transição para IPD

Figura 13: Relações entre participantes de contratos em SPE-IPD e Multilateral 798

Figura 14: Diagrama de relações em contratos Multilaterais em IPD. 809

Figura 15: Processo de projeto tradicional segundo o AIA e no Brasil. 876

Figura 1: Diferenças no processo de projeto tradicional e integrado. .86

Figura 17: A chance de reduzir o custo de falhas do edifício em relação ao avanço do empreendimento 89

Figura 18: Fases iniciais do ciclo de vida do negócio 120 
Figura 19: Capacidade de Influenciar recursos na evolução do empreendimento 12020

Figura 20: Mudança de processo de construção tradicional para industrializado 121

Figura 21: Adequações nas etapas do processo de projeto atual na empresa para o processo em Modelagem da Informação da Construção 123

Figura 22: Fluxograma do processo de projeto da empresa estudada - Etapa de Estudo de Massa / Concepção do Projeto ..... 1243

Figura 23: Fluxograma do processo de projeto da empresa estudada - Etapa de Estudo Preliminar/Desenvolvimento Preliminar 1254

Figura 24: Fluxograma do processo de projeto da empresa estudada - Etapa de desenvolvimento e compatibilização/Projeto Básico e Projeto Executivo...1265

Figura 25: Fluxograma do processo de projeto da empresa estudada - Etapa de Desenhos de Construção / Projeto Executivo 1276 


\section{LISTA DE TABELAS}

Tabela 1- Guias de Implementação de BIM

Tabela 2: Sistemas Contratuais conforme o AIA (American Institute of Architects) 599

Tabela 3: Documentos Contratuais do AIA para a Família de Projetos Digitais .633

Tabela 4: Documentos Contratuais do AIA para a Família de Projeto Integrado 655

Tabela 5: Transformação do processo de projeto tradicional para integrado. 865

Tabela 6: Etapas de Empreendimentos Integrados e suas atividades 909

Tabela 7: Níveis de Desenvolvimento do Modelo segundo o AIA 954

Tabela 8: Elenco de dificuldades de implementação e uso da modelagem da informação da construção

Tabela 9: Motivos para adoção da modelagem da informação da construção.

Tabela 10: Grau de impacto da modelagem da informação da construção nas mudanças dos processos das empresas

Tabela 11: Perfil dos profissionais do núcleo BIM.

Tabela 12: Processos de Estudo de Viabilidade com uso da modelagem da informação da construção 1288

Tabela 13: Estrutura de modelagem do estudo de viabilidade. 13030

Tabela 14: Processos de orçamento preliminar com uso da modelagem da informação da construção 1332

Tabela 15: Processos de compatibilização de projetos com uso da modelagem da informação da construção 1354

Tabela 16: Processos de planejamento de obras e montagem de pré-fabricados com uso da modelagem da informação da construção 13840

Tabela 17: Estrutura de contratos de projeto da empresa caso 144 
Tabela 18: Comparação entre os modelos de contrato do AIA e o modelo de contrato padrão da empresa caso .......................................................... 14751 


\section{LISTA DE ABREVIATURAS}

AEC

AIA

BIM

BNDES

CIB

DB

DBB

DECONCIC

EMBRAESP

FIDIC

FINEP

GSA

ICE

IDDS

IFC

IPD

KPI

LCI

LCJ

LOD
Arquitetura, Engenharia e Construção

American Institute of Architects

Building Information Modeling

Banco Nacional do Desenvolvimento

International Council for Research and Innovation in Building and Construction

Design Build

Design Bid Build

Departamento da Indústria da Construção

Empresa Brasileira de Estudos de Patrimônio

Fédération Internationale Des Ingénieurs-Conseils

Financiadora de Estudos e Projetos

General Services Administration

Institute of Civil Engineers

Integrated Design Delivery Solutions

Industry Foundation Classes

Integrated Project Delivery

Key Performance Indicator

Lean Construction Institute

Lean Construction Journal

Level of Development ou Level of Detail 
MDIC Ministério do Desenvolvimento, Indústria e Comércio Exterior

NEC

New Engineering Contract

NIST

National Institute of Standards and Technology

PAC Programa de Aceleração do Crescimento

PIB Produto Interno Bruto

PMI Project Management Institute

PPC Porcentagem do Plano Concluído

PSU Pennsy/vania State University

SBPQ Simpósio Brasileiro de Qualidade do Projeto no Ambiente Construído

SECOVI Sindicato das Empresas de Compra, Venda, Locação e Administração de Imóveis Residenciais e Comerciais

SINDUSCON-SP Sindicato da Indústria da Construção Civil do Estado de São Paulo

SPE

Sociedade de Propósito Específico

STI

Secretaria de Tecnologia Industrial

TIC

Tecnologia de Informação e Comunicação na Construção 


\section{INTRODUÇÃO}

\subsection{CONTEXTUALIZAÇÃO}

Desde 2005, o Brasil vem apresentado uma curva crescente no investimento em construção (DEPARTAMENTO DA INDÚSTRIA DA CONSTRUÇÃO - DECONCIC, 2010). Apesar da crise financeira internacional de 2009, os índices de crescimento tiveram somente um decréscimo na sua aceleração, sem comprometimento dos resultados no setor. Até 2009, o aumento dos investimentos no setor da construção foi de $46 \%$, passando de $R \$ 167,7$ Bilhões (2005) para $R \$ 244,4$ Bilhões (2009), acompanhado pelo crescimento no PIB da cadeia produtiva, que, no mesmo período, cresceu 48,5\%, passando a representar 9,2\% do PIB Brasileiro.

Para manter o crescimento estável e dar continuidade aos investimentos em construção, o Governo brasileiro lançou, em 2009, o programa Minha Casa Minha Vida, que, junto com o PAC (Programa de Aceleração do Crescimento), é um dos programas de produção de unidades habitacionais que vêm ao encontro da expansão do crédito imobiliário. Para os projetos de infraestrutura, houve forte investimento do BNDES, garantindo a escalada do PIB do setor da construção (Figura 1).

A partir de análise de variáveis macroeconômicas, o Construbusiness 2010 (DECONCIC, 2010) define que, para estruturar o crescimento estimado de $5 \%$ do PIB Brasileiro ao ano (e de 6,1\% ao ano no PIB da construção), é pressuposta uma taxa média de crescimento de $3 \%$ ao ano na produtividade da mão de obra, o que significa, dentro da cadeia da construção: (i) promover a mudança tecnológica nos processos construtivos e materiais, (ii) aumentar o uso de máquinas e equipamentos e (iii) qualificar a mão de obra que ingressa nesse mercado. 
Figura 2 - Evolução do PIB Nacional e do PIB da Construção Civil

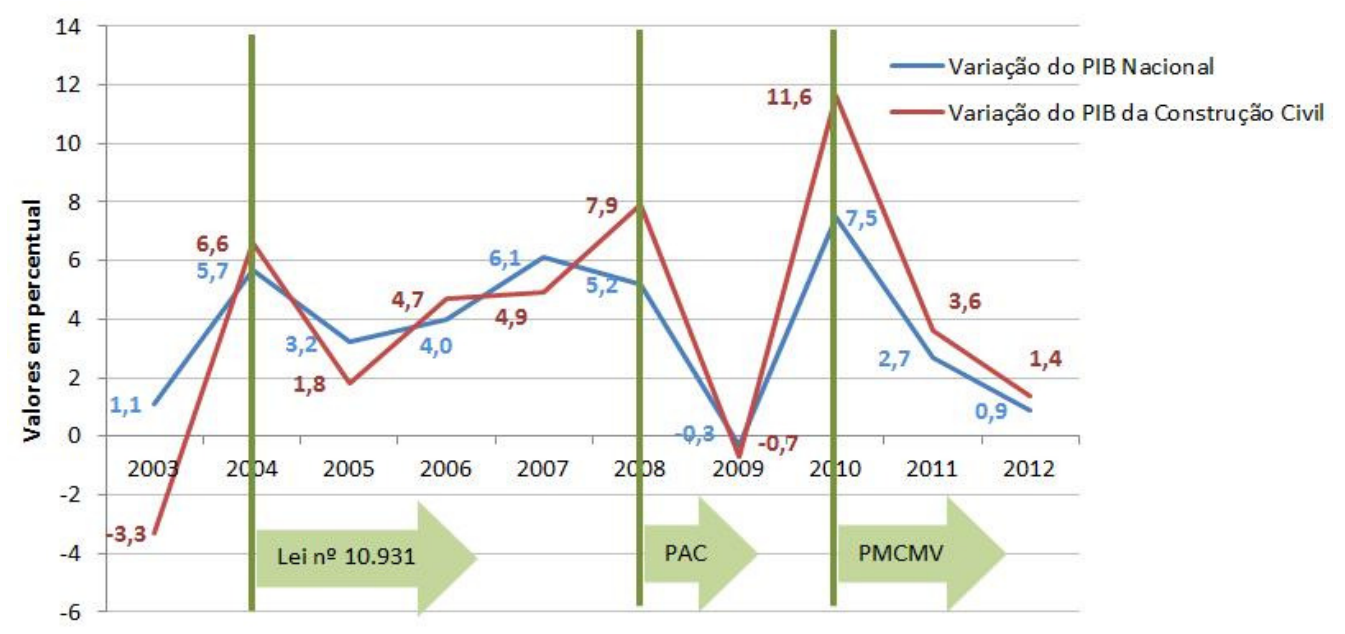

Fonte: Adaptado de CBCIC, 2013.

São apontadas pelo DECONCIC (2010), quatro principais diretrizes para o aumento na produtividade na construção: aumento da intensidade de capital, adoção de técnicas construtivas inovadoras, aumento das escalas de produção e qualificação da mão de obra.

A partir das demandas por maiores índices de produtividade, dá-se início à busca por tecnologias e processos que possam incrementar os resultados da cadeia da construção, incluindo-se a observação dos modelos que estão sendo implementados em países em que há um maior nível de industrialização da construção civil.

O mercado da construção civil tem demonstrado uma evolução tecnológica lenta, se comparada a outros setores industriais (MINISTÉRIO DO DESENVOLVIMENTO, INDÚSTRIA E COMÉRCIO EXTERIOR - MDIC, 2010). Até a década de 80, a maior parte do lucro era associada a produtos de incorporação imobiliária, levando a uma depreciação do processo produtivo. Nos anos 90, a partir de diversas iniciativas, as empresas da construção civil buscaram associar seu lucro ao aumento da produtividade ou utilização de novas soluções gerenciais, procurando aumentar o nível de industrialização do processo produtivo, porém ainda é considerada tradicional e conservadora por diversos pesquisadores (SECRETARIA DE TECNOLOGIA INDUSTRIAL - STI, 2003). 
Segundo Toledo et al. (2000), em função dos grandes investimentos realizados no fim da década de 70 , sem a devida associação a programas de qualidade, as empresas da construção civil não se comprometeram com o desenvolvimento de inovações.

A informação é reforçada pela deficiência do setor na escolha dos métodos construtivos, baixo treinamento dos trabalhadores e supervisores e fraca gestão do empreendimento. Também é reforçada a falta de políticas industriais para o setor, em função do seu crescimento desordenado e politicamente manipulado para absorver grande volume de mão de obra desqualificada (SCHEER et al., 2007).

O cenário de crescimento do setor, as políticas de investimento dos programas do Governo e o vigor, a partir de março de 2013, da Norma de desempenho - NBR 15.575, demandam adequações nas práticas do setor da construção civil, que direcionem os resultados para melhores índices de qualidade e produtividade dos empreendimentos.

Assim, o desenvolvimento das tecnologias de informação e comunicação na construção (TICs) aparece como alternativa. Segundo Nascimento e Santos (2003), o uso das TICs tem grande potencial para implementar melhorias na produtividade e competitividade do setor da construção.

No cenário mundial, observa-se o crescimento do uso da Modelagem da Informação da Construção, ou BIM (Building Information Modeling) como uma das principais TICs na indústria da construção (WONG et al. 2010), e diversos países vêm investindo em políticas nacionais de incentivo à sua implementação.

Nos Estados Unidos, a General Services Administration (GSA), órgão norte-americano responsável pela administração dos edifícios públicos, lançou em 2007 um guia de diretrizes que determina a entrega de informações de projeto em formato IFC (Industry Foundation Classes) para sua aprovação automática pelos softwares BIM utilizados por esta instituição.

No Reino Unido, em 2011, foi emitido pelo governo britânico o documento intitulado Government Construction Strategy, no qual é enfatizada a importância da implementação de inovações no setor da construção civil, para o atendimento das 
metas de crescimento do Governo. Como desdobramento dessa determinação, foi lançado, ainda em 2011, um novo documento (Building Information Modelling Working Party Strategy Paper), em que é detalhada a estratégia estabelecida e a sua relação com a Modelagem de Informações de Construção, para a qual foi mobilizado um grupo de trabalho voltado à adoção do BIM, com abrangência setorial, o Building Information Modelling Task Group.

Na Finlândia, a Senate Properties, empresa estatal responsável pela gestão do patrimônio imobiliário do governo lançou, em 2007, um guia de requisitos de especificações para os projetos de edifícios estatais em BIM, no qual são detalhados os procedimentos operacionais para construção de modelos. $O$ guia também prevê a utilização do IFC como formato padrão de informação para intercâmbio e utilização dos fornecedores (projetistas) e cliente (Senate Properties).

A Austrália, por meio do Departamento da Indústria, Inovação, Ciência, Pesquisa e Educação Terciária (Department of Industry, Innovation, Science, Research and Tertiary Education), publicou, em junho de 2012, o primeiro volume do National Building Information Modelling Initiative, resultado de uma série de projetos de pesquisa e eventos realizados em conjunto com a Australasia BuildingSMART, que geraram, por fim, esse documento, com o objetivo de coordenar as iniciativas do governo e da indústria da construção civil australiana para acelerar a adoção do BIM no país.

O documento prevê uma série de recomendações para a implementação da Modelagem da Informação, tais como a adoção completa de padrões abertos de informação em 3D até 2016, assim como a proposição de uma série de projetos a serem desenvolvidos, como guias de diretrizes para uso do BIM pelos agentes do setor, bibliotecas de elementos e estímulo à adequação dos programas educacionais para incorporação de um currículo multidisciplinar com o uso da modelagem nas carreiras do setor da construção.

Segundo Wong et al (2010), na Dinamarca, o uso do BIM já foi incorporado por três instituições governamentais (The Palaces and Properties Agency, The Danish University e Property Agency and Defence Construction Service). Na Noruega está 
sendo desenvolvido um projeto piloto com o uso do BIM para um cliente do governo, além da existência de forte iniciativa para a implementação do IFC.

Estes autores ainda definem as iniciativas em Cingapura, com o uso de um código de checagem automático de leitura de IFC para aprovação de projetos junto às agências governamentais desde 2007, e a aplicação do BIM para estudos de tecnologia, sustentabilidade e coordenação da construção de projetos de habitação popular em Hong Kong.

No Brasil, desde 2007, algumas empresas do setor privado, incluindo construtoras, incorporadoras e projetistas têm se mobilizado para a implementação do conceito BIM. Desde então, algumas instituições representantes de profissionais e empresas, também vêm se mobilizado no sentido de discutir a implementação do BIM, bem como de promover a sua aplicação, no contexto setorial. No entanto, conforme Souza et al. (2013), verifica-se que, apesar das iniciativas, o conceito de BIM ainda não está amplamente difundido no setor da construção civil do Brasil.

\subsection{OBJETIVO}

O objetivo deste trabalho é apresentar e discutir os modelos de contratação de empreendimentos da construção civil, apropriados ao uso da modelagem da informação da construção, enquanto mecanismos de suporte à colaboração entre os agentes do empreendimento, no contexto da construção civil brasileira.

Para tanto, buscou-se estudar os modelos de contratos relacionais disponíveis em utilização na construção civil e a sua aplicabilidade ao mercado brasileiro, dando ênfase ao impacto na etapa de projetos dos empreendimentos, sob o ponto de vista da colaboração entre os agentes, a fim de estruturar recomendações para os aspectos dos contratos relacionais que possam ser adotados no Brasil.

As questões de pesquisa elaboradas e apresentadas nesta dissertação referem-se aos seguintes temas: 
1) Identificação e apresentação das modalidades de contratos relacionais já aplicadas no mercado internacional da construção civil;

2) Análise dos principais modelos de contrato propostos pelo AIA (American Institute of Architects) para a implementação do IPD enquanto contrato relacional e para a formação de equipes colaborativas;

3) Análise dos processos decorrentes da implementação da modelagem da informação da construção nas empresas brasileiras de construção civil (estudo de caso);

4) Verificação da aplicabilidade do modelo de contrato de projeto integrado do AIA ao mercado brasileiro da construção civil.

\subsubsection{Delimitação do tema e condições de contorno}

Esta dissertação aborda, especialmente, os aspectos contratuais relacionados a primeira e a segunda fase do empreendimento definidas por Melhado (1994), a partir dos estudos de viabilidade do empreendimento, sua concepção, contratação e o desenvolvimento dos projetos e contratação da construção, porém sob a perspectiva da influência positiva na participação dos agentes de forma ativa em etapas iniciais do processo.

O trabalho tem como enfoque a etapa de projetos dos empreendimentos, e avaliará, a partir do estudo de caso realizado, a aplicabilidade da utilização dessa modalidade de contrato relacional (IPD) no mercado brasileiro.

O estudo de caso tem como objetivo específico as seguintes análises:

1) Análise dos processos decorrentes da implementação da modelagem da informação da construção nas empresas brasileiras de construção civil (incorporadoras, construtoras e projetistas) para estudo de caso;

2) Avaliação da aderência dos modelos contratuais utilizados nos empreendimentos estudados às práticas observadas;

3) Identificação dos potenciais de aplicação de contratos relacionais e, especificamente, de características do IPD, nas relações entre os agentes dos empreendimentos estudados nas empresas brasileiras; 
4) Identificação dos aspectos restritivos para a implementação de contratos relacionais no mercado brasileiro e das oportunidades de adequação, a partir de ações complementares de gestão do processo de projeto.

\subsection{JUSTIFICATIVA}

A indústria da construção civil tem grande influência no crescimento econômico do país, levando as instituições e agências governamentais a buscarem o desenvolvimento do setor por meio de investimentos em programas habitacionais e, atualmente, com destaque para os empreendimentos voltados para o atendimento $\mathrm{e}$ infraestrutura para os eventos esportivos da Copa do Mundo de Futebol em 2014 e os Jogos Olímpicos, em 2016, ambos a serem sediados no Brasil.

O grande volume de obras em construção e a serem construídas nesse período e as diretrizes de industrialização da cadeia da construção voltam as pesquisas do setor para os processos de inovação e melhorias tecnológicas, com vistas ao alcance de maior produtividade e melhores resultados para o setor.

Em especial no que diz respeito à inovação e agregação de valor ao processo produtivo da construção civil, deve-se atentar para a agenda de pesquisas em desenvolvimento pelo CIB (International Council for Research and Innovation in Building and Construction), órgão internacional que tem como objetivo facilitar a troca internacional de informações entre as instituições de pesquisa do setor da construção, estendendo-se a uma rede de mais de 5000 especialistas e mais de 500 organizações acadêmicas, da indústria ou governamentais, que trabalham para 0 desenvolvimento de pesquisas em inovação na construção.

O CIB define, no contexto do Integrated Design Delivery Solutions (IDDS), um de seus temas prioritários, uma série de temas de pesquisa que auxiliam na definição do foco da maioria das comissões e grupos de tarefas, por meio do desenvolvimento de diretrizes de pesquisa destinadas a orientar entre quatro e cinco mil 
pesquisadores fazendo uso de um processo interativo na condução da agenda de investigação.

A IDDS tem por objetivo apresentar uma visão holística para a transformação do setor, ao contrário de definir uma série de metas isoladas que tratam de questões pontuais.

Para que se alcance a plenitude dos objetivos da IDDS, ou seja, soluções integradas para implementação de empreendimentos, foi definida uma progressão lógica da implementação de melhorias de desempenho do setor, culminando na implementação da modelagem da informação da construção.

No entanto, a implementação da modelagem da informação da construção e mesmo do Integrated Project Delivery (IPD) vem ocorrendo sem a devida consideração das relações globais entre pessoas, processos e tecnologia, em que se destacam quatro aspectos essenciais a ser resolvidos (OWEN, AMOR et al. 2010):

- Processos colaborativos em todas as fases do projeto;

- Habilidades das equipes;

- Integração da informação e automatização dos sistemas;

- Gestão do conhecimento.

Ainda na linha de pesquisa de outro órgão de desenvolvimento e pesquisa tecnológica, o National Institute of Standards and Technology (NIST) solicitou em 2008 a convocação de um comitê para desenvolver diretrizes para o aumento da competitividade e produtividade no setor da construção civil americana, por meio do National Research Council of the National Academies (instituto de pesquisa privado e não lucrativo americano, formado pela National Academy of Sciences, National Academy of Engineering, Institute of Medicine, e pelo National Research Council).

A iniciativa resultou em um workshop realizado pelos membros do comitê, no qual foram identificadas as tecnologias, processos e atividades de desenvolvimento que apresentassem o maior potencial para aumentar significativamente a produtividade e competitividade dos ativos do setor de construção civil americana nos 20 anos subsequentes. 
As diretrizes determinadas nesse workshop e publicadas pelo National Research Council visam aumentar a eficiência das atividades do setor da Arquitetura, Engenharia e Construção (AEC), pela redução de desperdício de tempo, custos, materiais, energia, habilidades e de mão de obra. $\mathrm{O}$ comitê define que o aumento da eficiência das atividades do setor levará diretamente ao aumento da sua produtividade (National Research Council of the National Academies, 2009).

Foram definidas 5 diretrizes inter-relacionadas, que, segundo o comitê, podem levar a melhorias inovadoras para o setor num período de 2 a 10 anos, alcançando melhores resultados quanto à qualidade, cumprimento de prazos, relação custobenefício e sustentabilidade dos empreendimentos de construção civil. São elas:

1. Desenvolvimento amplo e uso de aplicações interoperáveis de tecnologia, também chamadas de BIM (Building Information Modeling);

2. Aumento da eficiência do canteiro de obras a partir de melhor interfaceamento de pessoas, processos, materiais, equipamento e informação;

3. Aumento no uso de pré-fabricados, pré-montados, modulação e técnicas e processos de fabricação industrializada.

4. Uso inovador e difundido de instalações modelo

5. Medições efetivas de desempenho para impulsionar e suportar a inovação.

A modelagem da informação da construção no Brasil, embora ainda incipiente, vem apresentando um número crescente de pesquisas relacionadas ao tema, conforme pode ser observado nos artigos apresentados em eventos nos últimos cinco anos (Anexo 1).

No contexto acadêmico, identifica-se uma série de iniciativas voltadas ao desenvolvimento de pesquisas sobre o conceito de modelagem da informação da construção, conduzidas por Universidades Brasileiras, assim como iniciativas em parceria com empresas privadas e associações representativas dos profissionais do setor, melhor descritas no item 2.2 desta dissertação: modelagem da informação da construção no Brasil. 


\subsubsection{Modelagem da informação da construção e colaboração}

Globalmente, o conceito de modelagem da informação da construção foi introduzido com o intuito de implementar um processo colaborativo integrado para projetos de empreendimentos. Seu uso agrega valor, desde que as informações geradas durante o processo sejam compartilhadas e gerenciadas adequadamente, levando a resultados econômicos positivos, a partir da prevenção e eliminação de falhas de projeto desde as fases iniciais do processo por meio da integração da informação de diversas disciplinas em um modelo virtual do edifício (SEBASTIAN, 2011; PENNSYLVANIA STATE UNIVERSITY, 2010; REKOLA, KOJIMA et al., 2010; MANZIONE, 2011).

A antecipação de atividades e decisões nos processos colaborativos da modelagem da informação da construção leva à ocorrência simultânea dos projetos com trabalhos de engenharia de planejamento e controle de qualidade. Essa concorrência aumenta a quantidade de informações geradas nas etapas iniciais, diferenciando-se do processo tradicional e dos acertos comerciais que são comumente praticados, em que as maiores parcelas de pagamento são associadas às fases finais do projeto quando ocorre o detalhamento e levantamento de quantitativos.

Esse trabalho colaborativo exige o envolvimento da construtora em estágios iniciais do processo, o que tradicionalmente não é contemplado nos modelos contratuais praticados no mercado da construção imobiliária no Brasil. Para atender a projetos colaborativos de modelagem da informação da construção, dois aspectos legais devem ser considerados (SEBASTIAN, 2011):

1) Diretrizes e regulamentação sobre as trocas de informação e comunicação:

Definição dos protocolos de troca de informação e gestão da comunicação entre os agentes do processo, definição da estrutura e formatos da informação e arquivamento.

2) Enfoque de implementação do empreendimento e seus arranjos contratuais: 
Definição do tipo de contrato, modelo de colaboração, compartilhamento de responsabilidades, riscos e benefícios entre as partes envolvidas, escopos de trabalho, e sua remuneração.

Assim, a necessidade de se desenvolver alternativas de contratos ou adequações dos existentes para processos colaborativos, como o proposto pelo uso da modelagem da informação da construção, faz-se relevante quanto aos fatores observados acima. Nessa dissertação, serão abordadas questões referentes ao enfoque da implementação do empreendimento e o uso do Integrated Project Delivery (IPD) como solução contratual para projetos colaborativos, no processo tradicional ou de modelagem da informação da construção'

O IPD - Integrated Project Delivery - foi definido em 2007, pelo American Institute of Architects (AIA) California Council como "um enfoque para implementação de empreendimentos que integra pessoas, sistemas, estruturas de negócios e práticas profissionais em um processo que colaborativamente aproveita os talentos e percepções de todos os participantes para otimizar resultados do empreendimento, aumentar o valor para o cliente, reduzir o desperdício e maximizar a eficiência em todas as etapas do projeto, fabricação e construção".

Segundo publicação do AIA (2010), os modelos contêm informações sobre a construção de empreendimentos muito além do que a maior parte das empresas de projeto no mercado americano poderiam deter. Os modelos não são somente ferramentas de desenho, eletrônicas ou renderizações tridimensionais, separadas da etapa de construção e seus documentos. E para alcançar um sistema integrado e paramétrico baseado no modelo, devem ocorrer mudanças radicais no processo de projeto e construção, inclusive relacionados à locação de riscos e compensação.

Do ponto de vista de coberturas de seguros e garantias contratuais, a utilização de um modelo paramétrico como banco de dados é de difícil análise. As empresas

1 O Project Management Institute (PMI) (2000) determina projeto (project) como "um esforço temporário empreendido para criar um produto, serviço ou resultado exclusivo". Nesta dissertação, o termo projeto será utilizado para identificar a atividade de projeto (design) conforme definida por Melhado e Agopyan (1995): "atividade ou serviço integrante do processo de construção, responsável pelo desenvolvimento, organização, registro e transmissão das características físicas e tecnológicas especificadas para uma obra, a serem consideradas na fase de execução". 
terão que se adequar, [partindo] do modelo de utilização de cópias físicas de projetos e especificações para um banco de dados digital interativo. Essa mudança do processo tradicional para o sistema integrado da modelagem exigirá a definição de novas diretrizes de negócio e responsabilidades das partes, como o IPD.

A definição de IPD segundo o IPD Guide (AIA, 2007), determina que o modelo de contratação IPD se fundamenta no princípio de colaboração, que, por sua vez, se baseia em relações de confiança. Se estruturada de forma eficaz, a colaboração baseada em confiança estimula os agentes a colocarem seu foco nos resultados do empreendimento ao invés de seus objetivos individuais.

Para essa estruturação, o guia acima define nove princípios, abordados com mais aprofundamento no desenvolvimento da dissertação, que devem ser incorporados no modelo contratual adotado - IPD. São eles: respeito e confiança mútua entre os agentes, Benefícios e Remuneração mútua, Tomadas de decisão e Inovações colaborativas, Envolvimento antecipado dos agentes-chave, Definição de objetivos e metas antecipada, Planejamento intensificado, Comunicação aberta, Uso de tecnologias apropriadas e, por fim, Organização e Liderança.

No entanto, o processo de projeto em sua configuração atual - ainda que sem a implementação da modelagem da informação da construção, apresenta grandes problemas de colaboração (AUSTIN et al., 1999; FABRÍCIO, 2002; FORMOSO et al., 1998; KALAY et al., 1998; KVAN, 2000; MANZIONE, 2006; MANZIONE et al., 2011; MELHADO, 2004)

Em pesquisa realizada com amostra de grupo de projetistas na cidade de São Paulo, Manzione et al. (2011) afirmam que a maior parte do grupo analisado entende colaboração apenas como "cumprimento de prazos e do escopo do projeto", o que demonstra falhas de compreensão do conceito, levando a falhas no seu relacionamento com os demais agentes do processo. Além disto, outra parcela considerável dos respondentes considera como postura colaborativa alertar o cliente de problemas nas especialidades dos demais projetistas, enquanto uma parcela menor tem a preocupação de dar retorno também aos respectivos autores dos projetos. 
A percepção de planejamento também é baseada somente nas datas de entregas de etapas de projeto, e não no processo de troca de informações entre os agentes, e somente uma baixa parcela da amostra tinha o hábito de compartilhar seus cronogramas com os membros da equipe.

Esses autores exprimem a preocupação de se amplificarem os problemas de colaboração encontrados em um processo tradicional de projetos para o ambiente da modelagem, mais rico e complexo em seus parâmetros e maior simultaneidade nas trocas de informação.

Nesse contexto, a aplicação de princípios do IPD para a estruturação de um processo colaborativo estruturado, baseado em modelo de contrato que visa à interação dos agentes e o compartilhamento de objetivos, riscos e benefícios, pode ser avaliado como hipótese também para aplicação em projetos 2D, de forma simplificada.

\subsection{MÉTODO DE PESQUISA}

Os métodos de pesquisa adotados para a análise da implementação de modelos de contratação de empreendimentos da construção civil apropriados à modelagem da informação da construção são do tipo qualitativo, realizados por meio de dois questionários estruturados e um estudo de caso.

Por definição, Estudo de Caso é

"Uma investigação empírica que investiga um fenômeno contemporâneo em profundidade e em seu contexto de vida real, especialmente quando os limites entre o fenômeno e o contexto não estão claramente definidos; enfrenta a situação tecnicamente diferenciada em que existiam muito mais variáveis de interesse do que pontos de dados, e como resultado conta com múltiplas fontes de evidência, com os dados precisando convergir de maneira triangular, e como outro resultado beneficia-se do desenvolvimento anterior das proposições teóricas para orientar a coleta e a análise de dados" (YIN, 2010). 
A escolha de estudo de caso como método de pesquisa deu-se em função de dois principais aspectos:

- Situação atual da implementação da modelagem da informação da construção no Brasil: há poucas empresas atuantes na modalidade 'Big BIM' (JERNIGAN, 2007) já participando no processo de produção de um modelo federado em conjunto com outras empresas contratadas para esse fim - em que é possível a avaliação organizacional e gerencial das relações entre elas.

- Necessidade de avaliação da aplicabilidade do objeto de pesquisa no mercado brasileiro, cujas condições de contorno para a sua implementação são diferenciadas daquelas para as quais foi pensado o IPD.

Para embasar o estudo de caso realizado, fez-se pesquisa bibliográfica com objetivo de analisar as publicações sobre o tema principal: IPD e os temas secundários: I) Contratos relacionais para empreendimentos de construção civil, II) Aspectos colaborativos do processo do empreendimento da construção civil, III) Aspectos colaborativos do uso da modelagem da informação da construção, IV) Implementação da modelagem da informação da construção no mercado brasileiro.

Além de periódicos e livros sobre os temas, foram examinadas as publicações em simpósios e congressos internacionais e nacionais, especialmente:

- Anais dos Congressos do International Council for Research and Innovation in Building and Construction (CIB) dos grupos:

○ W096 - Workgroup for Architectural Management

- W078 - Information Technology for Construction

- Anais de Eventos Brasileiros relacionados à Tecnologia de Informação e Gestão na Construção Civil:

- Workshop Brasileiro de Gestão do Processo de Projetos na Construção de Edifícios;

- SBPQ - Simpósio Brasileiro de Qualidade do Projeto no Ambiente Construído;

- TIC - Encontro de Tecnologia e Informação da Comunicação na Construção. 
Para análise do estágio atual e métodos contratuais de serviços de projetos para construção civil foi distribuído um questionário estruturado no evento Soluções Para Empresas de Projeto, promovido pelo grupo de pesquisa de Gestão do Processo de Projeto/ TGP da Escola Politécnica da USP, na data de 15 de abril de 2011, envolvendo empresas de projeto, profissionais autônomos de projeto, e contratantes de projeto, na qual são abordadas questões relacionadas às formas de contratação utilizadas e o entendimento e a percepção dos respondentes quanto a formas alternativas contratuais que buscam maior integração do projeto.

Como dados adicionais para análise do estágio atual da implementação da modelagem da informação da construção no Brasil e caracterização das empresas que vêm se utilizando dela, foram utilizados os resultados da pesquisa realizada durante o V Encontro de Tecnologia de Informação e Comunicação na Construção (TIC 2011), promovido pela Rede BIM Brasil e realizado nos dias 4 e 5 de Agosto de 2011, em Salvador, Bahia.

O estudo de caso foi realizado entre os meses de outubro de 2012 e abril de 2013 e as ferramentas utilizadas foram questionários estruturados de entrevistas, análise de documentação contratual entre o cliente e prestadores de serviço e análise de documentos gerados durante o processo de projeto pelas empresas-caso contratos, cronogramas, formulários de avaliação do projeto, formulários de avaliação dos prestadores de serviço.

Foram abordadas relações contratuais e aspectos do processo de projeto entre uma empresa de incorporação do setor da construção civil brasileira e os seus prestadores de serviços de projeto que usam a modelagem da informação da construção.

Os critérios de escolha que levaram à determinação da empresa estudada foram a presente utilização da modelagem da informação da construção na fase de projetos de seus empreendimentos, e a disponibilidade para participação no estudo de caso.

Foram abordadas três diferentes empresas incorporadoras e construtoras de grande representatividade no mercado da construção civil brasileira, todas com sede em 
São Paulo, porém apenas uma teve disponibilidade para participação em todas as etapas do estudo de caso, relatado nesta dissertação.

Como objetivos específicos do estudo de caso estão as avaliações do contrato aplicado pela empresa nos seguintes contextos:

- Contratação de projetos em BIM.

- Desenvolvimento de projetos em BIM (dentro do escopo e das etapas contratadas pela empresa):

I. Fluxo de Informações

II. Aspectos colaborativos do trabalho em BIM

III. Recebimento de projetos/modelos BIM

IV. Subprodutos do modelo

V. Análise crítica do projeto/modelo BIM pela empresa

VI. Avaliação de desempenho da equipe contratada

- Análise das interfaces do projeto/modelo BIM com áreas de orçamento, produção (obras) e pós-obra da empresa.

Para complementação das informações observadas nas empresas contratantes, foi realizado também o acompanhamento de atividades referentes ao desenvolvimento do projeto junto a empresas contratadas, nos seguintes aspectos:

- Elaboração de propostas para desenvolvimentos de projeto em BIM.

- Desenvolvimento de projetos em BIM:

I. Fluxo de Informações

II. Aspectos colaborativos do trabalho em BIM

III. Entregas de projetos/modelos BIM

IV. Subprodutos do modelo

- Análise de desempenho da empresa em projetos BIM em relação a projetos em 2D. 
A Coleta de dados ocorreu pela observação das rotinas de trabalho dos profissionais, análise de documentos, ferramentas, procedimentos e acompanhamento de eventos (reuniões, treinamentos). Foram elaborados relatórios sistemáticos de análise dos dados coletados, e a consolidação do estudo de caso ocorreu com a elaboração de um relatório final de síntese das informações coletadas e analisadas, disponibilizado, inclusive, para as empresas colaboradoras.

Para a análise dos resultados foi realizada a comparação do contrato utilizado pela empresa estudada e um dos modelos de contrato de projeto integrado proposto pelo AIA, e avaliou-se os potenciais de melhoria do contrato aplicado levando-se em conta o processo de projeto observado, e os empecilhos para a sua aplicação.

\subsection{ESTRUTURA DO TRABALHO}

O presente trabalho foi desenvolvido em 7 capítulos. O Capítulo 1, Introdução, apresenta o cenário em que se insere a pesquisa, com a descrição do contexto do mercado da construção civil, e das diretrizes de desenvolvimento de pesquisa acadêmica relacionadas com o tema da dissertação (especialmente modelagem da informação da construção e projeto integrado).

Ainda neste capítulo são descritos os objetivos do trabalho e a metodologia proposta para o seu alcance - questionários estruturados e estudo de caso.

O Capítulo 2, Modelagem da informação da construção, identifica os principais conceitos relacionados a este tema, e suas estratégias de implantação em diversos países. Também é apresentado um panorama das iniciativas de implementação e desenvolvimento da modelagem da informação da construção no Brasil e as principais barreiras para uso de seu potencial completo. Este capítulo identifica uma lacuna no desenvolvimento dos processos relacionados à modelagem da informação da construção, vinculado com os temas de contratos da construção civil e projeto integrado, desenvolvidos no Capítulo 3 e Capítulo 4, respectivamente. 
O Capítulo 3, Contratos da construção civil, descreve os principais sistemas contratuais utilizados pelo mercado da construção, e a diferenciação entre contratos transacionais e relacionais, apontando o segundo como alternativa mais adequada aos processos colaborativos associados à modelagem da informação da construção. Ao fim do capítulo são apresentadas as famílias e documentos contratuais do American Institute of Architects (AIA) para empreendimentos que fazem uso da modelagem.

O Capítulo 4 dá enfoque ao Projeto Integrado ou IPD, descrevendo toda a sua estrutura conceitual conforme proposta pelo AIA. São apresentados os modelos de relações contratuais possíveis, os critérios de formação de equipes, os papéis dos principais agentes e a relação dos produtos gerados com a métrica contratual, estabelecendo o modelo como documento contratual.

São ainda identificadas as relações do projeto integrado com os conceitos da Lean Construction e, ao fim do capítulo, são relatados sinteticamente as características e resultados dos estudos de caso de empreendimentos que utilizaram o IPD realizados pelo AIA.

O Capítulo 5 inicia a apresentação dos dados coletados para análise da implementação da modelagem da informação da construção no Brasil, a partir de dois questionários estruturados; o primeiro, mais abrangente, foi utilizado nesta pesquisa para avaliar a maturidade do mercado brasileiro quanto ao uso da modelagem. O segundo, mais específico, aborda questões relacionadas ao projeto integrado, estruturas de contrato e colaboração na etapa de projetos.

No Capítulo 6, as questões de implementação da modelagem e análise dos processos e contratos da etapa de projetos são aprofundadas na apresentação do estudo de caso realizado.

É realizada a caracterização da empresa caso, demonstrando a sua representatividade no mercado, e os objetivos específicos que a levaram a adoção da modelagem da informação da construção.

São então apresentadas a equipe responsável pelo desenvolvimento dos processos de modelagem e as diferentes etapas dos processos de projeto em que foram 
utilizadas, com o desenho dos fluxogramas dos processos e descrição das atividades relacionadas à modelagem.

Também é caracterizado o modelo padrão de documento contratual utilizado pela empresa caso, para que seja feita a análise da sua adequação aos processos de modelagem já implementados.

$\mathrm{Na}$ análise do estudo de caso é realizada uma comparação do contrato padrão da empresa com um dos modelos do AIA para projeto integrado, e são apontadas algumas oportunidades de desenvolvimento do documento da empresa caso para dar maior suporte à colaboração nas atividades de projeto. Além disso, são identificadas as principais barreiras à implementação do modelo de projeto integrado observadas na empresa, que em alguns casos podem ser estendidas às demais empresas do mercado da construção civil.

O último capítulo - Capítulo 7 - descreve as considerações finais sobre o tema, analisa os resultados da pesquisa frente aos objetivos determinados no início do trabalho, apresenta um quadro de diretrizes sugeridas para a adequação dos modelos contratuais praticados na empresa caso às características relacionais do IPD considerados aplicáveis no mercado da construção no Brasil, e apresenta sugestões de trabalhos futuros a serem desenvolvidos. 


\section{MODELAGEM DA INFORMAÇÃO DA CONSTRUÇÃO OU BUILDING INFORMATION MODELING (BIM)}

Este capítulo tem por objetivo apresentar o conceito de Modelagem da Informação da Construção e as principais modificações e ganhos que seu uso proporciona ao mercado da construção civil, em especial quanto à colaboração entre seus agentes.

São apresentadas algumas diretrizes de implementação da modelagem, sendo realizada uma análise da situação atual da sua implementação no Brasil, quanto ao desenvolvimento de pesquisas e iniciativas setoriais.

Ao fim do capítulo, são identificadas as principais dificuldades e os obstáculos para a sua implementação, e é novamente dada ênfase à questão da colaboração e da abordagem de processos para suporte à modelagem da informação da construção.

\subsection{CONCEITOS DE MODELAGEM DA INFORMAÇÃO DA CONSTRUÇÃO (BIM)}

BIM - Building Information Modeling ou Modelagem da Informação da Construção - é um processo baseado em modelos digitais, compartilhados, integrados $\mathrm{e}$ interoperáveis denominados modelos da informação da construção. Assim, a Modelagem da Informação da Construção pode ser definida como um processo que permite a gestão da informação, e o Modelo da informação da construção é o conjunto de modelos compartilhados, digitais, tridimensionais e semanticamente ricos que são a base para o processo de modelagem (UNDERWOOD, ISIKDAG, 2010).

A escolha da modelagem da informação da construção como alternativa para os modelos de representação do empreendimento é justificada por sua abordagem sistêmica e integrada de todas as fases do ciclo de vida, apresentadas em um modelo único e compartilhado das informações, levando a melhores resultados e a 
menos interferências entre a produção e as informações utilizadas pelos diversos agentes envolvidos no processo.

Diversas instituições, órgãos regulamentadores e empresas da indústria da construção civil de diferentes países definem a modelagem da informação da construção, em função da abordagem que buscam enfatizar. Entre elas destacamse:

Uma representação computável das características físicas e funcionais de uma instalação e suas informações de projeto / ciclo de vida relacionados, utilizando padrões abertos da indústria para dar base à tomada de decisão para a realização de um melhor valor. (NATIONAL INSTITUTE OF BUILDING SCIENCES)

Um único repositório para documentos gráficos - desenhos - e não gráficos - especificações, agendas e outras informações. (GRAPHISOFT)

Modelagem dos aspectos gráficos e não gráficos de todo o ciclo de vida do edifício em um grande sistema de gerenciamento de banco de dados federado. (BENTLEY)

Uma metodologia do processo de projeto do edifício e de sua documentação caracterizada pela criação e uso coordenado de um sistema intrinsicamente consistente e computável das informações do projeto de um edifício e de sua construção. (AUTODESK)

Building Information Modeling é o desenvolvimento e o uso de um modelo de dados computadorizado multifacetado não só para documentar o projeto do edifício, mas para simular a sua construção, operação e reforma. O resultante Building Information Model é um conjunto rico de dados, baseado em objetos, inteligente, representação digital e paramétrica do edifício com pontos de vista apropriados para gerar informações para vários perfis de usuários. Esses dados podem ser extraídos, analisados e podem gerar retroalimentação e melhorias no projeto. (U.S. GSA - UNITED STATES GENERAL SERVICES ADMINISTRATION)

Projeto e Construção virtual é o uso de modelos de performance multidisciplinares, incluindo o do produto, processos de trabalho e organização da equipe de projeto--construção-operação para suportar os objetivos do negócio. (CIFE - STANFORD UNIVERSITY) 
BIM é um modelo digital do edifício que representa não só suas características geométricas, mas também o inter--relacionamento entre seus componentes e os inúmeros parâmetros e atributos destes, fornecendo informações relevantes para a tomada de decisão pelos diferentes agentes envolvidos no empreendimento, em todo o ciclo de vida da edificação. (SANTOS, E. T)

Para a obtenção de sucesso com a implementação da modelagem da informação da construção, alguns aspectos relacionados à tecnologia e aos processos da construção civil devem ser desenvolvidos; segundo o relatório Introperability in the Construction Market (MCGRAW HILL, 2007), a interoperabilidade, seja ela técnica referente à possibilidade de troca e gerenciamento de dados eletrônicos, ou cultural - referente às relações colaborativas que devem ser estabelecidas entre os membros das equipes interdisciplinares do empreendimento, é uma das premissas básicas para que exista a troca de informações e dados da Modelagem da Informação entre a equipe do empreendimento.

Nesse mesmo relatório, são apresentados os dados referentes aos custos relacionados à falta de interoperabilidade em empreendimentos da construção civil, resultado de uma pesquisa realizada pela McGraw Hill entre agentes do setor da AEC Norte Americana. A análise dos resultados dessa pesquisa estima que os problemas relacionados à falta de interoperabilidade geram uma perda de $3 \%$ dos custos dos empreendimentos.

Nesta mesma linha de raciocínio, Santos (2009), determina duas premissas básicas para a implementação da modelagem da informação da construção em seu potencial completo:

1) "Colaboração entre diferentes agentes em diferentes fases do ciclo de vida do edifício, permitindo inserir, extrair, atualizar ou modificar informações da modelagem para suportar e refletir os papéis daqueles agentes".

A atuação dos diversos agentes em um mesmo modelo (seja ela simultânea ou sequencial) exige que estes se relacionem de forma colaborativa, agregando valor às soluções do modelo e do empreendimento como um todo, ao invés de 
competirem pela priorização de suas disciplinas de projeto, facilidade construtiva ou resultados de uma característica específica de desempenho.

2) "O BIM é uma representação digital compartilhada, fundada em padrões abertos para interoperabilidade"

Para que seja possível a atuação e análise do modelo por diferentes pessoas e empresas é necessário que este não apresente restrições para seu acesso ou modificações em função da adoção de diferentes softwares e diferentes extensões de arquivos por esses agentes, ou seja, devem ser utilizadas linguagens abertas para a troca de dados e informações - no caso da modelagem da informação da construção, a linguagem IFC (Industry Foundation Classes) - mais adequadas para que se obtenham melhores resultados na integração do processo do empreendimento.

Como exemplos das mudanças a serem realizadas, Owen, Amor et al (2010) comentam que, com a difusão da modelagem da informação da construção, a sua implementação, em muitos casos, vem acontecendo de forma análoga ao que ocorreu com a implementação da tecnologia CAD, na medida em que se reproduz um processo corrente, de forma praticamente inalterada.

Para maximizar o potencial da tecnologia da modelagem da informação da construção se pressupõem uma análise e uma reengenharia dos processos afetados além de uma reavaliação do papel dos profissionais em cada um desses processos. Essa mesma conclusão é também compartilhada por Taylor (2009) e Kiviniemi (2008), pois esses pesquisadores entendem que o aspecto cultural a ser modificado é desafiador, especialmente no desenvolvimento de confiança dentro de um setor desconfiado e propagador de riscos.

Em geral, no mercado da construção civil, prevalecem a cultura e a mentalidade de "silos de conhecimento" e as trocas baseadas apenas em documentos entre os profissionais e a cadeia produtiva ocorrem de forma descoordenada e com baixa inteligência. As decisões são tomadas, frequentemente, de maneira autônoma, sem a participação multidisciplinar e com a ausência de uma compreensão holística e acurada. 
O uso de um processo de projeto interativo e desenvolvido a partir das necessidades do cliente é virtualmente impossível ou muito difícil de ser obtido dentro das estruturas correntes. (OWEN, AMOR et al., 2010).

\subsection{DIRETRIZES DE IMPLEMENTAÇÃO DA MODELAGEM DA INFORMAÇÃO DA CONSTRUÇÃO}

Observam-se, em diferentes países, iniciativas de determinação de diretrizes para implementação da modelagem da informação da construção por organizações governamentais, acadêmicas e da própria indústria da construção. Tais diretrizes resultam na produção de guias e manuais que buscam apresentar uma estrutura do processo de trabalho para a modelagem da informação da construção.

Succar (2009) realizou um levantamento das principais produções que objetivam determinar as diretrizes de trabalho com a modelagem da informação da construção, aqui identificadas na Tabela 1.

Tabela 1- Guias de Implementação de BIM

\begin{tabular}{lcccc}
\hline Origem & Organização & Projeto & Descrição & Data \\
\hline Austrália & CRC & $\begin{array}{c}\text { National Guidelines and } \\
\text { Case Studies }\end{array}$ & $\begin{array}{c}\text { Guia de Diretrizes e } \\
\text { estudos de caso }\end{array}$ & 2008 \\
\hline Dinamarca & BIPS & Digital Construction & Guia de Diretrizes & 2007 \\
\hline Finlândia & $\begin{array}{c}\text { SENATE } \\
\text { Properties }\end{array}$ & BIM Requirements & Guia de Diretrizes & 2007 \\
\hline Holanda & TNO & E-BOUW & Estrutura de Trabalho & 2008 \\
\hline Noruega & STATSBYGG & HITOS & BIM & \\
\hline Estados & AGC & Contractors Guide to BIM & Guia de Diretrizes & 2006 \\
\cline { 2 - 5 } & AlA & Integrated Project Delivery & Guia de Diretrizes & 2007 \\
\hline
\end{tabular}




\begin{tabular}{|c|c|c|c|c|}
\hline Origem & Organização & Projeto & Descrição & Data \\
\hline & GSA & 3D - 4D BIM Program & Guia de Diretrizes & 2006 \\
\hline & & NBIMS National Building & & \\
\hline & NIST & Information Modelling & Guia de Diretrizes & 2007 \\
\hline & & Standards & & \\
\hline & & & Mapa de implementação & \\
\hline & & & BIM para resolução dos & \\
\hline & USACE & US Army Corps of Engineers & desafios de tempo e custo & \\
\hline & & & da MILCON & \\
\hline & & & Transformation & \\
\hline & USCG & U.S. Coast Guard & $\begin{array}{c}\text { Guia de usuários e } \\
\text { padrões }\end{array}$ & \\
\hline \multirow{4}{*}{$\begin{array}{l}\text { Europa } \\
\text { Europa } \\
\text { Europa } \\
\text { Europa }\end{array}$} & $\begin{array}{l}\text { Consortium of } \\
\text { organizations }\end{array}$ & InPro & Relatório & $\begin{array}{l}2006 a \\
2010\end{array}$ \\
\hline & $\begin{array}{l}\text { Consortium of } \\
\text { organizations }\end{array}$ & $\begin{array}{c}\text { CONCUR -Concurrent } \\
\text { Engineering in Building and } \\
\text { Civil Engineering }\end{array}$ & Projeto Demonstrativo & 2002 \\
\hline & $\begin{array}{l}\text { Consortium of } \\
\text { organizations }\end{array}$ & ERABUILD & Relatório & 2008 \\
\hline & $\begin{array}{l}\text { Consortium of } \\
\text { organizations }\end{array}$ & STAND-INN & $\begin{array}{c}\text { Guia rápido de } \\
\text { desenvolvimento de } \\
\text { processos }\end{array}$ & 2007 \\
\hline
\end{tabular}

Fonte: Adaptado de Succar, 2009

Ainda em 2009, foi publicado o BIM - Project Execution Planning Guide, produzido pela Pennsylvania State University (PSU) (2009), o qual determina diretrizes para que se utilize a modelagem da informação da construção em projetos e também disponibiliza uma abordagem da sua implementação no contexto dos processos realizados pelas empresas e organizações envolvidas, permitindo uma análise do impacto das mudanças técnicas e gerenciais que ocorrem com o uso desse processo. 
Esse guia estabelece que a modelagem da informação da construção é uma representação digital das características físicas e funcionais de um empreendimento, e para se obter sucesso na sua implementação e uso, os agentes do empreendimento, em especial os clientes ou incorporação, devem definir um plano de produção detalhado e abrangente, do empreendimento em questão. Esse plano de produção deve ser bem documentado e registrado no princípio do projeto, devendo garantir o esclarecimento de todas as partes envolvidas quanto às oportunidades e responsabilidades associadas com a incorporação da modelagem no processo do empreendimento.

Além disso, deve determinar os usos da modelagem da informação da construção no empreendimento em diversos aspectos e etapas do seu ciclo de vida, tais como autoria e responsabilidades no processo de projeto e produto, estimativa de custos e coordenação de projetos.

Todo o planejamento dos processos previstos no ciclo de vida do empreendimento também deve constar no plano, que, uma vez finalizado, servirá como guia para monitoramento do progresso na implementação da modelagem da informação da construção e avaliação dos benefícios alcançados durante o processo.

A PSU (2009) propõe diretrizes estruturadas para elaboração e implementação do plano de produção do empreendimento em modelagem da informação da construção, resumidas em quatro passos:

1. Identificação dos usos e benefícios da modelagem da informação da construção durante o planejamento, projeto, construção e operação do empreendimento;

2. Criação de mapas dos processos do empreendimento em modelagem da informação da construção;

3. Determinação das entregas e produtos da modelagem da informação da construção (desenhados nos mapas de processos como documentos de troca de informações);

4. Desenvolvimento da infraestrutura do empreendimento na forma de contratos, procedimentos para comunicação, tecnologia e controle de qualidade, para dar suporte ao processo de implementação.

Quanto aos contratos para modelagem da informação da construção, a PSU (2009) 
chama a atenção para a antecipação da determinação do modelo contratual, que deve ocorrer antes do início do empreendimento. A escolha do modelo contratual é tratada como estratégica para o sucesso do empreendimento e sugere a utilização de abordagens contratuais mais integradas, tais como o Design Build (DB) e o Integrated Project Delivery (IPD).

A sugestão é justificada pelas características de relacionamentos altamente colaborativos, proporcionados por essas modalidades de contrato e os melhores resultados, geralmente obtidos com a utilização desses modelos em empreendimentos em modelagem da informação da construção, como será discutido nos capítulos posteriores desta dissertação.

O guia aborda, ainda, outras questões relacionadas com a seleção da equipe do empreendimento, apontando a necessidade de avaliação das experiências em projetos em modelagem da informação da construção das contratadas, a fim de determinar a sua competência para o cumprimento das responsabilidades que um projeto desta natureza requer, inclusive no que se refere à colaboração com os outros membros da equipe.

A relação de responsabilidade sobre a produção do empreendimento ganha um novo ponto de vista em projetos de modelagem, nos quais a criação do modelo e soluções projetuais e construtivas são fruto de uma experiência conjunta da equipe, e o grau de responsabilidade atribuído a cada membro deve ser um dos pontos de cuidado na redação de um contrato para empreendimentos de modelagem da informação da construção.

\subsection{MODELAGEM DA INFORMAÇÃO DA CONSTRUÇÃO NO BRASIL}

Desde 2007, observa-se no Brasil um início de movimentação no setor privado para a implementação da modelagem da informação da construção (SOUZA et al., 2013). Essa demanda por conhecimento relacionado ao tema levou algumas instituições representantes de profissionais e empresas a se mobilizarem no sentido de discutir sua implementação, suas aplicações no contexto setorial e as barreiras de 
implementação, com a realização de cursos e eventos. Porém, conforme Souza et al. (2013), o conceito de modelagem da informação da construção ainda não está amplamente difundido no setor da construção civil do Brasil.

Esses autores apresentam a situação da produção acadêmica difundida na Figura 2, que demonstra a ocorrência de pesquisas com os seguintes temas nos Estados Brasileiros: processo de projeto, difusão acadêmica, tecnologia e difusão no setor da construção. Os dados foram obtidos nos anais Encontro de Tecnologia da Informação (TIC), em 2009 e 2011. Foram analisados 48 trabalhos e 8 artigos $(16,6 \%)$ foram classificados como Processo de Projeto, 7 artigos (14,6\%) como Difusão Acadêmica, 28 (58,3\%) como Tecnologia e $5(10,5 \%)$ como Difusão Setorial.

Observa-se, a partir da Figura 2 que o desenvolvimento das pesquisas se concentra na maior parte dos Estados da costa leste do Brasil e Minas Gerais, ficando as demais regiões à margem da discussão desse tema. Outro aspecto interessante demonstrado no mapa é que os únicos Estados que contêm pesquisas sobre os quatro temas identificados são Bahia e São Paulo, seguidos por Rio de Janeiro e Minas Gerais que estão trabalhando três dos quatro temas destacados. 
Figura 3 - Iniciativas de modelagem da informação da construção no Brasil

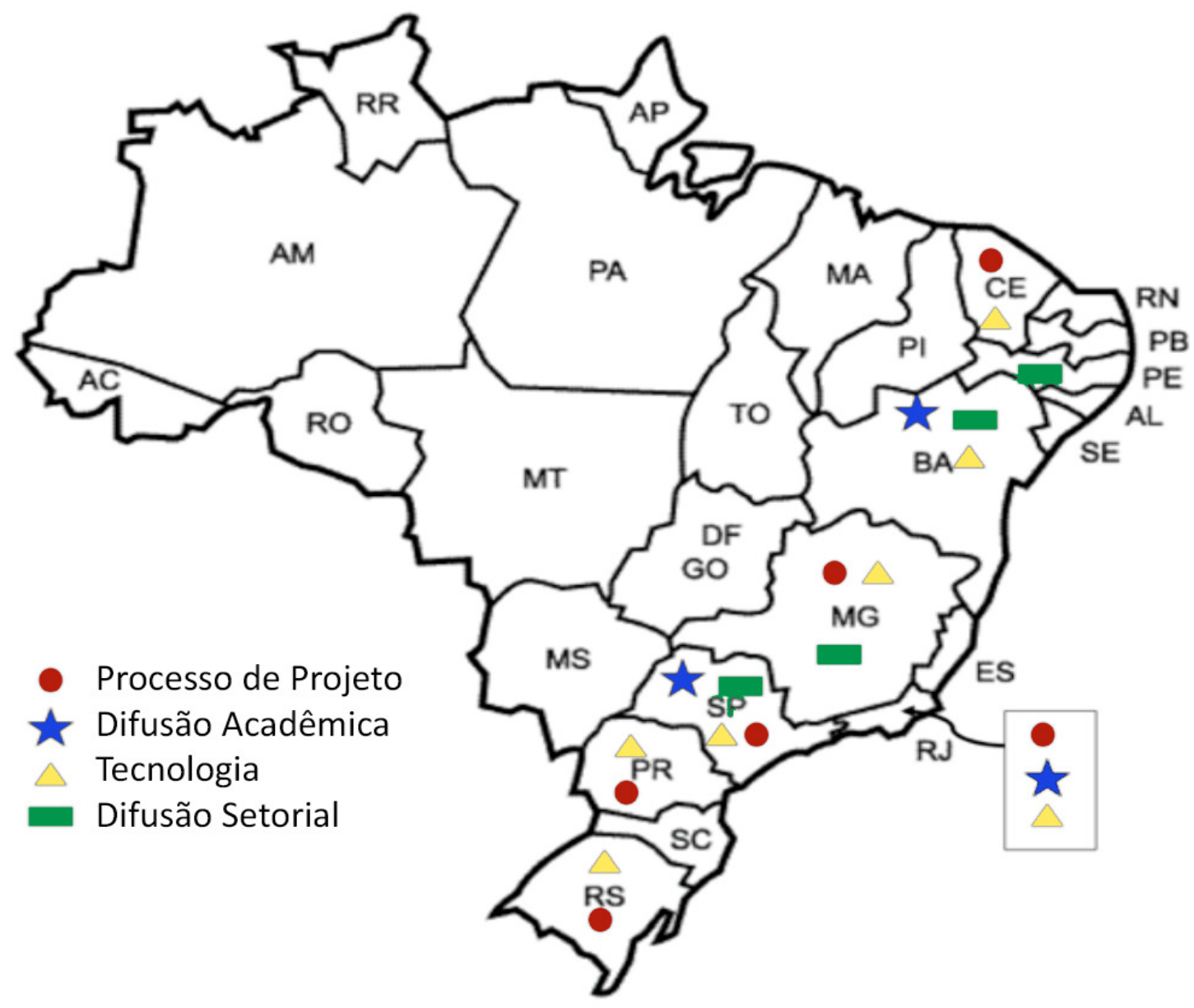

Fonte: Souza, Wyse e Melhado (2013)

Ainda no contexto acadêmico, observa-se a crescente importância da modelagem da informação da construção em eventos: o TIC 2011 (V Encontro de Tecnologia de Informação e Comunicação na Construção) teve como tema central: BIM MODELANDO A CONSTRUÇÃO DO FUTURO, com o objetivo de contribuir para a difusão das propostas que, valendo-se de novas formas de modelagem da informação da construção, propiciem uma base mais eficiente para colaboração, simultaneidade nos processos, melhoria da produtividade e da qualidade dos produtos gerados.

Pode-se destacar também o interesse da FINEP no desenvolvimento de projetos de pesquisa científica, tecnológica e de inovação, voltados para a área de habitação, traduzido, no que se refere à modelagem da informação da construção, no apoio 
financeiro aplicado ao tema 2.1 do Edital de Chamada Pública de Propostas MCT/MCIDADES/FINEP/Ação Transversal - Saneamento Ambiental e Habitação 7/2009:

Tema 2.1: desenvolvimento de soluções inovadoras em tecnologia da informação e comunicação aplicadas à construção, visando à melhoria da qualidade e produtividade do segmento da habitação de interesse social, com destaque para: Building Information Modeling (BIM) e outras soluções para suporte ao processo de gerenciamento de projetos; simulação de desempenho; e operação de edificações.

Para esse projeto, foi selecionada a proposta de trabalho integrado entre 7 universidades Brasileiras (USP, UNICAMP, UFPR, UFC, UFBA, UFRGS e Mackenzie) para o desenvolvimento de pesquisas em modelagem da informação da construção, atualmente em produção.

Ainda no contexto nacional, têm ênfase quatro iniciativas de associações representativas do setor da construção congregadas com a academia para a implementação e o desenvolvimento da modelagem da informação da construção IM no Brasil. São elas: (i)Grupo BIM Interdisciplinar, (ii) Rede BIM Brasil, (iii) SindusconSP e (iv) Comitê de desenvolvimento de Normas BIM.

\subsection{BARREIRAS PARA A IMPLEMENTAÇÃO DA MODELAGEM DA INFORMAÇÃO DA CONSTRUÇÃO NO BRASIL}

Na maioria dos casos, as empresas da construção civil investem muitos recursos na implantação de inovações, em especial novas tecnologias sem, necessariamente, compreender os impactos e as mudanças que a sua adoção irá criar (MANZIONE et al., 2011). Conforme Owen, Palmer et al.(2009), as tecnologias existem para dar suporte aos processos, os quais existem para dar suporte à criação e manutenção de informações coerentes e relevantes, que, por sua vez, existem para dar suporte à 
colaboração das pessoas envolvidas em um mesmo projeto, conforme demonstrado na Figura 3.

Amor e Owen (2011), a partir de sua observação de pesquisas, afirmam que a tendência corrente de muitos é utilizar a modelagem da informação da construção mais como tecnologia, o que denominam como "BIM simples" (sBim) e muito menos como um processo integrado ou inteligente (iBIM), embora, nessa segunda forma, existam muito mais vantagens financeiras, especialmente se ligadas aos processos de construção enxuta e a novos processos de colaboração, como o IPD (Integrated Project Delivery).

Succar (2009), estabelece uma estrutura de trabalho que determina três domínios de aplicabilidade da modelagem da informação da construção - Políticas, Processos e Tecnologia - e estágios de maturidade da sua implementação, graduais e consecutivos.

Segundo o autor, os três domínios devem ser desenvolvidos de maneira equilibrada buscando proporcionar um ambiente favorável à implementação da modelagem da informação da construção, pelos diversos agentes do mercado, gerando melhores resultados para todas as partes.

Figura 4: Relação entre Tecnologia, Processos, Informações e Colaboração no processo de projeto da modelagem da informação da construção

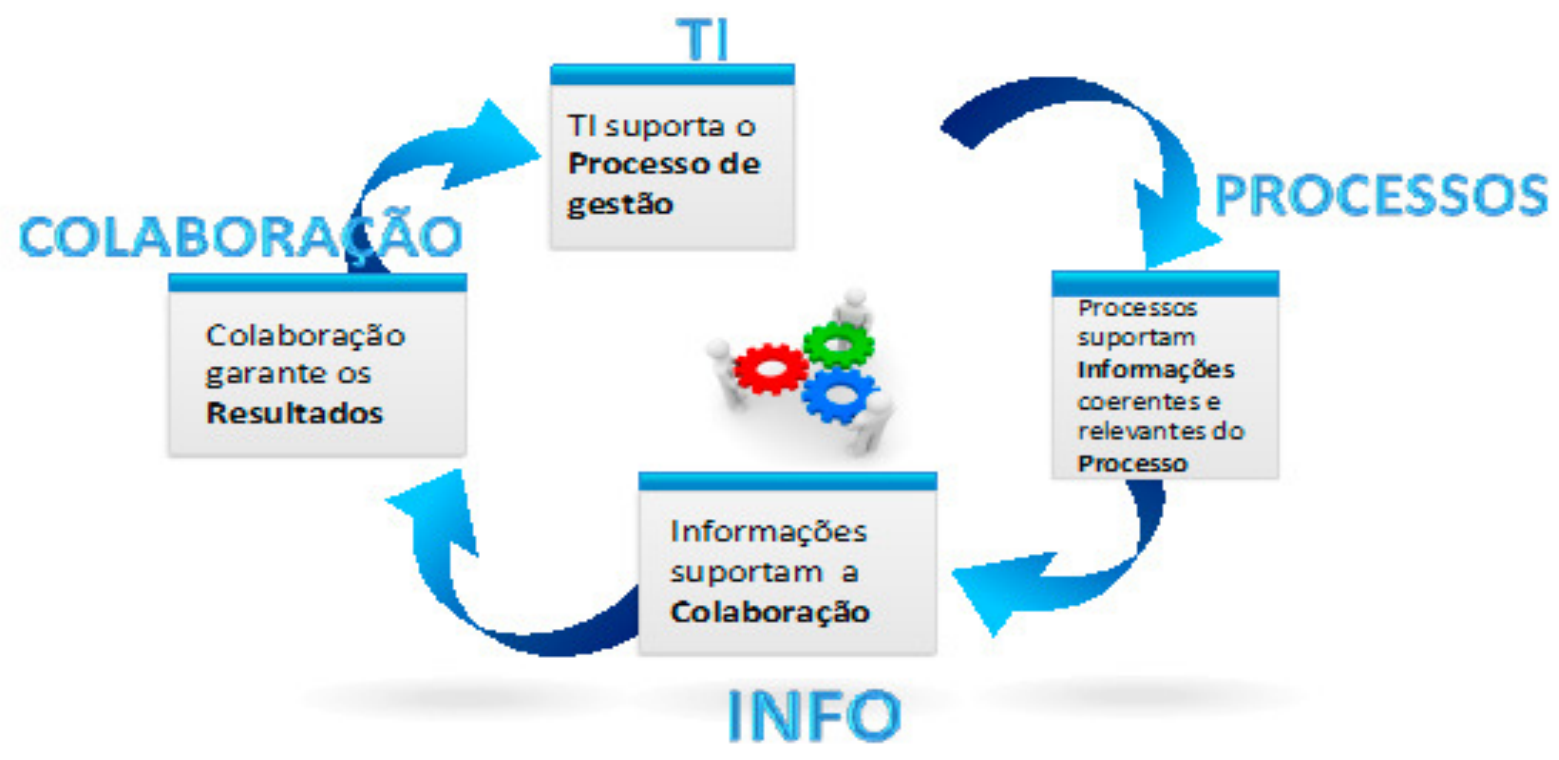


Fonte: Manzione et al. (2011) adaptado de Owen, Palmer et. al (2009)

Conforme demonstrado na Figura 3, atualmente no Brasil observa-se uma inclinação para a produção de pesquisas relacionadas aos aspectos tecnológicos da modelagem, enquanto é menor o número de pesquisas relacionadas a políticas e processos.

Segundo Fox e Hietanen (2010) e Owen, Palmer et al. (2009), processos e tecnologia são codependentes e, no contexto da modelagem da informação da construção, protocolos de processos e padrões são fundamentais para se alcançar a colaboração entre os agentes. Seguindo essa lógica, é importante para a comunidade acadêmica brasileira reavaliar suas estratégias de pesquisa e dar a devida importância aos temas relacionados a processos e políticas para a implementação da modelagem da informação da construção (SOUZA et al., 2013).

Assim, devemos observar a implementação da modelagem da informação da construção no Brasil sob os aspectos tanto tecnológicos quanto gerenciais, especialmente no que diz respeito aos processos e fluxo de informações que devem passar por adequações no novo cenário, e na reflexão das práticas aplicadas aos contratos utilizados entre as empresas e seus prestadores de serviços. 


\section{CONTRATOS DA CONSTRUÇÃO CIVIL}

Neste capítulo é identificado o contexto atual da construção civil brasileira imobiliária como cenário para a apresentação de seus principais processos.

A análise dos processos tradicionais nesse setor é associada à ocorrência dos descompassos entre os agentes da cadeia produtiva. A seguir são apresentados os sistemas contratuais que estruturam as relações entre os agentes e os principais modelos tradicionalmente utilizados.

Como alternativa aos modelos tradicionais, é introduzido o conceito de contrato relacional, que preza pela colaboração e relações equilibradas entre as partes, e os modelos existentes dessa categoria, como a Aliança de Projetos e o Projeto Integrado.

Ao fim do capítulo, são apresentadas as estruturas de documentos oferecidas por instituições de classes profissionais da $A E C$, para que se exerçam os diversos modelos contratuais apresentados. É dada ênfase ao detalhamento dos modelos contratuais os quais estruturam empreendimentos que usam a modelagem da informação da construção e o Projeto Integrado.

No ano de 2012, o mercado da construção civil brasileira, em especial o nicho voltado à construção imobiliária, passou por um período de ajustes e busca de equilíbrio em função de fatores econômicos, tanto no âmbito nacional quanto no mundial, além da necessidade de adequação à capacidade de produção por parte das empresas (SECOVI, 2012).

$\mathrm{Na}$ cidade de São Paulo, o volume de lançamentos de novas unidades em 2012 foi de 27.835, 27\% inferior às 38.149 unidades lançadas em 2011 (EMBRAESP, 2012). Segundo o Secovi-SP (Sindicato da Habitação) essa redução busca o equilíbrio entre os novos lançamentos e a comercialização, e a previsão para 2013 é de retomada do crescimento de maneira sustentável e constante. Prevê-se o lançamento de 31 mil unidades residenciais (10\% a mais que em 2012), e aumento de $3,5 \%$ a $5 \%$ nas vendas, em relação ao ano passado (SECOVI, 2012). 
Segundo a entidade, esse crescimento baseia-se na expectativa da manutenção da taxa de juros de financiamento residencial e desonerações tributárias, além de melhorias, em função da revisão do Plano Diretor e do Código de Obras e Edificações da cidade de São Paulo, que poderão impulsionar novamente o mercado imobiliário.

Figura 5: Evolução de lançamentos na cidade de São Paulo

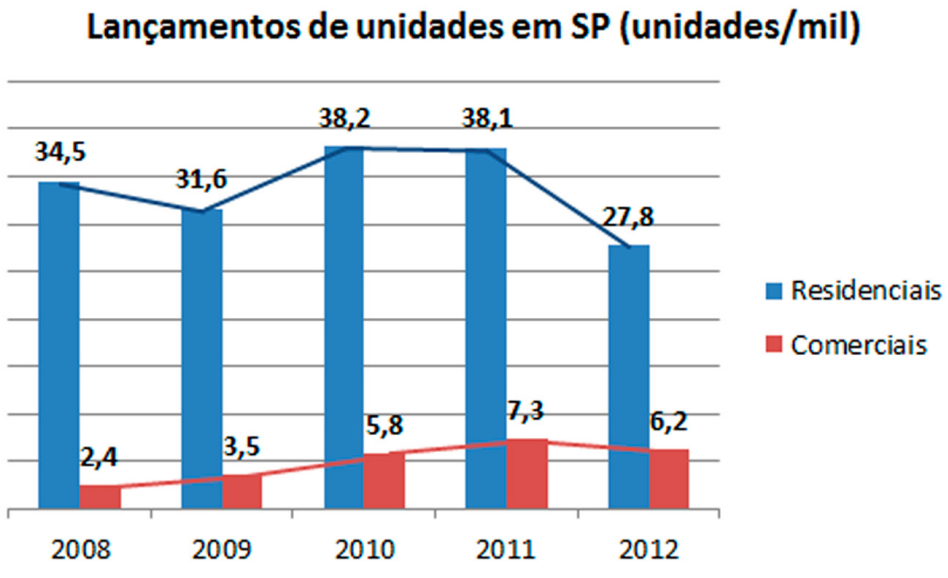

Fonte: Adaptado a partir de dados do SECOVI (2012)

A abordagem do Secovi, no entanto, não endereça questões relacionadas com a necessidade de melhora no desempenho das empresas incorporadoras por meio da tratativa de seus processos. Em geral observa-se que, no âmbito processual, são mantidas práticas burocráticas e com baixa inteligência de negócio, desde as suas estruturas organizacionais até a gestão dos empreendimentos, passando pelos contratos utilizados, práticas ainda incoerentes com as demandas de produção atuais e a potencialidade de crescimento, diagnosticada para os próximos anos (SOUZA et al., 2013). 


\subsection{PROCESSOS DE EMPREENDIMENTOS DE CONSTRUÇÃO CIVIL}

O processo do empreendimento de construção civil é dividido em quatro grandes etapas, às quais se referem os principais agentes do processo. Essas etapas são sequenciais e conceitualmente progressivas e, a cada uma delas, vai se agregando maior nível de detalhe das soluções, sendo reduzida a possibilidade de troca de alternativas (MELHADO, 1994). O processo e suas etapas estão representados na Figura 5.

A primeira grande etapa é a de concepção inicial do produto e estudos de viabilidade do empreendimento. $\mathrm{O}$ agente a que se refere é o empreendedor. Nessa etapa, é determinado o programa de necessidades do empreendimento e são estabelecidos aspectos de custo, tecnologias, restrições legais e outras características que serão restritivas no empreendimento, e que devem ser traduzidas em um Estudo Preliminar, que, caso não atenda todos os requisitos, deverá ser refeito até cumprir todas as restrições antes de seguir para próxima fase.

A segunda etapa é a de desenvolvimento do projeto, representado por fases tais como anteprojeto, projeto legal ou básico de diversas disciplinas, a que são agregadas informações e o nível de detalhamento do projeto aumenta até que se produza o projeto executivo. Também é nesta grande etapa que ocorre a análise da construtibilidade do empreendimento, traduzida pelos projetos para produção. Os agentes principais dessa etapa são os profissionais ou empresas projetistas, determinados como equipe de projeto. Todas as informações produzidas na segunda etapa devem seguir as diretrizes da primeira, ocorrendo, se necessárias, aprovações parciais junto ao empreendedor.

A terceira etapa refere-se à contratação (seleção, licitação e contratação) da empresa construtora, planejamento da construção do empreendimento e sua execução. Nota-se que, nessa etapa, é essencial a participação dos projetistas, dando suporte à execução da obra.

$\mathrm{Na}$ quarta e última etapa ocorre a entrega do produto e a sua utilização pelo usuário final. É quando são colhidas informações para retroalimentar o processo produtivo, 
com vistas de retroalimentar o processo de melhoria contínua. O principal agente dessa etapa é o usuário final.

Figura 6: Proposta para o processo de desenvolvimento do projeto com a ação dos quatro participantes do empreendimento

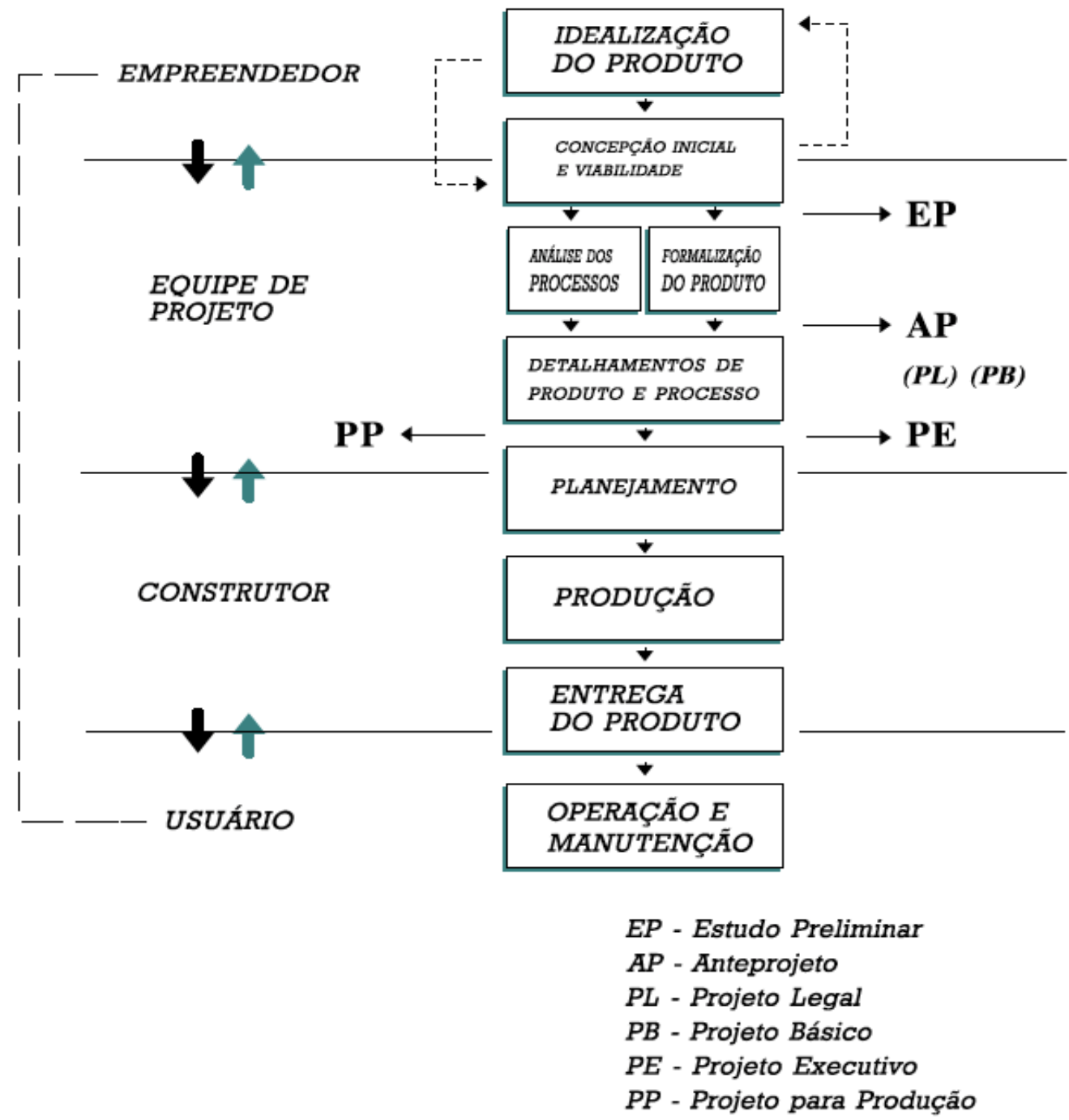

Fonte: Melhado, 1994.

Todos os agentes participantes do processo descrito têm influência no processo em sua etapa particular e, em função da relação entre elas, no processo como um todo. No entanto, os modelos contratuais são aplicados a etapas distintas, sendo um deles referente ao conjunto de informações para orçamento e contratação da obra (documentos de projeto) e outro referente à etapa de execução do empreendimento. 
Ainda que exista relação entre os profissionais participantes desses distintos grupos, como é o caso dos profissionais projetistas que assessoram a produção em canteiro, ou ainda mais próximos da etapa executiva os projetistas para produção, ligados à construtora, que são responsáveis pela engenharia de construção e trazem a visão do processo (MELHADO, 1994), as contratações ocorrem de forma distinta e, muitas vezes, não estabelecem os vínculos apontados como necessários para garantir a qualidade do processo do empreendimento e do produto final.

Os agentes relacionados a cada uma das etapas (o empreendedor, a equipe de projetos, a construtora e os usuários finais) definem as partes dos contratos do empreendimento (BUCKER, 2010). Para que existam condições contratuais adequadas para a execução do empreendimento deve ser determinada a organização dos agentes quanto à sua participação em cada uma das fases, suas responsabilidades e as garantias que são conferidas a cada um deles, tendo em mente que tais arranjos e a estruturação do empreendimento podem criar ou reduzir os conflitos durante o processo (MURDOCH; HUGUES, 2008).

No setor da construção civil, a existência de conflitos é bastante comum (BUCKER, 2010), sendo considerada como inerente a este setor (PEÑA-MORA; SOSA; MCCONE, 2002), os quais ocorrem devido às características de empreendimentos da construção civil, em que as variáveis são muitas e sempre distintas das de outros empreendimentos (CARDOSO, 1996), como projeto e construção únicos, interferência do clima, interferências políticas e econômicas, todos multiplicadas pelo longo período de tempo e necessidade de alto valor, investido típicos de empreendimentos deste setor.

Além disso, a exigência de muitos agentes especialistas no processo (MURDOCH; HUGUES, 2008) leva a uma grande divisão das tarefas e, consequentemente, também das responsabilidades, que podem chegar a conflitos, em função do descumprimento da expectativa de qualquer uma das partes envolvidas. (BUCKER, 2010).

O envolvimento de diversos agentes no empreendimento, sendo de diferentes valores e culturas (aspecto amplificado pela oportunidade de realização de negócios globalizados) reforça a diferença entre a expectativa de cada um deles, seja quanto 
ao resultado da construção ou, ainda, quanto às resoluções dos conflitos criados como atrasos na obra ou, ainda, qualidade insuficiente. Para evitar essas ocorrências, devem-se promover mecanismos de prevenção e solução dos conflitos e gerenciamento das interfaces dos contratos (BUCKER, 2010).

No entanto, os modelos contratuais utilizados mais amplamente no setor reforçam as divergências de expectativas entre as partes e focam na determinação de limites de responsabilidades e deveres de cada uma delas.

A definição de Batavia (2000) para contrato é a seguinte:

Um contrato providencia um registro de um compromisso e acordo entre o contratante e o contratado. Contratos providenciam a base para decisões legais, se um das partes falharem no seu desempenho. Um contrato, para ser administrável, deve definir o escopo do trabalho, a obrigação de cada parte assim como os limites de atuação de cada parte.

Segundo Ricardino et al (2008):

O contrato é estabelecido pelas partes para regulação dos próprios interesses, a partir de um conjunto de funções estruturadas, com fundamentação legal, constituindo uma fonte de obrigações para ambas as partes. E ainda:

$\mathrm{O}$ acordo entre as partes contratante e contratada deve pautar-se por uma política clara e coerente de distribuição do risco, criando uma base firme para a resolução das controvérsias que possivelmente irão ocorrer na execução. (RICARDINO; SILVA; ALENCAR. 2008)

Observa-se que a definição dos contratos prevê o compartilhamento e mecanismos de prevenção de riscos, porém nunca dos benefícios ou resultado do empreendimento. Essa unilateralidade do compartilhamento visa somente reforçar os deveres de cada uma das partes e propor formas estruturadas de resolução, caso falhem - ou seja, formas de punição - não estimulando o trabalho colaborativo entre os participantes do contrato, pois cada um terá, como meta, atingir tão somente aquilo que está comprometido via contrato a entregar, reforçando a divergência de expectativas entre as partes. 


\subsection{SISTEMAS CONTRATUAIS}

Grilo e Melhado (2002) afirmam que a definição do sistema contratual do empreendimento tem influência na sua gestão, uma vez que define as relações contratuais e funcionais entre os participantes; quando não escolhido de forma apropriada (levando em consideração as particularidades do empreendimento), pode ter impacto negativo nos resultados obtidos, tais como acréscimos de custo e prazo, reivindicações e disputas, além de perda na qualidade.

Assim, a escolha da modalidade contratual deve considerar as características do empreendimento, tais como: tipo de edifício, alocação de risco, complexidade e tamanho do empreendimento, prazos para o projeto e construção, realização de concorrências, seleção das equipes e flexibilidade do escopo de trabalho (GRILO; MELHADO, 2000). Esses autores definem, ainda que a crescente complexidade técnica e gerencial da construção de edifícios abriu caminho para a utilização de novas formas de contratação e organização dos empreendimentos, os quais buscam favorecer as relações de harmonia entre os principais agentes: projetistas, construtores e clientes.

Para desenvolvimento dos capítulos relacionados às modalidades contratuais possíveis, serão adotados os seguintes conceitos, definidos por Grilo e Melhado (2002):

- Sistema contratual (project delivery system): sistema para contratação e organização das atividades de projeto e construção, necessárias à obtenção de uma edificação por um cliente;

- Forma de contratação (type of contract): modalidade de acordo no empreendimento, compreendendo a modalidade de pagamento e 0 arranjo funcional de empregados;

- Arranjo funcional (functional grouping): arranjos organizacionais das equipes de projeto, construção e gerenciamento;

- Método de seleção (selection procedure): método de seleção dos 
projetistas, construtores e consultores especialistas;

- Desempenho do empreendimento (construction quality): eficácia na entrega do produto, eficiência no projeto e na construção, e a conformidade aos requisitos e expectativas do cliente.

As principais modalidades contratuais utilizadas no setor são organizadas na Figura 6, adaptada de Kumaraswamy e Dissanayaka (1998), por Grilo e Melhado (2002).

Figura 7: Modelo genérico para Sistemas Contratuais

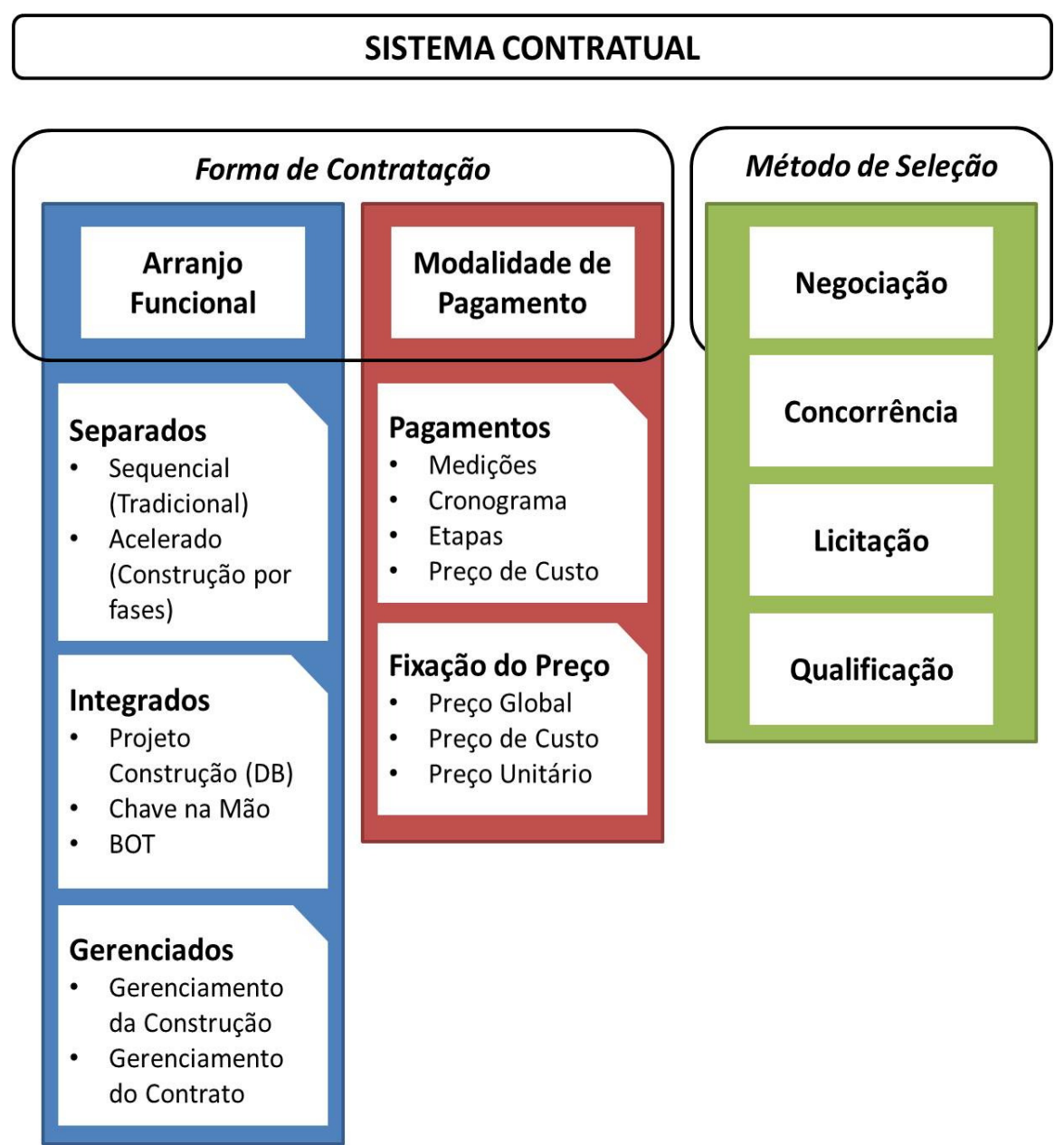

Fonte: Adaptado de Kumaraswamy e Dissanayaka (1998) 


\subsection{CONTRATOS TRADICIONAIS}

Os sistemas contratuais abordados neste trabalho terão ênfase na distinção dos arranjos funcionais adotados, em especial no que diz respeito à integração da etapa de projetos com as demais etapas do empreendimento.

Segundo Grilo e Melhado (2002), diversos estudos sugerem uma correlação entre o arranjo funcional e integração dos agentes para o sucesso do empreendimento quanto aos prazos, custos, qualidade, ausência de disputa e retorno do investimento ao empreendedor, devido à coordenação sistêmica do processo e à convergência dos objetivos dos participantes.

\subsubsection{Contrato sequencial ou design bid build (DBB)}

Nesse modelo de contrato, o arranjo funcional é separado, e a etapa de projetos ocorre desvinculada da construção do empreendimento.

O Contrato Sequencial (tradicional) ou Design Bid Build (DBB) é o modelo mais tradicionalmente utilizado em empreendimentos de grande porte (BUCKER, 2010). Segundo Grilo e Melhado (2002), essa modalidade é utilizada em aproximadamente $60 \%$ do mercado não residencial americano, e sugere-se que também seja utilizada na maioria dos empreendimentos brasileiros.

O DBB é caracterizado pela participação de três agentes principais: cliente, projetistas e construtor. O Cliente realiza contratos separados com os esses agentes, que são comprometidos somente com as etapas específicas de sua participação, não tendo nenhuma responsabilidade pelo todo da obra, ficando a cargo do proprietário a conclusão do empreendimento, operação e manutenção. (GORDON, 1991 apud BUCKER, 2010; GRILO e MELHADO, 2002; FREITAS et al, 2010).

Nessa modalidade, as etapas de projeto, concorrência e construção ocorrem sequencialmente, assim como o envolvimento dos seus respectivos agentes. $\mathrm{Na}$ 
primeira etapa do projeto, são atuantes o cliente e os projetistas, em especial arquitetos, que auxiliam o cliente a reproduzir suas necessidades pela definição do programa e requisitos, resultando nos documentos de projeto, que serão, na segunda etapa, repassados ao construtor, anteriormente à sua seleção.

O construtor, na segunda etapa e de posse do projeto, é então responsável pela execução da obra, de acordo com a documentação produzida: projetos e contrato, e deve cumprir os requisitos estipulados em ambos, de especificações, qualidade, preços e prazos.

Sobre os principais benefícios e riscos dessa modalidade, do ponto de vista do cliente, Moolenaar et al.(1998) definem que os principais benefícios são as análises sistemáticas do desempenho da construção pelo arquiteto, que atua como seu representante; o período longo para modificações no projeto, realizadas a um custo moderado; o preço fixo antes da construção; e os riscos transferidos para o construtor. Os principais riscos para o cliente envolvem tempo de entrega longo; falta de incorporação de construtibilidade; possibilidade de conflitos entre os participantes e alterações de projeto (MOLENAAR et. al, 1998).

Também é apontado como desvantagem o risco de modificações dos projetos devido a erros ou omissões por parte dos projetistas, levando a reivindicações e aditamentos dos contratos de construção e, eventualmente, gerando conflitos entre os agentes.

Em uma segunda avaliação (GRILO; MELHADO, 2002), esses autores enumeram as seguintes limitações do sistema tradicional:

- Relações conflitantes e não cooperativas: a indústria da construção consome recursos vultosos com disputas judiciais nos países desenvolvidos;

- Culturas profissionais próprias: o aumento da especialização proporcionou uma estrutura institucionalizada e funcionalmente separada;

- Níveis de percepção distintos: o projetista enfoca a qualidade do produto. O construtor, selecionado por preço, focaliza a racionalização e a economia. 
Bucker (2010) aponta como principal benefício para o cliente a possibilidade de antevisão dos custos e benefícios do empreendimento a partir dos resultados das fases já produzidas, antes de realizar a contratação de suas sucessoras. Também reforça a relação contratual direta do cliente com os prestadores de serviços, o que permite um acompanhamento mais próximo da produção de cada etapa e maior possibilidade de intervenção; no entanto, o cliente retém, também, a maior parcela de riscos, uma vez que são de sua responsabilidade as atividades de comissionamento - assegurar que todos os sistemas e componentes da construção sejam projetados, fabricados, instalados, testados, operados e mantidos de acordo com as especificações.

Como problemas, Bucker (2010) aponta a extensão dos prazos de projeto e, por consequência, para o término do empreendimento, além da fragmentação das obrigações, o que torna mais difícil a determinação de responsabilidades e pode levar a conflitos.

Esse é o modelo utilizado no Brasil para licitações públicas, determinado pela Lei 8.666/1993 como mecanismo de escolha de melhores condições financeiras para os empreendimentos - o que, no entanto, pode ter impacto na qualidade e prazos do empreendimento, se não houver cuidado com o desenvolvimento dos projetos, que devem ter as especificações e orientações necessárias sobre o trabalho, de forma a permitir aos concorrentes um orçamento adequado e realista.

\subsubsection{Projeto-construção ou design build (DB)}

Esse modelo de arranjo funcional integrado é apontado como alternativa ao modelo tradicional considerado lento, oneroso e conflituoso para a complexidade dos novos empreendimentos de construção civil (GRILO, MELHADO, 2002).

O Design Build é caracterizado pelos dois agentes principais: cliente e construtoraprojetista, e por etapas de projeto e construção simultâneas. 
O cliente define o anteprojeto e as demais etapas devem ser desenvolvidas pela construtora (BUCKER, 2010), com a qual é estabelecido um único contrato e uma linha direta de comunicação.

O construtor tem como opções trabalhar com equipes de projeto internas ou montar uma equipe com empresas parceiras - que podem ser de projeto e construção para o desenvolvimento do projeto e subcontratos de execução. No entanto, assim como a escolha da equipe, a responsabilidade do cumprimento do contrato e entrega da obra é da empresa ligada ao cliente, via contrato. É comum que o método de pagamento escolhido seja o custo global e que a empresa contratada apresente seguro de risco e fiança bancária (BUCKER, 2010)

Os principais benefícios apontados por Bucker (2010) e Moolenaar (1998) são: concentração da responsabilidade em um só agente, projetos de duração mais curta, elevada construtibilidade, redução do número de aditamentos, relação menos conflitante entre os agentes e gestão rápida das mudanças de escopo.

Os maiores riscos para o cliente-empreendedor são: participação reduzida no processo e dificuldade de alterações, redução nas análises críticas do desempenho do projeto e construção, uma vez que são responsabilidade de uma mesma equipe, necessidade de definições antecipadas na etapa de anteprojeto e dificuldade de distribuição do risco. Para o construtor-projetista os maiores problemas são quanto ao risco assumido na estimativa de custo em fase antecipada do projeto, e a incorporação da gestão e rastreamento de mudanças de escopo, além do aumento na equipe (MOOLENAAR; GRANSBERG, 2001).

Grilo e Melhado apontam, ainda, algumas limitações para a implementação do Design Build no Brasil, tais como a necessidade de comprometimento antecipado do cliente, o conflito de interesses com gerenciadoras influentes nas concorrências do setor privado, restrições legais para a associação de projetistas e construtores e a falta de capacitação das construtoras para o gerenciamento do projeto.

Os aspectos colaborativos dessa modalidade contratual são elevados, em relação ao Design-bid-build, pelos aspectos técnicos de compartilhamento das soluções entre projetistas e construtores e pelos aspectos de redução de conflitos e 
dissidências entre os agentes do empreendimento com a redução de interfaces. $O$ Design Build ainda não apresenta uma solução para o compartilhamento de riscos do empreendimento, além de criar um distanciamento do cliente empreendedor das etapas de desenvolvimento do produto, o que pode levar a resultados insatisfatórios.

Em tal cenário, são mantidas as divergências de expectativas das partes, uma vez que o cliente quer reduzir os riscos de investimento no empreendimento, sem perder qualidade, mas o construtor-projetista irá buscar atender os requisitos exigidos com o menor custo possível, reduzindo, assim, a sua margem de risco financeiro no empreendimento.

\subsection{CONTRATOS TRANSACIONAIS E CONTRATOS RELACIONAIS}

Em todos os empreendimentos de construção, uma característica praticamente inevitável é a de mudanças constantes, especialmente dado o crescente dinamismo dos projetos. Tendo isto em vista, para que se alcancem resultados consideráveis é necessária a definição de modelos contratuais, especificamente desenhados para abranger e gerenciar as mudanças (SAKAL, 2005).

Conforme analisado, os contratos tradicionais da construção civil abordam as mudanças como anomalias, focando na antecipação da sua ocorrência pela previsão dos piores cenários possíveis, ao invés de focar na cooperação necessária para abordar e contornar tais mudanças, antes que se tornem demasiado problemáticas, conforme Cochram (2002) apud Sakal (2005).

\subsubsection{Contratos transacionais}

Os contratos tradicionais ou transacionais, como são chamados pela ênfase na troca de um produto ou serviço prestado, não têm como meta estabelecida a maximização dos resultados ou estruturas de trabalho que criem um ambiente colaborativo para as partes; ao contrário, definem meticulosamente os produtos finais (deliverables) e estabelecem cláusulas de proteção contra o risco do empreendimento, os quais vão 
se refletindo, contrato a contrato, do cliente para a construtora e projetistas, e desses para seus parceiros e subcontratados, criando uma rede de interfaces que aumenta as relações conflituosas entre as partes, o que não é interessante para o projeto (STEEN, 1994).

Em edição especial dedicada à discussão da relação de contratos relacionais e construção enxuta o Lean Construction Journal(LCJ) (Vol.2, abril/2005) divulgou algumas definições e análises realizadas sobre o uso de contratos tradicionais e a sua inadequação a modelos de projetos de empreendimentos dinâmicos, reforçando que

\begin{abstract}
A indústria da construção civil preocupa-se em evoluir para modelos contratuais que permitam relações dinâmicas entre os agentes, como se pode observar pela crescente implementação da modalidade de Design Build, na qual, apesar de se modificar a relação dos participantes, não foram abordadas questões relacionadas ao processo de trabalho, tendo afinal pouco impacto no método de produção dos projetos e empreendimentos (LCJ, 2005).
\end{abstract}

Rahman e Kumaraswamy (2004) apontam que os modelos transacionais alocam 0 risco aos participantes por meio de seus contratos, e que a natureza complexa e incerta de empreendimentos de construção não permite prever todos os riscos durante o processo. Para superar esses riscos imprevisíveis, as partes do contrato deveriam unir-se em sua gestão, utilizando-se de contratos de abordagem relacional, nos quais há a formação de alianças, parcerias ou trabalho em equipe, tendo esses mecanismos como ferramentas para transcender as barreiras organizacionais e mitigar os riscos do empreendimento.

\title{
3.5.2 Contratos relacionais
}

Contratos relacionais são aqueles que, em oposição aos contratos transacionais, caracterizados pela troca de bens e serviços, são formados por pequenas sociedades nucleares que possuem um sistema interno de desenvolvimento de regras (WILLIAMSON, 1979), o que determina o foco no processo de trabalho. 
Essa abordagem é mais consistente com a análise de fluxos e teorias de geração de valor desenvolvidas pela linha de pesquisas da Lean Construction - construção enxuta - para o atendimento ao dinamismo dos projetos de construção civil.

Colledge (2005) define algumas características dos contratos relacionais: i) relações equilibradas entre as partes; ii) compartilhamento de riscos e benefícios, iii) maior interdependência entre os participantes e iv) governança bilateral e unificada.

A partir dessa estrutura, são construídos laços de confiança e parceria entre os participantes do contrato, e como resultado observam-se: (1) Melhoria nas relações de trabalho, (2) Facilidade em alcançar processos eficazes e eficientes de construção, (3) Melhorias nos retorno dos investimentos e (4) Maior facilidade na resolução de conflitos; além de reforçar a sustentabilidade da relação entre os participantes de um grupo ou comunidade que, com o tempo e experiência de integração, podem ter ganhos significativos de produtividade e lucratividade.

Cheung et al. (2006) definem os contratos relacionais como:

Acordos que envolvem um código de conduta não formalizado que garante o comportamento entre as partes por meio de princípios de confiança e continuidade do relacionamento entre eles.

As principais características apontadas por esse autor são: i) a interação pessoal é crucial; ii) a transação normalmente tem longa duração; iii) grande flexibilidade para superar riscos e obstáculos imprevisíveis e iv) grandes oportunidade futuras de cooperação entre as partes.

Baker et al. (2002) definem contrato relacional como "um acordo entre partes tão baseado em sua experiência compartilhada que não pode ser implementada por modelos, e sim pelas próprias partes".

Segundo Wang (2008), o uso de contratos relacionais para o estabelecimento de parcerias leva à definição de regras comportamentais que conectam todas as partes do empreendimento como uma única equipe. Assim, todos podem esforçar-se para melhorar a performance geral do empreendimento por meio de colaboração e trabalho em equipe. 
Todas as definições compartilham a ênfase no aspecto de relacionamento entre as partes para a definição das regras comportamentais e normas sobre as quais ocorrerá a formação do modelo de contrato e da produção.

A seguir serão descritos os modelos e características de contratos relacionais

\subsubsection{Alianças de projetos}

Aliança de Projeto ou Project Alliance (PA) é um modelo de contrato relacional originalmente desenvolvido no início dos anos 90, pela British Petroleum, empresa multinacional que atua no setor de energia, petróleo e gás, com o objetivo de desenvolver uma modalidade de acordo contratual que reduzisse os custos de desenvolvimento de projetos para exploração de reservas de tamanho pequeno, em que o risco alocado era maior. A primeira tentativa de resolução envolvia somente a atualização das tecnologias utilizadas, o que não demonstrou os resultados esperados, levando a empresa a buscar uma solução que modificasse também suas estratégias de negócio, passando de concorrências por preço e alocação do risco nos contratados a uma abordagem de alinhamento dos interesses das partes com os resultados do projeto. (SAKKAL, 2005)

Foi definido, então, um modelo de compensação de compartilhamento dos lucros e prejuízos, em um contrato que previa a transparência da contabilidade referente ao projeto, compartilhamento de todos os riscos (inclusive os imprevisíveis) entre os participantes do projeto e a definição de um custo alvo por todos os membros da equipe. Ao fim do projeto, o custo alvo seria comparado ao custo final e a diferença no resultado, positiva ou negativa, seria dividida entre os participantes.

Também foi adotada uma nova política de seleção dos participantes, em que foram avaliados e escolhidos não mais pelo orçamento apresentado, mas pela qualidade do seu trabalho, uma vez que os resultados do projeto dependiam da sua performance.

No projeto piloto em que foi testada, a Aliança de Projetos obteve resultados acima dos esperados, em relação ao custo final e ao prazo de conclusão do projeto, 
levando ao refinamento da metodologia contratual e à sua adoção em outros empreendimentos em diversos países.

Ross (2003) aponta o uso da Aliança de Projetos como uma alternativa adequada a projetos complexos, em que o número de incertezas e riscos é alto. No caso de projetos com escopo definido e riscos razoavelmente previsíveis, a escolha de modelos contratuais de transferência de risco será, provavelmente, a escolha que trará melhores resultados para o contratante--empreendedor. Assim, a escolha da modalidade contratual deve ser realizada considerando-se as características do projeto.

Segundo Ross (2003), as principais características, essenciais e definidoras da Aliança de Projetos são:

- Deveres e objetivos de desempenho estabelecidos no contrato devem ser coletivos, nunca individuais.

- Os reembolsos das partes contratadas são sujeitos à verificação da contabilidade da empresa via auditoria, e serão consideradas as três situações, a seguir, no modelo de compensação definido pelos membros da aliança:

- Reembolso de $100 \%$ do custo direto do projeto, incluindo despesas gerais.

- Pagamento de uma taxa fixa referente aos custos indiretos e lucro mínimo.

- Parcela proporcional de lucros ou prejuízos do projeto, em função da comparação do resultado final com as metas estabelecidas, de performance geral e custo alvo.

- O projeto será liderado pelo "Conselho da Aliança de Projetos", com representantes de todas as partes com autoridade para responder por elas. Todas as decisões do conselho devem ser unânimes.

- O gerenciamento de curto prazo - dia a dia - será responsabilidade de uma equipe específica, cujos membros são escolhidos pela capacidade gerencial, e não com base na empresa da qual fazem parte. 
- Fica registrado em contrato o comprometimento de todas as partes em resolver os problemas internos à aliança sem a utilização de processos legais, com exceção de casos de incumprimento doloso (falha intencional por uma das partes do contrato).

- Fica registrado o comprometimento de todos os membros em trabalhar em acordo com os Princípios da Aliança de Projetos (princípios de trabalho desenvolvidos em conjunto pelos membros da aliança).

- O sistema de implementação do empreendimento é focado no gerenciamento das pessoas e na alta performance e resultados acima dos esperados.

Ross (2003) ainda descreve as diretrizes mais comuns contempladas nos "Princípios da Aliança de Projetos, documento complementar ao contrato e que é desenvolvido em conjunto pelos membros, com o objetivo de fundamentar a formação da aliança:

- Ênfase primária nos resultados do negócio em que todas as partes ganham ou todas as partes perdem.

- Responsabilidade coletiva pela performance e distribuição proporcional de riscos e recompensas.

- Relação igualitária entre as partes em que todas têm o mesmo poder de voz.

- Decisões devem ter em vista o melhor resultado para o projeto.

- Clareza nas responsabilidades de cada um dentro de uma cultura de isenção de culpa.

- Abertura e disponibilização completa dos recursos, habilidades e especialidades de todas as partes.

- Todas as transações são completamente transparentes.

- Incentivo a inovação com o compromisso de alcançar resultados melhores do que os previstos.

- Comunicação aberta e honesta, sem omissões de informações ou intenções.

- Suporte incondicional dos membros de alta hierarquia dentro de todas as organizações e empresas participantes.

Quanto aos modelos de compensação, devem ser discutidos e acordados entre os membros da aliança assim que esta é formada. Ross (2003) faz a seguinte 
descrição, que pode ser exportada para outros modelos de contratos relacionais, como será abordado no capítulo 4 desta dissertação: IPD.

Figura 8: Adaptação de Modelo de Compensação para Aliança de Projetos (Ross, 2003)

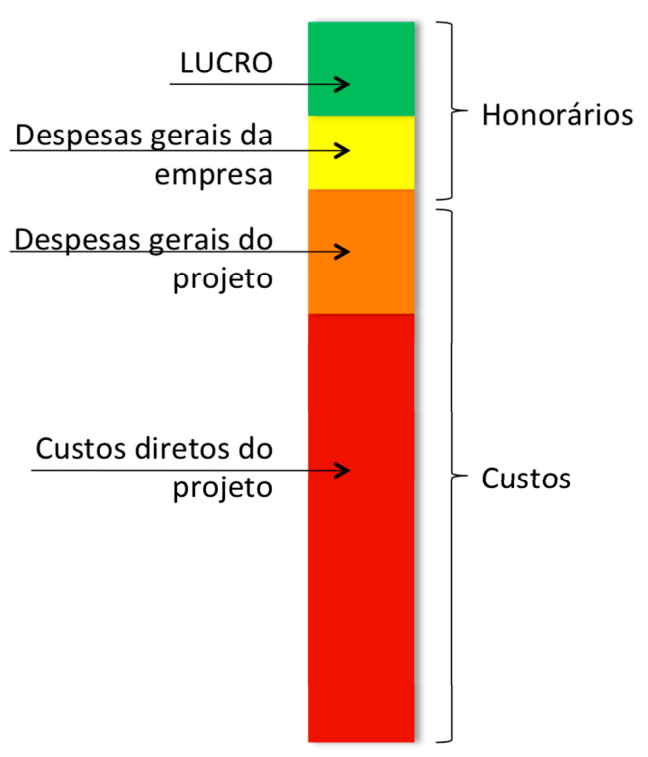

Fonte: Adaptado de Ross, 2003.

Os custos e as despesas do projeto (custos diretos do projeto) são determinados por empresa, além do valor de despesas gerais (custos indiretos) e lucro (Figura 7). Esta somatória é registrada ao longo do trabalho pela empresa e registrada, para que possa ser auditada em acordo com a regra de "abertura da contabilidade" definida pela aliança, em que os custos e despesas declarados por todos os participantes do projeto são passíveis de fiscalização por uma terceira parte não envolvida no empreendimento.

O valor determinado pela soma dos custos e honorários da empresa resulta no chamado Custo Alvo, que servirá de referência para a divisão do lucro ou custo adicional obtido, conforme a Figura 8. 
Figura 9: Distribuição de resultados na Aliança de Projetos

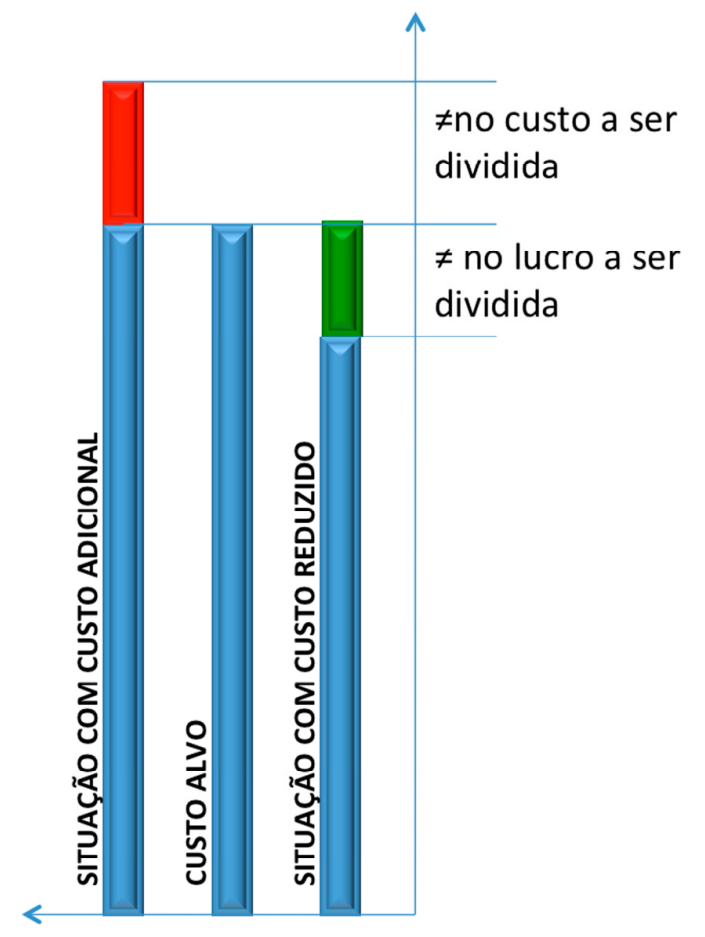

Fonte: Adaptado de Ross, 2003

A primeira parcela de pagamento das empresas é referente ao custo direto registrado mensalmente, inclusive parcelas referentes a retrabalho, cujos custos devem ser registrados e estar disponíveis para visualização por todos os membros da aliança.

A segunda parcela de pagamento refere-se aos custos diretos da empresa, no que se aplica ao seu projeto e aos lucros mínimos. O montante de lucro mínimo é determinado pela AP, sendo calculado a partir de uma porcentagem do custo alvo.

A terceira parcela é relacionada aos resultados do empreendimento, e calculada ao seu final, quando todas as empresas apresentam suas contas e, com base em uma fórmula de distribuição de lucro (ou custo adicional), ele é repassado às partes envolvidas. Como regra geral, $50 \%$ do resultado, seja ele positivo ou negativo é atribuído ao cliente/contratante e os outros $50 \%$ distribuídos entre a equipe do empreendimento em função da porcentagem relativa que lhe é atribuída no momento de definição do modelo de compensação. 
A fórmula de distribuição dos resultados não leva somente em conta os resultados financeiros do empreendimento, mas também metas de qualidade e desempenho, determinadas no princípio do projeto como, por exemplo, prazo, qualidade e desempenho ambiental, que devem ser monitoradas com o uso de indicadores de performance - KPIs (Key Performance Indicators) para cada uma destas metas.

Para que o modelo de compensação não seja desfavorável aos contratados, é determinada uma restrição na distribuição dos riscos, no que diz respeito aos custos apresentados. Define-se que, caso o projeto não alcance o custo alvo, os únicos valores de parcelas a receber que podem ser sacrificados pelos contratados são aqueles referentes aos honorários (custos indiretos e lucro), garantindo a cobertura dos custos diretos do projeto e despesas gerais a ela relacionadas.Ainda que a parcela de prejuízo a ser coberta, proporcionalmente, seja maior que esse montante, a diferença será absorvida pelo cliente.

Ainda sobre as alianças de projetos, Sakkal (2005) e Ross (2003) reforçam como importante parte do processo a seleção dos participantes, uma vez que todo o resultado do empreendimento depende do seu empenho. Segundo ele, a seleção deve considerar critérios que avaliem o potencial de dedicação que aquele membro terá em relação aos objetivos da Aliança de Projetos, devendo, portanto, buscar avaliar além das habilidades técnicas a sua disposição para integrar e abraçar as ideias de compartilhamento de risco, comunicação aberta e transparente e da cultura de isenção de culpa que incentiva a colaboração e inovação.

Os principais critérios para seleção das equipes, segundo Ross (2003) são:

1) Demonstrar capacidade técnica, financeira e gerencial para atender ao escopo de trabalho;

2) Ter entendimento e comprometimento com a forma de negócios da aliança;

3) Possuir capacidade de registrar e superar os resultados quanto à qualidade, segurança, gestão ambiental e relacionamento com a comunidade;

4) Apresentar ideias preliminares para inovar as estratégias de execução do projeto, com potencial para superar os resultados do projeto e da construção;

5) Deixar clara a intenção de comprometer-se com os objetivos do projeto e metas flexíveis; 
6) Demonstrar registros e habilidade de trabalhar em conjunto com outras empresas parceiras.

7) Observar a qualidade dos participantes do projeto e afinidade para trabalhar em conjunto com as outras empresas como uma equipe de alta performance.

Um exemplo de sucesso no processo seletivo descrito por Hauck (2004) é o do projeto do Museu Nacional da Austrália (National Museum of Australia), em que foram estabelecidos 12 critérios para a seleção dos membros da equipe:

1) Demonstrar habilidade para cumprimento do escopo de trabalho, incluindo a contribuição para especialidades de projeto de arquitetura, estrutura, equipamentos mecânicos e paisagismo.

2) Demonstrar habilidade para minimizar os custos financeiros e operacionais, sem sacrifício da qualidade do empreendimento.

3) Demonstrar habilidade em alcançar resultados acima dos esperados.

4) Demonstrar habilidade em disponibilizar os recursos necessários para o empreendimento e alcance do programa determinado (incluindo currículos dos membros da empresa envolvidos no projeto).

5) Demonstrar habilidade em agregar valor e contribuir com a inovação no projeto.

6) Demonstrar habilidade de alcançar resultados acima do esperado quanto à segurança no trabalho.

7) Demonstrar habilidade de alcançar resultados acima do esperado quanto às relações no ambiente de trabalho.

8) Ter relações públicas de sucesso e reconhecimento da indústria.

9) Ter experiência prática, demonstrada quanto à abordagem de temas como o desenvolvimento de práticas sustentáveis e gestão ambiental.

10) Demonstrar entendimento e afinidade para operar como membro de uma aliança (referindo-se à experiência colaborativa e a esquemas de distribuição dos resultados)

11) Aceitar os documentos da aliança referentes aos códigos de conduta, propostas de apoio à indústria local e criação de oportunidades para a população local. 
12) Demonstrar comprometimento em exceder os objetivos do projeto.

Como síntese das principais etapas desse modelo, Ross (2003) apresenta um fluxograma do processo de formação da Aliança de Projetos, demonstrado na Figura 9.

Figura 10: Adaptação de Diagrama do Processo de Formação da Aliança de Projetos

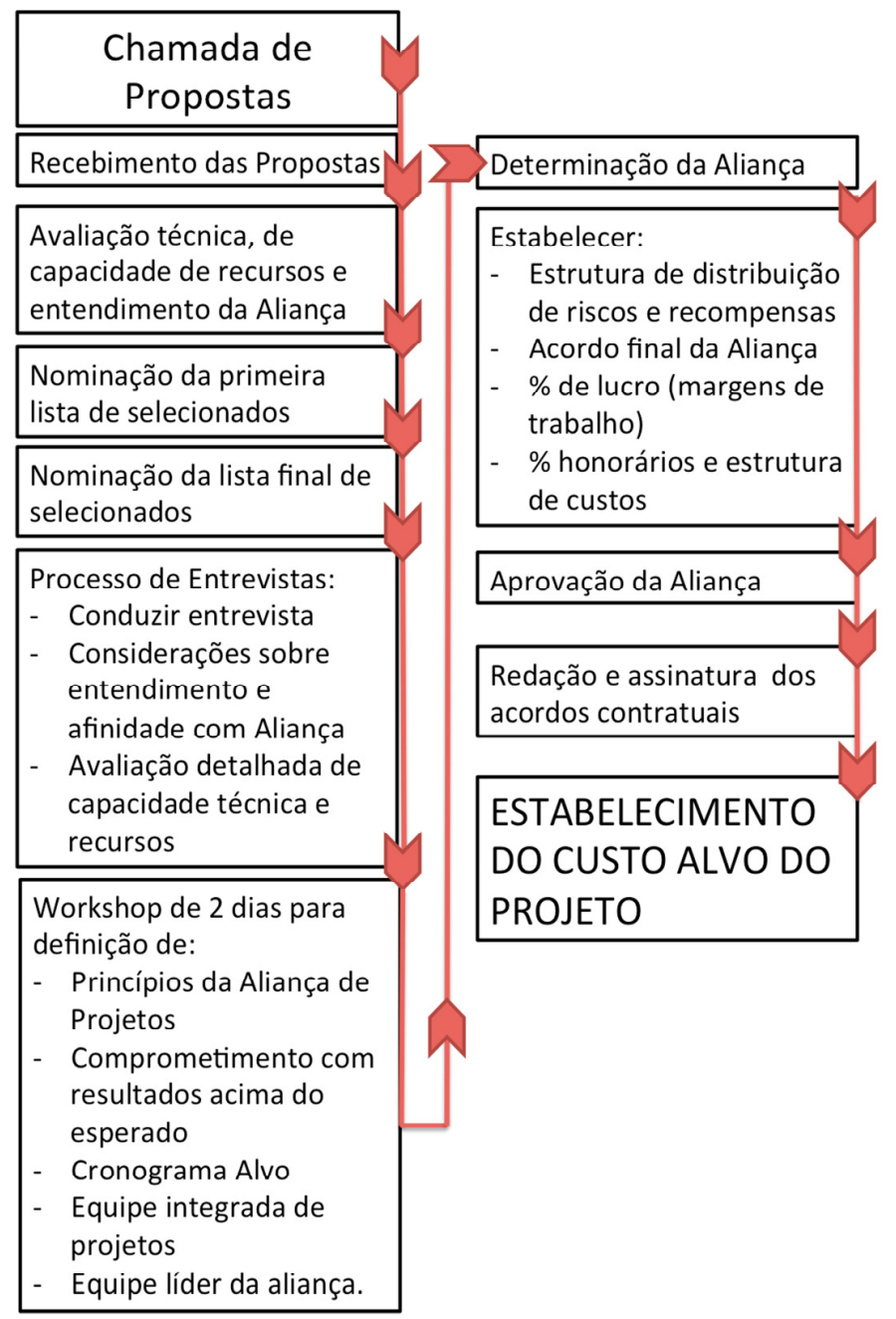

Fonte: Adaptado de Ross, 2003. 


\subsubsection{Integrated Project Delivery (IPD) ou Projeto Integrado}

Assim como a Aliança de Projetos, o IPD foi criado a partir da necessidade de uma empresa do ramo da construção civil, neste caso a Westbrook ${ }^{2}$, empresa de construção civil americana, cujos contratos nos modelos de DB e DBB passaram a oferecer resultados aquém dos esperados. Após experiências nos modelos contratuais aplicados em sua relação com empresas parceiras, desenvolveram uma modalidade contratual relacional nominada Integrated Project Delivery (IPD) em que todos os membros da equipe contratada tinham seus interesses alinhados e direcionados a um objetivo comum (MATHEWS; HOWELL, 2005).

De modo semelhante à Aliança de Projetos, o IPD utiliza mecanismos de compartilhamento dos riscos e recompensas para estimular a colaboração e o trabalho em equipe dos participantes.

Esse modelo de contrato relacional foi abordado em 2007, pelo AIA (American Institute of Architects) e pelo Conselho Nacional da Califórnia do AIA, que, em conjunto, publicaram o IPD Guide, com o objetivo de orientar contratantes, construtoras e profissionais de projeto para implementarem modelos de contrato integrado visando à melhoria de seus processos de projeto, construção e operação.

Nesse guia, além da caracterização do IPD, é determinada a relação entre a utilização dessa metodologia de implementação do empreendimento e as melhorias em seu processo, detalhadas no capítulo sobre IPD desta dissertação. Como síntese, em relação com os demais modelos de contrato relacional apresentados, o IPD destaca-se pelos aspectos colaborativos reforçados pela relação de confiança entre as partes contratuais, que direcionam o foco de todos os envolvidos nos resultados gerais do empreendimento em oposição aos interesses pessoais de cada participante.

2 Westbrook é uma empresa de construção civil, localizada na Flórida, Estados Unidos (www.westbrookfl.com) 


\subsection{MODELOS DE DOCUMENTOS CONTRATUAIS}

No setor da construção civil, a diversidade de tipos de empreendimentos entre obras de arte, obras de infraestrutura ou, ainda, empreendimentos imobiliários mantém três critérios comuns em todos seus contratos - o cumprimento de prazo e orçamento e o atingimento da qualidade requerida (BUCKER, 2010).

Em alguns países, os órgãos de classe profissional propõem modelos contratuais para engenheiros, para empreendimentos da construção civil, como no caso do AIA, para arquitetos nos EUA e do ICE no Reino Unido, ENAA no Japão e FIDIC na França, contratos esses, cujo objetivo é definir padrões contratuais para diferentes tipos de empreendimentos e moldes de negociação para empreendimentos de construção; buscam, também, definir condições equilibradas entre as partes envolvidas e em formatos apropriados para atender as demandas de mercado.

As instituições responsáveis pela sua elaboração afirmam apoiar-se no próprio mercado da construção civil para obter informações de retroalimentação e atualização dos documentos contratuais, assim como contam com o apoio de profissionais de todas as etapas da cadeia produtiva como colaboradores. Salvaguardadas as características específicas dos mercados de seus países de origem, esses documentos podem ser utilizados para negociações em todo o mundo, pois são oferecidos em formato editável que permite a adequação de seu conteúdo.

Os padrões contratuais da FIDIC, em especial, são utilizados amplamente pelas principais organizações internacionais de financiamento de empreendimentos (BUCKER, 2010) e, com exceção do ICE e AIA, as demais instituições fornecedoras dos modelos contratuais não possuem modelos de contratos relacionais ou que incitem a colaboração dos agentes.

O ICE possui duas famílias de contratos, o ICE Conditions of Contract - Condições de contrato do ICE - em que são definidas cláusulas padrão; e o New Engineering Contract (NEC) - Novo padrão de contrato de Engenharia, em que, entre os 
contratos de construção e prestação de serviços, se encontra o NEC Partnering Contrato de Parceria.

O NEC Partnering procura estabelecer condições de colaboração e parceria, baseados no cumprimento das cláusulas de contrato em espírito de mútua confiança e colaboração (tradução direta da cláusula 10.1: "act as stated in this contract and in a spirit of mutual trust and co-operation") e na implementação de mecanismos de gerenciamento do processo do empreendimento.

Nesse modelo, é proposta a definição de indicadores-chave de performance do empreendimento, tais como prazo, custo, risco e alterações como mecanismos de suporte a colaboração, que permitem a definição de eventos de compensação ou antecipação nas notificações sobre os resultados. Também é possível formatar esse modelo contratual para o envolvimento antecipado do construtor, assim como a formação de parcerias de várias partes.

A FIDIC possui, entre seus modelos contratuais, um documento voltado para a formação de joint ventures ou organizações $A d$-Hoc, porém, no próprio corpo introdutório desse documento, é ressaltada a dificuldade do estabelecimento de responsabilidades entre as partes, dentro da organização conjunta, sugerindo, inclusive, a utilização de um acordo contratual ou "sub contrato" entre as participantes, independente do contrato entre a joint venture e o cliente, no qual se definam as suas responsabilidades específicas, multas e compensações em função do andamento do negócio.

Os modelos de contrato propostos pela ENAA buscam abranger projetos de plantas industriais ou plantas de usinas de energia, e em ambos os casos o sistema contratual utilizado é o Turnkey ou Design Build. Já o AIA possui seus documentos contratuais classificados em famílias e séries, que definem respectivamente, os sistemas contratuais e os tipos de contrato.

A seguir, são identificados os sistemas contratuais reconhecidos pelo AIA (Tabela 2). É importante observar que, no modelo americano de contratação de projetos de empreendimentos de construção civil, os projetistas de instalações, estrutura e demais especialidades são, normalmente, subcontratados pelo arquiteto, que 
assume responsabilidade gerencial pelo desenvolvimento do projeto. Os modelos contratuais do AIA não mencionam tais agentes como partes relevantes dos sistemas contratuais, porém podemos avaliar seu papel como paralelo ao do arquiteto, enquanto desenvolvedores de serviços de projeto.

Tabela 2: Sistemas Contratuais conforme o AIA (American Institute of Architects)

\section{Família de}

\section{Contrato}

\section{Descrição}

Família

Convencional

(A201)

(Conventional

Family)

Indicada no caso de contratos separados para as etapas de projeto e construção do empreendimento. É a tipologia de contrato mais utilizada pela sua adequação da abordagem de contratação de entregas na fase de projetos e ao Contrato Sequencial (Design Bid Build). Os documentos podem ser utilizados para empreendimentos de pequeno a grande porte.

Indicada quando o incorporador contrata um agente terceirizado

Gerenciamento para agir em seu nome nas atividades de gerenciamento durante de Obra o desenvolvimento do projeto e da construção. Sua utilização está

Terceirizada vinculada à necessidade de uma abordagem especializada e

(Construction independente das partes contratuais (imparcial aos interesses

Manager as financeiros das partes e com foco no trabalho de construção) para

Adviser (CMa) gerenciar o empreendimento do início ao fim. Sua utilização é Family) indicada para empreendimentos de pequeno a grande porte em ambos os setores público e privado.

Indicada quando os serviços de gerenciamento da obra serão

Gerenciamento pela Construtora (Construction

Manager as Constructor (CMc) Family) responsabilidade da construtora. Nessa abordagem, as funções de gestão e produção da obra são atribuídas a um único agente, que pode ou não trabalhar com um teto de preço máximo garantido. Nessa modalidade, a construtora é, tipicamente, a responsável pelo contrato direto de terceirizados para o trabalho de construção. Os documentos dessa família podem ser utilizados em empreendimentos de pequeno a grande porte no setor 
privado.

Indicada quando o método de entrega do empreendimento é caracterizado pela contratação pelo empreendedor de um único

Projeto agente responsável pela produção do projeto e da construção. $A$

Construção contratação da equipe de projetos (terceirizada ou interna),

(Design-Build construtoras e demais agentes necessários à produção do projeto

Family) e obra são realizadas pela contratada. Os documentos dessa família podem ser utilizados em empreendimentos de pequeno a grande porte.

Projeto integrado é uma abordagem de entrega de empreendimentos que busca utilizar os talentos e especialidades de todos os participantes do empreendimento, ao longo das fases de projeto e construção. O AIA disponibiliza documentos para três níveis nesta tipologia contratual:

Os Modelos Transacionais são indicados para ocasiões em que já existem contratos/acordos para o gerenciamento da construção. (É considerado como um primeiro passo, mais sutil, na adoção do Projeto Integrado como metodologia contratual).

Projeto Integrado (Integrated

Project Delivery (IPD) Family)

Os Modelos Multilaterais são um contrato único entre todas as partes envolvidas nas atividades de projeto e construção do empreendimento com os princípios do Projeto Integrado.

Os Modelos de SPE (Sociedade de Propósito Específico) agrupam os agentes em uma única empresa, criada com objetivos específicos e por um período limitado para a execução de um empreendimento. Essa modalidade cria uma condição diferenciada (ainda que limitada) de atribuição de responsabilidade à empresa criada quanto aos resultados de planejamento, projeto e construção do empreendimento. O modelo permite compartilhamento completo dos riscos e benefícios, por meio de um processo colaborativo de produção de distribuição de resultados. 
Os documentos do AIA para IPD são indicados para utilização em empreendimentos comerciais ou institucionais de porte médio a grande porte.

Decoração (Interiors Family)
Essa modalidade de contrato é indicada para atividades de fornecimento de mobiliário, equipamentos e serviços de aquisição deste tipo de material combinados com atividades de projeto de interiores (decoração) e execução da obra ou reforma. O modelo de contrato e compra de equipamentos é apresentado em documento separado dos serviços de desenvolvimento do projeto e obra, a fim de preservar a independência monetária das duas atividades. Os documentos para essa família de contratos podem ser usados em empreendimentos de pequeno à grande porte.

Modelos previstos para utilização por arquitetos Americanos em empreendimentos localizados em outros países, em função da

Contratos não existência de um cadastro profissional que permita a sua Internacionais (International Family) atuação como prestador de serviços de arquitetura ou construção fora de seu país. Como solução, esse modelo de contrato identifica o serviço de arquitetura como uma consultoria. Os documentos para essa família de contratos podem ser usados em empreendimentos de pequeno a grande porte.

Indicados para utilização em empreendimentos de pequeno porte ou curta duração (menos de um ano entre o início do projeto e o término da construção), que não exigem concorrência para

Pequenos Empreendimentos (Small Projects Family) contratação dos serviços, e nos quais os agentes já possuem experiência prévia e um relacionamento positivo de trabalho conjunto. Essa família de documentos é indicada para empreendimentos comerciais de pequeno porte, empreendimentos residenciais e outros empreendimentos com custo e duração relativamente baixos.

Projetos digitais Modelos previstos para utilização em empreendimentos que (Digital Practice envolvam informações digitalizadas ou Modelagem da Informação 


\begin{tabular}{ll}
\hline Documents) & na Construção. Os documentos preveem um acordo de \\
& licenciamento para a transmissão de dados e informação em \\
& formato digital, estabelecem protocolos para o gerenciamento \\
& desse tipo de dados e gerenciamento na modelagem da \\
& informação da construção. Essa família de contratos é indicada \\
& para uso em empreendimentos de pequeno a grande porte.
\end{tabular}

Administração e

Gerenciamento Essa família é aplicável em todos os métodos de entrega de de empreendimentos. São disponibilizados vários documentos que

Empreendimentos embasam atividades tipicamente gerenciais, como controle de (Contract qualidade, requisição de informação, ordens de serviço de

Administration modificações, diretrizes construtivas e certificados de pagamento. and Project Os formulários podem ser utilizados em empreendimentos de Management pequeno a grande porte.

Forms)

\section{Fonte: AIA Contract Documents}

Outra estrutura de classificação dos documentos de contratos apresentada pelo AIA é a partir da relação entre os agentes envolvidos e documentos contratuais acessórios à efetiva implementação dos termos de contrato:

- Série "A": Contratos entre Incorporadora e Construtora;

- Série "B": Contratos entre Incorporadora e Arquiteto;

- Série "C": Outros contratos: Projeto Integrado, Modelagem da Informação na Construção, joint ventures e outros modelos diferenciados das séries A e B;

- Série "D": documentos acessórios de definição métodos de cálculos de áreas e volumes, checklists para o empreendimento, guia para empreendimentos sustentáveis;

- Série "E": documentos acessórios de protocolo de disponibilização e troca de dados digitais e modelos da informação da construção;

- Série "G": documentos acessórios para atividades de gestão de empreendimentos. 


\subsubsection{Modelos contratuais propostos pelo AIA para modelagem da informação da construção e projeto integrado (IPD)}

Em seus documentos contratuais, o AIA define a Modelagem da Informação da Construção como um conjunto de processos e tecnologias utilizado para a representação física e funcional das características do empreendimento em um modelo digital. (HARNESS, 2008). A aplicação dos documentos referentes a empreendimentos em modelagem pode ocorrer, independente do método de entrega do empreendimento e seu sistema contratual, desde o Projeto Sequencial até o Projeto Integrado.

A família de documentos identificada como Digital Practice Documents, aqui traduzida por Projetos Digitais, prevê os seguintes documentos, descritos na Tabela 3.

Documento

de Contrato

\section{Descrição}

Este documento prevê uma estrutura para uso e transmissão de dados digitais entre diferentes partes. Os dados a serem operados são C106 ${ }^{\mathrm{TM}}$-2007, categorizados como informação, comunicação, desenhos e projetos Acordo padrão criados ou armazenados em uma linguagem digital específica. para Licenciamento O C106 ${ }^{\mathrm{TM}}$-2007 permite o oferecimento de licença parcial e não exclusiva de Dados Digitais por uma das partes de utilização dos dados de um projeto específico à outra parte. Além disso, determina os procedimentos para a transmissão dos dados digitais e estabelece as restrições da sua licença de utilização. É prevista a possibilidade de cobrança de uma taxa de utilização dos dados digitais disponibilizados por cada uma das partes. 
Este é um modelo de documento contratual acessório, que deve ser utilizado como referência para os procedimentos acordados entre as E201 ${ }^{\mathrm{TM}}-2007$, partes quanto à transmissão e troca de dados digitais.

Protocolo de

Dados Digitais O E201 não prevê nenhuma regra quanto às licenças de utilização dos dados digitais, uma vez que o documento ao qual será acessório já deverá prever essas restrições.

O documento E202 ${ }^{\mathrm{TM}}$-2008 foi previsto como uma ferramenta para a gestão da modelagem da informação da construção durante o empreendimento. Nele são estabelecidos os requisitos de conteúdo do modelo em cinco diferentes níveis de desenvolvimento, e as autorizações de utilização do modelo conforme seu conteúdo e etapa do E202 ${ }^{\mathrm{TM}}$-2008, empreendimento.

Protocolo de Modelagem da Informação da Construção

Parte desse documento é uma tabela a ser preenchida com informações dos agentes do empreendimento, a partir da qual serão estabelecidas as autorias dos elementos do modelo por etapa do empreendimento. Também são definidos neste documento o grau de precisão e confiabilidade das informações inseridas no modelo, determinando diretrizes de padronização de formatos de arquivo e o escopo referente ao gerenciamento do modelo, ao longo do seu ciclo de vida.

\section{Fonte: AIA Contract Documents}

A estrutura documental oferecida pelo AIA para apoio a contratos de Projeto Integrado passa pelas séries $A, B$ e $C$ dos documentos de contrato. Foi lançada em 2007, em conjunto com o IPD Guide (AIA, 2007). Esse conjunto de documentos tem por objetivo facilitar e oferecer diretrizes para a implementação efetiva dos aspectos colaborativos do Projeto Integrado (HARNESS, 2008).

Apesar de os modelos contratuais referentes à Modelagem da Informação da Construção poderem ser aplicados a qualquer modalidade contratual, o AIA restringe a utilização dos modelos contratuais de Projeto Integrado a empreendimentos que utilizem a modelagem. A modelagem da Informação da construção é identificada como catalizadora do projeto integrado (HARNESS, 2008), 
já que a produção virtual do modelo do edifício antecipa a identificação de conflitos, permitindo uma etapa de produção mais eficiente, reduzindo o número de reivindicações de modificação e gerando um processo mais eficiente. Harness (2008) estabelece que, na prática, o uso da modelagem da informação da construção demanda uma postura colaborativa dos agentes (construtor e projetistas) prévia à etapa de construção do edifício, e facilita o alcance das metas estabelecidas no Projeto Integrado.

Os modelos contratuais que compõem a Família de documentos de Projeto Integrado estão identificados e descritos na Tabela 4.

Tabela 4: Documentos Contratuais do AIA para a Família de Projeto Integrado

Documento de

Contrato

\section{Descrição}

Este documento prevê o acordo entre a empresa incorporadora e a construtora dentro dos princípios do Projeto Integrado. Além dos termos gerais do negócio, são estabelecidos os termos e as

A195 TM-2008, Formulário- padrão de contrato entre incorporadora e Construtora para Projeto Integrado condições únicos da relação entre estes dois agentes, como detalhes de compensação e licenciamento de instrumentos de serviço.

Esse modelo não inclui o escopo de trabalho da construtora, mas referencia o A295 ${ }^{\mathrm{TM}}$-2008, documento contratual das condições gerais para contratos de Projeto Integrado, que determina as obrigações do cliente (incorporadora), arquiteto e da construtora em cada uma das seis fases identificadas do empreendimento O A1952008 prevê a garantia de um preço máximo pela construtora, estabelecido em documento contratual acessório.

A295 ${ }^{\mathrm{TM}}-2008$, Condições Gerais de contrato para Projeto Integrado.
Este documento fornece os termos e condições para a implementação de outros dois documentos desse grupo, o A195TM_2008 (contrato entre incorporadora e construtora) e o $\mathrm{B} 195^{\mathrm{TM}}-2008$ (contrato entre incorporadora e arquiteto).

Nele são determinados os escopos dos serviços de arquitetura, 


\section{Documento de}

\section{Descrição}

construção e outras condições referentes a serviços de construção civil. Também são estabelecidos os deveres do cliente (incorporadora), arquiteto e construtora, e a estrutura pela qual irão trabalhar colaborativamente nas seis fases do empreendimento: conceituação, determinação dos critérios de projeto, detalhamento do projeto, documentação para produção, construção e entrega final.

O A295 requer o uso de Modelagem da Informação da Construção por todas as partes.

Este documento prevê o acordo entre a empresa incorporadora e a

B195 TM-2008, Formulário padrão de contrato entre incorporadora e Arquiteto para Projeto Integrado projetista de arquitetura dentro dos princípios do Projeto Integrado. Além dos termos gerais do negócio, são estabelecidos termos e condições únicos da relação entre estes dois agentes, como detalhes de compensação e licenciamento de instrumentos de serviço.

Este modelo não inclui o escopo de trabalho da construtora, mas

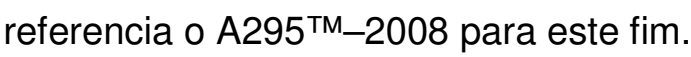

C191 ${ }^{\mathrm{TM}}-2009$, Formulário padrão de contrato Multilateral para Projeto Integrado
O C191 ${ }^{\mathrm{TM}}$-2009 é o documento padrão para acordo multilateral entre o cliente (incorporadora), arquiteto, construtora e outros participantes chave do empreendimento. Nesse único acordo, são previstas as execuções das atividades de projeto, construção e comissionamento do empreendimento.

O documento determina a estrutura de trabalho para o ambiente colaborativo em que as partes irão operar, sempre tendo em vista atingir as metas de custo e desempenho estabelecidas em conjunto pelas partes.

Excluído o cliente (incorporadora) as demais partes são remuneradas a partir de um modelo de compensação baseado em seus custos de produção. Esse modelo de compensação também é orientado pelas 


\section{Documento de}

\section{Descrição}

metas do contrato, estabelecendo incentivos para a colaboração durante o projeto e a construção.

O gerenciamento do empreendimento é responsabilidade de uma equipe de Gerenciamento (formada por membros representantes das principais partes envolvidas no contrato). Há, ainda, um nível mais estratégico de gestão responsável pela fiscalização dos resultados do empreendimento e resolução de conflitos, a chamada Equipe Executiva do Empreendimento (também formada por membros representantes das principais partes envolvidas no contrato).

Observa-se que o processo de resolução de conflitos tem o objetivo de dar soluções rápidas e efetivas aos problemas conforme o seu surgimento.

Este documento prevê a formação de uma Sociedade de Propósitos Específicos (SPE) em que o cliente (incorporadora), arquiteto, construtora, gerenciadora e outros participantes-chave do C195 ${ }^{\mathrm{TM}}$ _ empreendimento tornam-se membros de uma sociedade de 2008, Formulário responsabilidade limitada.

padrão para Sociedade de

Propósito

O único objetivo dessa sociedade é o projeto e construção de um empreendimento de construção civil, utilizando-se os princípios do Projeto Integrado, conforme previstos no IPD Guide (2009).

Específico

O documento determina a estrutura de trabalho para o ambiente colaborativo em que as partes irão operar, sempre tendo em vista atingir as metas de custo e desempenho, estabelecidas em conjunto pelas partes.

Para financiamento do empreendimento, a sociedade estabelece um acordo separado com a incorporadora, e para remuneração das atividades de seus membros, a sociedade estabelece contratos 


\section{Descrição}

específicos com cada um dos agentes envolvidos. Esses contratos específicos (exceto com a incorporadora) utilizam um modelo de compensação, baseado nos custos de produção das partes. Tal modelo de compensação também é orientado pelas metas do contrato estabelecidas em conjunto pelas partes, e fornece incentivos para a colaboração durante o projeto e a construção.

O documento C196 ${ }^{\mathrm{TM}}$-2008 é o acordo padrão entre a Sociedade de Propósitos Específicos (SPE) e a empresa incorporadora do

C196 ${ }^{\mathrm{TM}}$ 2008,

Formulário padrão entre Incorporadora e Sociedade de Propósito Específico (SPE) para Projeto empreendimento (cliente).

Sua utilização ocorre coordenada com outros documentos de contrato padrão deste grupo, como o C195TM_2008 (Formulário padrão para SPE em Projeto Integrado), e prevê a realização de metas estabelecidas mutuamente entre as partes e o cliente.

No C196 são fornecidos os termos de financiamento da produção da Integrado SPE pela incorporadora, em troca dos serviços de projeto e construção, os quais, por sua vez, são financiados pela SPE em contratos específicos com seus agentes (como o C197TM_2008).

C197'TM 2008,

Formulário padrão entre Sociedade de Propósito Específico (SPE) e demais agentes para Projeto Integrado
O documento contratual $\mathrm{C} 197^{\mathrm{TM}}-2008$ prevê o acordo entre a Sociedade de Propósitos Específicos (SPE) e os agentes do empreendimento, excetuando-se a incorporadora (cliente).

Sua utilização ocorre coordenada com outros documentos de contrato padrão desse grupo, como o C195 ${ }^{\mathrm{TM}}-2008$ (Formulário padrão para SPE em Projeto Integrado), e prevê a realização de metas estabelecidas mutuamente entre as partes e o cliente.

São determinados os termos pelos quais os agentes irão fornecer serviços à SPE para realização dos projetos e construção do empreendimento. É estabelecida uma Matriz Integrada de Escopos de 


\section{Descrição}

Serviço, que especifica detalhadamente o escopo de cada um dos membros da SPE, apresentada como acessória a esse documento contratual e constando na emenda referente ao Custo Alvo no C195 ${ }^{\mathrm{TM}}-2008$.

Em troca de seus serviços, os membros da SPE (exceto Incorporadora) são remunerados pelos seus custos diretos e indiretos referentes ao empreendimento. O C197 possibilita, também, a distribuição adicional dos lucros do empreendimento, por meio de um modelo de compensação relacionado com o atingimento das metas do Projeto Integrado.

O documento contratual $\mathrm{C} 198^{\mathrm{TM}}-2010$ prevê o acordo entre a Sociedade de Propósitos Específicos (SPE) e consultorias para o empreendimento.

C198 ${ }^{\mathrm{TM}}$ 2010, Formulário padrão entre

Sua utilização ocorre coordenada com outros documentos de contrato padrão desse grupo, como o C195 ${ }^{\mathrm{TM}}$-2008 (Formulário padrão para SPE em Projeto Integrado), a fim de implementar os princípios do Projeto Integrado.

Os serviços específicos da consultoria contratada estão relacionados na Matriz Integrada de Escopos de Serviço, prevista na emenda Sociedade de referente ao Custo Alvo do C195'TM-2008.

Propósito

Específico (SPE) e consultorias para Projeto Integrado

Além do estabelecimento de pagamento pelos seus serviços, o C198 possibilita também a distribuição adicional de parte dos lucros do empreendimento para a empresa consultora, por meio de um modelo de compensação relacionado com o atingimento das metas do Projeto Integrado.

C199TM2010, Formulário O C199 padrão entre 
Documento de

Contrato

\section{Descrição}

Sociedade de de Propósitos Específicos (SPE) e a empresa construtora.

Propósito

Específico Sua utilização ocorre coordenada com outros documentos de

(SPE) e construtora contrato- padrão desse grupo, como o C195TM-2008 (Formulário para Projeto padrão para SPE em Projeto Integrado), a fim de implementar os Integrado princípios do Projeto Integrado.

O C199 flexibiliza a escolha dos serviços prestados pela construtora, que podem participar somente da etapa de construção ou podem participar das etapas prévias à construção.

Os serviços específicos da consultoria contratada estão relacionados na Matriz Integrada de Escopos de Serviço, prevista na emenda referente ao Custo Alvo do $\mathrm{C} 195^{\mathrm{TM}}-2008$.

Além do estabelecimento de pagamento pelos seus serviços, o C199 possibilita também a distribuição adicional de parte dos lucros do empreendimento para a empresa consultora, por meio de um modelo de compensação relacionado com o atingimento das metas do Projeto Integrado.

Seu uso não é adequado para concorrências e licitações, pois determina a escolha de uma das seguintes metodologias para determinação de custo de seus serviços: a) custo fixo ou b) custo de trabalho somado a uma cota ou taxa de serviços.

Além dessas formas de remuneração, o C199 possibilita, também, a distribuição adicional de parte dos lucros do empreendimento para a empresa construtora por meio de um modelo de compensação, relacionado com o atingimento das metas do Projeto Integrado. 


\section{PROJETO INTEGRADO OU INTEGRATED PROJECT DELIVERY (IPD)}

Este capítulo tem como objetivo introduzir os conceitos de Projeto Integrado e suas principais características. São apresentadas as estruturas contratuais e de relacionamento entre os agentes, as quais podem ser utilizadas na abordagem do Projeto Integrado, em modelos parciais e integrais de colaboração e compartilhamento de resultados.

Apresentam-se as principais modificações do processo tradicional geradas pela abordagem integrada, apontando para os possíveis resultados. É também realizada a análise de sua relação de interdependência e potencialização com a modelagem da informação da construção.

Ao fim do capítulo são apresentados os resultados de estudos de casos de empreendimentos em que se utilizou o Projeto Integrado, disponibilizado pelo AIA (2012).

\subsection{O PROJETO INTEGRADO COMO SOLUÇÃO ALTERNATIVA}

O IPD (Integrated Project Delivery) é um modelo de contrato relacional desenvolvido, inicialmente, por um grupo de profissionais da construção civil, liderados pela Westbrook Air Conditioning, em 1998, e que foi transformado em marca registrada: Integrated Project Delivery ${ }^{\mathrm{TM}}$. O modelo contratual de IPD utiliza princípios de gerenciamento para a implementação de contratos relacionais.

O desenvolvimento e a definição do IPD como metodologia de contrato para a construção civil ocorreram a partir do desenvolvimento de pesquisas de alternativas contratuais ao modelo tradicional utilizado pela indústria da construção, baseado em contratos transacionais, em que ocorrem simples trocas por bens e serviços. $\mathrm{Na}$ maior parte das vezes, os contratos da AEC são formados por meio de licitações por preço, desenvolvidas a partir dos projetos de construção. Esse modelo tradicional de 
contratação gera um isolamento entre as etapas de concepção e construção do empreendimento, observado no caso do Design Bid Build - Contrato Sequencial e do Design Build - Projeto Construção.

Wang (2008) define que a rigidez dos contratos da indústria da construção, como a contratação a partir de licitações baseadas em projetos, resulta em baixo desempenho geral do empreendimento, causa essa que pode identificada nos problemas gerados pelas formas tradicionais de contratação - transacional, destacando-se, de acordo com Mathews e Howell (2005), os quatro motivos seguintes:

1) Boas ideias são postergadas;

O envolvimento tardio de alguns agentes do processo -, como no caso de projetistas de instalações no contexto brasileiro, e dos desenvolvedores do detalhamento desses projetos - contractors - no contexto americano, a fim de baratear as primeiras etapas de concepção dos projetos, acaba por atrasar a sua participação nas decisões tomadas referentes ao empreendimento.

Apesar de algumas empresas praticarem consultorias informais a esses agentes, para alinhar as soluções de projeto com as suas disciplinas específicas, não há comprometimento desses profissionais, por não existir vínculo formal entre eles e o empreendedor, não havendo como garantir a sua contratação, por ser comum que a contratante realize consultas com diferentes empresas de uma mesma disciplina de projeto, para um único empreendimento.

Esse processo gera um ambiente de competição entre as empresas "consultoras" que, ao serem procuradas sobre a qualidade técnica ou sobre alguma sugestão referente aos projetos que receberam (normalmente ainda não concluídos e podendo ter seu desenvolvimento redirecionado por uma sugestão que aperfeiçoe resultados), não disponibilizavam qualquer sugestão, ocultando-as para serem utilizadas como diferenciais em sua proposta e, assim, impedindo a sua incorporação antecipada aos projetos, 
nos quais a discussão e implementação seriam mais ricas e melhor desenvolvidas.

2) A colaboração e a inovação são limitadas pelas características contratuais.

Os contratos de construção civil, sejam entre o empreendedor e a construtora, ou ainda entre esta e seus subcontratados, são definidos por acordos limitantes para ambas as partes. Conforme definido por Batavia (2000): "Um contrato, para ser administrável, deve definir o escopo do trabalho, a obrigação de cada parte assim como os limites de atuação de cada parte".

A definição do que consta do escopo contratual é, também, por exclusão, uma definição do que não faz parte dele e, portanto, daquilo pelo qual o participante do contrato não poderá ser responsabilizado.

Em ambientes férteis para a geração de conflitos, como é o caso da construção civil (BUCKER, 2010; PEÑA-MORA; SOSA; MCCONE, 2002), as divergências observadas entre os serviços prestados e o contrato podem ser utilizadas como justificativa para abertura de processos legais contra 0 participante do contrato, se a outra parte estiver insatisfeita e não acreditar cumpridas as expectativas expressas no contrato.

Sob esta perspectiva de condenação, é comum observar que os participantes do contrato inibam o desenvolvimento e a incorporação de soluções inovadoras, buscando evitar o questionamento das suas ações fora do cenário definido pelo documento de contrato. (MATHEWS; HOWELL, 2005).

3) Há muitas barreiras para a efetiva coordenação dos projetos;

Os inúmeros subcontratados e empresas terceirizadas participantes do empreendimento definem um grande volume de interfaces a serem tratadas e compatibilizadas no projeto e, portanto, diversos interesses individuais de cada uma das partes. Os eventos previstos para promover a coordenação do empreendimento e a colaboração entre as partes são muitas vezes ineficientes, inclusive pela participação de representantes das empresas que não são os responsáveis diretos pela produção do projeto, e não poderão 
contribuir como tais. Isso se agrava em ambientes em que o término do desenvolvimento do projeto (requerido para o fechamento do contrato e pagamentos) é responsabilidade desses subcontratados ou fornecedores, como ocorre na indústria de AEC americana, levando à ocorrência de muitas interferências e incoerências entre as disciplinas, uma vez que as informações nos projetos não são tratadas tendo em vista a compatibilização entre eles e as metas do empreendimento, mas sim a ação de entrega final.

4) Pratica-se a valorização individual das partes em detrimento da otimização global.

Em empreendimentos com diversos agentes, entre prestadores de serviços, projetistas e fornecedores, cada qual com contrato diferenciado com escopos extensos e não necessariamente integrados, a busca por desempenho é comum a todos os participantes, porém sob diferentes pontos de vista, e levando a soluções divergentes de um mesmo projeto. Cada um dos participantes tenta alcançar os melhores resultados possíveis em qualidade, custo ou construtibilidade referentes à especialidade para a qual foram contratados. No âmbito global do empreendimento, essa otimização pontual pode ir de encontro aos melhores resultados de outras partes e inclusive dos resultados empreendimento como um todo.

Buscando-se alternativas para essa situação, nas últimas duas décadas foram desenvolvidas pesquisas de metodologias mais eficientes de contratações e desenvolvimento de empreendimentos de construção civil. Segundo Wang (2008), o resultado de tais pesquisas aponta para os contratos relacionais que envolvem os participantes (contratados e contratante) e introduzem um mecanismo de compartilhamento de riscos e de benefícios, como a forma contratual escolhida, por atingir maiores níveis de inovação, eficiência e resultados para o empreendimento.

O IPD destaca-se dentro dessa modalidade contratual, pois incita a colaboração no trabalho em equipe pela integração dos participantes em uma única equipe (WANG, 2008). 
O AIA (American Institute of Architects) define, no IPD Guide (2007), diretrizes para os contratantes, projetistas e construtores para a implementação de projetos integrados.

O conceito de IPD definido pelo AIA em 2007 no IPD Guide é o seguinte:

IPD é um enfoque para implementação de empreendimentos que integra pessoas, sistemas, estruturas de negócios e práticas profissionais em um processo que colaborativamente aproveita os talentos e percepções de todos os participantes para otimizar resultados do empreendimento, aumentar o valor para o cliente, reduzir o desperdício e maximizar a eficiência em todas as etapas do projeto, fabricação e construção.

E ainda:

Os princípios do IPD podem ser aplicados para uma variedade de negociações contratuais, e as equipes de IPD podem incluir membros além da tríade básica cliente-arquiteto-construtor. Em todos os casos, os projetos integrados são distintos pela colaboração altamente efetiva entre o cliente, o principal projetista e o responsável pela construção, desde o princípio do projeto e continuadamente até a entrega da construção.

\subsection{RELAÇÕES CONTRATUAIS NO PROJETO INTEGRADO (IPD)}

As relações contratuais no IPD podem ocorrer de duas formas (Wang, 2008):

- Focadas no processo ou

- SPE-IPD - Associação de empresas para formação do IPD como entidade corporativa ou Sociedade de Propósitos Específicos.

No primeiro caso, somente um contrato é formalmente assinado entre o cliente e o líder da equipe de projetos e/ou construção. As demais relações são definidas por um acordo ou pacto relacional entre as partes, conforme demonstrado na Figura 10. 
Figura 11: Relações entre agentes em contratos de IPD focados no processo

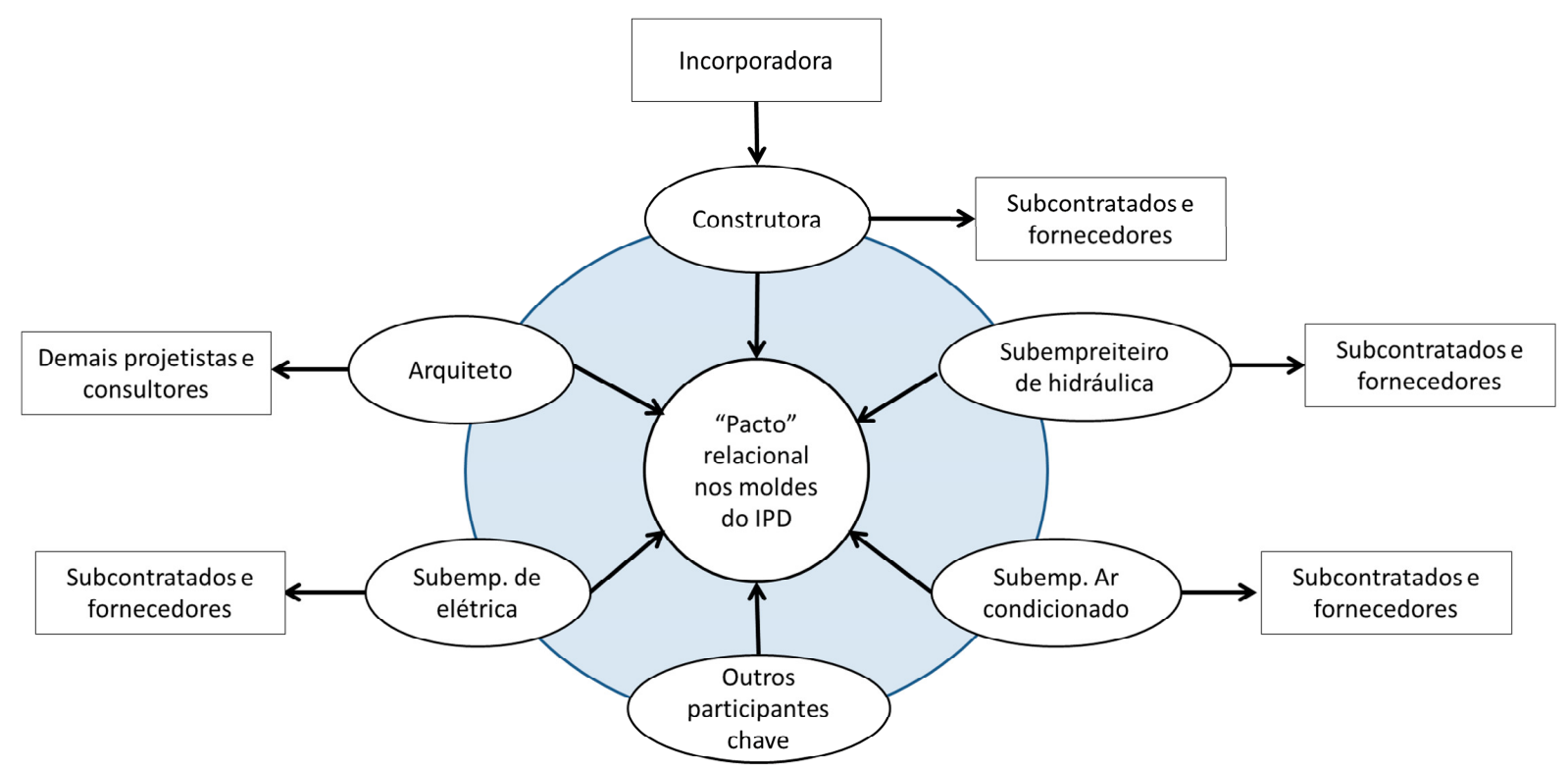

Fonte: Wang (2008)

Conforme os modelos contratuais do AIA, especificamente os modelos A195 e B195, a implementação do contrato de IPD pode ocorrer parcialmente, entre o incorporador e um agente específico de importância, no empreendimento. Esses modelos determinam os critérios para relacionamento, dentro de um contrato relacional entre o incorporador e o arquiteto (A195) ou a construtora (B195). No mercado americano, tais agentes são os principais representantes das etapas de projeto e construção, respectivamente, e, por vezes, são os responsáveis pela relação dos fornecedores específicos para essas duas etapas que, em alguns casos, são configurados em relações informais, sem o estabelecimento de contrato, conforme demonstrado nas Figuras 11 e 12. 
Figura 12: Relações entre participantes de contratos em IPD focados no Processo

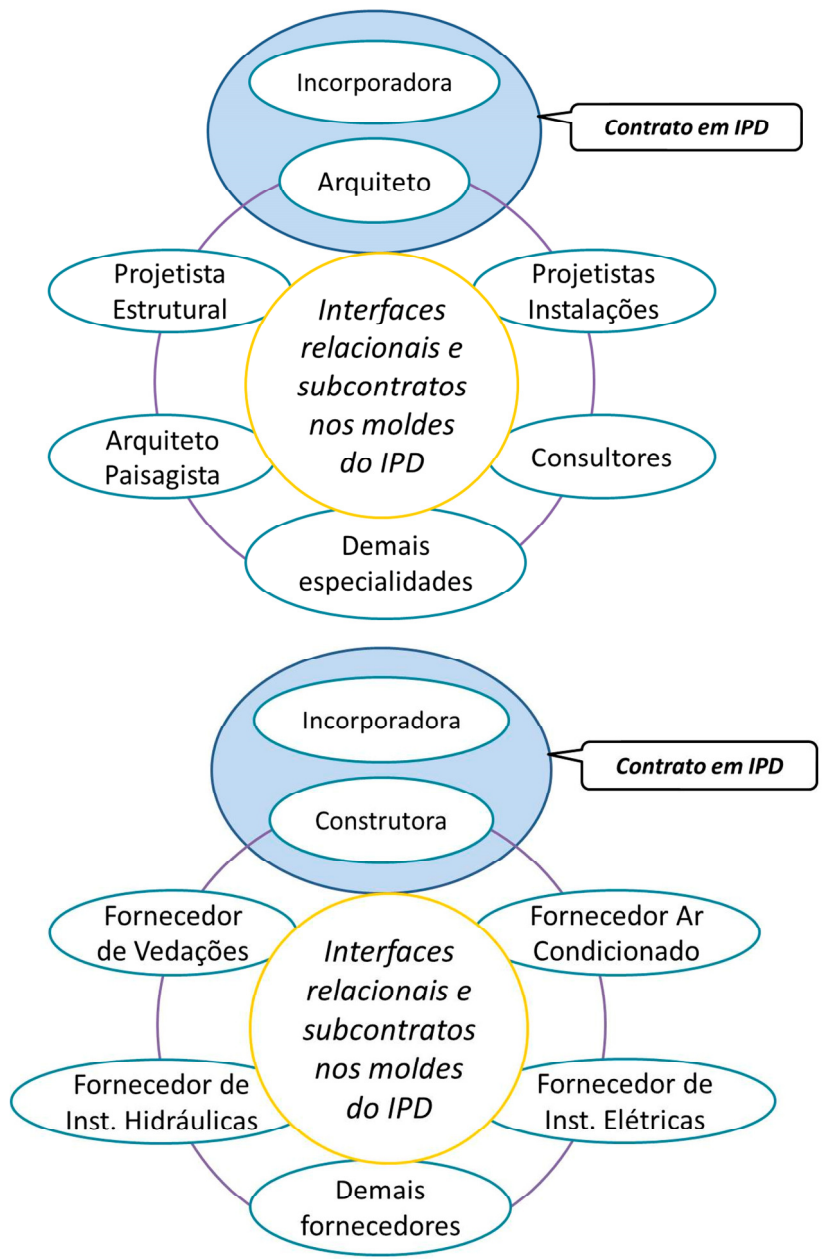

Fonte: Adaptado de "Relações no modelo de IPD focado no processo" (Wang, 2008)

Figura 13: Relações contratuais em modelos de contrato de transição para IPD

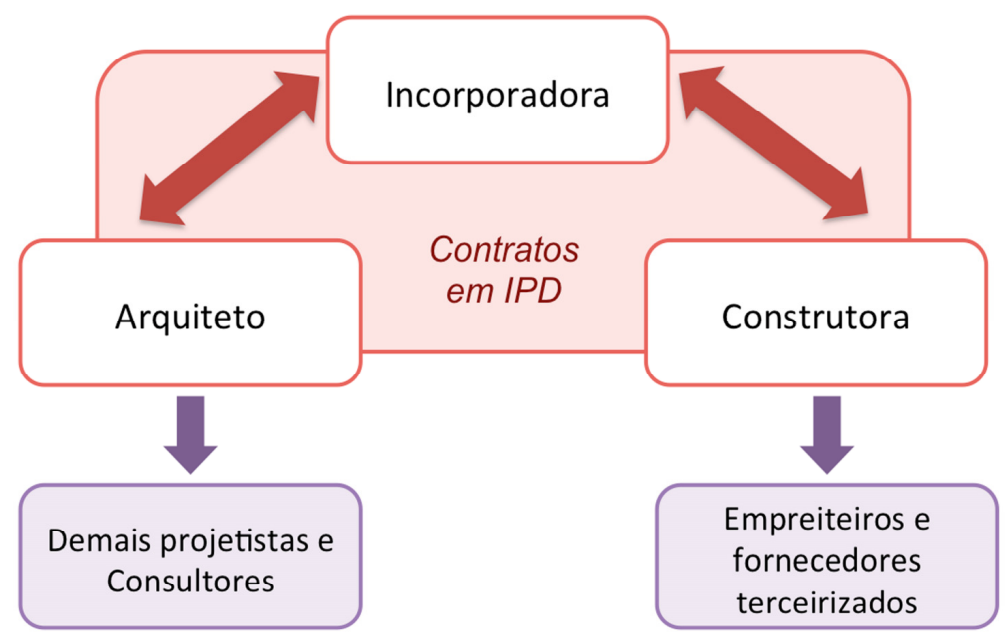


Fonte: Adaptado de AIA (2012)

No modelo SPE-IPD todas as empresas participantes são acionistas dentro do negócio e, automaticamente, compartilham a responsabilidade sobre os resultados. Neste caso, a corporação montada para a execução do IPD é temporária e estabelece diversos contratos com os participantes. Todos os lucros obtidos são divididos entre os acionistas ao fim dos projetos, por meio da SPE.

O mesmo senso de compartilhamento ocorre na aplicação de contratos multilaterais entre as partes envolvidas, conforme demonstrado nas Figuras 13 e 14.

Em todos os casos, o IPD é baseado na formação de contratos relacionais e de parcerias entre os participantes, com o objetivo de alinhar seus interesses aos do projeto. 
Figura 14: Relações entre participantes de contratos em SPE-IPD e Multilateral

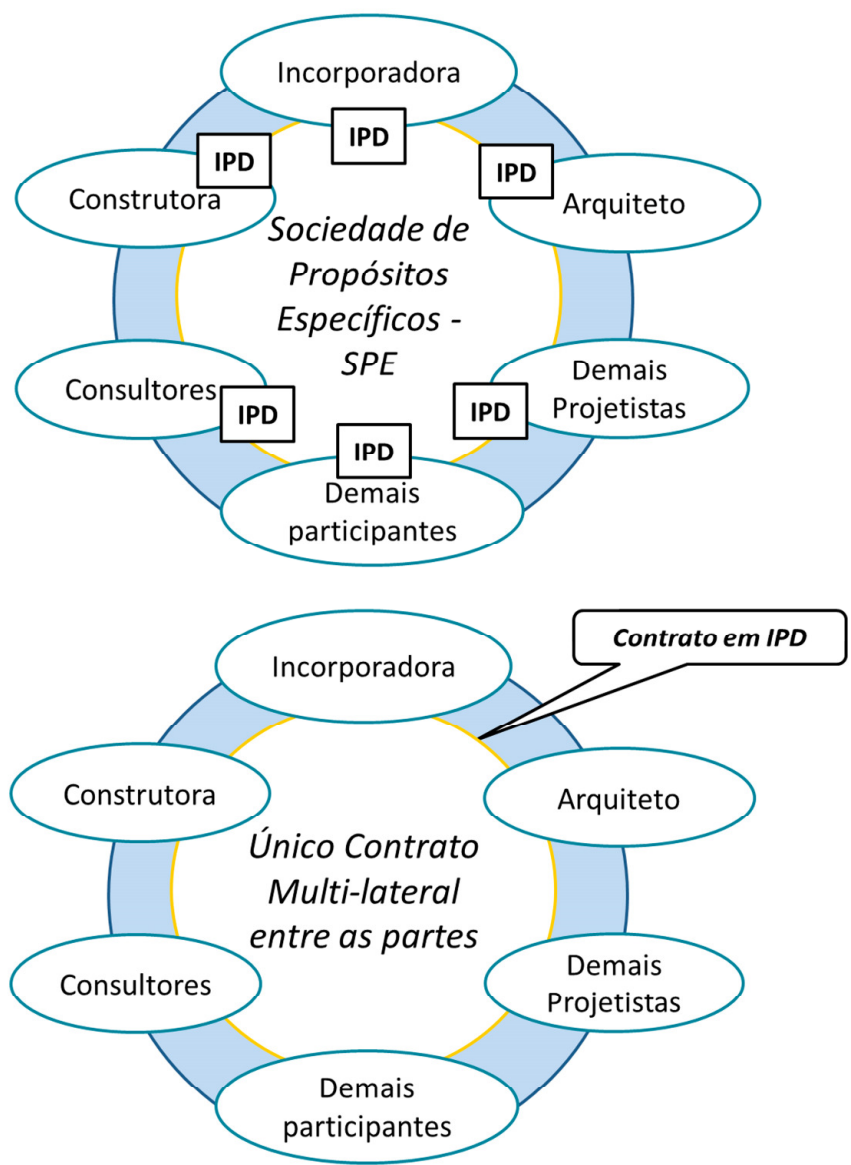

Fonte: Adaptado de "Relações no modelo IPD Inc" (Wang, 2008) 
Figura 15: Diagrama de relações em contratos Multilaterais em IPD

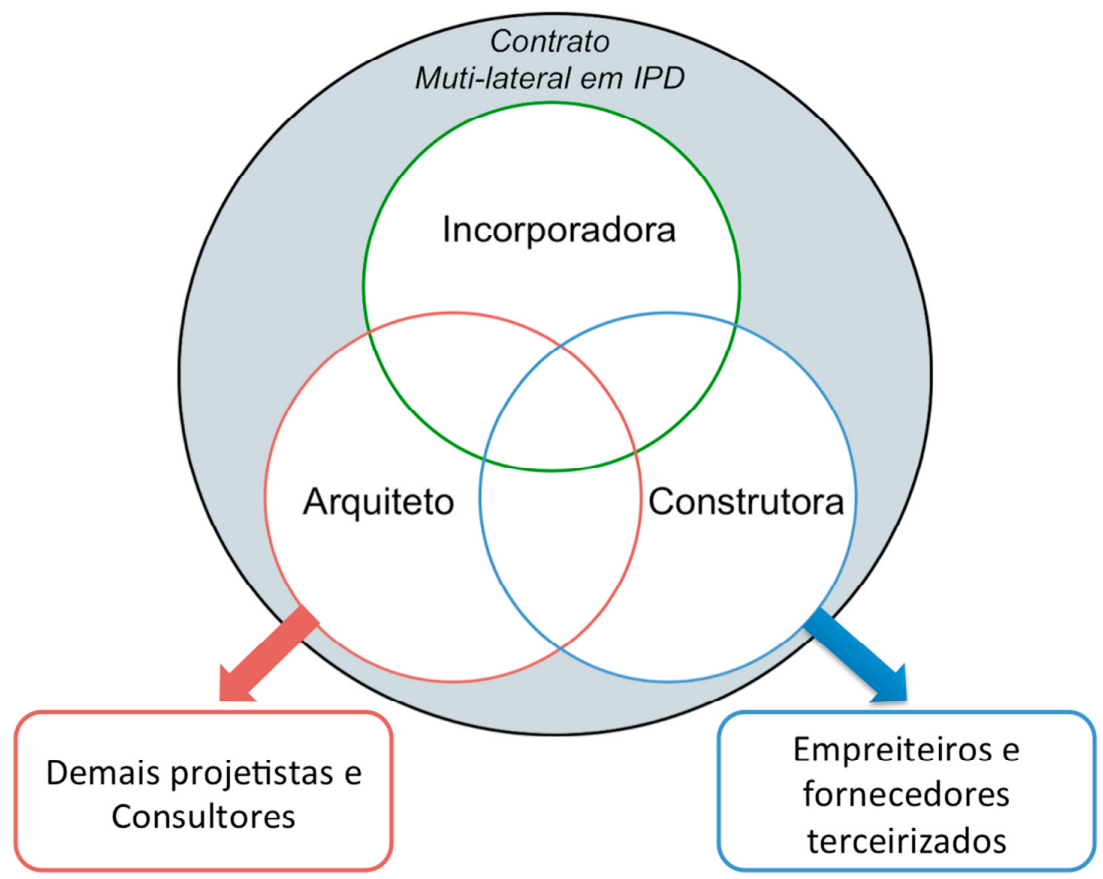

Fonte: Adaptado de AIA (2012)

O principal princípio de governança das relações contratuais externas, isto é, entre os membros da equipe de projetos e construção e o cliente, é o de que todos os membros são responsáveis pelo cumprimento do contrato primário com o cliente, o que significa que o atendimento às metas do contrato é o principal objetivo das partes (COLLEDGE, 2005).

Internamente, o acordo estabelecido entre as partes define a sua participação igualitária no contrato primário. $\mathrm{O}$ acordo de parceria entre as partes (podendo, por exemplo, constituir-se nos moldes da Aliança de Projetos), define a formação de interações nos moldes relacionais entre os participantes, levando às seguintes vantagens:

- Equilíbrio entre interesses pessoais, colaboração e justiça (MACNEIL, 1978);

- Gerenciamento conjunto dos riscos e incertezas do empreendimento (RAHMAN, KUMARASWAMY, 2004);

- Incentivo à colaboração e inovação que levam a resultados acima dos esperados no projeto (ROSS, 2003; LICHTIG, 2005). 


\subsection{FORMAÇÃO DE EQUIPE PARA PROJETOS INTEGRADOS}

\subsubsection{Processo de seleção}

Assim como nas Alianças de Projeto, a seleção dos membros do IPD é uma etapa essencial no processo, e diretamente relacionada aos resultados obtidos, que dependem do comprometimento dos participantes (WANG, 2008).

Segundo o AIA California Council (2007), a chave para o sucesso em um Projeto Integrado é a montagem de uma equipe comprometida com os processos colaborativos e com capacidade de trabalhar efetivamente em conjunto. Esse mesmo documento determina alguns passos para a formação da equipe. São eles:

1) Identificação dos agentes-chave e seus papéis no empreendimento:

2) Pré-qualificação dos agentes (profissionais e empresas) baseada nos seguintes critérios:

- Competência técnica;

- Comprometimento com as práticas integradas e processo colaborativo;

- Registro de experiências anteriores;

- Integridade.

3) Avaliação dos interesses dos agentes participantes e busca de envolvimento das partes interessadas.

4) Escolha da estrutura organizacional e de negócio mais adequada às necessidades e restrições dos participantes (escolha do modelo contratual a ser utilizado).

5) Desenvolvimento dos acordos contratuais quanto às funções e responsabilidades dos participantes. Deve-se atentar para que essas definições estejam de acordo com o modelo de negócio e estrutura organizacional escolhidos. As definições de modelo de compensação, obrigações e alocação de riscos devem ser apresentadas 
com clareza. Alguns itens de influência na postura colaborativa dos agentes que devem ser definidos são:

- Modelos de compensação e incentivos:

- Compartilhamento de lucros;

- Transparência na contabilidade das empresas e profissionais;

- Bônus por desempenho.

- Protocolos de comunicação e troca de informações:

- Tecnologias a serem utilizadas;

- Padrões, protocolos e diretrizes a serem utilizados;

- Auditorias e registros de documentos.

- Obrigações e fiscalização;

- Processos de tomada de decisão no empreendimento;

- Responsabilização técnica e profissional;

- Alocação de riscos;

- Seguros.

Segundo Wang (2008), os critérios de seleção devem seguir os mesmos princípios determinados por Ross (2003) para a seleção de membros para Alianças de Projeto, passando sempre pela revisão das características do projeto que devam ser incorporadas neste processo, como a necessidade de habilidades ou conhecimentos específicos, ou a incorporação de diretrizes gerais de sustentabilidade, ambiental ou social ao empreendimento e, por extensão, às empresas participantes.

Wang (2008) dá ênfase a dois critérios gerais que devem ser observados na determinação da equipe do IPD:

1) Confiabilidade: este critério pode ser medido objetiva ou subjetivamente, sendo a métrica utilizada para uma avaliação objetiva a observação dos resultados obtidos em projetos anteriores, além da realização de entrevistas com antigos parceiros de trabalho do candidato. Já a avaliação subjetiva deve ocorrer durante o processo de entrevistas, pela avaliação da personalidade e de habilidades demonstradas nesta interação. 
2) Afinidade com a equipe e princípios do IPD: deve haver clareza na estrutura de trabalho e o acordo do candidato com as condições demonstradas, que têm aspectos positivos e negativos. Como aspectos negativos, podem ser apontados (a) a carga horária aumentada em relação a projetos tradicionais em cerca de $10 \%$ a $20 \%$ em horas adicionais (em relação a um projeto no modelo projeto-construção/DB) e (b) modelo de compensação que aloca os riscos em todos os participantes. Como aspectos positivos, identifica-se (a) 0 modelo de compensação, em conjunto com os resultados de trabalho, valoriza os esforços das partes de maneira mais equilibrada que outras modalidades contratuais e (b) a pressão individual em projetos em IPD é menor e os participantes são incentivados a trabalhar de forma criativa e colaborativa.

\subsubsection{Equipe líder do projeto}

Dentro da equipe do IPD deve determinar-se um grupo de pessoas responsáveis pela liderança técnica do projeto, determinadas no modelo contratual do AIA como Project Executive Team, que é responsável pela tomada de decisões, planejamento e gerenciamento do projeto de forma a propiciar as condições para que todas as partes contribuam no alcance dos objetivos do projeto nas suas definições e soluções técnicas e tecnológicas.

Essa equipe líder deve ter participantes de todas as empresas representativas do projeto, sendo constituído minimamente por um representante do cliente, um representante do arquiteto (respondendo por todas as especialidades de projeto) e um representante da construtora, os quais devem ter autoridade reconhecida dentro de suas organizações para falar e responder por elas nas questões relacionadas ao projeto.

As decisões da liderança do projeto devem ser unânimes, e na ocorrência de um caso em que isto não seja possível, pode haver intervenção do contratante para determinação das diretrizes a serem seguidas no assunto. 


\subsubsection{Equipe gerencial do projeto}

Além da equipe líder, deve ser montada uma equipe de gerenciamento do projeto, 0 chamado Project Management Team (AIA, 2007), responsável pela execução das diretrizes da equipe de liderança e gerenciamento de curto prazo do projeto, tais como o planejamento de atividades e cronograma de curto prazo e a coordenação das ações entre os membros da equipe.

Também deve ser composto por participantes das principais empresas do projeto e suas decisões devem ser unânimes; caso isto não seja possível, o assunto deve ser direcionado à equipe líder do projeto.

A equipe de gerenciamento se relaciona com a equipe líder por meio do desenvolvimento de planos de trabalho e de metas orientados pelas diretrizes da equipe líder, e que devem ser validados por ela. Junto a esse plano, é apresentado o planejamento do processo pelo qual a equipe gerencial pretende alcançar os objetivos do projeto e sua completude.

No caso de formação de equipes de IPD com foco no processo, é necessária a determinação de um representante líder, que deve ser escolhido, dada a importância de sua disciplina; geralmente, o membro escolhido para este cargo é o arquiteto, em virtude de sua visão sistêmica do empreendimento, mas no caso de empreendimentos focados em disciplinas específicas, como distribuição de instalações de uma indústria, o fornecedor dos componentes mecânicos e equipamentos ou o projetista de instalações podem ser designados líderes (WANG, 2008).

O papel do líder nesse modelo de IPD é o de gerenciar o empreendimento em suas fases, contando com o auxílio de membros de outras empresas participantes da equipe de projetos com habilidades gerenciais, formando uma equipe gerencial; o líder deve também fornecer uma referência externa para tratativas do contrato com o cliente. 


\subsection{MODELO DE COMPENSAÇÃO E DISTRIBUIÇÃO DOS RESULTADOS}

O sistema de compensação de um contrato relacional é o responsável pelo incentivo aos participantes para atingir melhores performances.

Para tanto, podem ser utilizados mecanismos de compensação como o descrito para a Aliança de Projetos, ou ainda, conforme descrito por Wang (2008) e nos modelos contratuais do AIA para Projeto Integrado (2012), que propõem uma simplificação do modelo da Aliança de Projetos, no qual são mantidas as características de transparência na contabilidade e registro do trabalho produzido.

A partir desses registos, os custos diretos são reembolsados e o compartilhamento dos resultados ocorre ao fim do empreendimento ou no cumprimento de metas parciais, a partir de uma fórmula de distribuição determinada previamente pela equipe do IPD (AIA, 2012; WANG, 2008).

A fórmula utilizada para distribuição dos resultados define quatro categorias de custos e a sua hierarquia quanto à importância que define os pesos nas variantes da fórmula são: mão de obra, aluguel e materiais, equipamentos e subempreitados.

O objetivo da fórmula é definir uma condição em que o lucro individual por empresa cresça ou diminua proporcionalmente ao lucro do empreendimento, estimulando os membros da equipe a buscarem melhores resultados no empreendimento como uma unidade, e a colaborar com as demais partes nos seus resultados.

Além disso, identifica-se o estímulo às empresas para desenvolverem os serviços sem terceirizá-los (e sem repassar a responsabilidade pelo objeto contratado), uma vez que a maior parte do lucro incorre sobre a variante mão de obra utilizada.

Esse modelo oferece a transparência necessária para que haja confiança nos valores declarados por cada uma das partes, além de permitir a identificação, com livros contábeis abertos, dos custos de projeto que foram inflados ou reduzidos a partir das ações da equipe, durante todo o processo de projeto e de implementação do empreendimento. Dessa forma, fica evidente o benefício da definição preliminar e 
antecipada de soluções pensadas e acordadas entre todos os participantes, que reduz a quantidade de retrabalho com revisões de projeto, além de reduzir os prazos de desenvolvimento (que no processo de projeto quer dizer também redução de custos).

\subsection{DETERMINAÇÃO DA ESTRUTURA DE TRABALHO}

\subsubsection{Mudanças no processo de projeto para projetos integrados}

Em modelos contratuais relacionais, a definição da equipe participante de todas as etapas do processo do empreendimento é antecipada preliminarmente, em relação aos contratos transacionais. Além disso, em relações contratuais que privilegiam posturas colaborativas, o processo de projeto e de formatação do empreendimento também passa por alterações significativas (SANTOS, 2010). As principais diferenças entre o processo tradicional e o processo integrado estão estabelecidas na Tabela 5.

Tabela 5: Transformação do processo de projeto tradicional para integrado

\section{Características do Processo Tradicional Características do Processo Integrado}

\begin{tabular}{ll}
\hline Processo linear, distinto e segregado & Processo concorrente e multinível \\
\hline $\begin{array}{l}\text { Conhecimento coletado somente quando } \\
\text { necessário }\end{array}$ & $\begin{array}{l}\text { Contribuições de conhecimento e expertise } \\
\text { antecipados }\end{array}$ \\
\hline Informação estocada & Informação abertamente compartilhada \\
\hline Silos de conhecimento e expertise & Confiança e respeito entre os participantes \\
\hline
\end{tabular}

Fonte: Santos, 2010.

É importante identificar no enfoque integrado a sobreposição das escolhas da equipe de projeto, objetos da produção e técnicas/ferramentas que serão utilizadas durante todo o processo. Isso demonstra o envolvimento adiantado de todas as 
partes nas decisões e escolhas de soluções para o empreendimento. Este adiantamento das participações gera uma concentração de informações nas etapas preliminares do empreendimento, prevenindo a ocorrência de retrabalho com diretrizes comuns de desenvolvimento de seus serviços.

$\mathrm{Na}$ Figura 15, estão representadas as principais etapas do processo tradicional de produção de empreendimentos, conforme identificadas pelo AIA no mercado da construção civil americana, e uma leitura da sua equivalência no mercado brasileiro, com as devidas adequações, isto é, a etapa de desenvolvimento do projeto é refletida nas etapas de projeto pré-executivo e executivo, e as aprovações estendem-se desde o término do anteprojeto até o início da construção.

Figura 16: Processo de projeto tradicional segundo o AIA e no Brasil

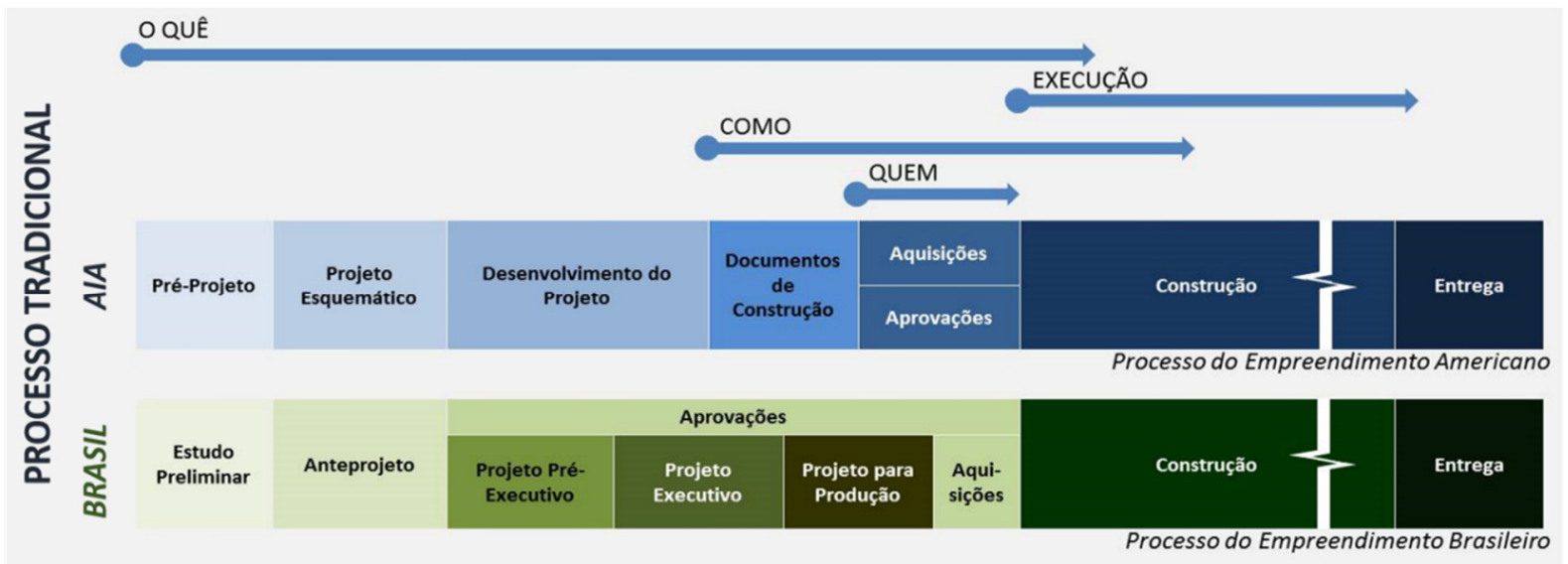

Fonte: Autora.

Figura 17: Diferenças no processo de projeto tradicional e integrado

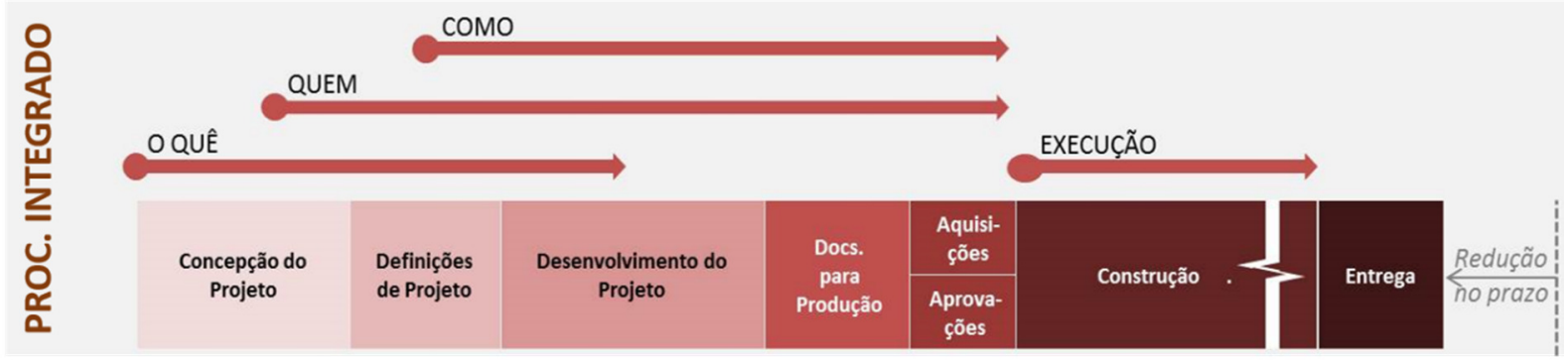

Fonte: Adaptado de AIA California Council (2007). 
Na Figura 16 está representada a abordagem do AIA das fases do projeto integrado, em que se notam (i) a redução do número de etapas, (ii) a antecipação dos agentes e (iii) a redução do prazo total em relação ao processo tradicional.

O mercado americano difere do mercado brasileiro quanto às suas fases de projeto. As etapas iniciais previstas pelo mercado americano, "Estudo Preliminar" e "Projeto Esquemático" são mais densas e contêm mais informações sobre o produto do que as duas primeiras fases do processo de projeto brasileiro "Estudo Preliminar" e "Anteprojeto".

Segundo o documento do AIA, "Best Practices" (2007), ao término dessas duas primeiras etapas de projeto já é possível extrair informações mais precisas sobre o custo de construção e indicadores confiáveis sobre as metas desse empreendimento. Em parte, isto se deve ao modelo de padronização dos processos, documentos, inclusive materiais disponíveis para o mercado americano e utilizados na cadeia construtiva da construção civil, o que permite uma maior assertividade nas informações associadas aos projetos, ainda nas suas primeiras etapas.

Hammarlund e Josephson (1991) evidenciaram, por meio do desenho de uma curva, ao longo das fases de um empreendimento da construção civil, a possibilidade de tomadas de decisão e interferência dos agentes do processo do empreendimento, em relação ao custo acumulado de produção em cada uma das fases do ciclo de vida da edificação.

Observa-se, na Figura 17, que as modificações de decisões e o custo de produção avançam em razão inversa, e que as primeiras fases são as mais propícias a modificações a baixos custos. 
Figura 18: A chance de reduzir o custo de falhas do edifício em relação ao avanço do empreendimento

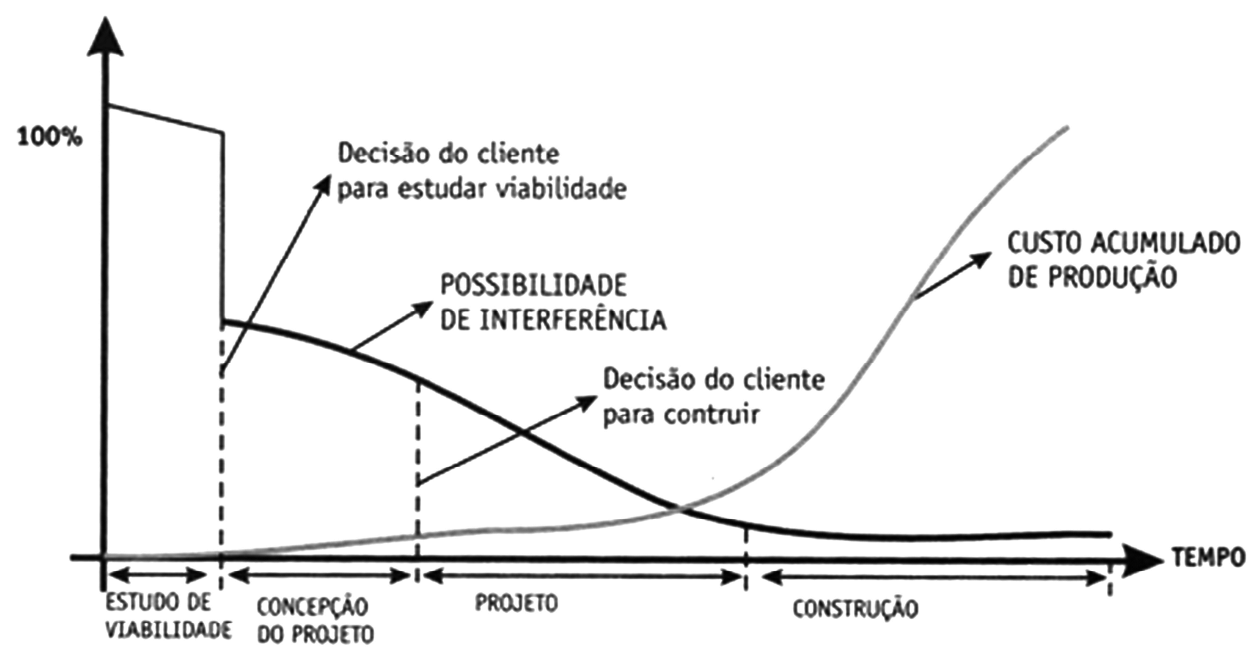

Fonte: Adaptado de Hammarlund e Josephson (1991)

\subsubsection{Determinação dos produtos do processo de projeto por etapa do empreendimento}

O alcance das expectativas entre as partes contratuais de um projeto depende da clareza na identificação da constituição do produto final e produtos secundários.

No caso de empreendimentos da construção civil, é essencial a determinação do escopo dos projetos e das características construtivas do empreendimento, assim como dos aspectos de qualidade e desempenho esperados. Para isso, a caracterização dos produtos e das etapas do projeto deve ser feita nos contratos, sejam eles relacionais ou tradicionais, nos itens "objeto" e "escopo de serviços".

No documento "Integrated Project Delivery: a Work Definition" (2007), o AIA sugere etapas para empreendimentos que utilizem a metodologia de Projeto Integrado, e determina o envolvimento antecipado dos participantes (Figura 15). Nesse mesmo documento, são identificadas as principais atividades das etapas do empreendimento, e a relação dessas atividades com os aspectos colaborativos do processo de projeto. 
As etapas do empreendimento, conforme identificadas pelo AIA (2007) e suas principais atividades e características, estão descritas na Tabela 6.

Tabela 6: Etapas de Empreendimentos Integrados e suas atividades

\section{Etapa do Empreendimento \\ Atividades}

Envolvimento das partes interessadas no desenvolvimento do Programa de usos e necessidades do empreendimento, com objetivo de obter o maior número de contribuições possível.

Identificação das tecnologias que serão utilizadas para o desenvolvimento do empreendimento, como o uso da Modelagem da informação da construção, e iniciar a determinação de parâmetros (interoperabilidade, nível de detalhe e fluxo de informações) e objetivos de utilização das mesmas.

Concepção do Empreendimento

Desenvolvimento da estrutura orçamentária detalhada do projeto (no mínimo por sistema construtivo). A estrutura orçamentária deve ser utilizada como estrutura de construção do modelo do empreendimento (itens representados por vistas), permitindo avaliações rápidas das decisões de projeto.

Determinação das metas de desempenho do empreendimento e a métrica a ser utilizada para sua aferição.

Desenvolvimento do cronograma preliminar do empreendimento e sua associação com o modelo em desenvolvimento.

Tomada de decisões, tendo em vista os resultados do empreendimento como um todo.

Definições de

Projeto

Modelo do empreendimento diretamente vinculado ao modelo de custos.

(etapa de seleção tecnológica, avaliação e teste de diferentes soluções de projeto e cenários no ambiente da modelagem)

Definições finais do escopo técnico e custo. Os clientes ou incorporadora validam essas definições, permitindo desenvolvimento e otimização do projeto pela equipe a partir das diretrizes determinadas.

Desenvolvimento do cronograma de atividades do projeto. $O$ cronograma tem um grau de confiabilidade alto em função do comprometimento gerado pela abordagem colaborativa na sua elaboração, que envolve todos os agentes. 
Identificação antecipada de aspectos de desempenho inadequado do empreendimento, garantindo a sua revisão antes da evolução para a próxima etapa. A atribuição de responsabilidade pelo não atendimento a critérios de desempenho estabelecidos é dificultada pela participação conjunta de diversos agentes na definição das soluções de projeto.

Determinação da tolerância e variações apropriadas ao processo de pré-fabricação.

Detalhamento de Projeto

(etapa de definição e detalhamento das soluções de projeto)
Conclusão do desenvolvimento do projeto e produto que, ao final desta etapa, se apresentam completamente coordenados e validados.

Preveem-se mais horas dedicadas a esta fase do Projeto Integrado do que para a sua correspondente no processo tradicional (detalhamento do projeto ou projeto executivo). Isto se deve ao grande volume de informações e ao processo colaborativo entre os agentes, que contribuem intensamente neste momento para solucionar completamente as inconsistências e interferências do projeto.

Detalhamento de todos os sistemas do edifício, incluindo mobiliário, iluminação e equipamentos.

Participação dos empreiteiros terceirizados e subcontratados no detalhamento das soluções e na coordenação e compatibilização do projeto.

Determinação dos padrões de qualidade previstos.

Desenvolvimento das especificações de projeto e memoriais descritivos dos sistemas.

A duração dessa etapa é significativamente reduzida pela definição e pelo detalhamento completo do projeto e produto.

O objetivo da etapa de documentação para produção é produzir

Documentação para Produção documentos que orientem a maneira como o projeto deverá ser utilizado na construção do edifício, e não gerar qualquer modificação no projeto existente.

Com a utilização da Modelagem de informações da construção, a fase de produção de projetos e desenhos para fabricação é substancialmente reduzida ou completamente eliminada. O modelo 


\section{Atividades}

existente da edificação será preparado para utilização direta pelas empresas de pré-fabricados.

A produção de elementos pré-fabricados pode ser iniciada, desde que garantida a consistência das informações do modelo.

O planejamento da etapa de construção pode ser ensaiado por meio do uso da Modelagem da informação da construção 4D.

Os custos detalhados da construção são finalizados por meio do uso da Modelagem da informação da construção 5D.

São produzidos memoriais descritivos detalhados dos documentos de projeto, para os fins necessários.

A etapa de documentação para produção gera informações para os seguintes processos do empreendimento: (a) Aquisições, (b) Montagem, (c) Logística e traçado de canteiro, (d) Cronograma detalhado de produção, (e) Comissionamento, (f) Requisitos Legais (aprovações legais junto ao Governo e outros organismos).

Utilização do modelo do edifício para análises de aprovação e certificações do empreendimento, por meio de processamento e checagem automática de parâmetros do modelo.

Órgãos técnicos públicos, Instituições financeiras e Organismos de Certificação
Envolvimento das equipes de construção e aquisições na elaboração de respostas e comentários solicitados pelas agencias e organismos certificadores.

Esta fase é iniciada desde a etapa de Definições de Projeto, sendo, porém, intensificada no momento anterior ao início da construção.

Todas as aquisições do empreendimento podem ser iniciadas ao término do detalhamento do projeto (antecipadamente se comparada à sua correspondente no processo tradicional).

Aquisições

Negociação das aquisições com fornecedores externos à equipe do Projeto Integrado. $O$ detalhamento dos custos permite melhores condições de negociação para a equipe do Projeto Integrado.

O modelo de informações da construção tem consistência suficiente para permitir licitações e aquisição contendo uma definição quantitativa 


\section{Atividades}

do elemento ou material a ser adquirido.

O envolvimento de uma empresa construtora no processo do Projeto Integrado, desde suas etapas preliminares, prevê a construção do edifício por essa empresa.

Redução da necessidade de resolução de interferências no canteiro de obra, em função da sua resolução prévia no ambiente virtual do modelo.

Menor número de interfaces e subcontratos, dado o envolvimento dos fornecedores nas etapas anteriores do projeto integrado.

Redução do período dedicado às atividades de planejamento de canteiro, gestão de resíduos e outras atividade relacionadas à logística da obra e dos profissionais, uma vez que já foram estudadas e definidas, previamente, no ambiente virtual do modelo.

Melhor compreensão do projeto do edifício e maior consistência nas informações para construção, a partir do modelo.

Ampliação no uso de pré-fabricados, permitida pela utilização da Modelagem da informação da construção e envolvimento antecipado desses fornecedores no processo.

Construção

Redução de perdas em função do aumento da pré-fabricação de elementos da construção.

Redução de acidentes de trabalho, uma vez que o ambiente do canteiro é controlado a partir do planejamento no ambiente virtual do modelo de construção.

Ajustes no modelo do edifício a partir das condições observadas na construção (as built).

Planejamento e controle do cronograma da produção associado a um modelo da etapa da construção do edifício (modelagem 4D), permitindo a avaliação de desvios e tomada de decisões, a partir da observação das projeções do modelo.

Possibilidade de associação de informações de garantia e de operação de elementos da construção no modelo. 
Disponibilização de um modelo completo da edificação para o cliente e/ou usuário final, para fins de manutenção e operação.

Entrega

Utilização do modelo BIM para os sistemas operacionais do edifício e gestão de ativos (modelagem 6D).

Utilização do modelo para comparar o desempenho previsto da edificação com o desempenho real observado.

\section{Fonte: Adaptado de AIA (2007)}

O controle do atendimento ao escopo e prazos de projeto deve ser realizado pela equipe de coordenação do empreendimento, com a utilização de ferramentas como checklists de informações de projeto, softwares de compatibilização, planejamento de curto prazo, cronograma geral dos projetos e análises periódicas de desempenho da equipe. Tais ferramentas, se utilizadas de forma preventiva, podem ajudar a redirecionar a equipe de projetos quanto aos seus objetivos, antes mesmo que se esboce uma situação de perda (de qualidade ou prazo).

No caso de projetos em modelagem da informação da construção, a equipe do IPD deve definir diretrizes sobre o desenvolvimento do modelo, sua verificação e análise, objetivos de utilização do modelo, e ainda determinar como ocorrerá a troca de informações entre os diversos modelos gerados e os participantes do projeto.

Sem essas diretrizes, a equipe irá trabalhar de forma divergente, e o modelo gerado poderá ser utilizado de forma errônea ou para fins que diferem dos objetivos do projeto como um todo. As definições da estrutura do trabalho de modelagem da informação da construção e características do produto final serão detalhadas pela definição dos usos do modelo e pelo nível de detalhe a ser alcançado em cada etapa de projeto. 


\subsubsection{Nível de desenvolvimento do projeto}

O desenvolvimento de projetos com o uso da modelagem da informação da construção demandou uma nova estrutura conceitual para a coordenação das informações no modelo do edifício (BEDRICK, 2008).

Essa estrutura conceitual deverá ser adequada aos usos previstos para o modelo do edifício, e deverá especificar a precisão das informações representadas no modelo, requeridas em cada etapa do empreendimento e realizada por agentes fornecedores de softwares para modelagem da informação da construção, com o objetivo de determinar as especificações da progressão do modelo (VICO, 2012).

O tema foi discutido no AIA, pelo grupo de trabalho do IPD (AIA California Council's Integrated Project Delivery (IPD) Task Force), que desenvolveu os níveis de detalhe das informações com o auxílio de representantes dos diversos agentes da cadeia produtiva da construção civil. O resultado desse trabalho foi incorporado pelo AIA, como parte de seus documentos contratuais, e publicado no documento "AIA E2022008: Building Information Modeling Protocol Exhibit”.

Nesse documento, o LOD é tratado como Nível de Desenvolvimento do Modelo, e determina cinco diferentes categorias de informações a serem apresentadas no modelo, por fase. Os níveis de desenvolvimento dos modelos conforme o AIA (2008) estão descritos na Tabela 7.

Tabela 7: Níveis de Desenvolvimento do Modelo segundo o AIA

\begin{tabular}{|c|c|c|c|c|}
\hline & $\begin{array}{l}\text { Conteúdo } \\
\text { requerido no } \\
\text { modelo }\end{array}$ & Usos autorizados & $\begin{array}{l}\text { Estimativa de } \\
\text { custos }\end{array}$ & Cronograma \\
\hline $\begin{array}{l}\text { LOD } \\
100\end{array}$ & $\begin{array}{c}\text { Estudo de massas } \\
\text { do edifício } \\
\text { contendo áreas, } \\
\text { alturas, volumes, } \\
\text { localização e } \\
\text { orientação do(s) } \\
\text { edifício(s) } \\
\text { (representados em } \\
\text { 3D ou de outras }\end{array}$ & $\begin{array}{c}\text { Análise das } \\
\text { informações de } \\
\text { áreas, alturas, } \\
\text { volumes, locação } \\
\text { e orientação do(s) } \\
\text { edifício(s) }\end{array}$ & $\begin{array}{l}\text { O modelo pode } \\
\text { ser utilizado para } \\
\text { gerar uma } \\
\text { estimativa de } \\
\text { custos baseada } \\
\text { em áreas, } \\
\text { volumes, ou outra } \\
\text { técnica conceitual } \\
\text { de estimativa de }\end{array}$ & $\begin{array}{c}\text { O modelo pode } \\
\text { ser utilizado para } \\
\text { projeção das fases } \\
\text { do } \\
\text { empreendimento }\end{array}$ \\
\hline
\end{tabular}




\begin{tabular}{|c|c|c|c|c|}
\hline & $\begin{array}{l}\text { Conteúdo } \\
\text { requerido no } \\
\text { modelo }\end{array}$ & Usos autorizados & $\begin{array}{l}\text { Estimativa de } \\
\text { custos }\end{array}$ & Cronograma \\
\hline & formas) & & custos. & \\
\hline $\begin{array}{l}\text { LOD } \\
200\end{array}$ & $\begin{array}{l}\text { Modelagem dos } \\
\text { sistemas do } \\
\text { edifício com } \\
\text { quantidades, } \\
\text { tamanho, forma, } \\
\text { localização e } \\
\text { orientação } \\
\text { aproximadas } \\
\text { Podem incluir } \\
\text { informações não } \\
\text { geométricas ao } \\
\text { modelo. }\end{array}$ & $\begin{array}{l}\text { Análises dos } \\
\text { sistemas } \\
\text { modelados. }\end{array}$ & $\begin{array}{c}\text { O modelo pode } \\
\text { ser utilizado para } \\
\text { gerar uma } \\
\text { estimativa de } \\
\text { custos baseada } \\
\text { nas informações e } \\
\text { sistemas } \\
\text { modelados } \\
\text { associados com } \\
\text { técnicas } \\
\text { conceituais de } \\
\text { estimativas de } \\
\text { custos. }\end{array}$ & $\begin{array}{l}\text { O modelo pode } \\
\text { ser utilizado para } \\
\text { demonstrar em } \\
\text { uma escala de } \\
\text { tempo os sistemas } \\
\text { construtivos } \\
\text { modelados. }\end{array}$ \\
\hline $\begin{array}{c}\text { LOD } \\
300\end{array}$ & $\begin{array}{l}\text { Modelagem dos } \\
\text { sistemas e } \\
\text { elementos do } \\
\text { edifício com } \\
\text { quantidades, } \\
\text { tamanho, forma, } \\
\text { localização e } \\
\text { orientação } \\
\text { precisas. Podem } \\
\text { incluir informações } \\
\text { não geométricas } \\
\text { ao modelo. }\end{array}$ & $\begin{array}{l}\text { Análises dos } \\
\text { sistemas e } \\
\text { elementos } \\
\text { modelados e } \\
\text { extração de } \\
\text { documentação } \\
\text { para produção. }\end{array}$ & $\begin{array}{c}\text { O modelo pode } \\
\text { ser utilizado para } \\
\text { gerar uma } \\
\text { estimativa de } \\
\text { custo baseada nas } \\
\text { informações } \\
\text { modeladas ou com } \\
\text { técnicas } \\
\text { conceituais de } \\
\text { estimativas de } \\
\text { custos. }\end{array}$ & $\begin{array}{l}\text { O modelo pode } \\
\text { ser utilizado para } \\
\text { demonstrar em } \\
\text { uma escala de } \\
\text { tempo os } \\
\text { elementos e } \\
\text { sistemas } \\
\text { construtivos } \\
\text { detalhados. }\end{array}$ \\
\hline $\begin{array}{l}\text { LOD } \\
400\end{array}$ & $\begin{array}{l}\text { Modelagem dos } \\
\text { sistemas e } \\
\text { elementos com } \\
\text { quantidades, } \\
\text { tamanho, forma, } \\
\text { localização e } \\
\text { orientação } \\
\text { precisos, além de } \\
\text { informações } \\
\text { detalhadas e } \\
\text { orientações para } \\
\text { fabricação. Podem } \\
\text { incluir informações } \\
\text { não geométricas } \\
\text { ao modelo. }\end{array}$ & $\begin{array}{l}\text { Construção: o } \\
\text { modelo é uma } \\
\text { representação } \\
\text { virtual da proposta } \\
\text { de construção. } \\
\text { Análises dos } \\
\text { sistemas e } \\
\text { elementos } \\
\text { modelados. }\end{array}$ & $\begin{array}{l}\text { Os custos são } \\
\text { baseados no custo } \\
\text { real dos elementos } \\
\text { construtivos. }\end{array}$ & $\begin{array}{l}\text { O modelo pode } \\
\text { ser utilizado para } \\
\text { demonstrar em } \\
\text { uma escala de } \\
\text { tempo os } \\
\text { elementos e } \\
\text { sistemas } \\
\text { construtivos } \\
\text { detalhados, } \\
\text { incluindo métodos } \\
\text { construtivos e a } \\
\text { logística da } \\
\text { produção. }\end{array}$ \\
\hline
\end{tabular}


Conteúdo

requerido no modelo

Usos autorizados

Estimativa de

custos
Cronograma

\begin{tabular}{|c|c|c|c|c|}
\hline $\begin{array}{c}\text { LOD } \\
500\end{array}$ & $\begin{array}{l}\text { Os elementos do } \\
\text { modelo estão em } \\
\text { acordo e precisão } \\
\text { com o edifício } \\
\text { construído quanto } \\
\text { a tamanho, forma, } \\
\text { localização, } \\
\text { quantidade e } \\
\text { orientação. Podem } \\
\text { existir informações } \\
\text { não geométricas } \\
\text { vinculadas aos } \\
\text { elementos do } \\
\text { modelo. }\end{array}$ & $\begin{array}{l}\text { O modelo pode } \\
\text { ser utilizado para } \\
\text { manutenção, } \\
\text { alterações e } \\
\text { reformas do } \\
\text { edifício ou } \\
\text { empreendimento, } \\
\text { porém somente } \\
\text { dentro das } \\
\text { especificações dos } \\
\text { acordos e licenças } \\
\text { de utilização do } \\
\text { modelo, cedidas } \\
\text { ao cliente ou } \\
\text { usuário final. }\end{array}$ & - & - \\
\hline
\end{tabular}

Fonte: AIA (2008)

Os níveis de desenvolvimento do modelo descritos pelo AIA são aplicados a todas as disciplinas e especialidades de projeto e soluções do empreendimento. Para cada disciplina são desenvolvidas tabelas especificas, relacionando elementos construtivos e informações referentes àquela especialidade, aplicando-se a eles o nível de detalhe previsto no nível de desenvolvimento do modelo a cada fase.

Além das informações referentes à representação digital em três dimensões espaciais, dimensão dos custos (4D), do planejamento da construção (5D) e da gestão de patrimônio (6D), há a necessidade de se determinar quem são os agentes responsáveis pela entrada de cada uma das informações no modelo (BEDRICK, 2008).

Segundo Bedrick (2008), a responsabilidade da inserção de informações ao modelo é compartilhada entre muitos agentes, como na modelagem de uma parede de gesso acartonado em que as informações da geometria da mesma são determinadas pela arquitetura, os custos pela construtora e os materiais para atender critérios de isolamento térmico e acústico pelos projetistas de instalações ou, ainda, por consultores específicos, criando diversas entradas de informação vindas de diferentes agentes para um único componente do modelo. 
Para ordenar essas entradas de informações, o AIA desenvolveu um documento para definir os autores dos componentes do modelo, que especifica quem é o agente responsável pela criação do elemento no modelo virtual, o qual, porém, não necessariamente, será o único responsável pelas informações referentes ao elemento modelado (BEDRICK, 2008).

Em um projeto tradicional, a responsabilidade pela modelagem de elementos específicos é normalmente associada ao principal agente da etapa construtiva (p.ex.: o arquiteto nas etapas de projeto, a construtora na etapa de construção), porém, em projetos em IPD, a participação simultânea e o compartilhamento nas definições de solução do modelo geram transferências quanto à responsabilidade de modelagem dos elementos.

\subsection{PROJETO INTEGRADO E MODELAGEM DA INFORMAÇÃO DA CONSTRUÇÃO}

Segundo o IPD Guide (2007), o uso da modelagem da informação da construção como uma ferramenta de banco de dados das informações de projeto é uma das ferramentas mais importantes para o suporte ao IPD, pois, além de ser capaz de combinar informações sobre todas as etapas do empreendimento - projeto, fabricação, logística de construção e uso em um único modelo e banco de dados - o processo de trabalho em modelagem da informação da construção permite o uso de plataformas colaborativas para o desenvolvimento das soluções do empreendimento.

As características colaborativas e de suporte ao processo simultâneo de trabalho e interação de todos os envolvidos no processo da modelagem da informação da construção são coerentes com o incentivo à colaboração, próprio de projetos relacionais, em especial do IPD. Sem a modalidade contratual adequada, os projetistas, construtores e demais envolvidos, ainda que trabalhando em modelagem, podem não ter a postura necessária para explorar o seu potencial 
colaborativo enquanto plataforma de desenvolvimento do empreendimento, minimizando os resultados do projeto.

Além da colaboração, a modelagem da informação da construção apresenta-se adequada ao IPD, por ser uma fonte de dados precisos do projeto e sua evolução, podendo fornecer uma atualização constante das soluções em desenvolvimento, em relação aos objetivos do projeto, seja em relação aos custos ou ao desempenho da edificação, que pode ser simulado por meio de softwares acessórios aos de modelagem.

Essa antecipação retroalimenta o processo de desenvolvimento do projeto, levando as equipes a redirecionarem seu trabalho para aumentar as chances de alcançar os objetivos definidos em conjunto com o cliente, e garantir o compartilhamento de resultados positivos.

Associada ao IPD, a modelagem da informação da construção como ferramenta de projetos é potencializada, e o IPD associado à modelagem tem um banco de dados preciso e confiável para a gestão do contrato e do projeto. Para tanto, as diretrizes de desenvolvimento do projeto e do produto devem ser definidas e acordadas entre as partes, assim como a métrica do trabalho produzido prevista pelo contrato Integrado.

Quanto à interoperabilidade do projeto em modelagem, deve-se optar, sempre que possível por softwares abertos ou que suportem todos os formatos utilizados pela equipe, de forma a fomentar a comunicação e colaboração entre os membros da equipe do IPD.

\subsubsection{O modelo como documento contratual}

O modelo - produto da modelagem da informação da construção - pode ser definido como documento de contrato, uma vez que contém informações sobre o produto e serviços desenvolvidos, e é a base de dados utilizada para monitorar os aspectos produtivos e de custos do IPD. Para tanto, devem ser definidos protocolos relacionados à sua utilização específica como documento contratual; por exemplo, 
se o objetivo é o registro e acompanhamento dos custos do projeto, devem-se determinar critérios para a criação e registro dos custos e a sua associação paramétrica ao modelo, assim como também se devem estabelecer os métodos de extração e troca das informações de custo do modelo (AIA, 2007).

Todas as definições sobre utilização do modelo e protocolos para gestão da informação devem ser decisões conjuntas da equipe do IPD, documentadas e disponibilizadas para todos os membros da equipe, de forma a garantir a consistência do modelo durante o processo de projeto.

\subsection{PROJETO INTEGRADO E CONSTRUÇÃO ENXUTA}

O IPD, assim como a construção enxuta, procura melhorar o desempenho do processo de projeto com a aplicação de metodologias de trabalho integrado que reduzem os desperdícios e alcançam melhores resultados do projeto como um todo.

O foco de ambos no sistema produtivo do empreendimento acrescenta valor ao processo uma vez que determina práticas abertas de envolvimento dos agentes da equipe em estruturas organizacionais e comerciais que dão suporte à gestão dos empreendimentos, por meio de contratos relacionais. Essa abordagem é coerente com a otimização do todo - e não das partes do projeto - que aponta para o principal objetivo do cliente/contratante, o de maximizar o valor do empreendimento com o menor custo e prazo possíveis $(\mathrm{LCl}, 2010)$.

Há, também, um alinhamento entre o entendimento quanto ao gerenciamento de riscos em ambas as abordagens, do IPD e da Construção Enxuta. Em contratos tradicionais, a gestão dos riscos é realizada pela sua locação nos contratos das equipes de projetos e construtoras, enquanto na abordagem relacional os riscos são compartilhados pelas partes do contrato, que desenvolvem estratégias coletivas para o seu gerenciamento e solução.

Em processos tradicionais, é comum observar-se imprevisibilidade no fluxo de trabalho, consequência da relação divergente entre o comando e o controle das 
operações de produção e o planejamento do empreendimento. Como exemplo prático da abordagem relacional dos riscos na construção enxuta, podemos citar o uso do Last Planner System ${ }^{\circledR}$ ou Porcentagem do Plano Concluído (PPC) como ferramenta de redução de riscos, adequado para a gestão de contratos em IPD.

Esse sistema define as tarefas num período semanal, garantindo a distribuição das atividades que devem ser geradas por todos, para o andamento simultâneo e concorrente dos diversos projetos e serviços. Permite, também, uma avaliação do andamento do processo por meio do índice da porcentagem concluída das atividades e identificação das causas do não cumprimento delas, levando a uma avaliação mais profunda dos pontos críticos ou participantes, cujo comprometimento está aquém, em relação aos demais membros da equipe.

Segundo o Lean Construction Institute (2010), os resultados observados em projetos gerenciados com o uso do PPC são extremamente positivos quanto à redução de prazos e custos do projeto. Além da abordagem direta dos benefícios alcançados com o uso dessa ferramenta, ele documenta que o resultado de projetos com esse modelo gerencial conduz à geração de equipes em que há confiança entre as partes, levando-as a buscar reforçar essa parceria em novos projetos.

\subsection{ESTUDOS DE CASO DE PROJETO INTEGRADO DOCUMENTADOS PELO AIA}

Cohen (2010) produziu um relatório para o AIA, documentando os estudos de caso de IPD identificados entre os usuários que acessaram o site do AIA e realizaram download do IPD Guide (2007). Em março de 2012, a partir de uma iniciativa da Universidade do Minnesota, foi dada continuidade ao trabalho de pesquisa com os estudos de caso já identificados e mais seis novos casos.

O desenvolvimento do estudo publicado em 2012 apresenta uma variedade maior de estudos de caso. São apresentados empreendimentos de diferentes escalas, tipologias, locais e equipes de diferentes tamanhos, composições e graus diferentes de experiência em IPD. 
Também é inédito nesse estudo o acompanhamento de empreendimentos desde as primeiras etapas de projeto até a sua entrega final e um mapeamento das ocorrências de Projeto Integrado, identificadas em um mapa dos Estados Unidos, com os dados da tipologia do empreendimento, área, custo e sua localização.

O relatório de 2012 demonstra, a partir dos estudos de caso, que a implementação do IPD é adaptada, particularmente, para cada um dos empreendimentos em que se aplica, e que a sua metodologia utiliza diversas estratégias para a geração de resultados e alta performance no trabalho colaborativo da equipe, os quais não podem ser alcançados pela simples aplicação de uma estrutura contratual e fórmulas de gestão (AIA, 2012). As estratégias e os recursos utilizados em cada um dos projetos foram comparados para avaliar o seu impacto nos resultados do empreendimento.

Apesar de o modelo contratual proposto pelo IPD ser novo, se comparado aos modelos tradicionais, foram observados resultados impactantes em equipes que já haviam tido experiências em contratos de IPD, ou, ao menos já tivessem participado conjuntamente em outros projetos.

Quanto à utilização dos modelos contratuais padrões do AIA para Projeto Integrado, o relatório aponta que poucos foram os casos que utilizaram os documentos sem modificá-los, e que as modificações mais usuais apontavam para a eliminação das cláusulas referentes ao compartilhamento das responsabilidade, riscos e benefícios.

Para avaliação dos estudos de caso, os princípios contratuais de Projeto Integrado identificados pelo AIA (2007) foram reavaliados em Marcos (características únicas de Projetos Integrados) e Estratégias (referindo-se aos métodos e estratégias utilizadas para dar suporte aos processos colaborativos do IPD). São eles:

Marcos de Projetos Integrados:

- Contratos Relacionais

- Proteção contra processos

- Alinhamento dos objetivos e metas do empreendimento (critérios desenvolvidos conjuntamente pelos membros da equipe). 
- Processo colaborativo de tomada de decisões

- Comunicação aberta

- Identificação e gestão antecipada dos riscos

Estratégias para Projetos Integrados:

- Igualdade na condição de participação dos principais agentes (acordos multilaterais)

- Envolvimento antecipado dos principais agentes e especialistas

- Relações pré-existentes entre os membros da equipe do Projeto Integrado

- Múltiplas lideranças

- Compartilhamento dos resultados financeiros

- Responsabilidade compartilhada entre os principais agentes

- Transparência contábil e fiscal por todos os participantes

- Utilização do modelo para suporte ao processo e simulações

- Utilização de processos lean

- Compartilhamento de espaço físico de produção (concentração física dos participantes em um mesmo ambiente de trabalho).

Dentre os principais motivos para utilização do IPD, o relatório do AIA (2012) destaca os seguintes:

- Vantagem Mercadológica: as empresas que utilizam IPD podem ser consideradas inovadoras na sua prática relacional. A apresentação de resultados positivos provenientes dessa inovação também é considerada uma vantagem mercadológica.

- Previsibilidade dos Custos

- Previsibilidade no Prazo 
- Gestão de Riscos: pode ser associada à previsibilidade de custos e prazo típicos do IPD. Os princípios de comunicação aberta do Projeto Integrado também são apresentados como vantajosos para a gestão dos riscos do empreendimento.

- Complexidade Técnica: o alto grau de complexidade técnica geralmente demanda níveis mais altos de integração, especialização e coordenação da equipe, facilitados pelas características do Projeto Integrado.

O relatório comenta que as táticas e características identificadas como vantajosas podem não ser exclusivas do IPD; porém para empreendimentos que buscam um ou mais itens entre os listados, a escolha pelo Projeto Integrado apresenta-se mais interessante. Além disso, os aspectos de colaboração e integração são incitados pela estrutura do contrato relacional.

Outros resultados foram registrados pelo relatório nos estudos de caso de Projeto Integrado:

- Sobre os princípios contratuais do IPD em acordos multilaterais: as características de compartilhamento da responsabilidade, riscos e benefícios e a transparência contábil e fiscal têm efeito positivo na equipe quanto ao desenvolvimento de respeito e confiança em seus parceiros.

- Uso de sistemas lean: apesar da utilização de princípios da construção enxuta ser considerada facilitadora no compartilhamento de informações e na eficiência geral de empreendimentos, não foi observada relação entre 0 seu uso e 0 desenvolvimento de relações positivas de respeito entre os participantes do contrato.

- A locação dos participantes no mesmo ambiente de trabalho é identificada como um dos aspectos mais positivos na melhoria da comunicação e integração pela maior parte dos participantes dos estudos de caso; porém, com o acompanhamento do desenvolvimento dos projetos, os participantes não perceberam real impacto ou efeito da locação na interação entre os agentes.

- A percepção da metodologia de desenvolvimento colaborativo do empreendimento teve avaliação positiva por todos os agentes envolvidos, embora em diferentes níveis; as construtoras e gerenciadoras atribuíram alto valor positivo à colaboração, 
enquanto os projetistas a avaliaram somente como regular, mas todos associaram a colaboração à melhoria na qualidade dos projetos. Nesse quesito, os arquitetos foram os que avaliaram esse efeito com menor impacto; os demais 


\section{QUESTIONÁRIOS ESTRUTURADOS DE AVALIAÇÃO DO MERCADO BRASILEIRO QUANTO À MODELAGEM DA INFORMAÇÃO DA CONSTRUÇÃO E AO CONTRATO DE PROJETO INTEGRADO}

Neste capítulo, serão apresentados os resultados de dois questionários estruturados sobre a implementação da modelagem da informação da construção e sobre a utilização de contratos integrados para serviços da construção civil. Ambos os questionários foram aplicados em eventos relacionados com os temas de gestão de projetos, tecnologia da informação na construção e modelagem da informação da construção.

O primeiro questionário, versando sobre modelos colaborativos de contratação de projetos, foi aplicado aos participantes do IV Seminário sobre Soluções de Gestão para Empresas de Projeto, organizado pelo Departamento de Engenharia de Construção Civil da Escola Politécnica da USP, no dia 15 de abril de 2011, no auditório da Faculdade de Arquitetura e Urbanismo da USP, em São Paulo. O evento teve como tema: "Arquitetura e as Novas Demandas - Sustentabilidade, Desempenho e Tecnologia da Informação em Projetos", e como público-alvo empresas prestadoras de serviços de projeto para construção civil. A organização do evento permitiu a aplicação do questionário para fins de pesquisa relacionados a esse trabalho.

O segundo questionário, referente à implementação da modelagem da informação da construção, foi aplicado aos participantes do V Encontro de Tecnologia de Informação e Comunicação na Construção (TIC 2011), realizado nos dias 04 e 05 de agosto de 2011, em Salvador, Bahia cujo tema foi: "BIM - modelando a Construção do futuro". Os resultados foram disponibilizados pela organização do evento e, então, avaliados para compor os dados desta dissertação.

Nos dois eventos, os questionários foram distribuídos ao público para preenchimento manual e entrega às organizações. As questões apresentadas estão relacionadas 
nos anexos 2 e 3 deste trabalho. A análise dos resultados está apresentada neste capítulo.

\subsection{QUESTIONÁRIO SOBRE O ESTÁGIO DOS MÉTODOS CONTRATUAIS DE SERVIÇOS DE PROJETOS PARA CONSTRUÇÃO CIVIL E SOBRE A IMPLEMENTAÇÃO DE MODELOS DE CONTRATO INTEGRADO}

Neste questionário são abordadas questões relacionadas às formas de contratação utilizadas e o entendimento e a percepção dos respondentes, quanto a formas alternativas contratuais que buscam maior integração do projeto.

Foi obtido um total de 20 questionários respondidos. Quanto ao grupo de respondentes, $60 \%$ são contratantes de serviços de projeto, os demais são fornecedores, em sua maioria empresas projetistas.

O evento em que foi aplicado o questionário é produto das discussões do Programa de Desenvolvimento Gerencial de Empresas de Projeto (PDGEP), cujo objetivo é o desenvolvimento de pequenas empresas de projeto, por meio de um modelo de gestão para empresas de projeto, proposto por Oliveira (2005). O PDGEP é, em sua maioria, frequentado por micro e pequenas empresas de projeto e, em alguns casos, também contratantes de projeto (terceirizações).

Foram apresentados exemplos de modelos contratuais do serviço de projeto (periódica, por etapa de projeto, contrato fechado) e $70 \%$ dos respondentes identificaram que praticam contratos associados a entregas de produtos por etapa de projeto - Projeto Básico, Anteprojeto, Projeto Pré-Executivo e Projeto Executivo ou Detalhamento. Identificou-se uma pequena porcentagem (5\%) de respondentes que não utilizam contratos formais, e confiam o acordo profissional somente à aceitação da proposta comercial do prestador de serviços.

Dentre os principais itens abordados nos contratos de fornecimento de projetos, os respondentes identificaram: Escopo de trabalho - 90\%; Definição das etapas de 
projeto a serem entregues - 85\%; Prazo de execução e entrega dos projetos por etapa - 75\%; Padrões e normas a serem utilizados - 70\%; Custo por etapa de projeto e previsão do material a ser produzido (plantas, relatórios, etc.) - 60\%; Visitas à obra e Prazo global do contrato - 50\%. Itens como "Identificação e recolhimento de ART" e "Itens Exclusos" foram identificados por menos de $50 \%$ dos respondentes como parte constante de seus contratos.

Observa-se nos dados dessas duas primeiras questões (sobre as tipologias de contrato e os itens desses contratos) a informalidade no estabelecimento de acordos entre a contratante e a empresa prestadora de serviço, uma vez que não há definições, em uma porcentagem considerável das respostas, de itens essenciais para o controle e acompanhamento do contrato, como a definição de prazo para execução dos serviços contratados. A inexistência de registro ou mesmo falta de clareza nas informações que estabelecem o acordo entre as partes pode levar à insatisfação ou à geração de conflitos pelas partes envolvidas.

Sobre a implementação da modelagem da informação da construção, $10 \%$ das empresas afirmaram já trabalhar com projetos em modelagem da informação da construção, enquanto 60\% afirmaram estar qualificando-se para prestar serviços e contratar serviços de projeto em modelagem, e 30\% não pensava em implementar a modelagem da informação da construção em suas empresas.

Entende-se que, por se tratar de um evento com tema relacionado à modelagem da informação da construção, público e respondentes representam uma parcela de mercado que já possui certo nível de conhecimento sobre o tema. Em alguns poucos casos, conforme se observou pela questão sobre implementação, já estão implementando a modelagem da informação da construção em seus escritórios. Porém, trata-se de um público diferenciado da maioria das empresas do mercado, e os resultados obtidos não podem ser extrapolados para análise.

Sobre modelos de contrato colaborativo, apenas $5 \%$ das empresas estava familiarizada com os modelos já disponibilizados no mercado de contratos conjuntos, como joint ventures. Ao serem apresentados ao conceito de Projeto Integrado e suas principais características, como o compartilhamento de resultados, $80 \%$ dos 
respondentes afirmou reconhecer nesse modelo um bom incentivo para a colaboração entre os participantes e melhores resultados para o empreendimento.

Entende-se que, por se tratar, em sua maioria, de empresas prestadoras de serviço de projeto, os respondentes tendem a reconhecer nos modelos de Projeto Integrado uma oportunidade de redução de retrabalho e melhor compensação pela sua participação no empreendimento.

Considerando-se as empresas projetistas como os agentes mais frágeis dentro da cadeia produtiva do empreendimento, os modelos colaborativos oferecem uma posição mais favorecida nas interfaces com os demais agentes, que passam a compartilhar as perdas de produtividade e o aumento do custo de produção, a partir do modelo de compartilhamento de resultados.

Além disso, a potencialização da colaboração entre projetistas que passam a compartilhar metas de projeto causa a redução das interferências entre os projetos, uma das principais causas de retrabalho em função das revisões de compatibilização.

$70 \%$ afirmaram que aceitariam participar de um contrato de Projeto Integrado, e $80 \%$ entenderam que o modelo é adequado para projetos de Modelagem da Informação da Construção.

Conforme observado anteriormente, é coerente que a maior parte dos respondentes tenha interesse no modelo de contrato colaborativo apresentado no questionário estruturado.

\subsection{QUESTIONÁRIO SOBRE A IMPLEMENTAÇÃO DA MODELAGEM DA INFORMAÇÃO DA CONSTRUÇÃO}

O objetivo do questionário aplicado pelo grupo de pesquisa BIM-BA, do Laboratório de Computação Gráfica Aplicada à Arquitetura e ao Desenho - LCAD da Faculdade de Arquitetura da UFBA, era caracterizar o perfil dos participantes do V Encontro de Tecnologia de Informação e Comunicação na Construção (TIC 2011). Devido ao alto 
número de respondentes, com participação de agentes representantes de diferentes papéis na cadeia produtiva de empreendimentos de construção civil, a análise das respostas cedidas pelos pesquisadores será útil para fazer considerações sobre a implementação da modelagem da informação da construção em empresas de construção civil. O total de respondentes foi de 187.

Como caracterização das áreas de atuação dos respondentes, $42 \%$ fornecem projetos de edificações, $25 \%$ representam empresas construtoras, $23 \%$ fazem gerenciamento de construção, $15 \%$ oferecem serviços de planejamento, $10 \%$ realizam incorporação imobiliária e menos de 10\% realizam serviços de projetos de infraestrutura, operação e manutenção de edificações e desenvolvimento de software.

Também nesse questionário observa-se uma maioria de empresas fornecedoras de projetos, e porcentagem considerável de empresas construtoras e fornecedoras de serviços de planejamento e gerenciamento de obras, todos serviços diretamente beneficiados pelo uso da modelagem da informação da construção. Novamente observa-se que o evento tem como tema a modelagem da informação da construção, e entende-se que o público geral e respondentes têm um conhecimento acima da média de mercado sobre modelagem da informação da construção.

Entre as empresas representadas, 38\% são consideradas grandes empresas (mais de 100 funcionários), 6\% médias empresas (entre 50 e 100 funcionários), 19\% pequenas empresas (entre 11 e 49 funcionários) e 14\% micro empresas (até 10 funcionários). Adotou-se para essa classificação o critério utilizado pela McGraw Hill no relatório de implementação da modelagem da informação da construção nos Estados Unidos e Europa - SmartMarket Report, (2009). Do total de respondentes, $23 \%$ representam instituições de ensino e pesquisa.

Nota-se um grande número de representantes de instituições de ensino e pesquisa, provavelmente em função da natureza acadêmica do evento. Tal informação reforça a observação de que o conhecimento do público do evento está acima da média de mercado, uma vez que a modelagem da informação da construção vem sendo tema de diversas pesquisas nos últimos anos. No evento que mencionamos foram 
apresentados 45 artigos, dos quais 35 eram relacionados à modelagem da informação da construção.

Quanto à modelagem da informação da construção, 28\% dos respondentes afirmaram já prestar serviços em modelagem, e 36\% afirmaram que já haviam realizado treinamento ou participado de cursos de modelagem da informação da construção.

Entre as dificuldades na implementação e no uso da modelagem, os respondentes identificaram os seguintes aspectos, descritos na Tabela 8:

Tabela 8: Elenco de dificuldades de implementação e uso da modelagem da informação da construção

\begin{tabular}{|c|c|c|}
\hline $\begin{array}{c}\text { Grupo de } \\
\text { Semelhantes }\end{array}$ & Dificuldades & Porcentagem \\
\hline Integração & A integração com a equipe de parceiros. & $7 \%$ \\
\hline Interoperabilidade & $\begin{array}{l}\text { A pouca compatibilidade com as ferramentas até então } \\
\text { utilizadas. }\end{array}$ & $11 \%$ \\
\hline Tempo & $\begin{array}{l}\text { O tempo necessário para implantação da tecnologia na } \\
\text { empresa. }\end{array}$ & $11 \%$ \\
\hline \multirow{3}{*}{$\begin{array}{l}\text { Formação e } \\
\text { aprendizado }\end{array}$} & A dificuldade no aprendizado das ferramentas. & $14 \%$ \\
\hline & $\begin{array}{l}\text { Pouco material de aprendizagem: manuais, livros e } \\
\text { bibliografia sobre o tema. }\end{array}$ & $14 \%$ \\
\hline & $\begin{array}{l}\text { Necessidade de formação de mão de obra } \\
\text { especializada. }\end{array}$ & $10 \%$ \\
\hline Custo & O custo elevado da adoção das ferramentas. & $12 \%$ \\
\hline \multirow[t]{2}{*}{$\begin{array}{l}\text { Resistência } \\
\text { mudanças }\end{array}$} & $\begin{array}{l}\text { Resistência da equipe em mudar as metodologias de } \\
\text { trabalho. }\end{array}$ & $9 \%$ \\
\hline & A complexidade da tecnologia. & $13 \%$ \\
\hline
\end{tabular}

Fonte: Dados de resposta dos questionários do V Encontro de Tecnologia de Informação e Comunicação na Construção (TIC 2011)

Para análise dessa questão, as dificuldades sugeridas pelo questionário estruturado foram agrupadas na Tabela 8 com outras de aspectos semelhantes. 
Observa-se que a distribuição das escolhas dos respondentes entre as opões não teve grande variação. Identifica-se, no entanto, que há uma atribuição significativa, no que diz respeito aos grupos relacionados à formação, ao aprendizado e à resistência a mudanças.

Tais aspectos são relacionados a partir da aceitação da hipótese de que não existam profissionais qualificados ou material disponível para a sua formação e treinamento, não havendo, portanto, opção para renovação dos profissionais do mercado. Outro ponto de vista seria avaliar se a afirmação de que não há profissionais atuantes está relacionada à resistência aos aspectos de mudança gerados pela implementação dos novos processos e tecnologias da modelagem.

Quanto aos motivos para a adoção da modelagem da informação da construção, os respondentes selecionaram os itens identificados na Tabela 9: Motivos para adoção da modelagem da informação da construção.

Tabela 9: Motivos para adoção da modelagem da informação da construção

\begin{tabular}{ll}
\hline Motivos para adoção & Porcentagem \\
\hline Para diminuir o prazo de entrega dos projetos. & $50 \%$ \\
\hline Por causa da complexidade dos projetos que desenvolve. & $42 \%$ \\
\hline $\begin{array}{l}\text { Por que a ferramenta BIM permite realizar alterações com } \\
\text { maior facilidade. }\end{array}$ & $69 \%$ \\
\hline Para melhorar a apresentação dos projetos. & $33 \%$ \\
\hline Por demanda do cliente. & $8 \%$ \\
\hline Por esperar maior retorno financeiro. & $23 \%$ \\
\hline
\end{tabular}

Fonte: Dados de resposta dos questionários do V Encontro de Tecnologia de Informação e Comunicação na Construção (TIC 2011)

Os três itens com maior percentual de escolha pelos respondentes são referentes à etapa de projetos do empreendimento. Essas escolhas podem ser associadas à maioria de empresas fornecedoras de projetos e empresas altamente impactadas 
pela qualidade, complexidade e prazo de desenvolvimento dos projetos (construtoras, gerenciadoras e incorporadoras).

As mudanças nos processos observadas pelos respondentes pelo uso da modelagem da informação da construção em suas empresas e o seu impacto foram identificadas conforme apresentado na Tabela 10: Grau de impacto da modelagem da informação da construção nas mudanças dos processos das empresas.

Tabela 10: Grau de impacto da modelagem da informação da construção nas mudanças dos processos das empresas

\section{Grau de Impacto Mudanças nos Processos}

$\begin{array}{ll}5 \text { (mais alto impacto de } & \text { Antecipação de problemas } \\ \text { mudança) } & \text { Visualização dos projetos }\end{array}$

Redução de erros de projeto

Geração de maiores detalhes de projeto

4

Possibilidade de escolha de melhores soluções

de projeto

Maior precisão de orçamento

Aceleração do processo de projeto

Aceleração da construção da edificação

3

Simulações (energéticas e estruturais)

Redução do custo da construção.

Fonte: Dados de resposta dos questionários do V Encontro de Tecnologia de Informação e Comunicação na Construção (TIC 2011)

Foram apresentadas algumas características associadas ao uso da modelagem da informação da construção para que os respondentes identificassem a importância que associam a cada uma delas. As características em sua colocação de importância conforme apontado pelos respondentes são as seguintes: $1^{\circ}$ ) Extração automática de quantitativos e custo, $2^{\mathrm{a}}$ ) Integração direta com aplicativos de custo, $3^{\circ}$ ) Integração direta com aplicativos de gerenciamento, 4ํ) Trabalho colaborativo, 
$\left.5^{\circ}\right)$ Permitir o trabalho multidisciplinar, 6ㅇ) Uso de bibliotecas padronizadas, $7^{\circ}$ ) Produção de projetos em larga escala, $8^{\circ}$ ) Facilidade na simulação energética, $9^{\circ}$ ) Possibilidade de customização do programa, 10ํ) Facilidade de desenvolvimento do

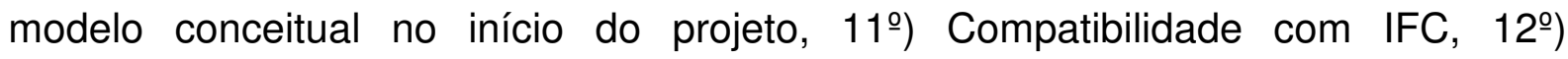
fotorrealismo, e $13^{\circ}$ ) Coordenação e configurações automáticas.

Observa-se, pelas respostas a essa questão, o apontamento para itens que geram redução no prazo total e redução de retrabalho na etapa de projetos $\left(1^{\underline{a}}\right.$ a $3^{\text {a }}$ colocadas). A identificação de vantagem no trabalho colaborativo pode ser interpretada como uma necessidade de melhoria nas interfaces entre os agentes conforme percebidas pelos respondentes, além da percepção da modelagem da informação da construção como oportunidade para reestruturar seus processos e a interação com esses agentes, levando a resultados melhores, em especial aos profissionais fornecedores de projetos.

\subsection{ANÁLISE DOS QUESTIONÁRIOS}

Ambos os questionários foram aplicados em um público selecionado, participante de eventos relacionados à modelagem da informação que o coloca em uma situação privilegiada de acesso ao conhecimento sobre o tema.

Dessa forma, os resultados apresentados sobre a implementação da modelagem da informação da construção podem ser considerados defasados em relação à média de mercado.

Em ambos os casos, a maior parte dos respondentes são fornecedores de projetos, o que transparece na análise dos dados, e direciona os resultados.

De forma geral, a análise dos questionários não permite conclusões definitivas. 
No entanto, pode-se afirmar que, quanto ao estágio de maturidade da implementação da modelagem da informação da construção entre os respondentes, o nível geral é o de Pré-BIM, conforme determinado pelo modelo de Succar (2009)3. Esse nível de implementação é caracterizado por relações adversas entre os agentes, contratos que buscam repassar os riscos do processo e há dependência da documentação em 2D gerada pelo processo tradicional de projeto.

Ainda que ocorra a utilização de informações do modelo em 3D e ele sirva para visualização geral ou extração de dados quantitativos e de especificações, essas informações não são reconhecidas como parte da documentação de projeto, e não estão vinculadas à documentação oficial.

\footnotetext{
${ }^{3}$ Segundo Succar (2009), os níveis de maturidade de Modelagem da Informação da Construção são os seguintes (do menor para o maior): pré BIM, modelagem de objetos, modelagem colaborativa, modelagem integrada e como maior nível, Projeto Integrado (IPD).
} 


\section{ESTUDO DE CASO}

Foi conduzido um estudo de caso em uma empresa incorporadora do mercado brasileiro, com o objetivo de avaliar a aderência e os benefícios dos contratos aplicados entre a contratante (empresa) e suas prestadoras de serviço, em especial projetistas.

Além da empresa contratante, foi realizado estudo com suas prestadoras de serviço de projeto para os empreendimentos em modelagem da informação da construção.

Conforme descrito na metodologia do estudo de caso, avaliaram-se os processos implementados na empresa para os empreendimentos em modelagem da informação da construção e a sua aderência aos contratos praticados.

Após a coleta de dados, foi realizada sua análise e a comparação do modelo contratual praticado por cada uma das empresas-caso com o modelo de IPD proposto pelo AIA (2007), buscando traçar paralelos e contrastes com os contratos observados no estudo de caso, avaliando-se a possibilidade de implementação de modelo semelhante no Brasil, e as principais diferenças no mercado da construção civil entre os dois países que se apresentam como empecilhos para a utilização de Projetos Integrados no Brasil.

\subsection{PERFIL DA EMPRESA}

A empresa estudada é uma empresa de incorporação imobiliária, com foco em desenvolvimento de empreendimentos residenciais e comerciais de alto padrão, shopping centers e hotéis. Para empreendimentos de shopping centers e hotéis, a empresa realiza, paralelamente, a administração como proprietária. Possui, também, participação no ramo de hotelaria de uma rede internacional de hotéis de alto padrão.

Atua há 39 anos no mercado imobiliário brasileiro, e desde a década de 80 está inserida no setor residencial, vindo a desenvolver empreendimentos comerciais e 
shoppings a partir do ano 2000. Em 2007, passou por um processo de abertura de capital e, em 2012, alcançou receita bruta de $R \$ M M 961,2$, lucro bruto de $R \$ M M$ 436,3 e líquido de $\mathrm{R} \$ \mathrm{MM} 184,2$.

A referida empresa recebeu, no ano de 2012, o "Ill Prêmio Pini Incorporadora do Ano". A avaliação é aplicada a empresas de capital aberto e calcula uma matriz de atributos de caráter econômico, financeiro e comportamentais em relação aos funcionários e fornecedores da empresa, relacionamento com Stakeholders e preocupação com a sociedade e o meio ambiente (a seleção de critérios foi realizada em parceria com o núcleo de Real Estate da Escola Politécnica da Universidade de São Paulo).

Além disso, a empresa foi avaliada como a $1^{1 \underline{a}}$ maior empresa em inovação pela revista Época Negócios em 2012, pelas características de aplicação de novas tecnologias e prospecção de mercados diferenciados. Como exemplo de inovação, desde 2011 a empresa estudada vem trabalhando com modelagem da informação da construção no setor de Engenharia Avançada.

A criação do seu setor de engenharia avançada teve por objetivo a operacionalização das metas estratégicas da empresa de desenvolver e implementar: (a) soluções racionalizadas e industrializadas de engenharia e projeto, (b) tecnologias e sistemas construtivos modernos e (c) inovação nos processos e construção sustentável, tendo em vista a redução do ciclo de vida de produção das edificações.

A partir de uma reflexão sobre o panorama do mercado e das oportunidades de atuação do setor de engenharia avançada, a empresa determinou como objetivos a manutenção do foco nas principais tendências do mercado, por meio do acesso e implementação de novas tecnologias, materiais, componentes e sistemas construtivos que promovam diferenciação, ganho de produtividade e racionalização. 


\subsection{ADOÇÃO DA MODELAGEM DA INFORMAÇÃO DA CONSTRUÇÃO}

A modelagem da informação da construção foi escolhida como parte do sistema de gestão e ferramentas da Engenharia avançada, tendo sido incorporada como uma ferramenta de melhoria de negócios, alinhada com os objetivos estratégicos da empresa.

Para a sua execução foram contratados quatro profissionais especialistas em modelagem da informação da construção para constituir o chamado Núcleo BIM da Engenharia Avançada. Esse conjunto de profissionais soma experiências nas áreas de implementação da modelagem da informação da construção em empresas de incorporação imobiliária e construção, desenvolvimento de projetos em modelagem da informação da construção, análise de viabilidade e estimativas orçamentárias a partir de modelos, além de experiência no desenvolvimento de empreendimentos no processo tradicional.

O perfil dos profissionais do núcleo BIM está representado na Tabela 11.

Tabela 11: Perfil dos profissionais do núcleo BIM

Profissional

Função

Principais atividades

Arquiteto

Coordenador de

empreendimentos

Coordenação e desenvolvimento de

produtos para o setor de engenharia

avançada

Relacionamento e desenvolvimento de

produtos e processos de modelagem

para atendimento às demandas do

setor de engenharia avançada 


\begin{tabular}{|c|c|c|c|}
\hline $\begin{array}{l}\text { Engenheiro com formação } \\
\text { em arquitetura e engenharia } \\
\text { Civil pelo programa de } \\
\text { dupla formação POLI-FAU }\end{array}$ & $\begin{array}{l}\text { Coordenador de } \\
\text { projetos em BIM }\end{array}$ & $\begin{array}{l}\text { Desenvolv } \\
\text { modelageı } \\
\text { departame } \\
\text { Contrataçà } \\
\text { prestadore } \\
\text { consultore }\end{array}$ & $\begin{array}{l}\text { imento de projetos em } \\
\text { n (paralelo com o } \\
\text { nto de produto da empresa) } \\
\text { so e relacionamento com } \\
\text { s. }\end{array}$ \\
\hline Arquiteto & $\begin{array}{l}\text { Desenvolvedor de } \\
\text { BIM }\end{array}$ & modelo & $\begin{array}{l}\text { Desenvolvimento de } \\
\text { modelos dos projetos da } \\
\text { empresa para fins de } \\
\text { análise de análise de } \\
\text { viabilidade, extração de } \\
\text { quantitativos, } \\
\text { compatibilização de } \\
\text { projetos e planejamento de } \\
\text { montagem de obras de } \\
\text { elementos pré-fabricados. }\end{array}$ \\
\hline Arquiteto & Especialista BIM & & $\begin{array}{l}\text { Desenho e } \\
\text { desenvolvimento de } \\
\text { processos de modelagem } \\
\text { Desenvolvimento e escolha } \\
\text { de ferramentas e artefatos } \\
\text { para utilização da } \\
\text { modelagem da informação } \\
\text { da construção de acordo } \\
\text { com os objetivos da } \\
\text { empresa } \\
\text { Extração de informações, } \\
\text { geração de relatórios e } \\
\text { demais saídas do modelo. }\end{array}$ \\
\hline
\end{tabular}

Fonte: Estudo de Caso 
Além da formação do Núcleo BIM, em 2012 foi contratada uma consultoria para estruturar a implementação da modelagem da informação da construção a partir da incorporação de ferramentas e desenvolvimento de novos processos alinhados com as metas estratégicas da empresa e seus objetivos com o uso da modelagem da informação da construção.

Segundo a empresa estudada, os principais objetivos para a adoção da modelagem da informação da construção são:

- Aumentar a participação da empresa nos processos do início do ciclo de vida no negócio, nos processos da etapa de análise de viabilidade e concepção (Figura 18),

Figura 19: Fases iniciais do ciclo de vida do negócio

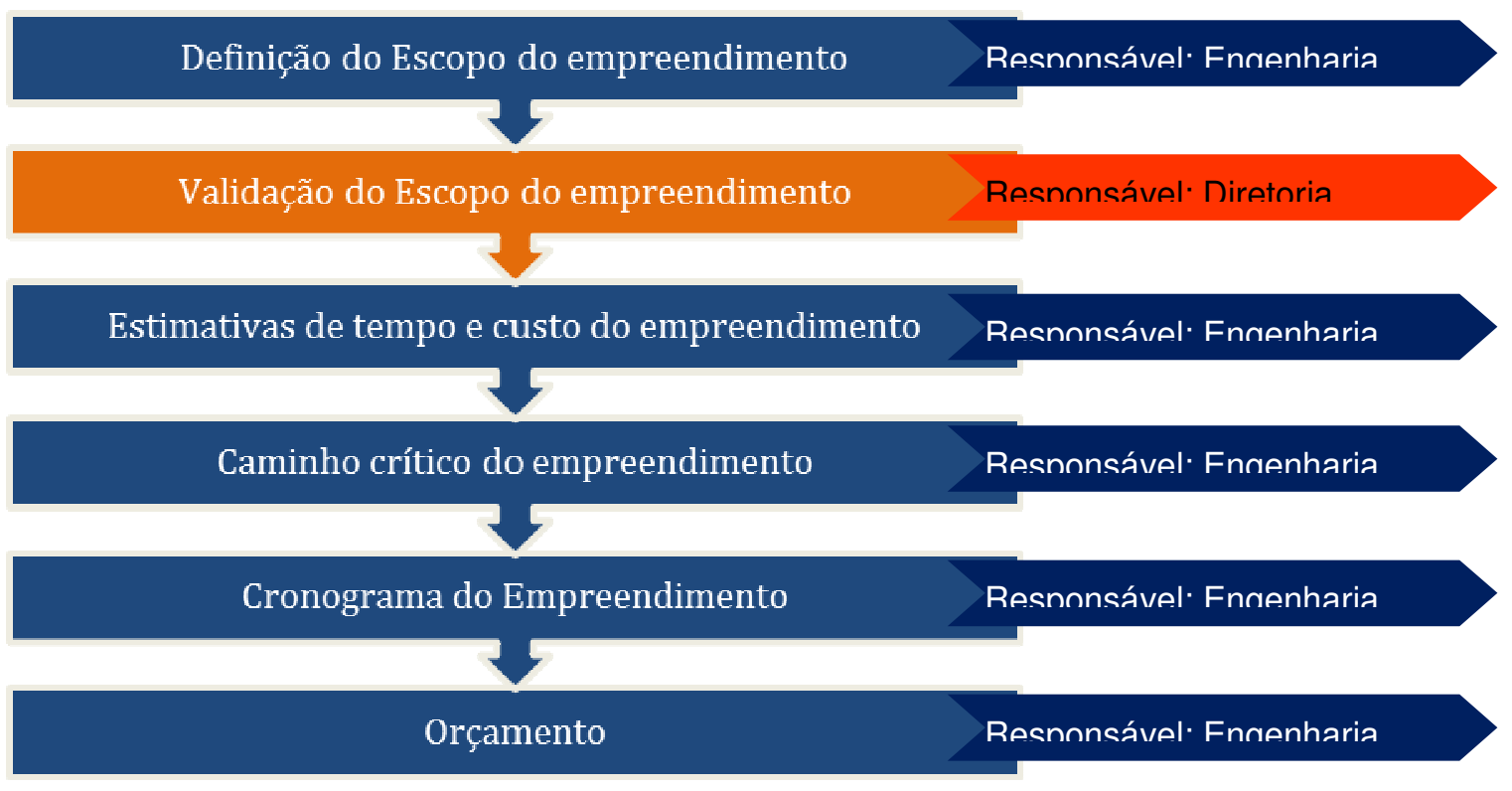

Fonte: Adaptado de documentos e apresentações disponibilizados pela empresa para 0 Estudo de Caso

- Ênfase na concepção e projetos como forma de influenciar custos, prazo e qualidade durante a fase de produção e agregar valor aos empreendimentos e aos serviços prestados (Figura 19). 
Figura 20: Capacidade de Influenciar recursos na evolução do empreendimento

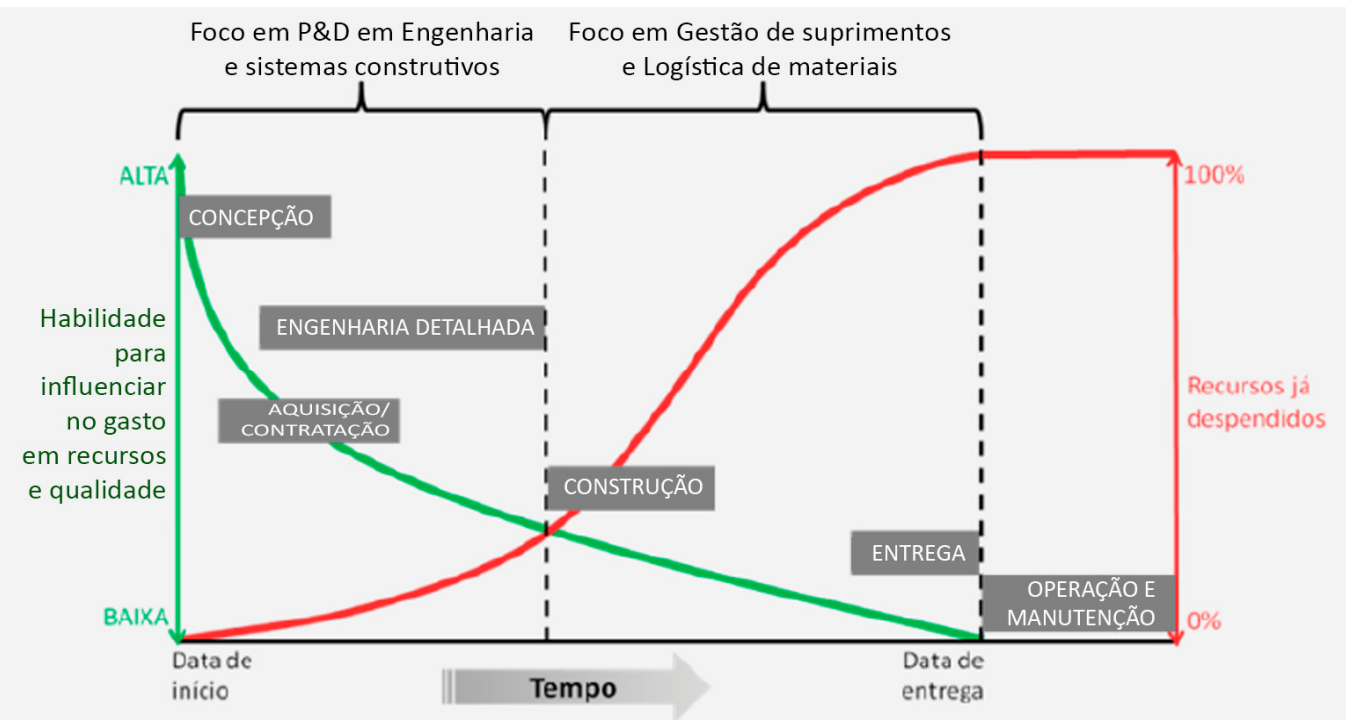

Fonte: Adaptado de Construction Industry Institute (1987)

- Garantia da integridade da produção e o fluxo de informações ágil e eficaz, ao longo do ciclo de vida do empreendimento.

- Redução da incerteza orçamentária no início do processo: A empresa observa variações de 30 a $50 \%$ do orçamento final, estimados na etapa de concepção de projetos, e com o uso da modelagem da informação da construção está buscando atingir uma meta de 10\% de variação em relação ao orçamento detalhado.

- Adoção de processo de construção industrializada, com inclusão de uma etapa para fabricação de elementos construtivos após o detalhamento dos projetos. O processo industrializado planejado pela empresa estudada está apresentado na Figura 20.

A consultoria apresentou e propôs a adoção de um software de análise de viabilidade, fornecido pela Beck Technology, o DProfiler ${ }^{\mathrm{TM}}$.

O software apresentado permite a criação simplificada de modelos do empreendimento na fase de concepção, e por meio de análises comparativas dos parâmetros modelados com bancos de dados inseridos no software gera simulações de custo, performance energética, planejamento da construção e desempenho durante o ciclo de vida do edifício. 
Figura 21: Mudança de processo de construção tradicional para industrializado

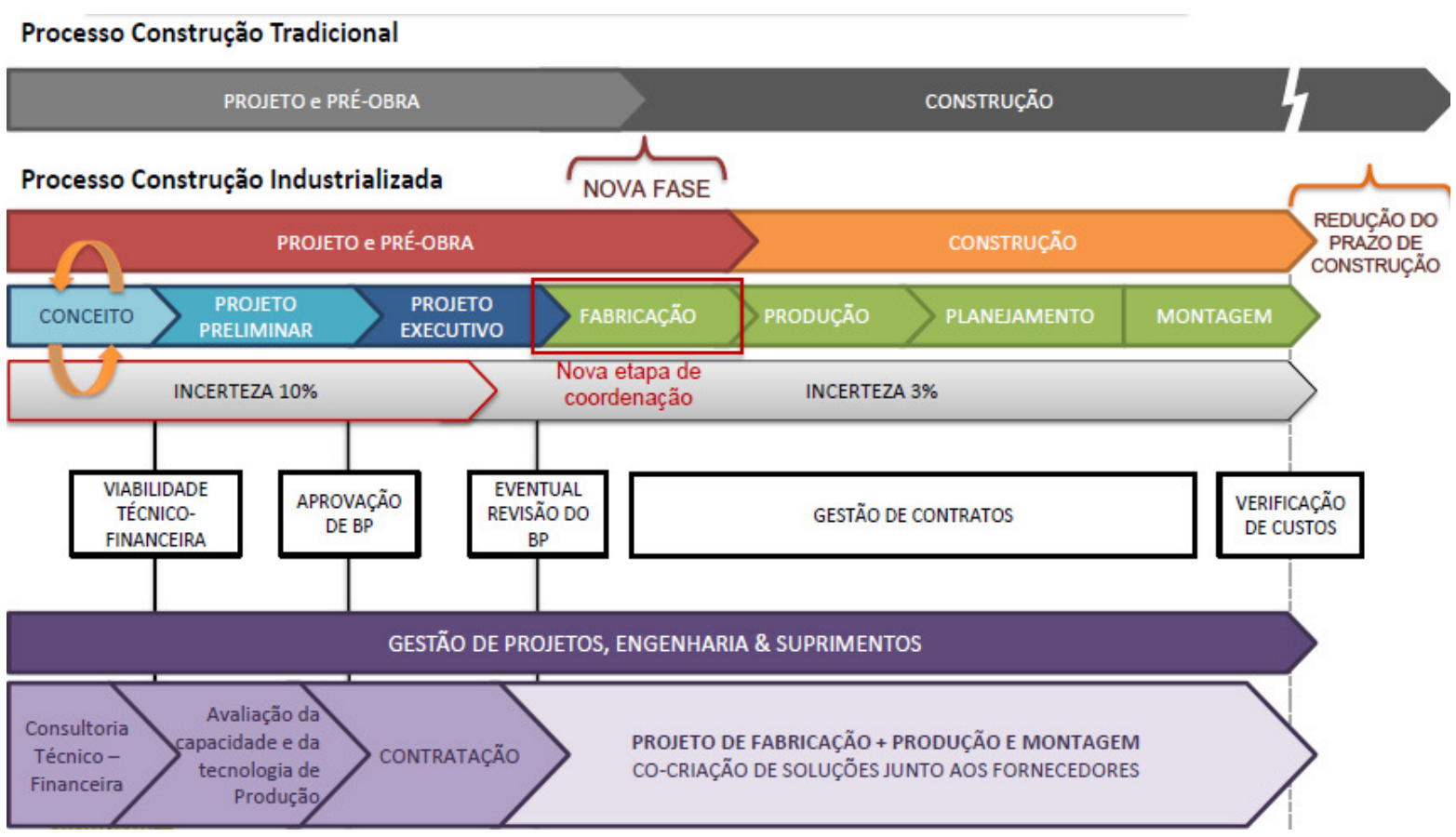

Fonte: Documentos e apresentações disponibilizados pela empresa para o Estudo de Caso

A consultoria foi descontinuada, e a empresa optou por não adquirir o software, decidindo por desenvolver internamente processos associados à modelagem e que atendessem às demandas dos clientes internos da área de engenharia avançada. Esses processos, observados no estudo de caso, estão descritos no item 6.3.

A decisão levou a empresa a elaborar soluções pontuais de uso da modelagem da informação da construção para atendimento das demandas internas e, apesar de apresentar alguns dos resultados planejados com maior rapidez, a visão sistêmica de processo de projeto na modelagem foi comprometida.

As principais demandas de clientes internos identificadas pelo Núcleo BIM da engenharia avançada foram as seguintes: (a) rapidez nas informações de prazo e custo; (b) comprometimento da engenharia com o modelo de negócio da empresa; (c) redução do número de alterações durante a concepção do projeto e (d) confiabilidade nas informações recebidas pelas áreas clientes. 


\subsection{PROCESSO DE PROJETO DA EMPRESA ESTUDADA}

As mudanças planejadas pela empresa no processo de projeto após a adoção da modelagem da informação da construção estão representadas na Figura 21.

Figura 22: Adequações nas etapas do processo de projeto atual na empresa para o processo em Modelagem da Informação da Construção

\begin{tabular}{|c|c|c|c|c|}
\hline & Concepção & $\begin{array}{l}\text { Desenvolviment } \\
\text { o Preliminar }\end{array}$ & $\begin{array}{l}\text { Desenvolvimento e } \\
\text { compatibilização }\end{array}$ & $\begin{array}{l}\text { Desenhos de } \\
\text { Construção }\end{array}$ \\
\hline & \begin{tabular}{c|c} 
Estudo de & Con- \\
massa & cepção
\end{tabular} & $\begin{array}{l}\text { Estudo } \\
\text { Preliminar }\end{array}$ & $\begin{array}{l}\text { Projeto } \\
\text { Básico }\end{array}$ & xecutivo \\
\hline
\end{tabular}

Fonte: Adaptado de documentos e apresentações disponibilizados pela empresa para o Estudo de Caso

A necessidade de atendimento das demandas internas e obtenção de rápidos resultados com a adoção da modelagem levou a empresa a desenvolver processos e soluções particulares para pontos críticos do processo do empreendimento.

Os processos desenvolvidos com o uso da modelagem da informação da construção na empresa estudada estão descritos nos itens de 6.3.1 a 6.3.4.

As soluções em modelagem estão inseridas dentro do processo de projeto da empresa, que é tradicional e em 2D, porém se utiliza da modelagem para obter informações mais precisas, em momentos de tomada de decisão.

As Figuras de 22 a 25 apresentam o conjunto de fluxogramas das etapas do processo de projeto da empresa estudada, com indicação dos principais agentes envolvidos e produtos gerados.

Os fluxogramas destacam, em vermelho, as atividades que utilizam ferramentas de modelagem da informação da construção e, em azul, o processo tradicional, que ocorre, por vezes, em paralelo ao processo de modelagem, em atividades repetidas nos dois processos. 
Figura 23: Fluxograma do processo de projeto da empresa estudada - Etapa de Estudo de Massa / Concepção do Projeto

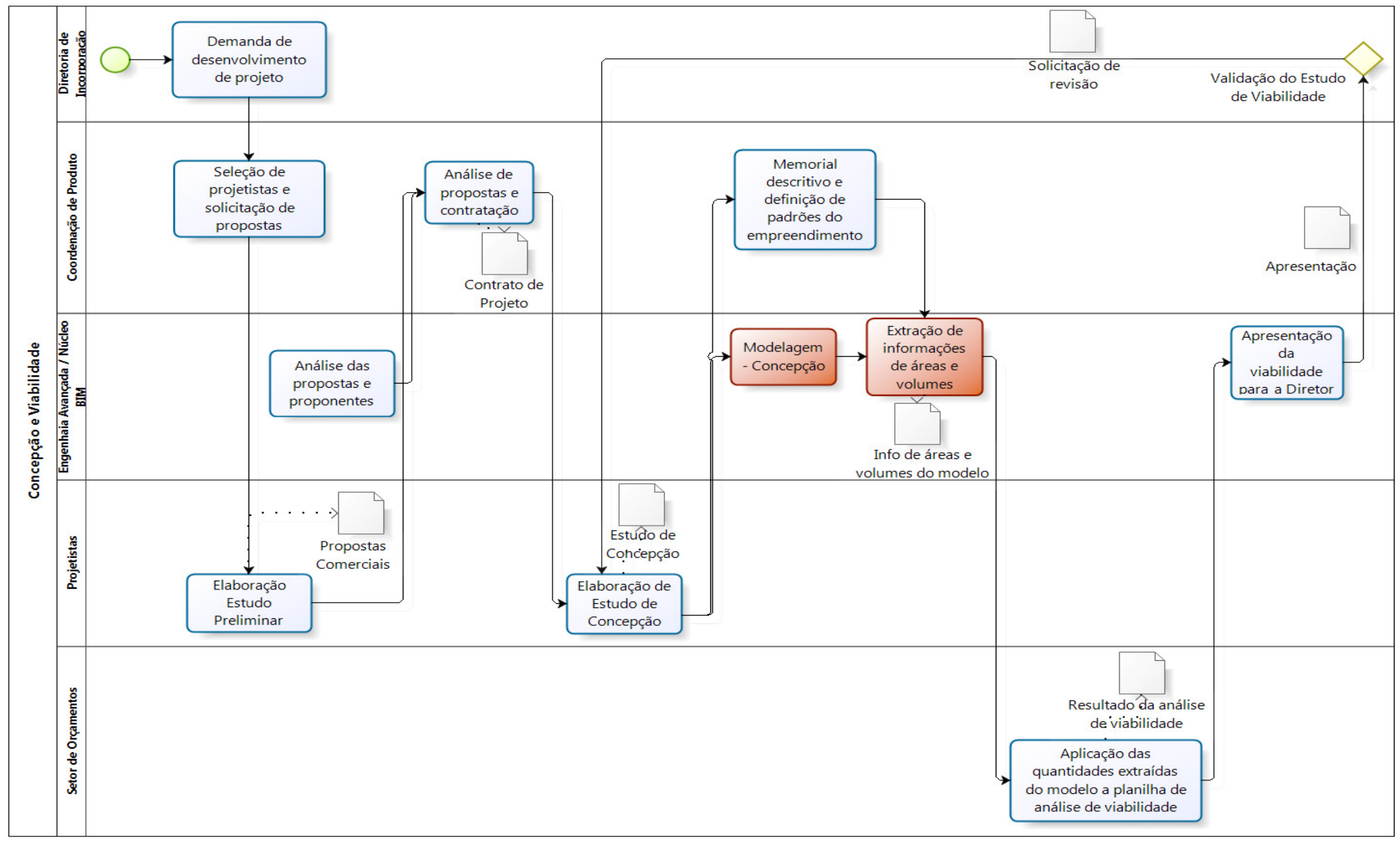

Fonte: Estudo de Caso 
Figura 24: Fluxograma do processo de projeto da empresa estudada - Etapa de Estudo Preliminar/Desenvolvimento Preliminar

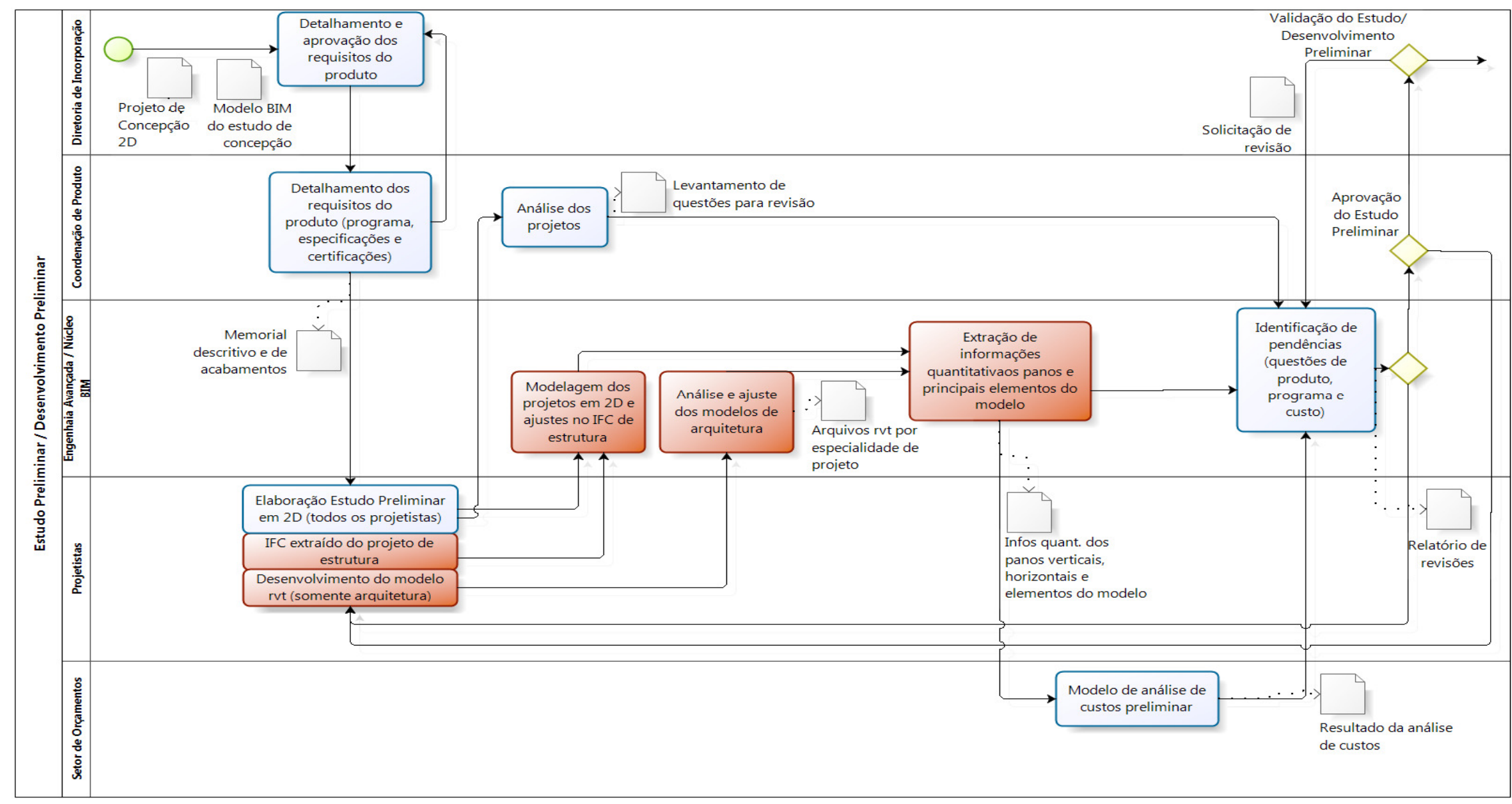

Fonte: Estudo de Caso 
Figura 25: Fluxograma do processo de projeto da empresa estudada - Etapa de desenvolvimento e compatibilização / Projeto Básico e Projeto Executivo

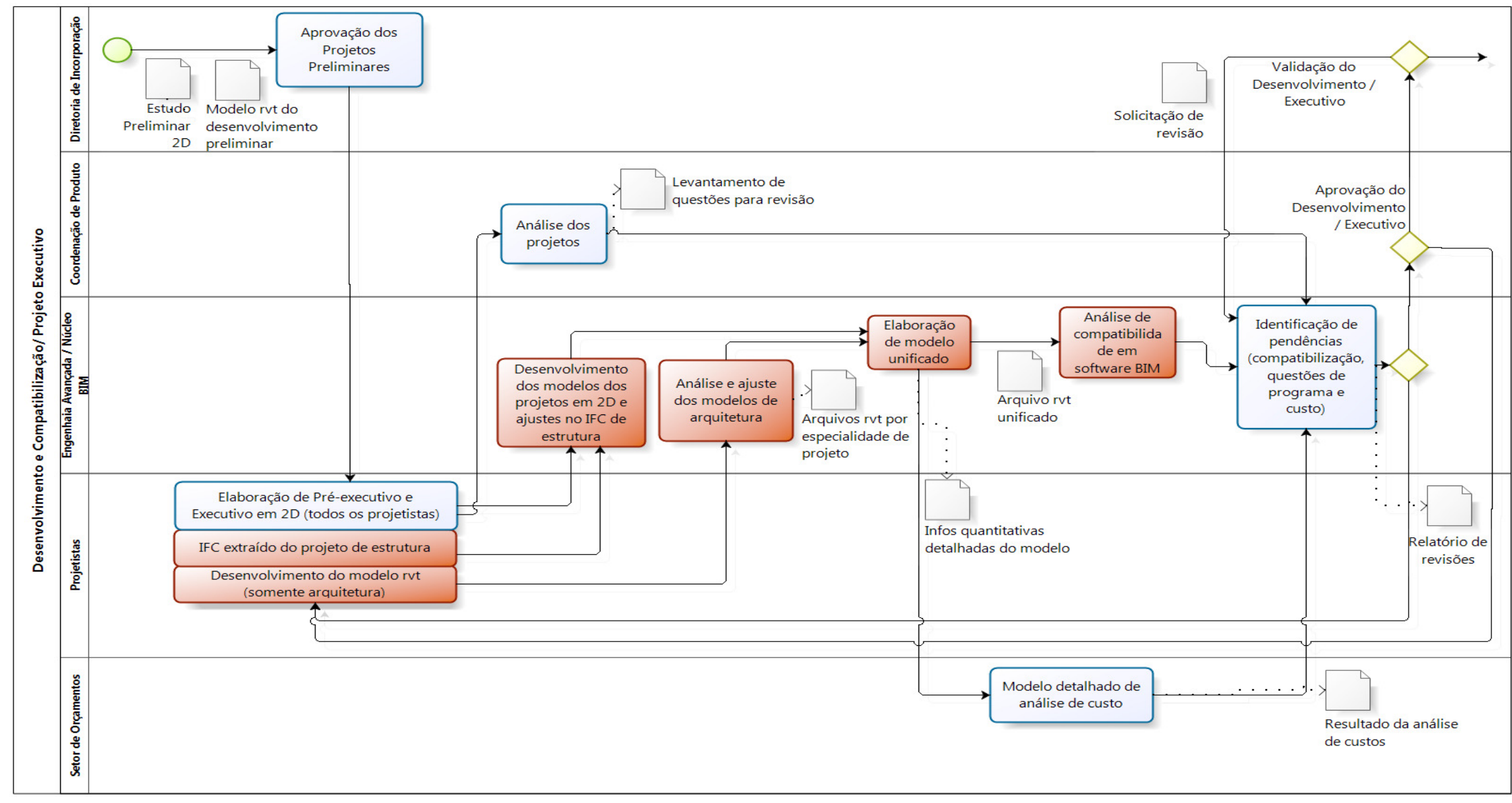

Fonte: Estudo de Caso 
Figura 26: Fluxograma do processo de projeto da empresa estudada - Etapa de Desenhos de Construção / Projeto Executivo

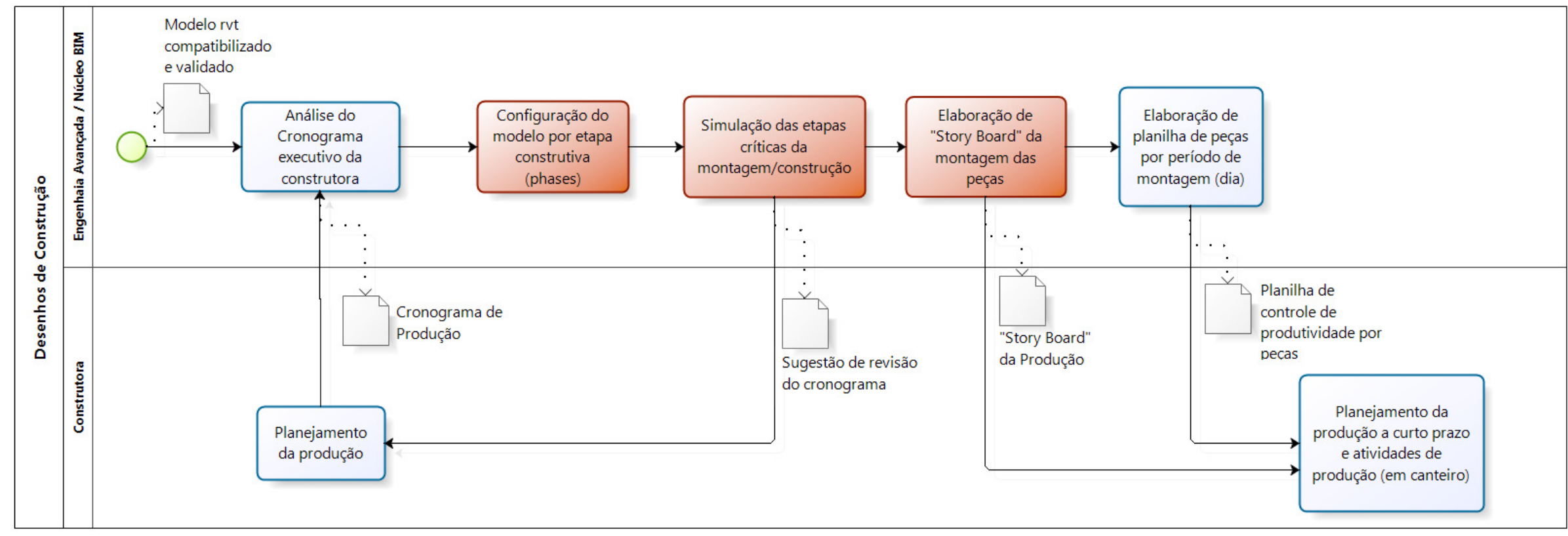

Fonte: Estudo de Caso 


\subsubsection{Estudo de viabilidade com uso da modelagem da informação da construção}

O Estudo de viabilidade com uso do BIM foi criado tendo como objetivo o desenvolvimento rápido de soluções de projeto, associado às informações de custo do empreendimento, detalhadas no processo seguinte - Orçamento preliminar com uso da modelagem da informação da construção. Além das informações mais precisas de custo, a modelagem do edifício e a possibilidade de visualização do projeto dão maior segurança à Diretoria da empresa na validação do empreendimento na fase de concepção.

O acompanhamento de atividades na empresa-caso, referente à etapa de Estudo de Viabilidade, teve como objeto um empreendimento de reforma e ampliação de shopping em bairro da zona sudeste de São Paulo.

Foram observados os seguintes processos relacionados ao Estudo da Viabilidade com uso do BIM (Tabela 12):

Tabela 12: Processos de Estudo de Viabilidade com uso da modelagem da informação da construção

\begin{tabular}{lllll}
\hline $\begin{array}{l}\text { Processo } \\
\text { Observado }\end{array}$ & Ferramentas & Entradas & Saídas & Participantes \\
\hline & & & & \\
& & Levantamento & & Coordenador \\
& & planialtimétrico, & Definição dos níveis & Coordenador \\
Compatibilização & Revit & projeto legal, & a serem mantidos & de Projetos, \\
projetos & Architecture ${ }^{\circledR}$ e & projeto as built, & nas demais etapas & Especialista \\
& AutoCAD ${ }^{\circledR}$ & imagens do & de projeto. & BIM e \\
& & edifício & & Desenvolvedor \\
\hline
\end{tabular}




\begin{tabular}{|c|c|c|c|c|}
\hline $\begin{array}{l}\text { Modelagem das } \\
\text { lajes do Shopping }\end{array}$ & $\begin{array}{l}\text { Revit } \\
\text { Architecture }^{\circledast} \mathrm{e} \\
\text { AutoCAD }^{\circledast}\end{array}$ & $\begin{array}{l}\text { Levantamento } \\
\text { planialtimétrico, } \\
\text { projeto legal, } \\
\text { projeto As Built, } \\
\text { imagens do } \\
\text { edifício }\end{array}$ & $\begin{array}{l}\text { Modelo } \\
\text { compatibilizado das } \\
\text { lajes existentes (a } \\
\text { manter e a demolir) } \\
\text { e das lajes } \\
\text { propostas (novo } \\
\text { projeto) }\end{array}$ & $\begin{array}{l}\text { Desenvolvedor } \\
\text { de modelo BIM }\end{array}$ \\
\hline $\begin{array}{l}\text { Checagem das } \\
\text { Inconsistências }\end{array}$ & $\begin{array}{l}\text { Revit } \\
\text { Architecture }^{\circledR}\end{array}$ & $\begin{array}{l}\text { Modelo das lajes e } \\
\text { levantamento } \\
\text { planialtimétrico, } \\
\text { projeto legal, } \\
\text { projeto As Built, } \\
\text { imagens do } \\
\text { edifício }\end{array}$ & $\begin{array}{l}\text { Relatório/Lista de } \\
\text { inconsistências a } \\
\text { serem verificadas } \\
\text { com a equipe e } \\
\text { fornecedores } \\
\text { (planialtimétrico e } \\
\text { as built) }\end{array}$ & $\begin{array}{l}\text { Desenvolvedor } \\
\text { de modelo BIM } \\
\text { e coordenador } \\
\text { de produto }\end{array}$ \\
\hline $\begin{array}{l}\text { Desenvolvimento } \\
\text { de Projeto Básico }\end{array}$ & $\begin{array}{l}\text { Revit } \\
\text { Architecture }\end{array}$ & $\begin{array}{l}\text { Modelo em Revit } \\
\text { das lajes a serem } \\
\text { demolidas e a } \\
\text { serem mantidas }\end{array}$ & $\begin{array}{l}\text { Projeto "unifilar" de } \\
\text { paredes e } \\
\text { fechamentos, } \\
\text { desenvolvido na } \\
\text { base do modelo, } \\
\text { com definição de } \\
\text { materiais e } \\
\text { revestimentos em } \\
\text { forma de memorial } \\
\text { descritivo }\end{array}$ & $\begin{array}{l}\text { Coordenação } \\
\text { de Produto } \\
\text { e/ou arquiteto } \\
\text { e diretoria }\end{array}$ \\
\hline $\begin{array}{l}\text { Modelagem do } \\
\text { Projeto Básico } \\
\text { para Viabilidade }\end{array}$ & $\begin{array}{l}\text { Revit } \\
\text { Architecture }\end{array}$ & $\begin{array}{l}\text { Projeto Unifilar } \\
\text { desenvolvido pela } \\
\text { coordenação de } \\
\text { produto, modelo } \\
\text { das lajes }\end{array}$ & $\begin{array}{l}\text { Modelo do Projeto } \\
\text { Básico para } \\
\text { Viabilidade }\end{array}$ & $\begin{array}{l}\text { Desenvolvedor } \\
\text { de modelo BIM }\end{array}$ \\
\hline
\end{tabular}




\begin{tabular}{|c|c|c|c|c|}
\hline $\begin{array}{l}\text { Extração de } \\
\text { Quantitativos }\end{array}$ & $\begin{array}{l}\text { Revit } \\
\text { Architecture }{ }^{\circledR}\end{array}$ & $\begin{array}{l}\text { Modelo em Revit } \\
\text { do Projeto com as } \\
\text { informações da } \\
\text { EAP de } \\
\text { Orçamentos }\end{array}$ & $\begin{array}{l}\text { Planilha em Excel } \\
\text { com abas referentes } \\
\text { a cada uma das } \\
\text { vistas de orçamento } \\
\text { extraídas do modelo }\end{array}$ & $\begin{array}{l}\text { Desenvolvedor } \\
\text { de modelo BIM }\end{array}$ \\
\hline Orçamento Básico & Excel & $\begin{array}{l}\text { Planilhas extraídas } \\
\text { do modelo do } \\
\text { projeto básico } \\
\text { para viabilidade e } \\
\text { memorial } \\
\text { descritivo do } \\
\text { projeto produzido } \\
\text { pela coordenação } \\
\text { de produto }\end{array}$ & $\begin{array}{l}\text { Planilha de } \\
\text { Viabilidade - } \\
\text { Planilha em Excel } \\
\text { com descrição, } \\
\text { quantidades e custo } \\
\text { unitário e global do } \\
\text { empreendimento }\end{array}$ & $\begin{array}{l}\text { Gerente de } \\
\text { Orçamento e } \\
\text { Orçamentistas }\end{array}$ \\
\hline $\begin{array}{l}\text { Apresentação } \\
\text { para validação da } \\
\text { viabilidade }\end{array}$ & Powerpoint & $\begin{array}{l}\text { Planilha de } \\
\text { Viabilidade, Vistas } \\
\text { do modelo } \\
\text { referentes a cada } \\
\text { um dos elementos } \\
\text { da EAP de } \\
\text { orçamentos }\end{array}$ & $\begin{array}{l}\text { Apresentação } \\
\text { sintética das } \\
\text { soluções de projeto } \\
\text { e custo global e } \\
\text { específica de custos } \\
\text { por elemento da } \\
\text { EAP, com } \\
\text { representação no } \\
\text { modelo dos itens } \\
\text { em destaque. }\end{array}$ & $\begin{array}{l}\text { Especialista } \\
\text { BIM, } \\
\text { Desenvolvedor } \\
\text { de modelo BIM } \\
\text { e Equipe de } \\
\text { orçamentos e } \\
\text { coordenação de } \\
\text { produto }\end{array}$ \\
\hline
\end{tabular}

\section{Fonte: Estudo de Caso}

O projeto em questão já possuía um histórico dentro da empresa. Em 2008, foi desenvolvido um projeto inicial de reforma que não foi viabilizado. Uma mudança na legislação permitiu uma ampliação no número de pavimentos, tornando o projeto viável, passando a ser uma reforma. Esta lacuna de tempo causou o encerramento dos contratos de projeto iniciais e, no momento da visita, não havia escritório de arquitetura contratado, justificando o desenvolvimento total do projeto pela equipe de produto e núcleo BIM da 
empresa (processo de modelagem das lajes, definição de níveis, desenvolvimento de projeto básico).

Observou-se constante interação entre o Desenvolvedor de modelo BIM estudando as informações de projeto e a equipe de coordenação de projetos e coordenação de produto, que discutiam com ele as informações a serem adotadas na modelagem.

A estrutura de modelagem (vistas do Revit Architecture ${ }^{\circledR}$ ) foi elaborada a partir da Estrutura Analítica de Projetos (EAP) utilizada pelo setor de orçamentos da empresa, e segue uma estrutura subdividida em três grandes grupos: implantação, fundações e edifício, aos quais são atrelados bancos de dados de custos unitários.

A modelagem do edifício segue a estrutura apresentada na Tabela 13.

Tabela 13: Estrutura de modelagem do estudo de viabilidade

\begin{tabular}{|c|c|c|}
\hline Grupos & \multicolumn{2}{|l|}{ Vistas } \\
\hline \multirow[t]{2}{*}{ VISTAS GERAIS } & \multicolumn{2}{|l|}{ >Seções } \\
\hline & \multicolumn{2}{|c|}{$>$ Drafting Views } \\
\hline \multirow[t]{3}{*}{$\mathrm{ARQ}$} & \multicolumn{2}{|c|}{ >Pisos_\#Pavto_ARQ_NomePavto/NomeLaje } \\
\hline & \multicolumn{2}{|l|}{ >Vistas 3D } \\
\hline & \multicolumn{2}{|c|}{ >Elevações_ELEV_NomedaRua } \\
\hline EXISTENTE & \multicolumn{2}{|c|}{ >PlantasPIso_\#Planta_EXIST_NomePlanta/NomeLaje } \\
\hline \multirow[t]{12}{*}{ ORÇAMENTO } & $>$ Vistas 3D & $>00 \_$Estrutura \\
\hline & & $>00 \_$Orç_3D \\
\hline & & $>01 \_$Piso \\
\hline & & >02_Impermeabilização \\
\hline & & $>03 \_$Alvenaria e \\
\hline & & Fechamentos \\
\hline & & $>04$ Revestimento \\
\hline & & Externo \\
\hline & & >05_Revestimento Interno \\
\hline & & >06_DryWall \\
\hline & & $>07$ Pinturas \\
\hline & & $>08$ Esquadrias \\
\hline
\end{tabular}




\begin{tabular}{ll}
\hline & $>12 \_$Louças, Pedras e \\
& Metais \\
\hline & $>13 \_$Coberturas \\
\hline ÁREAS & $>14 \_$Fachada \\
\hline & $>15 \_$Perfil Divisor \\
\hline
\end{tabular}

Fonte: Estudo de Caso

Após a geração dos custos básicos é estruturada uma apresentação para validação do empreendimento junto à Diretoria da empresa, em que são apresentados os custos por sistema construtivo, em imagens do modelo em que aparecem destacados. Segundo os profissionais entrevistados, nessa reunião é recorrente a revisão de algumas decisões tomadas pela coordenação de produto quanto à determinação dos materiais e acabamentos.

Caso o projeto não seja validado, o processo retorna para a etapa de desenvolvimento do projeto básico, e será reestruturado para atender às demandas da Diretoria.

\subsubsection{Orçamento preliminar com uso da modelagem da informação da construção}

A geração de um orçamento preliminar preciso (com até 10\% de variação em relação ao custo real do empreendimento) é um dos principais objetivos da empresa com o uso da modelagem da informação da construção.

A estrutura de modelagem foi desenhada para se relacionar diretamente com a EAP orçamentária, por meio de tabelas de quantitativos extraídas do modelo no Revit Architecture $\AA$, que determinam as quantidades por vistas do modelo. Dessa forma, é permitida a exportação dos valores para uma tabela em Excel, os quais podem ser diretamente importados para as planilhas de custo.

O acompanhamento de atividades na empresa-caso, referentes à etapa de orçamento preliminar teve como objeto um empreendimento de reforma e ampliação de shopping, em bairro da zona sudeste de São Paulo. 
Os processos observados, relacionados à etapa de orçamento preliminar, estão descritas na Tabela 14.

Tabela 14: Processos de orçamento preliminar com uso da modelagem da informação da construção

\begin{tabular}{|c|c|c|c|c|}
\hline $\begin{array}{l}\text { Processo } \\
\text { Observado }\end{array}$ & Ferramentas & Entradas & Saídas & Participantes \\
\hline $\begin{array}{l}\text { Extração de } \\
\text { Quantitativos }\end{array}$ & $\begin{array}{l}\text { Revit } \\
\text { Architecture }\end{array}$ & $\begin{array}{l}\text { Modelo em Revit } \\
\text { do Projeto com as } \\
\text { informações da } \\
\text { EAP de } \\
\text { Orçamentos }\end{array}$ & $\begin{array}{l}\text { Planilha em excel } \\
\text { com abas referentes } \\
\text { a cada uma das vistas } \\
\text { de orçamento } \\
\text { extraídas do modelo }\end{array}$ & $\begin{array}{l}\text { Desenvolvedor } \\
\text { de modelo BIM }\end{array}$ \\
\hline $\begin{array}{l}\text { Orçamento } \\
\text { Básico }\end{array}$ & Excel & $\begin{array}{l}\text { Planilhas } \\
\text { extraídas do } \\
\text { modelo do } \\
\text { projeto básico } \\
\text { para viabilidade e } \\
\text { memorial } \\
\text { descritivo do } \\
\text { projeto produzido } \\
\text { pela coordenação } \\
\text { de produto }\end{array}$ & $\begin{array}{l}\text { Planilha de } \\
\text { Viabilidade - Planilha } \\
\text { em Excel com } \\
\text { descrição, } \\
\text { quantidades e custo } \\
\text { unitário e global do } \\
\text { empreendimento }\end{array}$ & $\begin{array}{l}\text { Gerente de } \\
\text { Orçamento e } \\
\text { Orçamentistas }\end{array}$ \\
\hline
\end{tabular}

\section{Fonte: Estudo de Caso}

A EAP orçamentária está associada a bancos de dados de custos unitários por item da composição orçamentária, permitindo a realização de uma composição apurada dos custos do empreendimento, desde que os quantitativos dos itens sejam precisos. A extração automática de quantitativos permitida pelo uso da modelagem da informação da construção contribui para que se obtenha um orçamento preliminar mais confiável, que alimenta as decisões de validação do empreendimento em suas etapas iniciais. 


\subsubsection{Compatibilização de Projetos com uso da modelagem da informação da construção}

A compatibilização de projetos com o uso de softwares de identificação de interferências físicas automatiza um processo que era realizado manualmente por profissionais experientes em coordenação de projetos. A automatização gera um ganho de tempo e reduz as falhas na compatibilização.

Para tanto, são necessários modelos das diferentes especialidades de projeto. No caso da empresa estudada, os modelos de arquitetura podem ser fornecidos pelo projetista ou desenvolvidos dentro da própria empresa. No caso de serem desenvolvidos por projetistas externos, deverão seguir os parâmetros determinados pela empresa na contratação, descritos no item 6.4 - Contratos de Projetos em modelagem da informação da construção.

Para os projetos estruturais, são utilizados os arquivos em formato IFC extraídos dos modelos em TQS4fornecidos pelos projetistas estruturais. No caso das instalações, a empresa estudada ainda não trabalha com fornecedores de projetos qualificados para a produção de projetos em modelagem da informação da construção. Os modelos dos principais sistemas de instalações prediais (Ar condicionado e pressurização, Hidráulica - água e esgoto e os principais dutos de elétrica) são produzidos pelo núcleo BIM da própria empresa.

O acompanhamento de atividades na empresa-caso, referentes à etapa de compatibilização de projetos teve como objeto um empreendimento de edifícios corporativos em um conjunto comercial com shopping e aeroporto na Av. Castelo Branco (SP-280).

\footnotetext{
4 TQS é uma empresa brasileira responsável pelo desenvolvimento do software de cálculo estrutural de mesmo nome (www.tqscom.br). Em 2010, para atendimento às demandas de interoperabilidade com softwares de modelagem da informação da construção a empresa apresentou uma interface bi-direcional com o Revit Structure ${ }^{\circledR}$. A interface disponibilizada permite a exportação em IFC de informações volumétricas dos modelos estruturais para visualização e análise de interferências entre os demais modelos e a estrutura.
} 
Os processos observados, relacionados à etapa de compatibilização de projetos, estão descritas na Tabela 15.

Tabela 15: Processos de compatibilização de projetos com uso da modelagem da informação da construção

\begin{tabular}{|c|c|c|c|c|c|}
\hline $\begin{array}{l}\text { Processo } \\
\text { Observado }\end{array}$ & Documentos & Ferramentas & Entradas & Saídas & ticipantes \\
\hline $\begin{array}{l} \\
\text { Orientação } \\
\text { sobre a } \\
\text { produção de } \\
\text { projetos em } \\
\text { BIM }\end{array}$ & $\begin{array}{l}\text { Planilhas de } \\
\text { determinação do } \\
\text { LOD (Nível de } \\
\text { desenvolvimento) } \\
\text { geral dos projetos } \\
\text { e do modelo em } \\
\text { relação à fase de } \\
\text { projeto; } \\
\text { Planilha de } \\
\text { detalhamento do } \\
\text { LOD por } \\
\text { especialidade de } \\
\text { projeto - } \\
\text { informação que a } \\
\text { especialidade } \\
\text { deve entregar nos } \\
\text { seus projetos em } \\
\text { 2d ou modelos } \\
\text { conforme a fase } \\
\text { de projeto, } \\
\text { divididos segundo } \\
\text { a estrutura geral } \\
\text { de modelagem } \\
\text { (piso, parede, } \\
\text { teto); Diretrizes } \\
\text { de nomenclatura } \\
\text { de elementos de } \\
\text { projeto (conforme } \\
\text { a ABNT/CEE- } \\
\text { 134); Diretrizes }\end{array}$ & $\begin{array}{l}\text { Microsoft } \\
\text { Word e } \\
\text { Microsoft } \\
\text { Excel }\end{array}$ & $\begin{array}{l}\text { Estrutura de } \\
\text { nível de detalhe } \\
\text { (LOD) geral e } \\
\text { por } \\
\text { especialidade } \\
\text { de projeto } \\
\text { (padrão da } \\
\text { empresa } \\
\text { desenvolvido a } \\
\text { partir dos } \\
\text { padrões de LOD } \\
\text { propostos pelo } \\
\text { AIA) para } \\
\text { projetos } \\
\text { entregues e } \\
\text { para os modelos } \\
\text { BIM após } \\
\text { adequados pela } \\
\text { empresa; } \\
\text { Diretrizes de } \\
\text { representação } \\
\text { de projetos da } \\
\text { empresa. }\end{array}$ & $\begin{array}{l}\text { Documentação } \\
\text { disponibilizada } \\
\text { no início dos } \\
\text { projetos para os } \\
\text { fornecedores de } \\
\text { serviços de } \\
\text { projeto - } \\
\text { orientações } \\
\text { sobre nível de } \\
\text { detalhe/LOD e } \\
\text { sobre } \\
\text { representação } \\
\text { do projeto em } \\
\text { softwares 2D e } \\
\text { 3D. }\end{array}$ & $\begin{array}{l} \\
\text { Coord. De } \\
\text { projeto, } \\
\text { coord. de } \\
\text { projetos } \\
\text { BIM, } \\
\text { especialista } \\
\text { BIM. }\end{array}$ \\
\hline
\end{tabular}




\begin{tabular}{llllll}
\hline $\begin{array}{l}\text { Processo } \\
\text { Observado }\end{array}$ & Documentos & Ferramentas & Entradas & Saídas & Participantes
\end{tabular}

\begin{tabular}{|c|c|c|c|c|c|}
\hline & $\begin{array}{l}\text { para } \\
\text { determinação de } \\
\text { pontos de origem } \\
\text { dos projetos e } \\
\text { modelos }\end{array}$ & & & & \\
\hline $\begin{array}{l}\text { Receber os } \\
\text { projetos/ } \\
\text { Download } \\
\text { dos projetos } \\
\text { do } \\
\text { gerenciador } \\
\text { de arquivos }\end{array}$ & $\begin{array}{l}\text { Relatórios de } \\
\text { entregas de } \\
\text { arquivos, } \\
\text { considerando o } \\
\text { versionamento }\end{array}$ & $\begin{array}{l}\text { Gerenciador } \\
\text { de arquivos }\end{array}$ & $\begin{array}{l}\text { Upload dos } \\
\text { projetos pelos } \\
\text { fornecedores no } \\
\text { gerenciador de } \\
\text { arquivos }\end{array}$ & $\begin{array}{l}\text { Retorno com } \\
\text { comentários } \\
\text { (relatório de } \\
\text { interferências } \\
\text { para revisão) } \\
\text { ou aprovação } \\
\text { do projeto } \\
\text { recebido. }\end{array}$ & $\begin{array}{l}\text { Especialista } \\
\text { BIM, } \\
\text { coordena- } \\
\text { dora de } \\
\text { projetos }\end{array}$ \\
\hline $\begin{array}{l}\text { Análise dos } \\
\text { projetos } \\
\text { conforme } \\
\text { LOD e etapa } \\
\text { de projeto } \\
\text { determinado } \\
\text { s }\end{array}$ & $\begin{array}{l}\text { Relatório de } \\
\text { inadequação dos } \\
\text { projetos } \\
\text { entregues às } \\
\text { diretrizes de LOD }\end{array}$ & $\begin{array}{l}\text { Revit } \\
\text { Architecture } \\
\circledR \text { ou } \\
\text { Navisworks }\end{array}$ & $\begin{array}{l}\text { Projetos } \\
\text { cadastrados no } \\
\text { gerenciador de } \\
\text { arquivos }\end{array}$ & $\begin{array}{l}\text { Início da } \\
\text { atividade de } \\
\text { adequação do } \\
\text { modelo ou de } \\
\text { modelagem do } \\
\text { projeto } 2 d \text {. }\end{array}$ & $\begin{array}{l}\text { Especialista } \\
\text { BIM }\end{array}$ \\
\hline $\begin{array}{l}\text { Adequação } \\
\text { dos modelos } \\
\text { recebidos ou } \\
\text { modelagem } \\
\text { dos projetos } \\
\text { 2D } \\
\text { recebidos }\end{array}$ & $\begin{array}{l}\text { Relatório de } \\
\text { inadequação dos } \\
\text { projetos } \\
\text { entregues às } \\
\text { diretrizes de LOD }\end{array}$ & $\begin{array}{l}\text { Revit } \\
\text { Architecture } \\
\circledR, \text { Revit } \\
\text { MEP® }\end{array}$ & $\begin{array}{l}\text { Projetos } \\
\text { cadastrados no } \\
\text { gerenciador de } \\
\text { arquivos }\end{array}$ & $\begin{array}{l}\text { Modelos das } \\
\text { especialidades } \\
\text { em } \\
\text { conformidade } \\
\text { com as } \\
\text { diretrizes de } \\
\text { LOD da } \\
\text { empresa para } \\
\text { modelos na } \\
\text { fase }\end{array}$ & $\begin{array}{l}\text { Especialista } \\
\text { BIM }\end{array}$ \\
\hline
\end{tabular}




\begin{tabular}{|c|c|c|c|c|c|}
\hline $\begin{array}{l}\text { Processo } \\
\text { Observado }\end{array}$ & Documentos & Ferramentas & Entradas & Saídas & ticipantes \\
\hline $\begin{array}{l}\text { Compatibili- } \\
\text { zação dos } \\
\text { modelos }\end{array}$ & $\begin{array}{l}\text { Relatório de } \\
\text { interferências }\end{array}$ & $\begin{array}{l}\text { NavisWorks } \\
\text { ® e Microsoft } \\
\text { Excel }\end{array}$ & $\begin{array}{l}\text { Modelos das } \\
\text { especialidades } \\
\text { em } \\
\text { conformidade } \\
\text { com as } \\
\text { diretrizes de } \\
\text { LOD da } \\
\text { empresa para } \\
\text { modelos na fase }\end{array}$ & $\begin{array}{l}\text { Modelo } \\
\text { composto } \\
\text { (revit link) por } \\
\text { informações } \\
\text { atualizadas } \\
\text { dos modelos } \\
\text { de cada uma } \\
\text { das } \\
\text { especialidades } \\
\text {, relatório de } \\
\text { interferências }\end{array}$ & $\begin{array}{l}\text { Especialista } \\
\text { BIM }\end{array}$ \\
\hline $\begin{array}{l}\text { Geração do } \\
\text { relatório de } \\
\text { interferên- } \\
\text { cias }\end{array}$ & $\begin{array}{l}\text { Relatório de } \\
\text { Interferências em } \\
\text { Excel }\end{array}$ & $\begin{array}{l}\text { NavisWorks } \\
\text { ® e Microsoft } \\
\text { Excel }\end{array}$ & $\begin{array}{l} \\
\text { Modelos } \\
\text { vinculados no } \\
\text { Revit link, } \\
\text { identificados por } \\
\text { especialidade } \\
\text { conforme } \\
\text { esquema de } \\
\text { identificação de } \\
\text { elementos } \\
\text { programado no } \\
\text { sistema. }\end{array}$ & $\begin{array}{l}\text { Model views } \\
\text { geradas a } \\
\text { partir dos } \\
\text { pontos de } \\
\text { visualização } \\
\text { das } \\
\text { interferências, } \\
\text { descrição das } \\
\text { interferências } \\
\text { e dos } \\
\text { responsáveis } \\
\text { pela solução } \\
\text { dos problemas } \\
\text { identificados, } \\
\text { informações } \\
\text { agregadas em } \\
\text { planilha Excel } \\
\text { que será } \\
\text { enviada para } \\
\text { os projetistas } \\
\text { e demais } \\
\text { agentes } \\
\text { envolvidos } \\
\text { (relatório de }\end{array}$ & $\begin{array}{l}\text { Especialista } \\
\text { BIM }\end{array}$ \\
\hline
\end{tabular}




\begin{tabular}{|c|c|c|c|c|c|}
\hline \multirow[t]{2}{*}{$\begin{array}{l}\text { Processo } \\
\text { Observado }\end{array}$} & \multirow[t]{2}{*}{ Documentos } & \multirow[t]{2}{*}{ Ferramentas } & \multirow[t]{2}{*}{ Entradas } & \multicolumn{2}{|c|}{ Participantes } \\
\hline & & & & interferências) & \\
\hline $\begin{array}{l}\text { Envio do } \\
\text { relatório de } \\
\text { interferência } \\
\text { s para os } \\
\text { projetistas }\end{array}$ & $\begin{array}{l}\text { Gerenciador de } \\
\text { Arquivos Online }\end{array}$ & & $\begin{array}{l}\text { Relatório de } \\
\text { interferências }\end{array}$ & $\begin{array}{l}\text { Início da } \\
\text { atividade de } \\
\text { análise das } \\
\text { interferências } \\
\text { pelos } \\
\text { projetistas e } \\
\text { demais } \\
\text { agentes } \\
\text { envolvidos }\end{array}$ & $\begin{array}{l}\text { Coordenado } \\
\text { ra de } \\
\text { projetos }\end{array}$ \\
\hline $\begin{array}{l}\text { Atualização } \\
\text { dos } \\
\text { relatórios de } \\
\text { interferên- } \\
\text { cias }\end{array}$ & $\begin{array}{l}\text { Relatório de } \\
\text { interferência } \\
\text { atualizado }\end{array}$ & $\begin{array}{l}\text { NavisWorks } \\
\circledR \text { e Microsoft } \\
\text { Excel }\end{array}$ & $\begin{array}{l} \\
\\
\text { Projetos } \\
\text { revisados } \\
\text { cadastrados no } \\
\text { gerenciador de } \\
\text { arquivos, } \\
\text { modelo com link } \\
\text { para os modelos } \\
\text { atualizados. }\end{array}$ & $\begin{array}{l}\text { Relatório de } \\
\text { interferências } \\
\text { atualizado } \\
\text { (identificação } \\
\text { das } \\
\text { pendências } \\
\text { resolvidas, das } \\
\text { novas } \\
\text { pendências e } \\
\text { das que se } \\
\text { mantiveram } \\
\text { sem } \\
\text { resolução). } \\
\text { Retroalimenta } \\
\text { ção do } \\
\text { processo de } \\
\text { compatibiliza- } \\
\text { ção. }\end{array}$ & $\begin{array}{l}\text { Especialista } \\
\text { BIM, } \\
\text { coordenado- } \\
\text { ra de } \\
\text { projetos }\end{array}$ \\
\hline
\end{tabular}

\section{Fonte: Estudo de Caso}

A planilha de nível de desenvolvimento citada na atividade de orientação da produção de projetos em modelagem da informação da construção determina níveis de desenvolvimento diferenciados para projetos e modelos (2D ou em modelagem) por especialidade e por etapa de projeto. 
Podem ocorrer duas situações de desacordo do projeto com a planilha de Nível de Desenvolvimento: 1. O fornecedor entrega modelos que não estão de acordo com as diretrizes de modelagem da empresa, estruturação de vistas ou mesmo que não contêm os detalhes requeridos pelo LOD determinado (digamos LOD 200), porém atendem à planilha para LOD 100. Nesse caso, a empresa corrige internamente qualquer desacordo com os padrões e complementa as informações para alcançar o LOD determinado para o modelo, no caso LOD 200. 2. O mesmo ocorre para projetos entregues em 2D, em que toda a modelagem é realizada pelo núcleo BIM, que agrega as informações faltantes para que o modelo alcance LOD 200.

Foi comentado pelo entrevistado, que se observou melhoria na qualidade das informações de projeto, conforme a evolução da relação do departamento com a empresa projetista. Um exemplo é o incremento de detalhes nos projetos de estrutura a partir do TQS, cujos pilares, a princípio, eram gerados com seções contínuas em toda a altura dos edifícios, e após solicitações em projetos diferenciados, passaram a ser entregues com o estrangulamento da seção que, no processo tradicional, somente eram identificadas no projeto executivo detalhamento da estrutura.

Quanto à utilização do Revit link para a compatibilização do modelo, é importante observar que essa ferramenta permite a atualização automática dos modelos compostos (com todas as especialidades) quando ocorrerem modificações nos arquivos individuais dos modelos aos quais está vinculado.

O processo de geração do relatório de interferências foi estruturado pela empresa de forma a facilitar a identificação das questões apontadas no modelo. São utilizados eixos de referência, tendo sido programado um sistema identificação por cores dos elementos de distintas especialidades de projeto. A identificação dos elementos é feita automaticamente pelo software, a partir da família à qual pertence (parâmetro importado do modelo Revit@) de maneira a facilitar o referenciamento das interferências no relatório geral do software, que é organizado por famílias, simplificando a análise pelas especialidades envolvidas. 
Os eixos de localização das interferências existem em três dimensões, facilitando a identificação do ponto de ocorrência da interferência identificada no relatório. O relatório geral do software apresenta a mesma interferência, repetidas vezes, a partir das diferentes especialidades que se cruzam, ou por elemento que apresenta inconsistência, passando a ser redundante e pouco prático como diretriz de revisão dos projetos. A solução para esse problema e para o problema de visualização das imagens de baixa resolução geradas automaticamente pelo software é a geração de viewpoints, "linkados" diretamente no relatório (que filtra o número de vezes que uma interferência é identificada e apresenta imagens maiores).

Além das interferências geradas pelo software de modelagem, são somados ao relatório os problemas identificados pela coordenadora de projetos que não tem representação física (atendimento aos requisitos de programa, alteração de soluções de produto, entre outros).

O relatório final é gerado em Excel, em planilha programada para identificar em cores diferentes as pendências que foram resolvidas, as pendências remanescentes e os novos pontos de interferências. Após a solução de uma ou mais interferências, o relatório é alimentado pelas informações atualizadas; as questões resolvidas são identificadas com a cor verde e uma imagem do ponto problemático com a solução adotada é adicionada à planilha.

Uma vez consolidado, o relatório de interferências é enviado pela coordenadora para os fornecedores e colaboradores com alguns dias de antecedência às reuniões de compatibilização, com a solicitação de que os colaboradores estudem as questões referentes às suas especialidades, já levando sugestões de solução e aumentando a produtividade das reuniões. 


\subsubsection{Planejamento de obras e montagem de pré-fabricados com uso da modelagem da informação da construção}

Esse processo está alinhado ao desenvolvimento de soluções industrializadas para os empreendimentos da empresa. O primeiro caso desenvolvido por eles foi um conjunto de casas em elementos pré-fabricados de concreto em um município do interior do Estado de São Paulo.

A modelagem da informação da construção foi utilizada para o estudo da logística de montagem das casas enquanto unidades e enquanto conjunto de produção, considerando os recursos de mão de obra, equipamento e tempo disponíveis.

O acompanhamento de atividades na empresa-caso, referentes à etapa de planejamento de obras e montagem de pré-fabricados, teve como objeto o conjunto de casas industrializadas em município do interior do Estado de São Paulo.

Os processos observados relacionados à etapa de planejamento de obras e montagem de pré-fabricados estão descritas na Tabela 16.

Tabela 16: Processos de planejamento de obras e montagem de pré-fabricados com uso da modelagem da informação da construção

\begin{tabular}{|c|c|c|c|c|c|}
\hline $\begin{array}{l}\text { Processo } \\
\text { Observado }\end{array}$ & Documentos & Ferramentas & Entradas & Saídas & cipantes \\
\hline $\begin{array}{l}\text { Análise do } \\
\text { Cronograma de } \\
\text { produção }\end{array}$ & $\begin{array}{l}\text { Cronograma } \\
\text { de produção } \\
\text { entregue pela } \\
\text { contratada. }\end{array}$ & $\begin{array}{l}\text { Microsoft } \\
\text { Project } \\
\text { Professional }\end{array}$ & $\begin{array}{l}\text { Cronograma de } \\
\text { Produção } \\
\text { entregue pela } \\
\text { contratada e } \\
\text { dados de } \\
\text { produtividade de } \\
\text { obras similares já } \\
\text { executadas pela } \\
\text { empresa. }\end{array}$ & $\begin{array}{l}\text { Identificação } \\
\text { das fases e } \\
\text { peças de } \\
\text { montagem por } \\
\text { dia de } \\
\text { produção, } \\
\text { projeção da } \\
\text { produtividade } \\
\text { de montagem } \\
\text { da obra. }\end{array}$ & $\begin{array}{l}\text { Especia- } \\
\text { lista BIM }\end{array}$ \\
\hline
\end{tabular}




\begin{tabular}{|c|c|c|c|c|c|}
\hline $\begin{array}{l}\text { Processo } \\
\text { Observado }\end{array}$ & Documentos & Ferramentas & Entradas & Saídas & cipantes \\
\hline $\begin{array}{l}\text { Representação } \\
\text { do Planejamento } \\
\text { do } \\
\text { Sequenciamento } \\
\text { de Montagem no } \\
\text { Revit }\end{array}$ & & $\begin{array}{l}\text { Revit } \\
\text { Architecture® }\end{array}$ & $\begin{array}{l}\text { Identificação do } \\
\text { sequenciamento } \\
\text { de montagem } \\
\text { das peças e } \\
\text { dados de } \\
\text { projeção da } \\
\text { produtividade. }\end{array}$ & $\begin{array}{l}\text { "Story Board" } \\
\text { com } \\
\text { sequencia- } \\
\text { mento de } \\
\text { montagem dia } \\
\text { a dia. }\end{array}$ & $\begin{array}{l}\text { Especia- } \\
\text { lista BIM }\end{array}$ \\
\hline $\begin{array}{l}\text { Desenvolvimento } \\
\text { da tabela de } \\
\text { controle da } \\
\text { produção }\end{array}$ & & $\begin{array}{l}\text { Revit } \\
\text { Architecture } \AA\end{array}$ & $\begin{array}{l}\text { "Story board" do } \\
\text { sequenciamento } \\
\text { de montagem e } \\
\text { dados de } \\
\text { produtividade de } \\
\text { obras anteriores. }\end{array}$ & $\begin{array}{l}\text { Planilhas com } \\
\text { identificação } \\
\text { por dia das } \\
\text { peças que } \\
\text { serão } \\
\text { montadas no } \\
\text { período } \\
\text { (plantas por } \\
\text { pavimento e } \\
\text { modelo 3D) e } \\
\text { espaços para } \\
\text { preenchimento } \\
\text { pela equipe do } \\
\text { tempo de mon- } \\
\text { tagem por } \\
\text { peça. }\end{array}$ & $\begin{array}{l}\text { Especia- } \\
\text { lista BIM }\end{array}$ \\
\hline
\end{tabular}

\section{Fonte: Estudo de Caso}

$\mathrm{Na}$ análise do cronograma, o especialista BIM faz uma avaliação do cronograma de produção entregue pela contratada para determinação das atividades que compõem o caminho crítico da montagem de pré-moldados.

Como o cronograma entregue não apresenta o detalhamento da montagem peça a peça, o especialista BIM se utiliza de dados de produtividade de montagem de obras anteriores para determinar o conjunto de elementos que serão montados por dia. Foi comentado pelo entrevistado que, nos próximos 
empreendimentos de pré-fabricados, se prevê a modelagem do processo de produção também dos acabamentos e demais elementos construtivos.

Para a representação do planejamento do sequenciamento de montagem é utilizada a ferramenta Phases do Revit Architecture® para identificação das peças que serão montadas por dia. A ferramenta permite que se observe 0 sequenciamento com a apresentação, em cores mais destacadas da produção prevista para aquele dia, e em cores menos destacadas o que já foi produzido.

Nesse ponto, é estudada a logística de montagem da obra, que deve considerar todo o sequenciamento e avaliar as melhores condições para a entrada de peças de maior tamanho e impacto, como os banheiros prontos existentes no empreendimento.

Após a proposta de sequenciamento de montagem pelo núcleo BIM, é realizada uma reunião com a equipe de produção (gerente de produção da empresa e contratada) para validar ou propor modificações à sequencia modelada, avaliação dos prazos previstos e validação de uma versão final, que será produzida como padrão de sequenciamento e dará entrada para o desenvolvimento da tabela de controle da produção.

\subsection{CONTRATOS DE PROJETOS DE MODELAGEM DA INFORMAÇÃO DA CONSTRUÇÃO}

O documento contratual disponibilizado para análise pela empresa estudada foi o template do modelo de contrato padrão para projetos de modelagem da informação da construção. Segundo o especialista BIM, responsável pelos contratos com fornecedores de projetos, além do contrato padrão, são enviados aos fornecedores alguns documentos anexos, que também têm validade contratual (Cronograma, documentos de planejamento e especificação das entregas - tabelas de níveis de desenvolvimento (LOD) dos modelos e projetos em 2D).

A estrutura padrão do contrato disponibilizado está desenhada na Tabela 17. 
I. Objeto

Elaboração de Projetos da disciplina X para o empreendimento $Y$

II. Escopo

Determinação das etapas de projeto, conforme previstas na NBR

13531/95: Elaboração de Projetos de Edificação

$>$ Preveem-se as seguintes etapas de projeto:

Levantamentos / Programa de Necessidades / Estudo

de Viabilidade / Anteprojeto / Projeto Legal / Projeto

Básico / Projeto para Execução / Liberado para Obra

Aponta a necessidade de previsão de etapas de licitação para as etapas a partir de projeto básico

Determinação de entregas físicas às quais se relacionam os itens econômicos e financeiros do contrato

Escopo técnico, com descrição das atividades e requisitos de informação do projeto por etapa, assim como os produtos (entregas e entradas para atividades sequenciais de clientes internos) de cada etapa.

III. Formas de Entrega

Bidimensional

RVT, DWG, Memorial Descritivo, Upload em "gerenciador de arquivos"e maquete.

Tridimensional (BIM)

$>$ RVT, Memorial descritivo, Upload em "gerenciador de arquivos" e maquete RVT.

Em acordo com o LOD definido pela empresa 
Formatos de entrega: upload em gerenciador de arquivos ou mídias (CD)

Representação das Entregas: plantas em CAD, com referencial determinado, carimbos e padrões JHSF.

IV. Prazo

Determina a necessidade de definição de prazo para as entregas e etapas de projeto e cronograma estruturado das entregas

V. Preço

Prevê a determinação do valor a ser remunerado entre a contratante (empresa caso) e a fornecedora de serviços de projeto.

VI. Faturamento

Prevê a determinação das condições de faturamento acordadas entre a contratante (empresa caso) e a fornecedora de serviços de projeto.

VII. Condições de Pagamento

Prevê a determinação das condições de pagamento acordadas entre a contratante (empresa caso) e a fornecedora de serviços de projeto.

VIII. Cláusulas e condições adicionais

Declarações

Emissão de ART pela contratada

Cláusula de comparecimento a reuniões (não determina um número previsto)

Compatibilização dos projetos da contratada com os demais projetos

Atendimento aos prazos estabelecidos 
Prevê aditivo desde que de etapas já recebidas tenham sido aprovadas pelo contratante e com prévia aprovação do orçamento por horas técnicas pela contratante

Prevê multa sobre atraso no pagamento de projeto de $2 \%$

Previsão, sem custos adicionais, de tantas revisões de projeto quantas forem necessárias, mesmo que a origem das revisões sejam de terceiros.

Projetos devem estar em acordo com as normas referentes.

Rescisão Contratual

$>$ Pela contratante por não cumprimento do contrato

$>$ Pela contratante por insolvência ou falência

$>$ Pela contratada no caso de não pagamento das obrigações pela contratante (com prazo de $\mathbf{3 0}$ dias para regularização)

Obrigações da Contratada

Fornecimento dos projetos conforme escopo técnico.

$>$ Uso de profissionais registrados

$>$ Garantia de segurança no trabalho para seus profissionais

$>$ Emissão de N.F. e pagamentos de impostos

> Cumprimento com a legislação e normas vigente e com as normas da contratante

Sigilo e confidencialidade quanto a qualquer informação referente ao empreendimento e à contratante

Inexistência de vínculos trabalhistas entre as partes 
Cessão de direitos autorais da contratada pela contratante, podendo ser usados livremente pela contratada.

IX. Anexos

Proposta

Cronograma

Planejamento

Especificações

Fonte: Estudo de Caso

\subsection{ANÁLISE DO ESTUDO DE CASO}

\subsubsection{Quanto ao modelo de implementação da modelagem da informação da construção na empresa caso}

Observou-se, nas atividades de acompanhamento, que o modelo proposto pela empresa para implementação da modelagem da informação da construção no processo do empreendimento não está sendo aplicado em sua integridade.

Foi demonstrado que o Núcleo BIM da empresa estruturou suas atividades para possibilitar o uso da modelagem da informação da construção como ferramenta auxiliar ao processo de projeto, porém ainda não se veem sinais de transição do estágio de Pré-BIM (SUCCAR, 2009) para os estágios mais avançados de uso da modelagem, pois não há reversão nos processos da empresa, os quais ainda se baseiam (i) no processo 2D, (ii) em entregas físicas de documentos e (iii) no desenvolvimento de relações contratuais unilaterais com seus fornecedores de serviços.

A criação de um setor interno de engenharia avançada, capacitada para atender a demandas pontuais pode ser interpretada como remediação, e não 
está alinhada com um processo de implementação da modelagem da informação da construção como inovação dentro da empresa. Não há previsão de internalizar os processos de modelagem dentro dos setores pré-existentes da empresa, ou da capacitação de seus profissionais, causando uma dependência pessoal dos profissionais do núcleo BIM, levando, portanto, à fragilidade dos processos com uso da modelagem da informação da construção.

Também, a escolha pela modelagem interna de projetos em 2D e o afastamento da empresa da responsabilidade de capacitação de seus fornecedores, em especial de projetos, não contribui para estruturação do mercado. Apesar de ter conhecimento para trabalhar em modelagem, e ter estruturado seu processo para aspectos de colaboração, e tendo em vista os objetivos da empresa para uso do modelo, essa demanda não é repassada para seus fornecedores, que continuam desenvolvendo seus projetos em 2D, sem perspectiva de mudança.

A partir da lógica de terceirização com a qual o mercado da construção civil trabalha atualmente, o modelo de implementação utilizado pela empresa estudada não pode ser considerado sustentável a longo prazo.

Além disso, a empresa-caso apresenta uma situação privilegiada, pois conta com profissionais qualificados, tanto no tema de modelagem quanto tecnicamente, o que lhe permite obter resultados positivos desse trabalho em conjunto das áreas. Porém, tal quadro não se estende às demais empresas de mercado, e há escassez de profissionais qualificados nesses quesitos e com habilidades de trabalho em grupo, motivo pelo qual a perda desses profissionais causaria um retrocesso no processo de implementação e perda dos benefícios alcançados com a modelagem. Assim, a situação atual da empresa pode ser considerada instável. 


\title{
6.5.2 Quanto ao processo de projeto e às atividades que utilizam a modelagem da informação da construção
}

\begin{abstract}
Apesar de declarar preferência por fornecedores de projetos qualificados para produção em modelagem (em especial nas especialidades de arquitetura e estrutura), o relacionamento da empresa-caso com seus contratados é estritamente transacional, no que diz respeito ao processo de projeto. Ainda que ambas as partes estejam incumbidas da produção de modelos (contratadas - arquitetura e estrutura, contratante - instalações), o processo é a exata réplica do processo sequencial em 2D, que ocorre em paralelo, conforme apresentado nas Figuras 23 e 24.
\end{abstract}

Os modelos são recebidos, analisados e devolvidos para os projetistas, sem disponibilizar as informações de outras especialidades. Mesmo no processo de compatibilização, não há compartilhamento de informações de modelagem, somente um relatório de pendências.

Esta postura diverge dos arranjos e artefatos que a empresa desenvolveu para o trabalho em modelagem da informação da construção, que tem características de suporte à colaboração, como o desenvolvimento de templates, a estruturação das especificações de nível de desenvolvimento e a estrutura de custos associada à modelagem.

Nota-se que, em suas atividades rotineiras, a empresa trabalha com relações colaborativas entre seus departamentos, e isso tem reflexo no processo de projeto. A participação de especialistas da empresa (profissionais com mais experiência técnica e conhecimento da cultura de produção da empresa) nas tomadas de decisão de projeto, por exemplo, contribui para as tomadas de decisão e soluções de projeto. O mesmo ocorre no trabalho do Núcleo BIM, no estudo de soluções de concepção de projetos, em que desenvolvem alternativas do produto e as propõem para os arquitetos fornecedores. Esta postura proativa em relação ao desenvolvimento de soluções está alinhada com os modelos de trabalho colaborativo que dão suporte ao Projeto Integrado, 
porém ocorre somente internamente à empresa, entre seus diferentes departamentos.

\subsubsection{Quanto ao modelo de contrato utilizado}

O modelo de contrato utilizado é aderente ao processo de projeto existente na empresa-caso. No entanto, isso ocorre, pois o processo atual é tradicional, em 2D. Não existe, na empresa-caso, processo de projeto apropriado ao uso da modelagem da informação da construção, situação em que este contrato não seria adequado.

A estrutura formal do contrato prevê cláusulas de mitigação de risco para a contratante, e somente para ela. Descreve uma série de responsabilidades, para com o cumprimento do escopo, atendimento aos prazos, comportamento da contratada em relação à contratante (reuniões, confidencialidade) e atribui a todas estas o risco de aplicação de multa caso não sejam atendidas. Não há, no entanto, qualquer exigência referente à contratante, quanto às suas responsabilidades (exceto a necessidade de remuneração da contratada). $O$ contrato, portanto, enquadra-se na categoria transacional, sem qualquer vínculo ou relacionamento adicional a seu escopo entre as partes.

A partir da análise do processo da empresa, foi identificado o potencial para desenvolvimento de relações mais colaborativas entre ela e suas contratantes, que poderiam consolidar-se nas bases de um contrato relacional.

A inclusão nos documentos contratuais de especificações de nível de desenvolvimento (LOD), planejamento das entregas (planos de trabalho e cronogramas) e dos modelos produzidos pelas contratadas criam um pano de fundo para o início da aplicação de contratos relacionais, com a finalidade de embasar um relacionamento de trabalho colaborativo. Para tanto, seria necessária a estruturação de um processo de projeto colaborativo com uso da modelagem da informação da construção e não apenas das aplicações pontuais de suas ferramentas. 
Nesse momento, não se observa na empresa postura que aponte para a colaboração com suas prestadoras de serviço de projetos em modelagem. Entende-se que isso possa ser reflexo dos vários anos de desenvolvimento de empreendimentos na estrutura transacional, e do desenvolvimento de resistência a modelos contratuais e de trabalho que apresentem maior risco para a contratante.

Somam-se a isso, características da empresa como incorporadora e construtora de civil de capital aberto, em que os acionistas estão em situação favorecida pela isenção de riscos e bons resultados dos negócios.

\subsubsection{Comparação entre a estrutura contratual de projetos integrados e da empresa caso.}

Conforme identificado, a empresa-caso possui estrutura para 0 desenvolvimento de um processo de projeto colaborativo. Para tanto, seria necessária uma adequação dos processos para incorporação da nova metodologia de trabalho e desenvolvimento dessa etapa do ciclo de vida do empreendimento.

A partir das ferramentas e dos potenciais de uso da modelagem da informação da construção observados na empresa-caso, este item da dissertação compara na Tabela 18 a estrutura do contrato atual da empresa com a estrutura para projeto integrado, propostas nos modelos B295 e C195, do AIA.

A partir dessa análise são apontados os itens que poderiam ser implementados no contrato existente da empresa para embasamento de uma relação colaborativa, mesmo que estes sejam ainda os modelos de documento de transição para o Projeto Integrado.

O documento "A295 - Condições Gerais de contrato para Projeto Integrado", do AIA, é normalmente apresentado como anexo ao documento de contrato entre as partes. Seu conteúdo determina os escopos de serviços e os deveres de todas as partes (arquitetos e projetistas, construtora e incorporadora). Também 
está prevista no A295 a estrutura de trabalho colaborativa e a definição das seis etapas de projeto do empreendimento.

Sua importância junto ao contrato que estabelece o relacionamento entre as partes (B195) é determinar o ambiente e as condições de contorno para o relacionamento, no caso em questão, entre projetistas e cliente. $O$ estabelecimento de informações, referentes ao conteúdo das etapas de projeto ao uso da modelagem da informação da construção e dos escopos de cada uma das partes, alinha a expectativa e reduz a possibilidade de ocorrência de conflitos.

O B195 - Formulário padrão de contrato entre Incorporadora e Arquiteto para Projeto Integrado estabelece o acordo entre esses dois agentes, dentro dos princípios do projeto integrado. São determinados os termos gerais do negócio e estabelecidos os termos de relacionamento entre as partes, como detalhes de compensação e licenciamento de instrumentos de serviço.

Tabela 18: Comparação entre os modelos de contrato do AIA e o modelo de contrato padrão da empresa caso

\section{Itens ou}

cláusulas de contrato
Contrato de projetos padrão da

B195 e A295

\section{Estabelecem os papéis dos agentes contratados (projetistas e construtora) e as exigências referentes aos cargos.}

Contratação

Determina os critérios e justificativas para o encerramento dos contratos e para a contratação de novos profissionais.
Não possui item referente à contratação

\section{Descrição de cada uma das etapas de}

Escopo

$$
\text { projeto }
$$

Definição do papel de cada um dos
Identificação das etapas de projeto conforme legislação 


\begin{tabular}{|c|c|c|}
\hline & $\begin{array}{l}\text { agentes e interação entre eles nas } \\
\text { diferentes etapas de projeto. } \\
\text { Determinação das informações a } \\
\text { serem desenvolvidas pelos agentes } \\
\text { em cada etapa do processo. }\end{array}$ & $\begin{array}{l}\text { físicas de projetos } \\
\text { Descrição dos requisitos de } \\
\text { informações por etapa de } \\
\text { projeto, por etapa, e seus } \\
\text { respectivos produtos. }\end{array}$ \\
\hline Entregas & $\begin{array}{l}\text { Prevê a disponibilização de } \\
\text { informações e serviços requeridos do } \\
\text { agente (projetistas, construtor e } \\
\text { cliente) em cada uma das etapas de } \\
\text { projeto. } \\
\text { Os principais itens descritos são: } \\
\text { - Informações (de projeto associadas } \\
\text { ao modelo em acordo com a } \\
\text { linguagem e software estabelecidos } \\
\text { no contrato) } \\
\text { - Cronograma de serviços da } \\
\text { especialidade } \\
\text { - Cronograma de serviços integrado } \\
\text { com os demais } \\
\text { - Relatórios de avaliação } \\
\text { - Propostas }\end{array}$ & $\begin{array}{l}\text { Prevê os formatos de entregas: } \\
\text { - Bidimensional (RVT, DWG, } \\
\text { memoriais e uploads no } \\
\text { gerenciador) } \\
\text { - Tridimensional (RVT, } \\
\text { memoriais, uploads no } \\
\text { gerenciador, e maquete } \\
{ }^{*} \text {.RVT). Devem atender ao } \\
\text { LOD adequado à etapa de } \\
\text { projeto }\end{array}$ \\
\hline Prazo & $\begin{array}{l}\text { Prevê cláusulas de concordância com } \\
\text { os prazos atualizados do cronograma } \\
\text { integrado (produzido em conjunto e } \\
\text { aceito por todos os agentes). }\end{array}$ & $\begin{array}{l}\text { Determina os prazos para as } \\
\text { entregas por etapa de projeto, } \\
\text { conforme cronograma. }\end{array}$ \\
\hline Preço & $\begin{array}{l}\text { O preço base é estabelecido pelo } \\
\text { planejamento do custo do trabalho por } \\
\text { etapa de projeto e frentes de trabalho. } \\
\text { O modelo contratual prevê um sistema } \\
\text { de controle de custos mensais do } \\
\text { trabalho que deve ser monitorado com } \\
\text { frequência e realizar previsões } \\
\text { estimadas de acompanhamento do } \\
\text { planejado. }\end{array}$ & $\begin{array}{l}\text { Prevê o valor a ser remunerado } \\
\text { pelos serviços da contratada. }\end{array}$ \\
\hline
\end{tabular}


Ao fim do projeto será realizada a

distribuição dos resultados conforme

acordado entre as partes.

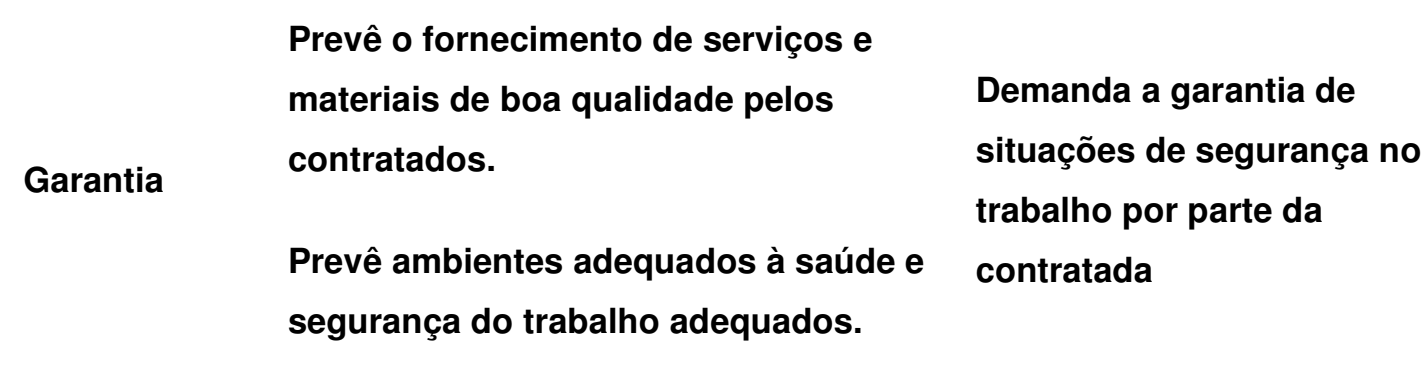

Solicitação de declarações de

concordância com a legislação

Prevê como responsabilidade

da contratada a

Atendimento às normas vigentes

compatibilização com os

Cláusulas e

Previsão de exceções no caso da

condições

adicionais

ocorrência de acidentes naturais e

demais projetos (com revisões

a seu próprio custo)

outros eventos de previsibilidade

Exigência de sigilo e

reduzida.

confidencialidade quanto a

informações do

empreendimento e do cliente

Previsão de multas de não

cumprimento de cláusulas

Identifica o modelo e todos os

documentos citados como parte do

corpo contratual. Utiliza referências de

Anexos outros documentos do AIA como o de

Propostas de trabalho de

projetos

determinação de nível de

desenvolvimento (LOD) para

especificações.

Cronograma de projetos

Especificações (LOD e outras

diretrizes da empresa)

Fonte: Estudo de Caso

Com objetivo de analisar o potencial de implementação de aspectos do projeto integrado na empresa-caso, foram avaliados os seguintes aspectos: 
- Quanto à incorporação de cláusulas referentes à contratação de fornecedores

O documento contratual da empresa-caso poderia incorporar em seu texto as definições dos papéis dos agentes em ambos os lados do acordo, suas reponsabilidades no que se refere a aprovações ou ao desenvolvimento de atividades, disponibilização de informações e validações na passagem de etapas de projeto. Da maneira como se apresenta, o contrato atual é unilateral e dispõe de cláusulas que beneficiam somente a contratante, o que, conforme demonstrado pela revisão bibliográfica, não possibilita o estabelecimento de uma relação de colaboração que agregue valor ao empreendimento.

- Quanto à definição do escopo contratual

A identificação das etapas de projeto conforme a NBR 13.531 não é adequada aos requisitos de informação solicitados para o desenvolvimento dos modelos 3D especificados nos níveis de desenvolvimento estabelecidos (LOD). A norma de 1995 ainda não atualizada não pode ser aplicada para projetos de modelagem. Assim, dois documentos que compõem o corpo contratual apresentam demandas incompatíveis. O fornecedor de serviços deve atender à solicitação mais alta, no caso a especificação do nível de desenvolvimento do projeto (LOD). Esta incompatibilidade leva o fornecedor a desenvolver os projetos em um prazo diferente do previsto para o processo em 2D, o que pode gerar perdas de qualidade, ou mesmo gerar custos imprevistos para as projetistas.

Levando-se em conta a situação atual da empresa, que ainda considera necessário o desenvolvimento do processo tradicional em paralelo, uma solução para a questão seria incorporar no contrato (ou como anexo) uma descrição das etapas de projeto e das informações requeridas em cada uma delas, utilizando-se critérios equivalentes para os dois processos (2D e modelagem). 
A determinação isolada dos produtos das etapas como "entregas" é tipicamente transacional, e opõe-se à proposta relacional que aborda a interação dos agentes nos processos e etapas do projeto. Não há no modelo da empresa-caso qualquer referência a esses pontos de interação, ocultando interfaces que podem ser conflituosas e cujos protocolos de resolução poderiam ser previstos no contrato. A proposta nesse caso é avaliar os pontos críticos do processo de projeto e propor mecanismos preventivos que facilitem a tomada de decisão ou evitem a criação de gargalos e retrabalho.

- Quanto à especificação das entregas de projeto

Quanto à determinação dos produtos de controle da produção ou entregas, sugere-se a associação do modelo como parte do documento contratual, para que seja utilizado na extração de informações de produção. No entanto, dada a sua utilização pontual no processo e o uso de somente uma disciplina para projetos modelados esse fim torna-se limitado. A descrição dos níveis de detalhamento é adequada, pois permite a avaliação das etapas produzidas baseadas nas informações requeridas para as decisões necessárias àquela etapa, e contempla a evolução dessas informações durante o processo de projeto. Também é adequada a determinação da extensão de arquivos e linguagens a serem utilizadas no processo. Além disso, os modelos do AIA agregam ao documento contratual os cronogramas atualizados (com replanejamento conjunto entre contratante e contratada), relatórios de avaliação do modelo e do processo (que possibilitam a retroalimentação dos requisitos da empresa por processos de gestão do conhecimento), assim como as propostas originalmente enviadas pelos projetistas, que podem conter detalhes que fogem ao escopo do contrato. Não há restrição para incorporação desses itens no modelo da contratada.

- Quanto à determinação de prazos e cronogramas

A elaboração conjunta do planejamento e cronograma de atividades integradas coloca a contratada em uma condição mais favorável de avaliação dos prazos. As contribuições da contratante na determinação de prazos para as atividades 
sob sua responsabilidade permitem também uma maior assertividade nos prazos estipulados.

Além disso, entende-se que o cronograma deva abordar o processo com foco no fluxo de informações entre as etapas e os agentes envolvidos, e não somente o apontamento de uma data de entrega que não leva em consideração a cadeia de eventos que a tornam possível. Essas melhorias não são exclusivas ao uso da modelagem da informação da construção e poderiam ser incorporadas pela coordenação de projetos da empresa estudada em todos seus contratos.

No caso do aumento da maturidade da empresa estudada na utilização da modelagem da informação da construção, torna-se ainda mais essencial à relação do planejamento com o fluxo de informações, o que permitirá a colaboração dos envolvidos na construção do modelo, ao invés de determinar controles pontuais de entregas.

- Quanto aos preços praticados e à gestão de custos

Neste momento existe uma série de restrições à aplicação do modelo de compartilhamento previsto no Projeto Integrado. O primeiro refere-se à gestão dos custos pelas empresas projetistas. Segundo Souza (2009), observa-se que os controles e demonstrativos associados à gestão financeira da maior parte das empresas de projeto são precários ou sequer existem. Assim, os controles de custos necessários para a determinação da diferença de resultado que poderá ser compartilhada, sem comprometer a saúde financeira da empresa, são indetectáveis. Também é impreciso o apontamento de preços para os serviços prestados.

Segundo Oliveira (2008), há modelos de sistemas estruturados de custo, apropriados às necessidades dessas empresas, e que são desenvolvidos com enfoque nas rotinas relacionadas à mensuração de seus custos operacionais, que poderiam ser adotados com facilidade pelos fornecedores de projeto. 
Porém, atualmente, esta limitação é restritiva para a implementação do modelo de compartilhamento conforme os moldes do Projeto Integrado.

Uma alternativa é o estabelecimento de metas de produção e metas de resultado, associadas a bônus financeiros para as empresas. No entanto, essa configuração ainda não estabelece uma relação colaborativa entre fornecedor e cliente e o valor agregado pela participação do cliente no processo é reduzido.

- Sobre as cláusulas e condições adicionais

Como observação das condições adicionais estabelecidas no contrato padrão da empresa-caso, nota-se que existem somente cláusulas restritivas aplicadas à contratada. São cláusulas que cerceiam a atuação das projetistas e não incitam a criatividade pela adoção de soluções inovadoras.

\subsubsection{Obstáculos gerais do mercado brasileiro de construção à implementação do projeto integrado}

Além das dificuldades para a implementação do Projeto Integrado, inerentes ao processo de projeto e características da empresa-caso, há empecilhos relacionados a características do mercado brasileiro da construção civil em geral.

Uma dessas dificuldades refere-se à estruturação dos custos do empreendimento para um orçamento preciso, com uso da modelagem da informação da construção, que não é possibilitada pelo modelo brasileiro de contratação separada das etapas de projeto e construção.

Gonçalves (2011) aponta a orçamentação por parametrização como alternativa ao levantamento e atribuição de valores por $\mathrm{m}^{2}$ construído, como é usual nas etapas iniciais dos projetos. Este método é adequado ao uso da modelagem da informação da construção, porém, em função da falta de padrões construtivos comuns a projetistas e construtoras no mercado brasileiro, pode haver um 
descolamento entre os valores orçados a partir do modelo e o custo real da construção.

Essa diferença entre os resultados extraídos do modelo e os resultados reais da edificação, que pode ter parâmetros modificados em relação ao projeto pela construtora, seria prejudicial aos resultados do projeto integrado. A perda de previsibilidade do custo ou mesmo de características de desempenho da edificação podem prejudicar a equipe do projeto se a obra não atender às metas previstas, reduzindo os resultados gerais do empreendimento e, portanto, reduzindo o lucro de todos os participantes do projeto integrado.

O mercado americano, berço do projeto integrado, apresenta uma situação mais favorável neste sentido, uma vez que a padronização de peças e elementos construtivos não permite uma divergência tão grande entre 0 produto do projeto e o orçamento que a construtora irá elaborar.

Além disso, no Brasil as construtoras prezam pela busca de alternativas que reduzam ao máximo o custo de construção, e geram divergências em relação às especificações de projeto. Nesse sentido, é fundamental a previsão de atividades como a preparação da execução de obras - PEO, para alinhamento da equipe de produção com os projetos entregues.

Diante deste quadro, a aplicação dos modelos de transição do projeto integrado proposta pelos documentos A195 (contrato de projeto integrado somente entre projetista e cliente) e B195 (contrato de projeto integrado somente entre construtora e cliente) do AIA é inadequada para o mercado brasileiro. A sua aplicação teria melhores resultados somente se houvesse colaboração da construtora com a incorporação e projetistas, por meio da disponibilização de suas bases de informações de custos unitários e no auxílio na definição de soluções com maior construtibilidade, mais próximas ao que ocorrerá na etapa de construção.

Além do afastamento da construtora da etapa de projetos, outro agente cuja antecipação é dificultada no mercado brasileiro de construção são as empresas fornecedoras de projetos para produção, como projeto de fachadas, esquadrias 
e outros. A dificuldade reside no afastamento do início do projeto e do momento de entrada/início de seus objetos de projeto na obra que, em empreendimentos de incorporação imobiliária, se aproximam de três anos.

A proposta do projeto integrado é a de que esses profissionais se comprometam em atividades de projeto colaborativo, sem obter remuneração direta, uma vez que a sua produção concreta é retardada em relação aos demais projetos. Uma alternativa para esta dificuldade seria a sua incorporação e remuneração como consultores, logo nas primeiras etapas de projeto.

Outro obstáculo para a implementação do projeto integrado no mercado brasileiro, apontado também na empresa-caso, é a dificuldade das empresas de projeto no dimensionamento de seus custos de produção. Além dos custos diretos relacionados ao projeto, existem questões de recursos humanos que devem ser refinadas: a estrutura de produção (pessoas) do escritório e a remuneração dos profissionais qualificados para produzir modelos de informação da construção devem aumentar.

Conforme apontado por Wang (2008), a colaboração demandada em um projeto integrado aumenta as horas dedicadas às atividades de projeto em $10 \mathrm{a}$ $20 \%$. Isto faz com que uma equipe dimensionada para atender a mais de um projeto ao mesmo tempo possa ter a sua produtividade reduzida, e talvez se faça necessária a contratação de mais profissionais para atender às demandas da empresa.

Outra questão consequente ao uso da modelagem da informação da construção é a incorporação de mais horas de profissionais de alta qualificação (arquitetos e engenheiros experientes) já nas primeiras etapas de projeto (concepção e definição de projeto), que se tornam mais caras do que no processo tradicional, o que irá afetar na remuneração dos projetistas.

No entanto, apesar do aumento dos custos e da importância das fases iniciais do empreendimento, prevê-se diminuição do retrabalho em função da redução de interferências e modificações proporcionadas pela confiabilidade de informações do modelo, o que dá ao incorporador maior segurança nas suas 
decisões, diminuindo, portanto, as solicitações de revisão e gerando um ganho de prazo total no projeto.

O compartilhamento de responsabilidades também é dificultado pela cultura resistente dos agentes da construção civil. A dimensão reduzida da maior parte dos escritórios de projeto coloca-os em posição desfavorável para assumir os custos de más decisões, sejam elas pessoais ou conjuntas, no caso do projeto integrado. Este seria um motivo para a baixa adesão das empresas de projeto ao modelo colaborativo.

Como protocolo para a redução desse risco devem existir definições claras sobre utilização do modelo como documento contratual, além de protocolos para gestão da informação, de forma que se evidenciem as decisões conjuntas da equipe do projeto integrado.

O último ponto de dificuldade para implementação do projeto integrado são as mudanças nos papéis de planejamento, orçamento e demais funções relacionadas ao processo de projeto causadas pelo uso da modelagem da informação da construção. A incorporação de novos processos, softwares e ferramentas, talvez exija a contratação de profissionais especialistas externos à empresa, gerando mais fragmentação no processo, e mais interfaces, situação que dificulta a colaboração prevista no projeto integrado. 


\section{CONSIDERAÇÕES FINAIS}

A implementação da modelagem da informação da construção já é uma realidade no Brasil, apesar do baixo nível de maturidade observado nas empresas que a empregam.

Parte das dificuldades de implementação pode ser atribuída aos processos tradicionais da cadeia produtiva da construção civil, que inibem a colaboração entre os agentes e reduzem o potencial do uso da modelagem.

A proposta de modelos alternativos como o projeto integrado vem ao encontro da necessidade de remodelagem dos processos e relações do mercado da construção civil, que não têm sido abordados nos processos de implementação praticados no Brasil.

O uso da modelagem gera uma nova relação de responsabilidade entre os agentes envolvidos na produção do empreendimento, uma vez que a criação do modelo é fruto de uma experiência conjunta, que deve ser refletida na redação dos contratos entre as partes interessadas.

Os principais obstáculos de mercado que originaram a criação do projeto integrado, enfatizados por Mathews e Howell (2005) são comuns ao mercado brasileiro, assim como os aspectos que dificultam a sua implementação:

- "Velhos hábitos são difíceis de ser eliminados": os agentes da construção civil têm dificuldade em modificar a estrutura de negócio, processo de projeto e inter-relacionamento entre os participantes do processo de um empreendimento do setor, principalmente pela fragilidade dos agentes de menor porte dentro da cadeia produtiva.

- "O único investimento adicional é de tempo, e, portanto, não infere custos adicionais": o tempo adicional requerido pela colaboração exigida em um projeto integrado deve ser considerado na estrutura de custo das empresas, e isto geraria um aumento no custo da fase de projetos do 
empreendimento. Esse aspecto é minimizado quando o cliente tem esclarecidos os benefícios e potenciais do uso do modelo colaborativo em comparação com os enfoques de contratação e gestão do empreendimento tradicionais. No Brasil, essa dificuldade é maior uma vez que as empresas, em especial as de projeto, têm grande dificuldade na gestão administrativa de seus negócios (SOUZA, 2009).

- "Implementação da produção puxada e otimização dos resultados deveriam ocorrer de cima para baixo: O cliente é o maior interessado no potencial do Projeto Integrado": há a necessidade de conscientização das partes para práticas racionalizadas, uma vez que todos influenciam no resultado final, porém, a cobrança do comprometimento de todos deve ser exercida pelo contratante, em especial no projeto integrado, quando ele é o maior beneficiado pelos potenciais resultados do empreendimento que 0 enfoque colaborativo e participativo pode gerar.

Essas dificuldades podem ser trabalhadas de maneira a facilitar a incorporação do projeto integrado e da modelagem da informação da construção, sendo a implementação a partir do cliente a de maior influência e impacto no mercado.

Há, porém, um obstáculo que deve ser observado e cuja solução tem sido pouco abordada nas iniciativas conhecidas de desenvolvimento da modelagem da informação da construção: a adoção da modelagem somente pelo viés da inovação tecnológica tem causado a reprodução de falhas de processos já existentes no processo tradicional de projeto, com o agravante, no caso da modelagem em que o ambiente de trocas de informação é mais rico e complexo, de multiplicação destas falhas, podendo gerar impactos ainda maiores do que no processo tradicional em 2D.

No processo tradicional, mesmo a tecnologia de reprodução de projetos mais amplamente utilizada (CAD) não foi explorada em seu potencial completo. É comum observar falhas técnicas com impactos relevantes no processo de projeto associadas ao mau uso da tecnologia (por exemplo: padrões de representação, referenciamento, pontos de origem e escalonamento, entre 
outros), e os mesmos problemas tem sido transferidos para processos de modelagem da informação da construção.

Além da falta de atenção a problemas associados à tecnologia, em um processo mais complexo e com maior número de agentes envolvidos com participação simultânea - e possivelmente colaborativa - são necessários mecanismos de gestão e coordenação do fluxo de informações mais eficazes, e uma compreensão e controle mais precisos do processo de projeto. A solução para estes empecilhos seria o desenvolvimento de pesquisas voltadas ao desenvolvimento de modelos para gestão na modelagem da informação da construção, e a maior capacitação dos coordenadores de projetos para suas funções específicas.

No Brasil, a implementação da modelagem da informação da construção no mercado tem sido iniciativa de empresas construtoras, que conseguem alcançar benefícios imediatos com o uso da modelagem, como a precisão orçamentária, o planejamento da construção e a redução de incompatibilidades. Porém, os maiores benefícios que podem ser alcançados com a modelagem da informação da construção são atribuído aos proprietários, durante a gestão de ativos (facilities).

O uso da modelagem da informação da construção na gestão de ativos permite a gestão estruturada a partir do modelo da maior parte do ciclo de vida da edificação, que é o seu uso e operação. Algumas das atividades que ocorrem a partir do modelo nesta fase são: programação e controle de desempenho da edificação com uso do modelo, registro de informações do edifício e agendamento das atividades de manutenção, gestão de bens e recursos (inseridos no edifício e modelo) e registro atualizado das condições do edifício.

Com a flexibilização das áreas de atuação das principais incorporadoras do país, que têm investido em empreendimentos dos quais se tornarão proprietárias, o uso da modelagem da informação da construção ganha força junto ao agente de maior influência no mercado da construção. 
Uma vez interessado nos resultados do empreendimento a longo prazo, o incorporador buscará em investir em processos que garantam soluções duráveis e de alto desempenho para a sua edificação, e o projeto integrado torna-se uma alternativa mais interessante do que é no modelo atual de incorporador desligado da operação do empreendimento.

O objetivo de discussão dos modelos de contratação de empreendimentos da construção civil apropriados ao uso da modelagem da informação da construção enquanto mecanismos de suporte à colaboração entre os agentes do empreendimento levou à identificação, na empresa caso, dos empecilhos à aplicação dos modelos propostos pelo AIA, e às necessidades de adequação de processos para suporte à colaboração.

A abordagem do painel mais abrangente de dificuldades, aplicadas não somente à empresa caso, mas ao mercado da construção civil como um todo, apontou para problemas relacionados à gestão de processos e interfaces, aspectos que podem ser melhorados pelo uso do projeto integrado, ainda que parcialmente.

Os aspectos de possível implementação imediata são apontados no capítulo 6 na avaliação da aderência do contrato da empresa caso ao seu processo de projeto. As observações feitas quanto aos pontos de utilização de práticas colaborativas consistentes com o projeto integrado são específicas dessa empresa, em função das características de exclusividade do processo de projeto da construção civil.

Entende-se, porém, que o modelo de análise do contrato e sua comparação com o processo de projeto de modelagem da informação da construção apontará, em qualquer empresa na qual se aplique, pontos de melhoria que permitem a adoção de práticas colaborativas, e, em longo prazo, do projeto integrado.

Os resultados das análises apresentadas nesta dissertação apontam para a possibilidade de adequação do processo de projeto observado no estudo de caso a aspectos mais eficientes utilizados em contratos colaborativos. $\mathrm{O}$ item 
7.1, a seguir, busca apontar estes aspectos e propõe contribuições práticas a partir da pesquisa realizada.

\title{
7.1 PROPOSTA DE DIRETRIZES PARA ADEQUAÇÃO DO PROCESSO OBSERVADO DE CONTRATAÇÃO DE PROJETOS DE MODELAGEM DA INFORMAÇÃO DA CONSTRUÇÃO
}

\begin{abstract}
Abaixo estão descritas propostas de diretrizes para dois grupos representativos da cadeia da construção civil e principais partes interessadas nos contratos de projeto (contratante/incorporadora e contratada/projetista), além de diretrizes que poderiam exploradas no âmbito setorial e acadêmico com o objetivo de facilitar a multiplicação das práticas colaborativas propostas:
\end{abstract}

\section{I) Qualificação das empresas de projeto na gestão administrativa de seus negócios}

\section{Empresas Contratantes}

- Demanda de controles de gestão adequados aos projetos colaborativos - gerando a necessidade de qualificação por parte dos prestadores de serviços

- Preferência à contratação de empresas bem estruturadas e com controles gerenciais implementados

\section{Empresas de Projeto}

- Contratação de profissionais com qualificação em gestão de projetos, investimento no estabelecimento de relações de mútuo investimento com seus profissionais - oferecimento de cursos, treinamentos e etc.

Âmbito Setorial

- Definição de atividades gerenciais acessórias à função produção das empresas de projeto como escopo de atuação de empresas projetistas e consultoras do setor de construção civil

- Elaboração e oferta de cursos para capacitação dos profissionais em atividades gerenciais ligadas à produção de projetos

Âmbito Acadêmico 
- Ajuste curricular para capacitação dos alunos de graduação de arquitetura e engenharia em habilidades de gestão de empresas e de projetos, em disciplinas que cubram os conceitos gerais de gestão de projetos e a especificidade da gestão no setor da construção civil

- Oferta de cursos de pós graduação e especialização em gestão de projetos na construção civil

\section{II) Fomento às práticas relacionais e colaborativas entre os agentes da cadeia produtiva dos empreendimentos}

Empresas Contratantes

- Utilização de contratos relacionais como instrumentos para incentivar a colaboração entre os agentes, uma vez que possuem o maior poder de influência na cadeia produtiva e são os maiores interessados nos potenciais resultados da colaboração entre os agentes

- Definição clara dos papéis e responsabilidades das partes interessadas, estabelecidos em conjunto com os envolvidos

- Definição dos padrões de ferramentas, processos e produtos alinhamento das expectativas entre todos os envolvidos e possibilidade de interoperabilidade durante a produção do projeto do empreendimento e sua construção

- Maior reconhecimento - por meio de ajustes de remuneração - da importância dos projetos na produção de empreendimentos

- Remuneração da participação de consultores nas etapas iniciais do processo de projeto (usualmente são tratadas como "consultas" e não remuneradas)

\section{Empresas de Projeto}

- Discussão dos papéis e responsabilidades das partes interessadas em conjunto com os contratantes, representantes setoriais e academia

- Postura participativa e colaborativa com seus contratantes e parceiros de projeto e construção - para tanto, é necessária a compreensão dos benefícios das práticas relacionais no mercado da construção civil

\section{Âmbito Setorial}

- Desenvolvimento de modelos de contratos relacionais e ambientes colaborativos para empreendimentos da construção civil

- Oferta e comunicação setorial destas alternativas de métodos de produção, fomentando a discussão entre as partes para aprimoramento dos modelos já existentes (internacionais) e adequação ao setor da construção civil brasileira 


\section{Âmbito Acadêmico}

- Desenvolvimento de projetos de pesquisa sobre a aplicação de contratos relacionais e ambientes colaborativos nos empreendimentos da construção civil

- Estabelecimento de canais de comunicação com contratantes, projetistas e representantes setoriais para esclarecimento sobre modelos colaborativos de produção e de contrato, seus benefícios e análise de adequação ao setor no Brasil

III) Qualificação das partes interessadas no desenvolvimento de empreendimentos com a modelagem da informação da construção e práticas relacionais

Empresas Contratantes

- Multiplicação de conhecimento entre as partes interessadas. Como principais interessadas, cabe às empresas contratantes o fomento e, se possível, oferta de cursos, treinamentos e especializações para seus profissionais e parceiros - fornecedores de serviços, projetistas, consultores, etc. - nas ferramentas de modelagem e práticas relacionais

Empresas de Projeto

- Busca por qualificação de seus profissionais nas ferramentas de modelagem e práticas relacionais

Âmbito Setorial

- Oferta de cursos, treinamentos e especializações nas ferramentas de modelagem e práticas relacionais

Âmbito Acadêmico

- Desenvolvimento de pesquisas, oferta de cursos e especializações nas ferramentas de modelagem e práticas relacionais

IV) Desenvolvimento dos processos relacionados à implantação da modelagem da informação da construção com o mesmo grau de importância dado à implantação de novas tecnologias

Empresas Contratantes / Empresas de Projeto

- Análise de seus processos de projeto com identificação das interfaces que sofrerão modificação ou podem ser adequadas, melhoradas e/ou 
potencializadas com o uso da modelagem da informação da construção para desenho dos processos

\section{Âmbito Setorial}

- Oferta de seminários, cursos e treinamentos relacionados à gestão de processos na construção civil, e a sua importância na implantação de inovações nas empresas do setor

- Maior ênfase no desenvolvimento de processos relacionados à implantação da modelagem da informação da construção nos seminários e cursos oferecidos relacionados ao tema

\section{Âmbito Acadêmico}

- Oferta de disciplinas relacionados à gestão de processos na construção civil, e a sua importância na implantação de inovações nas empresas do setor, e em especial na implantação da modelagem da informação da construção

- Maior ênfase no desenvolvimento de processos relacionados à implantação da modelagem da informação da construção nas disciplinas e cursos relacionados ao tema

\section{V) Desenvolvimento e uso de modelos de informação da construção para a gestão de ativos}

Empresas Contratantes

- Nos casos em que a empresa contratante de projetos é também responsável pela operação do edifício, a mesma pode beneficiar-se do uso do modelo na gestão de ativos - durante a fase mais longa do ciclo de vida da edificação que é o seu uso e operação - para atividades relacionadas à manutenção e controle da eficiência dos sistemas prediais de maneira proativa e preventiva, controle e logística de elementos no edifício, além de servir como base atualizada das informações da construção para possíveis reformas ou adequações no edifício

\section{Empresas de Projeto}

- Além de apresentar-se como uma oportunidade de negócios - uma vez que é o uso do BIM relacionado a maior parte do ciclo de vida de uma edificação - o desenvolvimento de BIM para gestão de ativos exige um nível de desenvolvimento gráfico reduzido em relação a outros usos do modelo, no entanto, demanda um maior volume de informações associadas ao modelo (NBS, 2012). A facilidade de associação de atributos sem a necessidade de detalhamento gráfico do modelo permite 
a sua rápida produção e aplicabilidade no mercado como produto pelas empresas de projeto

\section{Âmbito Setorial}

- Oferta de seminários, cursos e treinamentos relacionados à gestão de ativos com uso da modelagem da informação da construção, com ênfase nos benefícios que podem ser adquiridos nesta atividade.

- Oferta de seminários e fóruns de discussão sobre a vinculação dos benefícios de se construir e operar um edifício, vantagens e desvantagens setoriais e relacionadas à qualidade e desempenho das edificações

Âmbito Acadêmico

- Desenvolvimento de pesquisas relacionadas à gestão de ativos com uso da modelagem da informação da construção, com ênfase nos benefícios que podem ser adquiridos nesta atividade, e a inovação que ela representa no mercado da construção civil brasileira

\section{VI) Clareza na definição do papel dos agentes envolvidos nos documentos contratuais}

\section{Empresas Contratantes}

- Devem prezar pelo estabelecimento de parâmetros equivalentes para ambas as partes contratuais no documento proposto, a fim de estabelecer com clareza as expectativas e exigências de responsabilidade de cada uma das partes interessadas, evitando a ocorrência de conflitos e permitindo a colaboração entre as partes

\section{Empresas de Projeto}

- Devem ter maior atenção aos documentos contratuais e compromissos assumidos na sua assinatura, por meio da solicitação de inclusão no contrato, de todas as informações acordadas com a contratante, no nível de detalhamento necessário para garantir que a mesma realize as ações que são de sua responsabilidade na tomada de decisões durante 0 processo de projeto e seu recebimento

\section{Âmbito Setorial}

- Desenvolvimento de diretrizes para elaboração de contratos que atendam aos modelos contratuais utilizados no mercado da construção civil brasileira, para oferta aos agentes do setor

- Proposta de novas alternativas relacionais para contratação de serviços de projeto e oferta de seminários, cursos e treinamentos relacionados ao desenvolvimento e/ou utilização e gestão de contratos de construção 
civil para os diferentes modelos contratuais praticados no mercado da construção civil brasileira

- Fomento à pesquisa e desenvolvimento de modelos contratuais alternativos para propostas de contratos relacionais aplicados ao mercado da construção civil brasileira

\section{Âmbito Acadêmico}

- Desenvolvimento de pesquisas relacionadas a elaboração de diretrizes ou modelos de contratação que possam ser aplicados ao mercado da construção civil Brasileira, que incorporem os aspectos colaborativos reportados nesta dissertação

\section{VII) Clareza na definição do escopo contratual}

\section{Empresas Contratantes}

- Desenvolvimento e especificação em documento contratual dos níveis de desenvolvimento do projeto (seja ele em 2D ou modelagem) ou ainda adoção de parâmetros consolidados de LOD no caso da modelagem da informação da construção

- Determinação e descrição do conteúdo e saídas (informações) de cada uma das fases/etapas do processo de projeto contratadas, associando a cada uma delas o nível de desenvolvimento solicitado

Empresas de Projeto

- Solicitação de especificações formais do nível de desenvolvimento e faseamento do projeto contratado, preferencialmente em documento contratual

\section{Âmbito Setorial}

- Atualização das normas existentes para a contratação de projetos, abrangendo características referentes a projetos desenvolvidos com a modelagem da informação da construção

Âmbito Acadêmico

- Apoio ao desenvolvimento de normas dentro do setor da construção civil

- Desenvolvimento de pesquisas relacionadas às diretrizes que podem ser incorporadas às normas existentes, sejam referentes ao detalhamento, faseamento e outras características do processo de projeto considerando o uso da modelagem da informação da construção 


\section{VIII) Associação do modelo do edifício como parte da documentação contratual}

\section{Empresas Contratantes}

- A definição e descrição das fases e do LOD do projeto de modelagem contratado permitem a validação da entrega a partir do próprio modelo da edificação produzido (checagem das informações existentes versus requisitos contratuais), garantindo maior segurança no recebimento e medição das etapas do processo de projeto

\section{Empresas de Projeto}

- A incorporação no modelo dos atributos e informações definidos como exigências para cada uma das etapas do processo de projeto, transformam o próprio modelo em um reflexo do contrato, e portanto, ponto de comparação e medição para validação e acerto entre as partes

- Elimina-se a necessidade de "entregas" formais de pacotes de serviço fechados, permitindo a continuidade da produção e a extração momentânea de informações nos momentos específicos de validações, tomada de decisão e medição por parte da contratante

\section{Âmbito Setorial}

- Desenvolvimento de diretrizes ou modelos contratuais que exemplifiquem e demonstrem as vantagens do uso do modelo da informação da construção como parte da documentação contratual, relacionando a sua utilização a benefícios tais como: redução do prazo de desenvolvimento dos projetos, redução e/ou mediação de conflitos, redução de gargalos relacionados a geração e gestão de documentos e maior registro formal das informações e soluções propostas na etapa de projeto

\section{Âmbito Acadêmico}

- Desenvolvimento de pesquisas sobre o uso do modelo da informação da construção como parte da documentação contratual, relacionando a sua utilização a benefícios tais como: redução do prazo de desenvolvimento dos projetos, redução e/ou mediação de conflitos, redução de gargalos relacionados a geração e gestão de documentos e maior registro formal das informações e soluções propostas na etapa de projeto 


\section{IX) Participação dos agentes envolvidos na definição de prazos e cronogramas}

\section{Empresas Contratantes / Empresas de Projeto}

- A colaboração entre projetistas e contratante na definição de prazos leva a uma maior precisão e comprometimento de todos com o cronograma do projeto acordado

- Incorporação no planejamento de atividades relacionadas ao fluxo de informações no processo de projeto, mais abrangente e crítica que a simples definição de entregas por etapa

\section{Âmbito Setorial}

- Esclarecimento e proposta de desconstrução do modelo simplificado de controle de prazos associados a entrega de pacotes de produtos aplicado de maneira generalizada no mercado da construção civil

- Oferta de seminários, cursos e treinamentos relacionados ao planejamento do processo de projeto com foco na gestão da informação e na iteratividade das atividades identificadas como principal ponto de gestão com foco em resultados

Âmbito Acadêmico

- Desenvolvimento de pesquisas e oferta de seminários de esclarecimento e apresentação de propostas de desconstrução do modelo simplificado de controle de prazos associados a entrega de pacotes de produtos aplicado de maneira generalizada no mercado da construção civil

- Oferta de disciplinas, cursos e especializações relacionados ao planejamento do processo de projeto com foco na gestão da informação e na iteratividade das atividades identificadas como principal ponto de gestão com foco em resultados

\section{X) Colaboração entre os agentes participantes na etapa de projetos e na etapa de construção para a elaboração de orçamentos mais assertivos para o empreendimento}

\section{Empresas Contratantes / Empresas de Projeto}

- A antecipação da participação da construtora permite que a mesma esclareça divergências que poderiam ser identificadas somente no momento da construção da edificação, levando ao desvio no orçamento definido a partir do projeto ou modelo

- Solicitação às construtoras contratadas do compartilhamento das bases de informações de custos unitários e de auxílio na definição de soluções visando a maior assertividade no orçamento 


\section{Âmbito Setorial / Âmbito Acadêmico}

- Produção e divulgação de bases de custos unitários realistas que possam ser incorporados como ferramentas de orçamentação e elaboração de preços para os agentes da cadeia construtiva

\subsection{DESENVOLVIMENTO DO TEMA DE PESQUISA}

O desenvolvimento deste tema de pesquisa - Projeto Integrado - e seus aspectos correlatos, como colaboração e implementação da modelagem da informação da construção poderão ser desenvolvidos em trabalhos futuros, sugeridos a seguir:

- Desenvolvimento de um conjunto de métricas do processo de projeto para empresas de projeto, criando uma estrutura interna de gestão da sua produção, permitindo a utilização, ainda que parcial, dos princípios do projeto integrado.

- Desenvolvimento de um modelo contratual relacional para as etapas de projetos e de produção de produtos da construção civil brasileira, com base nos princípios do projeto integrado, considerando-se as adequações necessárias ao contexto nacional. 


\section{REFERÊNCIAS BIBLIOGRÁFICAS}

AMOR, R.; OWEN, R. Beyond BIM - It's not the end of the road! AECBytes

Viewpoint. n.58, 2011. Disponível em: <http://www.aecbytes.com/viewpoint/ 2011/issue_58.html>. Accesso em: abr 2011.

AUSTIN, S.. Analytical design planning technique: a model of the detailed building design process. Design Studies, v. 20, n.3, p 279-296, 1999.

AYRES, C.; SCHEER, S. Diferentes abordagens no uso do CAD no processo de projeto arquitetônico. In: WORKSHOP BRASILEIRO DE GESTÃO DO PROCESSO DE PROJETO NA CONSTRUÇÃO DE EDIFÍCIOS, 7., 2007, Curitiba. Anais...Curitiba. 2007.

BAKER, G. P.; GIBBONS, R.; MURPHY, K. J. Relational contracts in strategic alliances. National Bureau of Economic Research. Cambridge, 2002. Disponível em: <http://www.nber.org/ confer/2002/itof02/baker2.pdf >. Acesso em: jan. 2012.

BATAVIA, R. How to maximize project success with the right contracting strategy. In: PROJECT MANAGEMENT INSTITUTE ANNUAL SEMINARS \& SIMPOSIUM, 2000, Houston. Proceedings... Houston: 2000. p. 6.

BEDRICK, J. Organizing the development of a building information model. Disponível em: <www.aecbytes.com/feature/2008/MPSforBIM.html>. Acesso em: abr.2013. 
BRASIL. CBCIC - Câmara Brasileira da Indústria da Construção. Informativo Econômico - Construção Civil: Desempenho e Perspectivas. Brasília, 2010. 21 p. Disponível em: <http://www.cbicdados.com.br/media/anexos/ 05_Balanco_2011.pdf>. Acesso em: jan 2011.

PIB Brasil e Construção Civil. 2012. Disponível em: <http://cbicdados-dev.gridz.com.br/menu/pib-e-investimento/pib-brasil-econstrucao-civil>. Acesso em: mai 2013.

BRASIL. DECONCIC - Departamento da Indústria da Construção/ FIESP. Construbusiness 2010. $9^{\circ}$ Congresso Brasileiro da Construção. São Paulo: 2010. $119 \mathrm{p}$.

Proposta de política industrial para a construção civil. São Paulo: 2008. 170 p.

BRASIL. MDIC - Ministério do Desenvolvimento, Indústria e Comércio Exterior. Plano plurianual 2008-2011. Relatório de avaliação. Brasília: MDIC, 2010. 59 p.

BRASIL. Sistema financeiro de habitação. Estatísticas do SFH 2011. Brasília, 2011. Disponível em: <http://www.bcb.gov.br/FIS/SFH/PORT/est2011/09/ Resumo.pdf>. Acesso em: jan 2011.

BRASIL. STI - Secretaria de Tecnologia Industrial, Ministério do 
Desenvolvimento, Indústria e Comércio Exterior/ Escola Politécnica da Universidade de São Paulo. O futuro da construção civil no Brasil: resultados de um estudo de prospecção tecnológica da cadeia produtiva da construção habitacional. São Paulo, 2003. 132 p.

BUCKER, M.B. Gerenciamento de conflitos, prevenção e solução de disputas em empreendimentos da construção civil. 2010. 178 p. Dissertação (Mestrado). Escola Politécnica, Universidade de São Paulo, São Paulo, 2010.

CARDOSO, F.F. Stratégies déntreprises et nouvelles formes de rationalisation de la production dans le Bâtiment au Brésil et en France. 1996. 479 p. Tese (Doutorado). Économie et Sciences Sociales, École National Des Ponts Et Chaussées, Paris. 1996.

CHEUNG, O. S.; KENNETH T. W.; CHIM S. P. How relational are construction contracts? Journal of Professional Issues in Engineering Education and Practice. v.132, n. 1, p 48-56. 2006.

COLLEDGE, B. Relational contracting - creating value beyond the project. Lean Construction Journal, v.2, n. 1, p 30-112. 2005.

COHEN, J. Integrated project delivery: case studies. 2010. (Relatório para o AIA/AIA-California Council). Disponível em: <http://www.aia.org/ about/initiatives/AIAB082049>. Acesso em: out. 2011. 
ESTADOS UNIDOS. American Institute of Architects (AIA). Contract documents. Disponível em <http://www.aia.org/contractdocs/aiab081513>. Acesso em: jan 2012.

. Integrated project delivery: a guide - version 1. AIA California Council, 2007, 62 p.

. Integrated project delivery: a working definition. AIA California Council, 2007. 12p.

. Contract relationship diagrams. AIA Contract Documents. 2012

AlA document 191 commentary. Disponível em: $<$ http://www.aia.org/_groups/aia/documents/pdf/aiab081495.pdf>. Acesso em: jan 2013.

. AlA Best Practices: Defining the Architect's Basic Services. 2007. Disponível em: <http://www.aia.org/aiaucmp/groups/ek_members/ documents/pdf/aiap026834.pdf>. Acesso em: mai 2013.

ESTADOS UNIDOS. Construction Industry Institute. Constructability: a primer. $2^{\text {nd }}$ ed. Austin: 1987. v. 3-1.

ESTADOS UNIDOS. MCGRAWHILL. Interoperability in the Construction Industry. 2007. 
The Business Value of BIM. 2009.

ESTADOS UNIDOS. Penssylvania State University - PSU - Computer Integrated Construction (CIC) Research Program. BIM Project execution planning guide - version 2.0. Pennsylvania: 2009. 127p.

EASTMAN, C. M. et al. BIM handbook: a guide to building information modeling for owners, managers, designers, engineers, and contractors. $2^{\text {nd }}$ Edition: John Wiley \& Sons, 2008.

EMBRAESP. Prêmio Top do Mercado Imobiliário. Disponível em: $<$ http://www.embraesp.com.br/102/Top-de-Mercado-mobiliario.aspx?navid $=110>$. Acesso em: fev. 2013

FABRICIO, M.M. Projeto Simultâneo na Construção de Edifícios. 2002. 350 p. Tese (Doutorado). Escola Politécnica, Universidade de São Paulo, São Paulo, 2002.

FORMOSO, C. LIEDTKE, M. Developing protocol for managing the design process in the building industry. In: INTERNATIONAL GROUP FOR LEAN CONSTRUCTION CONFERENCE, 6., 1998, Guarujá. Proceedings... Guarujá: 1998.

FREITAS, E. M.; ROSA, S. A.; ALENCAR, C. T. Modalidades contratuais e o sucesso de um projeto de construção civil. In: CONFERÊNCIA 
INTERNACIONAL DA LATIN AMERICAN REAL STATE SOCIETY. 10., 2010, São Paulo. Anais... São Paulo: 2010.

GONÇALVES, C.M.M. Método para gestão do custo da construção no processo de projeto de edificações. 2011. 182 p. Dissertação (Mestrado). Escola Politécnica, Universidade de São Paulo, São Paulo, 2011.

GORDON, C. M. Compatibility of construction contracting methods with projects and owners. 1991. 173 p. Thesis (Master of Science). Department. of Civil Engineering, Massachusetts Institute of Technology. Cambridge, 1991.

GRILO, L.; MELHADO, S.B. Novas formas de contratação e organização dos empreendimentos no segmento de construção de edifícios para terceiros. ENTAC - ENCONTRO NACIONAL DE TECNOLOGIA DO AMBIENTE CONSTRUíDO, 9., 2002, Foz do Iguaçu. Anais... Foz do Iguaçu: 2002.

HAMMARLUND, Y. JOSEPHSON, P.E. Sources of Quality Failures in building. In: European Symposium on Management, Quality and Economics in Housing and other Building Sectors, 1991, Lisbon. Proceedings... Lisbon: 1991. p. 671679.

HAUCK, A. J. Project Alliancing at National Museum of Australia- Collaborative Process. Journal of Construction Engineering and Management, v.130. n 1. P. 143-152. 2004. 
HARNESS, S. H. AlA documents advance the use of bim and integrated project delivery. 2008. Disponível em: < http://www.aia.org/groups/aia/ documents/pdf/aiab078753.pdf>. Acesso em: jan 2013.

JERNIGAN, F., BIG BIM little bim: The practical approach to building information modeling. 1a Ed., 4Site Press, Salisbury, 2007

KALAY, Y. E. P: Computational environment to support design collaboration. Automation in Construction. n. 8, p. 37-48, 1998.

KIVINIEMI, A., TARANDI, V., KARLSHOJ, J., BELL, H. and KARUD, O.J. Review of the Development and Implementation of IFC compatible BIM. Erabuild, 2008. 128 p.

Drivers and Trends of Integrated BIM. Apresentação de evento. 2º Seminário BIM. Sincuscon-SP. 2011

KUMARASWAMY, M. M.; DISSANAYAKA, S. M. Linking procurement systems to project priorities. Building Research \& Information. v.26, p. 223-238. 1998.

KVAN, T. Collaborative design: what is it? Automation in Construction. n. 9, p. 409-415. 2000.

LEAN CONSTRUCTION INSTITUTE - LCI. Special Report. 2010. Disponível em: <http://www.leanconstruction.org/pdf/SpecialReportENR.pdf>. Acesso em: fev 2012. 
LICHTIG, W. A. Sutter Health: developing a contracting model to support lean project delivery. Lean Construction Journal, v. 2, n. 1, p. 105-112. 2005.

LING, Y. Y. F, RAHMAN, M. M.; Ng L. T. Incorporating contractual incentives to facilitate relational contracting. Journal of Professional Issues in Engineering Education and Practice, v.132, n. 1, p. 57-66. 2006.

MANZIONE, L. Estudo de Métodos de Planejamento do Processo de Projeto de Edifícios. 2006. 267 p .Dissertação (Mestrado). Escola Politécnica, Universidade de São Paulo, São Paulo, 2006.

MANZIONE, L. WYSE, L. OWEN, R. MELHADO, S.B. Challenges for Implementation of a New Model of Collaborative Design Management: Analyzing the Impact of Human Factor. In: CIB W96, 2011, Vienna. Proceedings... Viena: 2011. p. 256-266.

MANZIONE, L. WYSE, M. SACKS, R. VAN BERLO, L. MELHADO, S.B. Key performance indicators to analyze and improve management of information flow in the BIM design process. In: CIB W96, 2011, Vienna. Proceedings... Viena: 2011. p. 256-266.

MATHEWS, O. HOWELL, G. A. Integrated project delivery: An example of relational contracting. Lean Construction Journal, v. 2, n. 1. 2005. 
MELHADO, S. B. Qualidade do Projeto na Construção de Edifícios. 2004. 294 p. Tese (Doutorado). Escola Politécnica, Universidade de São Paulo, São Paulo, 2004.

MELHADO, S. B.; AGOPYAN, V. O conceito de projeto na construção de edifícios: Diretrizes para sua elaboração e controle. São Paulo, EPUSP, 1995 (Boletim Técnico BT/PCC/139). Departamento de Engenharia de Construção Civil, 1995.

MOLENAAR, K. GRANSBERG, D. Design Builder Selection for small high-way projects. Journal of Management in Engineering. v.17, n. 4, p. 214-223. 2001.

MOLENAAR, K. ZIMRING, C. GODFRIED, A. A guide to project delivery for federal buildings. Washington, 1998. (Report to the U.S. General Services Administration).

MURDOCH, J; HUGHES, W. Construction Contracts: law and management. 4th edition. Oxon, Taylor \& Francis Group, 2008. 401p.

NASCIMENTO, L. A.; SANTOS, E. T. A Contribuição da Tecnologia da Informação ao Processo de Projeto na Construção Civil. In: WORKSHOP NACIONAL GESTÃO DO PROCESSO DE PROJETOS NA CONSTRUÇÃO DE EDIFÍCIOS, 1., 2001, São Carlos. Anais... São Carlos: 2001.

Barreiras para o Uso da Tecnologia da Informação na Indústria da Construção Civil. In: WORKSHOP NACIONAL GESTÃO DO PROCESSO DE 
PROJetos NA CONSTRUÇÃO DE EDIFíCIOS, 2., 2002, Porto Alegre. Anais... Porto Alegre: 2002.

A indústria da construção na era da informação. Ambiente Construído, v.3, n. 1. p. 69-81, 2003.

National Research Council of the National Academies. Advancing the competitiveness of the U.S. Washington, 2009. Disponível em: <www.nap.edu> Acesso em: dez. 2012.

NBS. The IFC/COBie Report 2012. Londres, 2012. Disponível em: <http://www.thenbs.com/topics/BIM/cobie/> Acesso em: jul. 2013.

OLIVEIRA, O.J. Modelo de Gestão para pequenas empresas de projeto de edifícios. 2005. 256 p. Tese (Doutorado) - Escola Politécnica, Universidade de São Paulo. São Paulo. 2005.

OWEN, R. L.; AMOR, R. et al. Challenges for Integrated Design and Delivery Solutions. Architectural Engineering and Design Management. Edição Especial: Integrated Design and Delivery Solutions. p. 232-240, 2010.

OWEN, R. L.; PALMER, M. E. et al. CIB White Paper on IDDS Integrated Design \& Delivery Solutions. CIB Publication n. 328. Rotterdam, 2009.

PEÑA-MORA, F.; SOSA, C. E.; MCCONE, D.S.; Introduction to Construction Dispute Resolution. New Jersey: Prentice Hall, 2002. 264p. 
RAHMAN, M.M.; KUMARASWAMY, M.M. Potential for implementing relational contracting and joint risk management. Journal of Management in Engineering, v.20, n. 4, p. 178-189. 2004

REINERSTSEN, D. G. Managing the Design Factory. New York: 1997.

REKOLA, M.; KOJIMA J., et al. Towards Integrated Design and Delivery Solutions: Pinpointed Challenges of Process Change. Architectural Engineering and Design Management. n. 6, p. 264-278, 2010.

RICARDINO, R.; SILVA, S.A.; ALENCAR, C.T. Administração de contratos em projetos de construção pesada no Brasil. Um estudo da interface com o processo da análise de risco. São Paulo, EPUSP, 2008 (Boletim Técnico BT/PCC/487). Departamento de Engenharia de Construção Civil,2008.

Boletim Técnico da Escola Politécnica da USP, Departamento de Engenharia da Construção Civil, BT/PCC/487. São Paulo: EPUSP, 2008. 24p.

ROSS, J. Introduction to Project Alliancing (on engineering and construction projects). In: Alliance Contracting Conference, 2003, Sydney. Proceedings... Sydney: 2003.

SANTOS, E.T. Material didático e apresentações do curso "Modelagem de Informações na Construção" - PCC 5113 - Escola Politécnica da Universidade de São Paulo. 2010. 
SAKAL, M. W. Project alliancing: a relational contracting mechanism for dynamic projects. Lean Construction Journal, v.2, n. 1, p. 67-79. 2005.

SAKKAL, M. W. Project Alliancing: A relational Contracting Mechanism for Dynamic Projects. Lean Construction Journal. v.5. 2005.

SCHEER, S. et al. The scenario and trends in the Brazilian IT Construction applications' experience. ITcon. v.12. p. 221-230. 2007

SEBASTIAN, R. BIM in different methods of project delivery. In: CIB W78W102, 2011, Sophia. Proceedings... Sophia: 2011.

SECOVI - SP. BALANÇO DO MERCADO IMOBILIÁRIO EM 2012. Disponivel em: <http://www.secovi.com.br/noticias/secovi-sp-divulga-balanco-do-mercado-imobiliario-em-2012/5947/>. Acesso em: jan. 2012.

SOUZA, F. R. Implementação de modelo de gestão para empresas de projetos de edifícios. 2009. 210 p. Dissertação (Mestrado). Escola Politécnica, Universidade de São Paulo, São Paulo, 2009.

SOUZA, F. WYSE, M. MELHADO, S. B. The Brazilian Design Manager Role and Responsibilities after the BIM Process Introduction. In: CIB WBC 2013, Queensland, 2013. Proceedings... Queensland: 2013. 
WYSE, M. SOUZA, F. MELHADO, HISAMOTO, M. As práticas de gestão do processo de projeto em uma empresa incorporadora: Uma avaliação com base em IDDS. SIMPÓSIO BRASILEIRO DE QUALIDADE DO PROJETO NO AMBIENTE CONSTRUÍDO, 3., 2013, Campinas. Anais... Campinas: 2013.

STEEN, R. H. Five Steps to Resolving Construction Disputes - Without Litigation. Journal of Management in Engineering. v.10. n.4. p 19-31. 1994.

SUCCAR, B. Building information modelling framework: A research and delivery foundation for industry stakeholders. Automation in Construction. v.18 p. 357-375. 2009.

TAYLOR, E. P. JOHN, G. B. Paradigm Trajectories of Building Information Modeling Practice in Project Networks. Journal of management in engineering. v. 25, n. 2 p. PP. 69-76, 2009.

TOLEDO, R.; ABREU, A.F.; JUNGLES, A.E. A difusão de inovações tecnológicas na indústria da construção civil. ENCONTRO NACIONAL DE TECNOLOGIA DO AMBIENTE CONSTRUÍDO - ANTAC, 8., 2000, Salvador. Anais... Salvador: 2000.

UNDERWOOD, J. ISIKDAG, U. Handbook of research on building information modeling and construction informatics: concepts and technologies. Salford: IGI Global, 2010. 757 p.

UNIVERSITY OF MINNESOTA. IPD Case Studies. 2012. Disponível em: $<$ http://www.aia.org/_groups/aia/documents/pdf/aiab093703.pdf>. Acesso em: 
out. 2012.

UNITED KINGDOM. UK Government Cabinet Office. BIM overlay to the RIBA outline pan of work. 2011. Disponível em: <http://www.bimtaskgroup.org>. Acesso em: nov. 2012.

UNITED KINGDOM.UK Government Cabinet Office. UK government construction strategy, 2011. Disponível em: <http://www.cabinetoffice.gov.uk /resource-library/ government-construction-strategy> . Acesso em: nov. 2012.

UNITED KINGDOM UK Government Cabinet Office. Strategy paper for the government construction client group from the BIM industry working group, 2011. Disponível em: <http://www. bimtaskgroup.org>. Acesso em: nov 2012.

ULRICH, K.T. Product design and development. New York: McGraw Hill, 1999.

VICO. Model progression specification. Disponível em: $<$ http://www.vicosoftware.com/model-progression-specification/tabid/85227 /Default. aspx>. Acesso em: abr. 2012.

WANG, J. Integrated Project Delivery - Achieving Relational Contracting through Traditional Project Management Methods. 2008. Thesis (Master of Science). Department. of Civil and Environmental Engineering: University of Cincinnati. Cincinnati. 2008. 
WILLIAMSON, O. E. Transaction cost economics: the governance of contractual relations. Journal of Law and Economics. v.22, n. 2. p. 233-261.

Wong, A. Wong, F. Nadeem, A. Attributes of Building Information Modelling Implementations in Various Countries. Architectural Engineering and Design Management. v.6, n.4. p. 288-302. 2010

WONG, A. WONG, F. NADEEM, A. Attributes of Building Information Modelling Implementations in Various Countries. Architectural Engineering and Design Management, v.6. n.4 p. 288-302. 2010.

YIN, R.K. Estudo de caso: planejamento e métodos. 4a Ed. Porto Alegre: Bookman, 2010. 
ANEXO I

ARTIGOS PUBLICADOS NO BRASIL COM O TEMA MODELAGEM DA INFORMAÇÃO DA CONSTRUÇÃO ENTRE 2007 E 2011 
Anexo I: Artigos publicados no Brasil com o tema Modelagem da Informação da Construção entre 2007 e 2011

\begin{tabular}{llll}
\hline 2007 - VII workshop brasileiro de gestão do processo de projetos na construção \\
de edifícios
\end{tabular}
2008 - VIII workshop brasileiro de gestão do processo de projetos na construção de edifícios

\begin{tabular}{lll}
\hline TIPO & TÍTULO & AUTORES \\
DOC. & & \\
\hline
\end{tabular}

\begin{tabular}{lll}
\hline Artigo & $\begin{array}{l}\text { Utilização do CAD-BIM para projeto de alvenaria de } \\
\text { blocos de concreto }\end{array}$ & $\begin{array}{l}\text { Fabíola Azuma, Cervantes } \\
\text { Ayres Filho, Sérgio Scheer }\end{array}$ \\
\hline
\end{tabular}

\begin{tabular}{lll}
\hline Artigo & Modelagem de Informações para Construção (BIM) & Celso Carlos Novaes, Sérgio \\
& e ambientes colaborativos para gestão de projetos & Salles Coelho \\
& na construção civil &
\end{tabular}

\begin{tabular}{lll}
\hline Mesa & Perspectiva do BIM na Gestão de Projetos & Eduardo Toledo, Sérgio \\
& Leusin Amorim, Sérgio \\
& Scheer.
\end{tabular}

10 SBPQ/2009 E IX Workshop Brasileiro de Gestão do Processo de Projeto na 


\begin{tabular}{|c|c|c|}
\hline \multicolumn{3}{|c|}{ Construção de Edifícios. } \\
\hline $\begin{array}{l}\text { TIPO } \\
\text { DOC. }\end{array}$ & TÍTULO & AUTORES \\
\hline Artigo & $\begin{array}{l}\text { Potencial da Implementação da BIM no Processo de } \\
\text { Aprovação de Projetos de Edificação na Prefeitura } \\
\text { Municipal de Curitiba }\end{array}$ & $\begin{array}{l}\text { Juliana Maria Romero, Sérgio } \\
\text { Scheer }\end{array}$ \\
\hline Artigo & Abordando a BIM em níveis de modelagem & $\begin{array}{l}\text { Sergio Scheer, Cervantes } \\
\text { Gonçalves Ayres Filho }\end{array}$ \\
\hline Artigo & $\begin{array}{l}\text { BIM: Conceitos, Cenário das Pesquisas Publicadas } \\
\text { no Brasil e Tendências }\end{array}$ & $\begin{array}{l}\text { Max Lira Andrade, Regina } \\
\text { Coeli Ruschel }\end{array}$ \\
\hline $20 \mathrm{~S}$ & $\begin{array}{l}\text { PQ/2011 E X Workshop Brasileiro de Gestão de } \\
\text { Construção de Edifícios }\end{array}$ & Processo de Projeto na \\
\hline $\begin{array}{l}\text { TIPO } \\
\text { DOC. }\end{array}$ & TíTULO & AUTORES \\
\hline Artigo & $\begin{array}{l}\text { O processo digital de geração da forma baseado no } \\
\text { desempenho com suporte em BIM: o caso do } \\
\text { Smithsonian Institution Courtyard Enclosure }\end{array}$ & $\begin{array}{l}\text { Max Lira Andrade, Regina } \\
\text { Ruschel }\end{array}$ \\
\hline Artigo & $\begin{array}{l}\text { Diretrizes para elaboração de Projetos de } \\
\text { Manutenção usando a tecnologia BIM }\end{array}$ & $\begin{array}{l}\text { Thiago Thielmann Araújo, } \\
\text { Maria Aparecida Steinherz } \\
\text { Hippert, José Gustavo } \\
\text { Francis Abdalla }\end{array}$ \\
\hline Artigo & $\begin{array}{l}\text { Alterações metodológicas na gestão de processo de } \\
\text { projeto aplicada com a utilização de software tipo } \\
\text { BIM }\end{array}$ & $\begin{array}{l}\text { Bárbara Suellen Andrade, } \\
\text { Sérgio Roberto LeuSin } \\
\text { Amorim }\end{array}$ \\
\hline Artigo & $\begin{array}{l}\text { Modelagem de Informações no Desenvolvimento } \\
\text { Enxuto de Projetos }\end{array}$ & $\begin{array}{l}\text { Emílio Lima do Nascimento, } \\
\text { Alexandre Augusto Biz, Maria } \\
\text { do Carmo Duarte Freitas, } \\
\text { Sérgio Scheer }\end{array}$ \\
\hline
\end{tabular}




\begin{tabular}{|c|c|c|}
\hline $\begin{array}{l}\text { TIPO } \\
\text { DOC. }\end{array}$ & TÍTULO & AUTORES \\
\hline Artigo & $\begin{array}{l}\text { Ferramentas BIM: Um desafio para a melhoria no } \\
\text { ciclo de vida do projeto. }\end{array}$ & $\begin{array}{l}\text { Cláudia Campos Crespo e } \\
\text { Regina Coeli Ruschel }\end{array}$ \\
\hline Artigo & $\begin{array}{l}\text { Contribuições do Buildin Information Modeling no } \\
\text { processo de projeto em arquitetura }\end{array}$ & Wilson Florio \\
\hline \multicolumn{3}{|c|}{ IV Encontro de Tecnologia de Informação e Comunicação na Construção - TIC } \\
\hline $\begin{array}{l}\text { TIPO } \\
\text { DOC. }\end{array}$ & TÍTULO & AUTORES \\
\hline \multicolumn{2}{|c|}{$\begin{array}{l}\text { Apresentação } \quad \text { Universidade de São Paulo, Brasil } \\
\text { para Workshop }\end{array}$} & Eduardo Toledo SANTOS \\
\hline \multicolumn{2}{|c|}{$\begin{array}{l}\text { Apresentação } \quad \text { Universidade Federal do Paraná, Brasil } \\
\text { para Workshop }\end{array}$} & Sergio Scheer \\
\hline \multicolumn{2}{|c|}{$\begin{array}{ll}\text { Apresentação } & \text { Universidade Federal Fluminense, Brasil } \\
\text { para Workshop } & \text { Gestão de custos e bibliotecas BIM }\end{array}$} & Sergio Leusin \\
\hline \multicolumn{3}{|c|}{$\begin{array}{l}\text { V Encontro de Tecnologia de Informação e Comunicação na Construção - TIC } \\
2011\end{array}$} \\
\hline $\begin{array}{l}\text { TIPO } \\
\text { DOC. }\end{array}$ & TÍTULO & AUTORES \\
\hline Artigo & $\begin{array}{l}\text { Atual cenário da implementação de BIM no mercado } \\
\text { da construção civil da cidade de São Paulo e } \\
\text { demanda por especialistas }\end{array}$ & $\begin{array}{l}\text { Maria Bernardete Barison, } \\
\text { Eduardo Toledo Santos }\end{array}$ \\
\hline Artigo & $\begin{array}{l}\text { Uso de realidade Aumentada para visualização do } \\
\text { modelo da edificação }\end{array}$ & $\begin{array}{l}\text { Ana Regina Mizrahy } \\
\text { Cuperschmid, Regina Coeli } \\
\text { Ruschel, Felipe Alonso } \\
\text { Martins }\end{array}$ \\
\hline Artigo & $\begin{array}{l}\text { A contribuição do BIM para a representação do } \\
\text { ambiente construído }\end{array}$ & $\begin{array}{l}\text { Thiago Thielmann de Araújo, } \\
\text { Maria Aparecida Steinherz } \\
\text { Hippert, José Gustavo }\end{array}$ \\
\hline
\end{tabular}


Francis Abdalla

\begin{tabular}{lll}
\hline Artigo Tendências atuais para o ensino de BIM & $\mathrm{M}^{\mathrm{a}}$ Bernardete Barison, \\
& Eduardo Toledo Santos
\end{tabular}

\begin{tabular}{llll}
\hline Artigo & $\begin{array}{l}\text { Proposta de modelo virtual de captação } \\
\text { requisitos de clientes para inserção no BIM }\end{array}$ & $\begin{array}{l}\text { Paula Lima Sombra, Lucas } \\
\text { de Oliveira Correia, José de } \\
\text { Paula Barros Neto }\end{array}$ \\
\hline Artigo & BIM e coordenação modular: Possibilidades de & Neliza Maria e Silva Romcy. \\
& melhorias para a indústria da AEC & Daniel Ribeiro Cardoso, \\
& & Alexandre Araújo Bertini, \\
& & André Nogueira Paes e Paula \\
& & Rodrigues
\end{tabular}

Artigo A abordagem BIM como contribuição para a Márcia Rebouças Freire, eficiência energética no ambiente construído Arivaldo Leão de Amorim

\begin{tabular}{lllll}
\hline Artigo & $\mathrm{O}$ Uso de software de manufatura & no & Eduardo Hernandes \\
& desenvolvimento de projetos de edificações pré- & Domingues, Claudia \\
& & Terezinha de Andrade \\
& & Oliveira
\end{tabular}

Artigo A experiência de implementação do sistema Eduardo Marques Arantes, colaborativo SISAC para a gestão de projetos em Homero Silva Junior, Caio uma entidade pública

Sergio Bedeschi D’Almeida

\begin{tabular}{llll}
\hline Artigo & $\begin{array}{l}\text { Análise do processo de projeto de um } \\
\text { empreendimento privado mediante implementação } \\
\text { de tecnologia Building Information Modeling }\end{array}$ & $\begin{array}{l}\text { Eduardo Marques Arantes, } \\
\text { Ezequiel Rosa Dias }\end{array}$ \\
\hline Artigo & $\begin{array}{l}\text { Contribuições da tecnologia BIM Eem processos de } \\
\text { projeto na construção civil em Belo Horizonte }\end{array}$ & $\begin{array}{l}\text { Miguel Pereira Stehling, } \\
\text { Eduardo Marques Arantes }\end{array}$ \\
\hline Artigo & $\begin{array}{l}\text { Rede neural artificial: Previsão de produtividade do } \\
\text { trabalho na execução de alvenaria }\end{array}$ & $\begin{array}{l}\text { Luci Mercedes De Mori, } \\
\text { Antônio Edésio Jungles }\end{array}$ \\
\hline Artigo & $\begin{array}{l}\text { BIM como instrumento de apoio à introdução da } \\
\text { ecoeficiência em projetos de biotérios }\end{array}$ & $\begin{array}{l}\text { Silvia Maria Soares de Araujo } \\
\text { Pereira, Sérgio Roberto }\end{array}$ \\
& & Leusin de Amorim \\
\hline Artigo & Uma análise do uso da simulação como ferramenta & Fábio Kellermann Schramm, \\
& do projeto do sistema de produção em & Carlos Torres Formoso \\
& &
\end{tabular}


empreendimentos da construção civil

\begin{tabular}{llll}
\hline Artigo & $\begin{array}{l}\text { O uso de tecnologias BIM em escritórios de } \\
\text { arquitetura relacionado ao modo de implantação }\end{array}$ & $\begin{array}{l}\text { Ludmila Cabizuca Oliveira, } \\
\text { Alice T. Cybis Pereira }\end{array}$ \\
\hline Artigo & $\begin{array}{l}\text { A contribuição dos sistemas de classificação para a } \\
\text { tecnologia BIM - Uma abordagem teórica }\end{array}$ & $\begin{array}{l}\text { Julio Cesar Bastos Silva, } \\
\text { Sérgio Roberto Leusin de } \\
\text { Amorim }\end{array}$ \\
& & \\
\hline Artigo & O pensamento complexo e suas implicações ao & Mariana Monteiro Xavier de \\
& processo de projeto & Lima, Sara Costa Maia, José \\
& & de Paula Barros Neto
\end{tabular}

\begin{tabular}{lll}
\hline Artigo & $\begin{array}{l}\text { Gestão da comunicação em projetos com uso de } \\
\text { ferramentas colaborativas em sistemas CAD-BIM }\end{array}$ & \\
\hline Artigo & Implantação de tecnologia BIM na incorporação & Bernardo de Alencar Bastos, \\
& imobiliária & Jealva Ávila Lins Fonseca, \\
& Ana Vitória Mello de Souza \\
& Gomes, Alane Amorim \\
& Santos
\end{tabular}

\begin{tabular}{lll}
\hline Artigo & $\begin{array}{l}\text { Aplicações paramétricas visando o projeto com } \\
\text { eficiência energética }\end{array}$ & Anarrita Bueno Buoro, Arthur \\
& Hunold Lara, Cristina Yukari \\
& Kawakita lkeda, Cynthia \\
& Nojimoto, Monica Camargo
\end{tabular}

Artigo O uso e eficiência do IFC entre produtos de proposta Michael Antony Carvalho, BIM no mercado atual Sérgio Scheer
Artigo Compatibilização de projetos: Comparação entre o Renata Heloisa de Tonissi e BIM e CAD 2D Buschinelli de Goes, Eduardo
Toledo Santos
Artigo Desafios para a implementação do processo de Leonardo Manzione, Mariana projeto colaborativo: Análise do fator humano Wyse Abaurre, Silvio Burrattino Melhado, Robert
Owen

\begin{tabular}{lll}
\hline Artigo & Desenvolvimento e aplicação de indicadores de & Leonardo Manzione, Mariana \\
desempenho na análise e melhoria da gestão do & Wyse Abaurre, Silvio \\
fluxo de informações do processo de projeto em BIM & Burrattino Melhado, Léon \\
& Berlo, Rafael Sacks
\end{tabular}




\begin{tabular}{|c|c|c|}
\hline Artigo & $\begin{array}{l}\text { Quadro sinóptico de três iniciativas de incentivo da } \\
\text { BIM no contexto francês }\end{array}$ & $\begin{array}{l}\text { Sandra Marques, Bernard } \\
\text { Ferriès }\end{array}$ \\
\hline Artigo & $\begin{array}{l}\text { Scripts em CAD e ambientes de programação visual } \\
\text { para modelagem paramétrica: Uma comparação do } \\
\text { ponto de vista pedagógico }\end{array}$ & $\begin{array}{l}\text { Maria Gabriela Caffarena } \\
\text { Celani, Carlos Eduardo } \\
\text { Verzola Vaz }\end{array}$ \\
\hline Artigo & $\begin{array}{l}\text { Conhecimento e uso de tecnologias BIM por } \\
\text { empresas de AEC e por cursos de arquitetura e } \\
\text { engenharia civil de Recife: Situação e desafios }\end{array}$ & $\begin{array}{l}\text { Rejane de Moraes Rêgo, } \\
\text { Aliomar Ferreira Nunes }\end{array}$ \\
\hline Artigo & $\begin{array}{l}\text { Utilização de modelagem BIM no processo de } \\
\text { integração entre projeto e orçamentação }\end{array}$ & $\begin{array}{l}\text { Lilian Cristine Witicovski, } \\
\text { Sergio Scheer }\end{array}$ \\
\hline Artigo & $\begin{array}{l}\text { A difusão das tecnologias BIM por pesquisadores do } \\
\text { Brasil }\end{array}$ & $\begin{array}{l}\text { Érica de Sousa Checcucci, } \\
\text { Ana Paula Carvalho Pereira, } \\
\text { Arivaldo Leão de Amorim }\end{array}$ \\
\hline Artigo & $\begin{array}{l}\text { Modelagem da informação da construção como } \\
\text { inovação tecnológica }\end{array}$ & $\begin{array}{l}\text { Érica de Sousa Checcucci, } \\
\text { Arivaldo Leão de Amorim }\end{array}$ \\
\hline Artigo & $\begin{array}{l}\text { Uma leitura visual do tema BIM no período de } 2005 \\
-2010 \text { nas revistas AECBYTES e ITCON }\end{array}$ & $\begin{array}{l}\text { César Augusto Vieira } \\
\text { Valente, Adriano de Alencar } \\
\text { Sales, Marcel Kater, Regina } \\
\text { Coeli Ruschel }\end{array}$ \\
\hline Artigo & $\begin{array}{l}\text { O ensino de BIM: Exemplos de implantação em } \\
\text { cursos de engenharia e arquitetura }\end{array}$ & $\begin{array}{l}\text { Regina Coeli Ruschel, Max } \\
\text { Lira Veras Xavier de } \\
\text { Andrade, Adriano de Alencar } \\
\text { Sales, Marcelo de Morais }\end{array}$ \\
\hline Artigo & $\begin{array}{l}\text { A tecnologia BIM na documentação e gestão da } \\
\text { manutenção de edifícios históricos }\end{array}$ & $\begin{array}{l}\text { Caroline Kehl, Luís Artur } \\
\text { Siviero, Eduardo Luis Isatto }\end{array}$ \\
\hline Artigo & $\begin{array}{l}\text { Representação do projeto para produção de } \\
\text { vedações verticais em alvenaria em um CAD-BIM }\end{array}$ & $\begin{array}{l}\text { Ari Monteiro, Eduardo Toledo } \\
\text { Santos }\end{array}$ \\
\hline Artigo & $\begin{array}{l}\text { Maquete virtual interativa: Proposta de uma } \\
\text { ferramenta de vendas para o mercado imobiliário } \\
\text { residencial }\end{array}$ & $\begin{array}{l}\text { Nilton Paulo Raimundo } \\
\text { Mendes, Eduardo Toledo } \\
\text { Santos }\end{array}$ \\
\hline Artigo & $\begin{array}{l}\text { Nuvem de pontos na criação de modelos BIM: } \\
\text { Aplicações em documentação arquitetônica }\end{array}$ & $\begin{array}{l}\text { Natalie Johanna Groetelaars, } \\
\text { Arivaldo Leão de Amorim }\end{array}$ \\
\hline
\end{tabular}




\begin{tabular}{llll}
\hline Artigo & Planejamento de edifícios com uso de software 4D & $\begin{array}{l}\text { Jean Fouquet, Sheyla Mara } \\
\text { Baptista Serra }\end{array}$ \\
\hline Artigo & $\begin{array}{l}\text { Ferramentas BIM para o projeto arquitetônico: } \\
\text { Estudo comparativo para adoção em cursos de }\end{array}$ & Anaula Ribeiro de Araujo \\
& graduação em arquitetura e urbanismo & \\
\hline Artigo & Processos criativos no desenvolvimento de projetos & Rosa Alejandra Cajavilca \\
& arquitetônicos em ambientes virtuais & Cepeda \\
\hline Artigo & International Collaborative & Construction & Juliana Nunes de Sá Brito, \\
& Management: Lições aprendidas e o papel da & Caroline Kehl, Eduardo Luis \\
& tecnologia da informação & Isatto, Carlos Torres Formoso \\
\end{tabular}


ANEXO II

QUESTIONÁRIO SOBRE IMPLEMENTAÇÃO DA MODELAGEM DA INFORMAÇÃO DA CONSTRUÇÃO APLICADO NO EVENTO TIC 2011 
Anexo II - Questionário sobre Implementação da Modelagem da Informação da Construção aplicado no evento TIC 2011

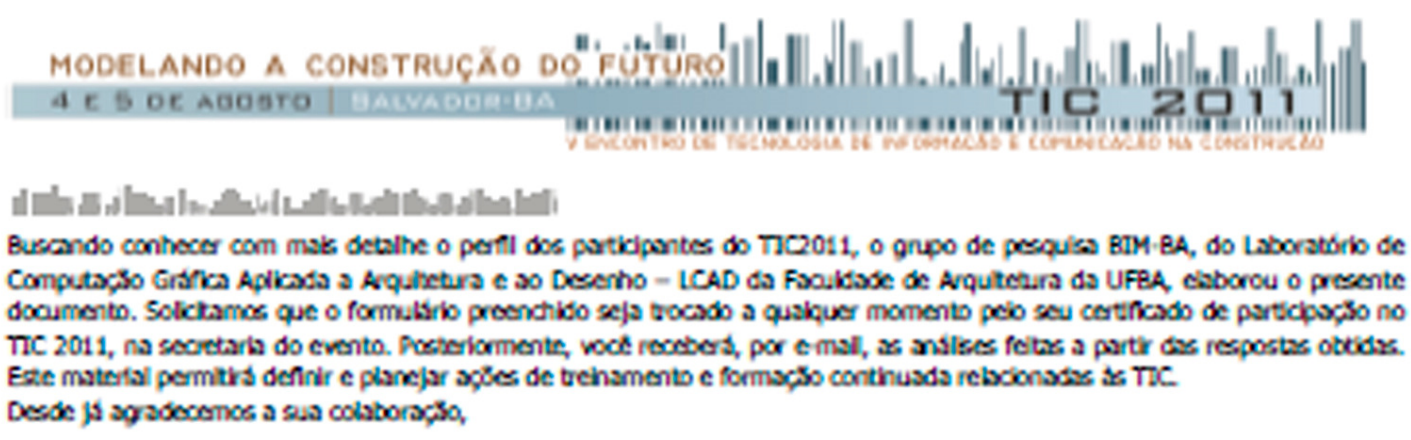

Comies So Orgoniasoon do TIC 2011

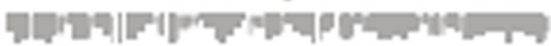

\section{QUESTIONÁRIODE PESQUISA}

\begin{tabular}{|l|l|}
\hline Nome: & E-mail: \\
\hline Cidade / Estado / Pais: & \\
\hline
\end{tabular}

\begin{tabular}{|c|c|}
\hline Escolaridade: (preencher o nome do curso que fez ou faz, e a instibuk, so de ensho) & $\begin{array}{l}\text { Concluido: } \\
\text { SIM NÄO }\end{array}$ \\
\hline Gradusç3o em: & \\
\hline TÉcnico em: & \\
\hline Especialkzaçうo em: & \\
\hline Mestrado em: & \\
\hline Doutcorado em: & \\
\hline
\end{tabular}

\begin{tabular}{|c|c|}
\hline \multicolumn{2}{|c|}{ Qual a sua área de atuaç̧o? (Se for o caso, aceinslar msis de ums area) } \\
\hline Projeso de edificadbo & Orçamento \\
\hline Prajeso de obras de infra-estrutura & Fornecedor de componente para edifcaçbo \\
\hline Planejamento de obra & Desenvolvedor de sotware \\
\hline Gerenchmento de construegso & Incorporsç3o mobildara \\
\hline Conestugb & Ensho \\
\hline Operacto e monutenciso do edifcosto & Outra Gusl? \\
\hline
\end{tabular}

\begin{tabular}{|c|c|c|}
\hline Qual o nome da empresa onde trabalha / estagia? & Trabalha & Estagia \\
\hline \multicolumn{3}{|l|}{ Qual o número aproximado de funcionários desta empresa? } \\
\hline Há aproximadamente quantos anos ela está no mercado? & & \\
\hline
\end{tabular}

Vocé utiliza as Tecnologias de Informaçio e Comunicaç3o (TIC) no seu traballho? 


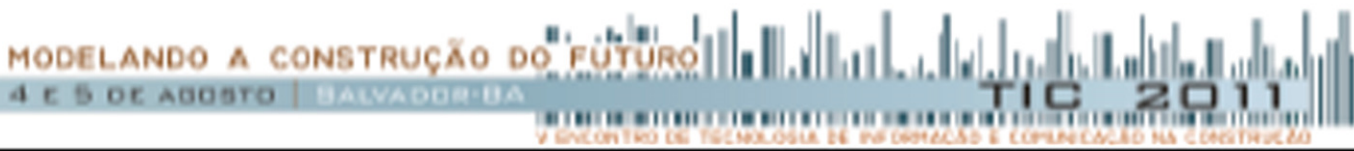

Se respondeu SIM, que ferramentas (sortware) utiliza?

Voct utiliza alguma ferramenta BIM no seu trabalho?

NĀO. Dor quê? SIM. Qual (quais)?

HS quanto tempo utiliza esta(s) ferramenta(s)?

Você fez algum curso especifico sobre BIM?

NÁO. SIM. Qual?

Em que ano?

Como vocế conceituaria o termo BIM e como o traduzinia para o pertugués?

As perguntas a seguir $\$ \delta$ dever 30 ser respondidas se você trabalhar com as tecnologias BIM.

Quais as maiores dificuldades que você sente no uso da tecnologia BIM?

(Numere em ordem crescente as respoetas peb ordem de imsortincla)

A integraciso com a equipe de porcerrok.

A difouldade no sprendzado das ferramentas.

o curto derado dis adocijo das ferramentas.

A complesidsde da teconobola.

A posca comostibildade com as ferramentas abe ent5o utilzadas.

Pouco materibl de sprendeasgem: msnusis, Evecs e beblibgrafis sobre o toms.

Resietelench da equipe em madar as metodologlas de trabolho.

Necceseidsde de formsço de mSo de obra espeotalesds.

0 tempo necessidib pora implantacho da tecnologis na empresa.

Niso evistem dificuldsdes.

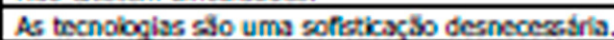

Outras. Quais? 


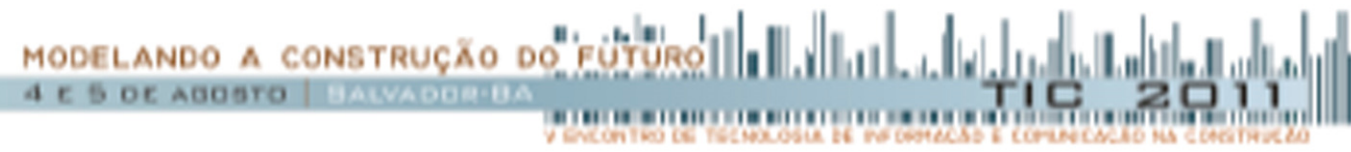

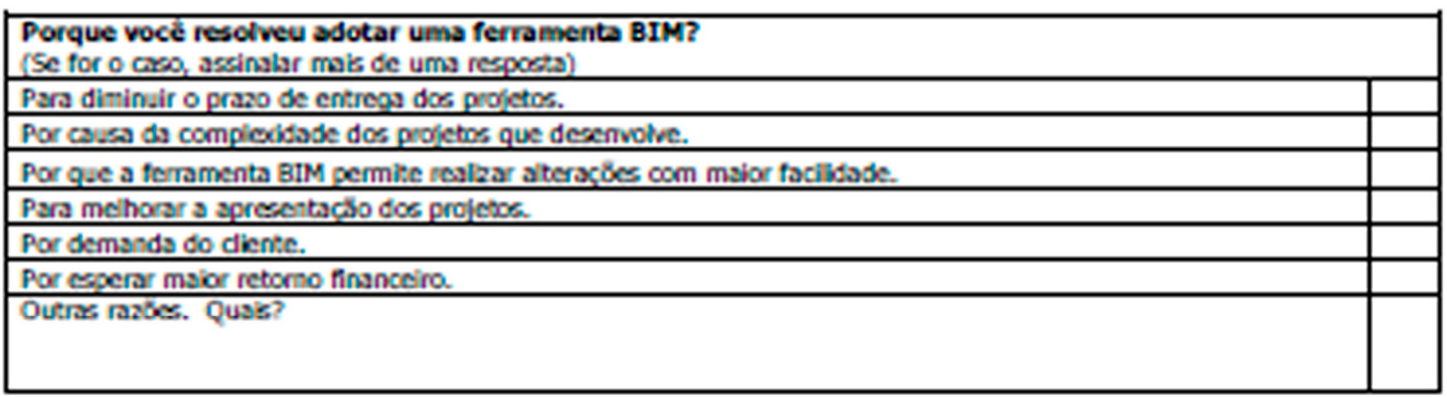

No quadro a seguir indicamos algumas mudancas teoricamente possheis de serem efetuadas no processo de projeto e construçbo, com a utilizaç̌̃o da tecnologia BIM. Numa escala de 1 a 5, onde 1 quer dizer que nada mudou e $\mathbf{5}$ que dizer que muito mudou, dề uma nota para cada item de acordo com a sua experikencia com a tecnologia.

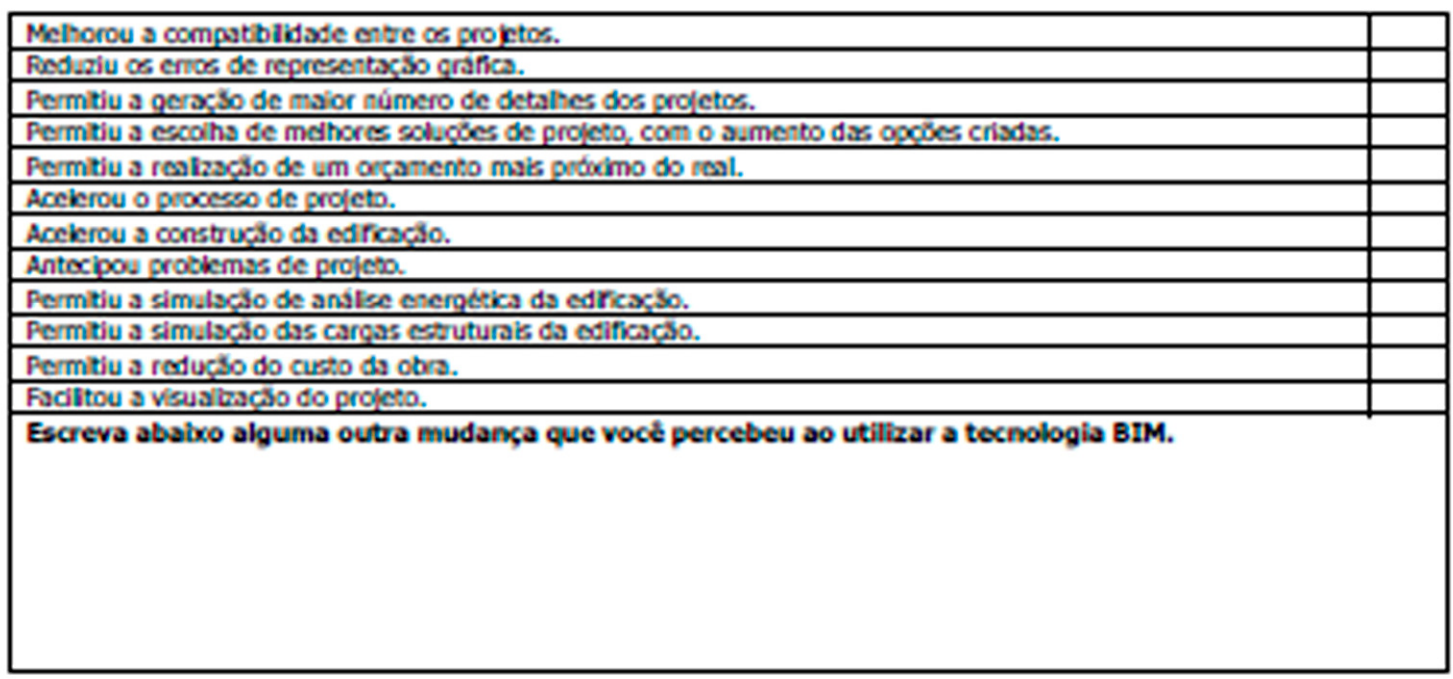

O que wock acha que mais dificulta a difusibo e a adoço da tecnologia BIM?

Que aspectos sobre a formaç̃o de profissionais da Śrea de Arquitetura, Engenharia e Construç̄o Civil vock considera relevante dentro do contexto BIM? 


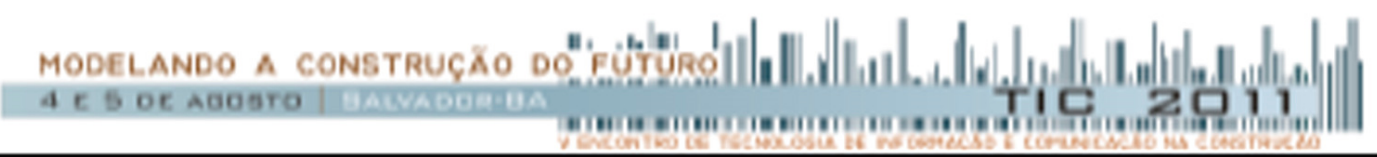

\begin{tabular}{|l|l|}
\hline $\begin{array}{l}\text { Qual vocé acha que deve ser o papel dos seguintes segmentos na implantoçso e o aperfeicoamento da } \\
\text { BIM? }\end{array}$ \\
\hline $\begin{array}{l}\text { Construttoras e } \\
\text { Incerporadoras }\end{array}$ & \\
\hline $\begin{array}{l}\text { Escritbrios de } \\
\text { projeto }\end{array}$ & \\
\hline $\begin{array}{l}\text { Entidades de } \\
\text { clasee }\end{array}$ & \\
\hline $\begin{array}{l}\text { Universidade } \\
\text { Fomecedores de } \\
\text { componentes } \\
\text { para a } \\
\text { construç3o }\end{array}$ & \\
\hline
\end{tabular}

No quadro a seguit, em cada linha colocamos dois pares de características desejóveis em uma ferramenta BIM, para que você escolha a que acha mais importante em cada par. Marque a coluna da esquerda se você preferir a primeira característica, a coluna da direita se optar pela seaunda e a coluna do meio se llhe for indiferente esta quest3o.

Um soltware BtM deve ter mais deservolvido seus recursos de documentacjo ou

Modelsgem de componentes controlads por restriçes rigidas, garantindo ums mabr integridade do modelo ou

Gerenclamento e coordenaçio de alteragbes completamente sutomstrads ou

Ferramenta mo's intultwa eficl de aprender os

\begin{tabular}{l|l|l|l|l|}
\hline ss & & & \\
& & & \\
& & & \\
& & & \\
\hline
\end{tabular}

Ele deve ter mais desenvolvido suss rocursos de modelagem tridmensional

Modelsoem mas ficodvel, onde o woudrín garante a integridade do modelo.

Gerenclamento e coordenactio de alteraches sem!sutomstzadx, porbm com maior rapidez.

Ferramenta ma's robusta, com maior capocidade de modelar formas complesas.

No quadro a seguir indicamos algumas caracteristicas desejbveis em uma ferramenta BIM, para que vock diga que importáncia dS a cada uma delas. Em uma escala de 1 a 5, onde 1 é pouco importante e 5 f́ muito importante đề uma nota para cada caracteristica.

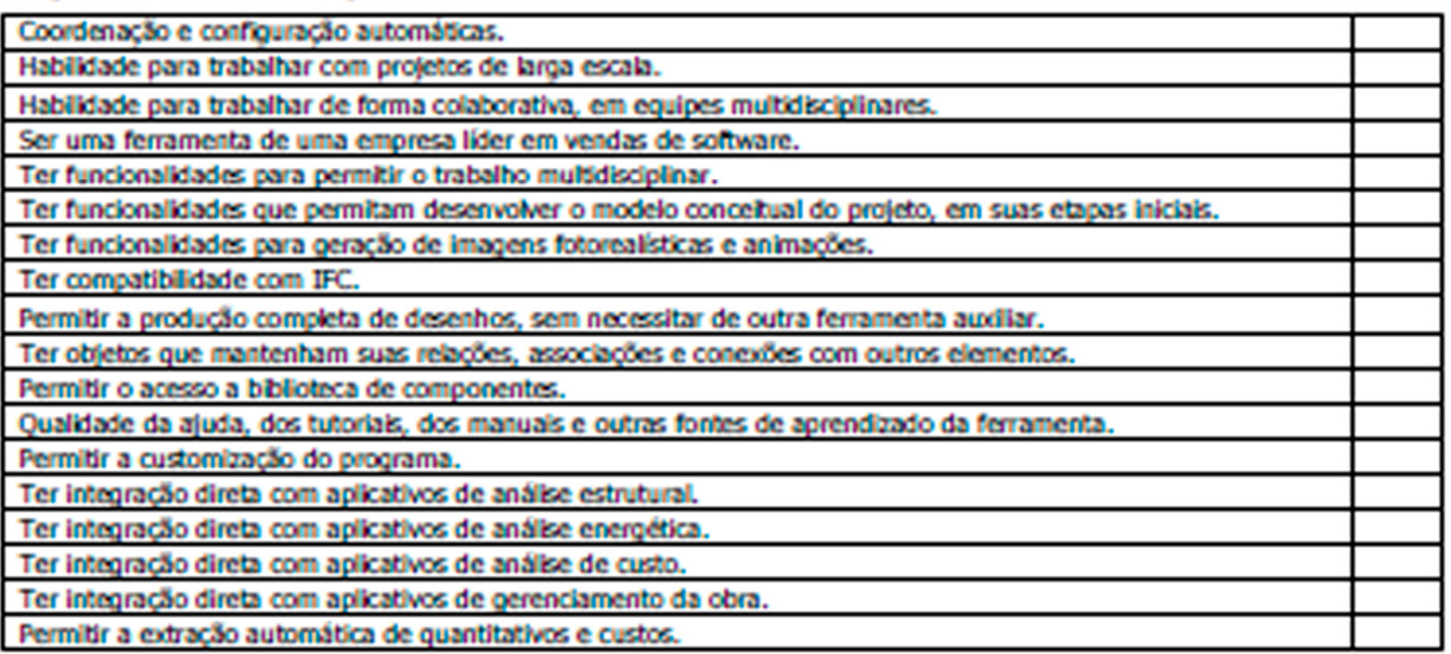




\begin{abstract}
ANEXO III
QUESTIONÁRIO SOBRE O USO DE CONTRATOS DE PROJETO INTEGRADO APLICADO NO EVENTO SOLUÇÕES PARA EMPRESAS DE PROJETO IV
\end{abstract}


Anexo III: Questionário sobre o uso de contratos de projeto integrado aplicado no evento Soluções para empresas de projeto IV

Questões

Contratantes

de projeto
Contratadas

p/ serviços

de projeto

1) Sua empresa é contratante ou responsável pela contratação de projetos?

\begin{tabular}{|c|c|c|c|}
\hline & Sim & 12 & 0 \\
\hline & Não & 0 & 8 \\
\hline \multirow[t]{6}{*}{ 2) } & Qual o modelo contratual mais comumente ut & lizado? & \\
\hline & $\begin{array}{l}\text { Não costumamos utilizar contratos formais de } \\
\text { projeto, utilizamos somente proposta (se } \\
\text { escolhido este item, assinalar um dos demais } \\
\text { itens considerando a PROPOSTA ao invés de } \\
\text { contrato) }\end{array}$ & 1 & 0 \\
\hline & $\begin{array}{l}\text { Contratação mensal ou periódica } \text { (os } \\
\text { pagamentos do valor total contratados são } \\
\text { liberados periodicamente a partir do início do } \\
\text { contrato) }\end{array}$ & 1 & 0 \\
\hline & $\begin{array}{l}\text { Contratação por etapa de projeto } \\
\text { pagamentos do valor total contratados são } \\
\text { liberados por fase de projeto) }\end{array}$ & 10 & 4 \\
\hline & $\begin{array}{l}\text { Contratação global (o pagamento do valor total } \\
\text { do contrato é liberado ao término do projeto) }\end{array}$ & 1 & 0 \\
\hline & Outras & & \\
\hline \multirow[t]{9}{*}{ 3) } & $\begin{array}{l}\text { Quais dos seguintes itens constam } \\
\text { propostas/contratos de projeto: }\end{array}$ & necessariamente & em suas \\
\hline & Escopo de trabalho & 12 & 6 \\
\hline & Definição das etapas de projeto a ser entregues & 11 & 6 \\
\hline & Prazo de execução por etapa & 10 & 5 \\
\hline & Prazo global & 7 & 3 \\
\hline & Custo por etapa de projeto & 9 & 2 \\
\hline & Custo global & 9 & 3 \\
\hline & $\begin{array}{l}\text { Previsão do material a ser produzido (pranchas, } \\
\text { relatórios, etc.) }\end{array}$ & 9 & 3 \\
\hline & Padrões e normas utilizados & 10 & 4 \\
\hline
\end{tabular}




\begin{tabular}{|c|c|c|c|}
\hline & Itens exclusos & 6 & 3 \\
\hline & Visitas à obra & 8 & 2 \\
\hline & Identificação do Recolhimento ou não de ART & 7 & 1 \\
\hline 4) & \multicolumn{3}{|c|}{$\begin{array}{l}\text { A empresa contratada costuma se LIMITAR às definições que constam na } \\
\text { proposta/contrato de projeto ou é comum ser demandada pelo contratante a } \\
\text { cumprir itens adicionais? }\end{array}$} \\
\hline & Sim & 8 & 2 \\
\hline & Não & 4 & 3 \\
\hline
\end{tabular}

5) A empresa já está trabalhando ou buscando se qualificar para projetar em BIM?

Sim, já estamos projetando em BIM
$\begin{aligned} & \text { Não, ainda não trabalhamos com BIM mas } \\ & \text { estamos nos qualificando para isso. }\end{aligned}$
$\begin{aligned} & \text { Não, não estamos pensando em trabalhar com } \\ & \text { BIM. }\end{aligned}$

6) A empresa conhece ou já participou de casos de contratação conjunta de duas ou mais empresas do ramo da construção civil (projetos, construtora, etc) em uma joint venture (associação de empresas com fins lucrativos para explorar determinado negócio, sem que nenhuma delas perca sua personalidade jurídica e que é dissolvida automaticamente ao término do projeto comum)?

\begin{tabular}{ccc}
\hline Sim & 1 & 0 \\
\hline Não & 11 & 5
\end{tabular}

7) O BIM irá exigir uma maior interação e colaboração entre os participantes do empreendimento, inclusive nas etapas de projeto. Existe a proposta de um modelo de contratação em formato de joint venture chamado IPD (Integrated Project Delivey) que propõe que os riscos e benefícios do projeto sejam compartilhados entre a equipe da joint venture. Se o projeto ultrapassa os resultados positivamente, o lucro de cada empresa aumenta em relação ao previsto. Se o resultado é inferior, este lucro é reduzido proporcionalmente entre as empresas. Vocês acreditam que este modelo serviria como bom incentivo para a colaboração entre os participantes do IPD na busca geral por melhores resultados para o empreendimento?

\begin{tabular}{ccc}
\hline Sim & 11 & 5 \\
\hline Não & 1 & 0
\end{tabular}

8) Sua empresa participaria de uma contratação no modelo proposto pelo IPD? 


\begin{tabular}{llcc}
\hline Sim & 11 & 4 \\
\hline Não & 1 & 0 \\
\hline 9) & Acreditam que o modelo do IPD é adequado para projetos em BIM? & \\
\hline Sim & 11 & 5 \\
\hline Não & 1 & 0 \\
\hline
\end{tabular}

